\title{
AVTA Federal Fleet PEV Readiness Data Logging and Characterization Study for the National Institute of Health
}

Stephen Schey

Jim Francfort

November 2014

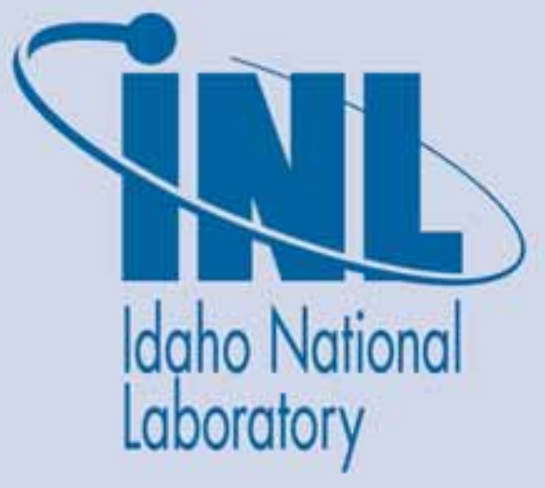

The INL is a U.S. Department of Energy National Laboratory operated by Battelle Energy Alliance 


\section{DISCLAIMER}

This information was prepared as an account of work sponsored by an agency of the U.S. Government. Neither the U.S. Government nor any agency thereof, nor any of their employees, makes any warranty, expressed or implied, or assumes any legal liability or responsibility for the accuracy, completeness, or usefulness, of any information, apparatus, product, or process disclosed, or represents that its use would not infringe privately owned rights. References herein to any specific commercial product, process, or service by trade name, trade mark, manufacturer, or otherwise, does not necessarily constitute or imply its endorsement, recommendation, or favoring by the U.S. Government or any agency thereof. The views and opinions of authors expressed herein do not necessarily state or reflect those of the U.S. Government or any agency thereof. 
INL/EXT-14- 33679

\title{
AVTA Federal Fleet PEV Readiness Data Logging and Characterization Study for the National Institute of Health
}

\author{
Stephen Schey \\ Jim Francfort ${ }^{2}$
${ }^{1}$ Stephen Schey, Project Manager, Infrastructure Planning and Analysis, Intertek Testing Services, North America, Phoenix, AZ
${ }^{2} \mathrm{Jim}$ Francfort, Vehicle Systems Principal Investigator, Idaho National Laboratory operated by Battelle Energy Alliance, Idaho Falls, ID

November 2014

Idaho National Laboratory
Idaho Falls, Idaho 83415

http://avt.inl.gov

Prepared for the

U.S. Department of Energy

Office of Nuclear Energy

Under DOE Idaho Operations Office

Contract DE-AC07-05ID14517 


\section{ABSTRACT}

Battelle Energy Alliance, LLC, managing and operating contractor for the U.S. Department of Energy's Idaho National Laboratory, is the lead laboratory for U.S. Department of Energy Advanced Vehicle Testing. Battelle Energy Alliance, LLC contracted with Intertek Testing Services, North America (Intertek) to collect and evaluate data on federal fleet operations as part of the Advanced Vehicle Testing Activity's Federal Fleet Vehicle Data Logging and Characterization Study. The Advanced Vehicle Testing Activity Study seeks to collect and evaluate data to validate the utilization of advanced plug-in electric vehicle (PEV) transportation.

This report focuses on the National Institute of Health's fleet to identify daily operational characteristics of select vehicles and report findings on vehicle and mission characterizations to support the successful introduction of PEVs into the agency's fleets.

Individual observations of these selected vehicles provide the basis for recommendations related to electric vehicle adoption and whether a battery electric vehicle or plug-in hybrid electric vehicle (collectively referred to as PEVs) can fulfill the mission requirements.

Intertek acknowledges the support of Idaho National Laboratory and the National Institute of Health for participation in the study. 


\section{EXECUTIVE SUMMARY}

Federal agencies are mandated to purchase alternative fuel vehicles, increase consumption of alternative fuels, and reduce petroleum consumption. Available plug-in electric vehicles (PEVs) provide an attractive option in the selection of alternative fuel vehicles. PEVs, which consist of both battery electric vehicles (BEVs) and plug-in hybrid electric vehicles (PHEVs), have significant advantages over internal combustion engine (ICE) vehicles in terms of energy efficiency, reduced petroleum consumption, and reduced production of greenhouse gas (GHG) emissions, and they provide performance benefits with quieter, smoother operation. This study is intended to evaluate the extent to which the National Institute of Health $(\mathrm{NIH})$ could convert part or all of their fleet of vehicles from petroleum-fueled vehicles to PEVs.

It is likely that more fuel-efficient ICE vehicles, including hybrid electric vehicles, exist that may provide improvements for the current fleet; however, this study's focus is on replacing ICE vehicles with suitable PEVs.

BEVs provide the greatest benefit when it comes to fuel and emissions savings because all motive power is provided by the energy stored in the onboard battery pack. These vehicles use no petroleum and emit no pollutants at their point of use. PHEVs provide similar savings when their battery provides the motive power; however, they also have the ability to extend their operating range with an onboard ICE. Because a PHEV can meet all transportation range needs, the adoption of a PHEV will be dependent on its ability to meet other transportation needs such as cargo or passenger carrying. Operation of PHEVs in battery-only mode can be increased with opportunity charging at available charging stations; it should be noted, however, that not all PHEVs have a mode in which the battery provides all motive power at all speeds. This study focuses on the mission requirements of the fleet of vehicles with the objective to identify vehicles that may be replaced with PEVs, with emphasis on BEVs that provide maximum benefit.

NIH with its main campus located in Bethesda, Maryland is a part of the U.S. Department of Health and Human Services. It is the nation's medical research agency - making important discoveries that improve health and save

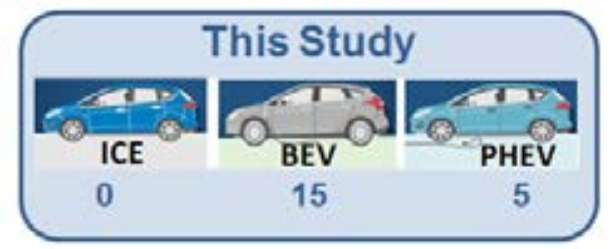
lives. NIH consists of 27 institutes and centers, each with a specific research agenda, often focusing on particular diseases or body systems. NIH leadership plays an active role in shaping the agency's research planning, activities, and outlook. NIH's mission is to seek fundamental knowledge about the nature and behavior of living systems and the application of that knowledge to enhance health, lengthen life, and reduce illness and disability. ${ }^{\text {a }} \mathrm{NIH}$ employs nearly 6,000 scientists in its own laboratories, mostly at the main campus, as part of 15,000 employees on 9 million square feet of space on 300 acres of land. $^{b}$

${ }^{\mathrm{a}}$ http://nih.gov/about/ [accessed October 2, 2014].

${ }^{\mathrm{b}}$ http://epa.gov/chp/documents/meeting_110110_albertini.pdf [accessed October 3, 2014]. 
The NIH complex has 319 vehicles in its fleet for all 27 institutes. Two-hundred forty-three of the vehicles were identified as part of NIH, with 20 identified as representative of the fleet and instrumented for data collection and analysis. Fleet vehicle

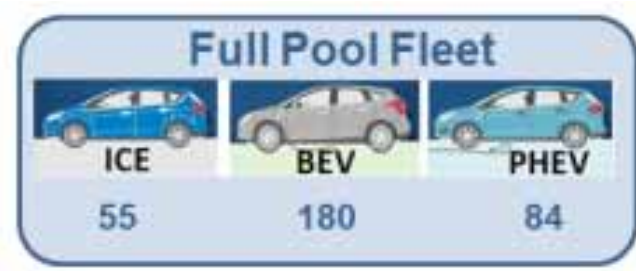
mission categories are defined in Section 4, and, while NIH vehicles conduct many different missions, four missions (i.e., pool, support, enforcement, and transport) were selected by agency management to be part of this fleet evaluation. These four mission categories accounted for 232 of the 243 total fleet vehicles. Seven of the remaining vehicles were specialty vehicles and four were buses. Of the 76 vehicles identified as belonging to other institutes, 69 have a support mission and seven have a transport mission.

This report observes that a mix of BEVs and PHEVs are capable of

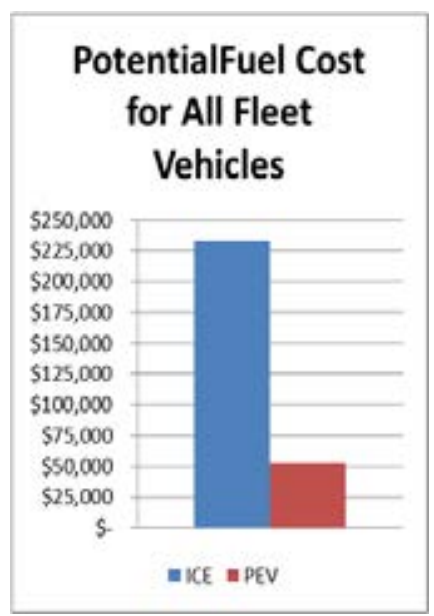
performing most of the required missions and of providing an alternative vehicle for the pool, support, enforcement, and transport vehicles. While some vehicles travel long distances, the group could support some BEVs for the short trips and PHEVs for the longer trips. The recommended mix of vehicles will provide sufficient range for individual trips and time is available each day for charging to accommodate multiple trips per day. These charging events could occur at the vehicle's home base. Replacement of vehicles in the current fleet would result in significant reductions in the emission of GHGs and in petroleum use, as well as reduced fleet operating costs.

Based on the data collected for the monitored vehicles, the 20 -vehicle fleet subset could possibly consist of $15 \mathrm{BEVs}$ and five PHEVs. The replacement of these 20 internal combustion vehicles with PEVs could result in an annual GHG savings over $53,700 \mathrm{lbs}-\mathrm{CO}_{2} \mathrm{e}(48 \%$ reduction) and an annual fuel cost savings of $\$ 15,240$ (76\% reduction).

Based on the data collected from the monitored vehicles and extrapolating to the 319 total vehicles, a fleet consisting of seven specialty vehicles, 32 conventional heavy-duty trucks, 12 conventional passenger vans, four buses, $180 \mathrm{BEVs}$, and 84 PHEVs may meet the agencies' needs. Replacement of the 264 ICE vehicles with PEVs could result in an annual GHG savings over $651,500 \mathrm{lbs}-\mathrm{CO}_{2} \mathrm{e}(50 \%$ reduction) and an annual fuel cost savings of over $\$ 179,700(77 \%$ reduction).

PEV charging stations could be located in various locations of NIH and could benefit not only NIH's own fleet vehicles but also the visiting public that own PEVs.

Intertek suggests that NIH may wish to move forward in the near future with replacement of pool, support, transport, and enforcement vehicles with PEVs

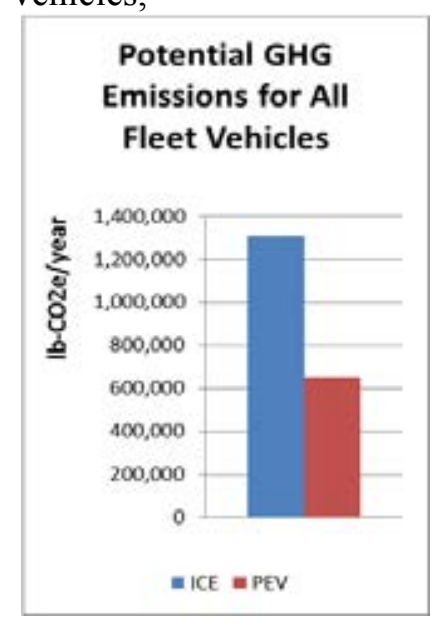


as current budget and vehicle replacement schedules allow. Certainly, the vehicle types studied in this report may be candidates for immediate replacement. 


\section{CONTENTS}

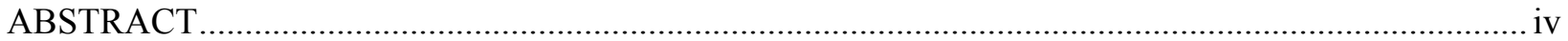

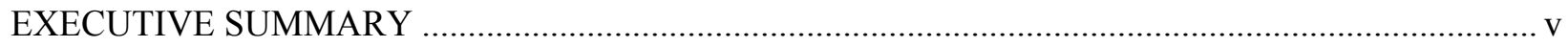

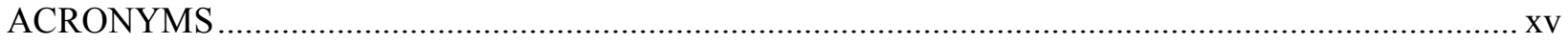

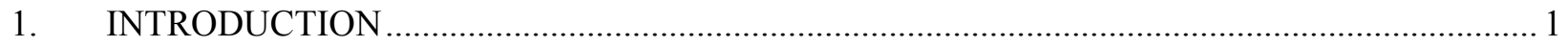

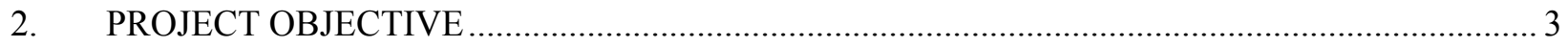

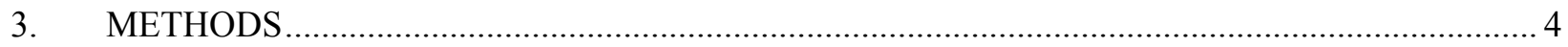

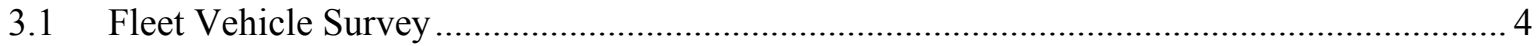

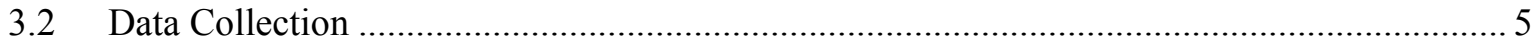

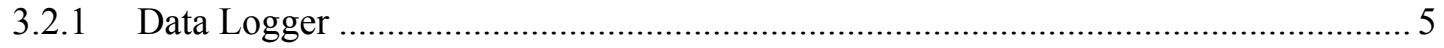

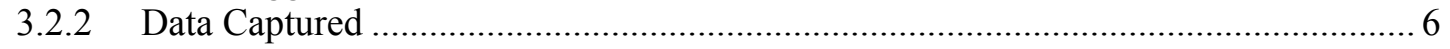

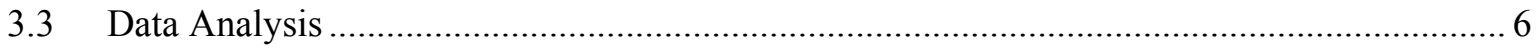

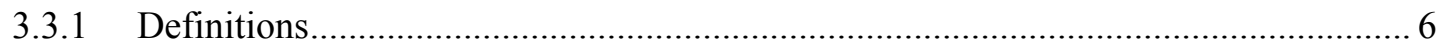

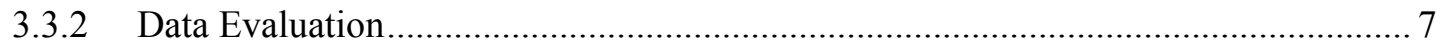

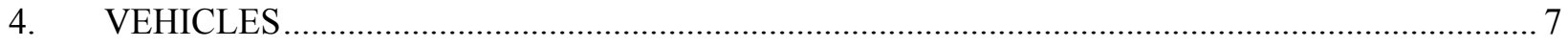

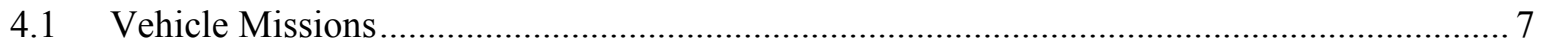

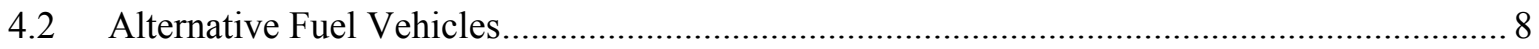

4.3 Battery Electric Vehicle and Plug-In Hybrid Electric Vehicle Benefits/Challenges .............. 9

4.3.1 Battery Electric Vehicle Benefits/Challenges ....................................................... 9

4.3.2 Plug-in Hybrid Electric Vehicle Benefits/Challenges............................................ 10

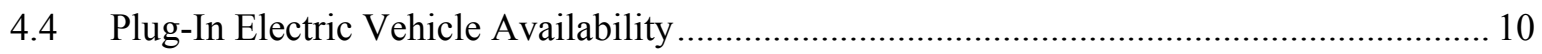

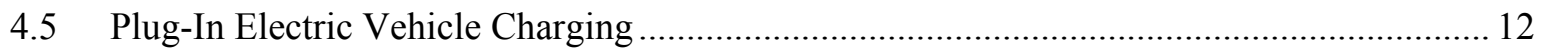

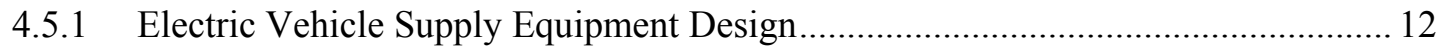

4.5.2 Electric Vehicle Supply Equipment Stations ....................................................... 15

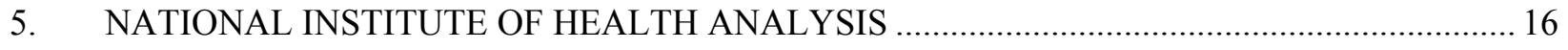

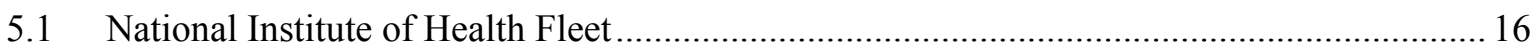

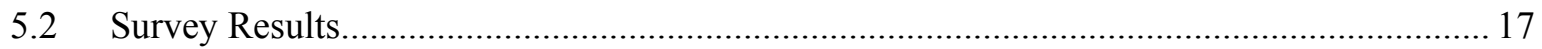

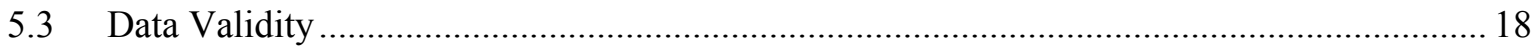


5.4 National Institute of Health Pool Vehicles Evaluation .................................................... 19

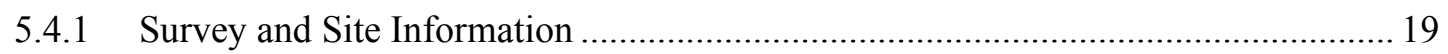

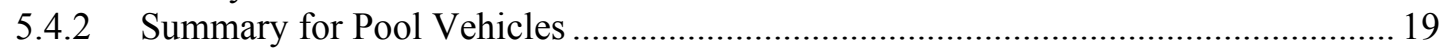

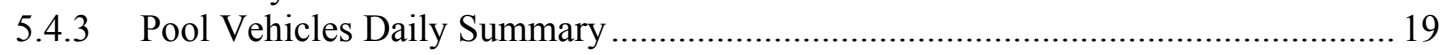

5.4.4 National Institute of Health Pool Vehicle Observations/Summary …....................... 21

5.4.5 National Institute of Health Pool Vehicle Charging Needs ...................................... 22

5.5 National Institute of Health Support Vehicles Evaluation ................................................. 24

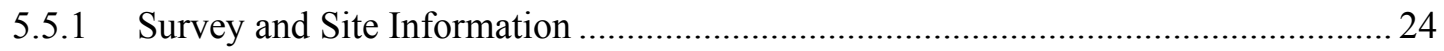

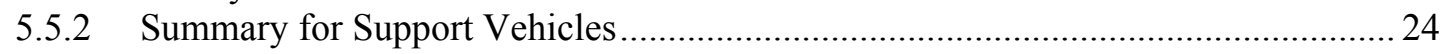

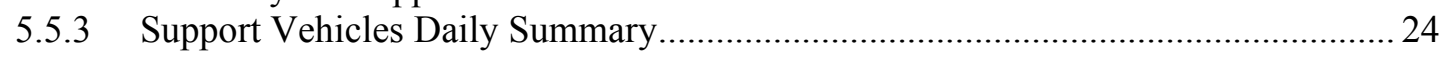

5.5.4 National Institute of Health Support Vehicle Observations/Summary ..................... 27

5.5.5 National Institute of Health Support Vehicle Charging Needs ................................ 28

5.6 National Institute of Health Law Enforcement Vehicles Evaluation .................................. 28

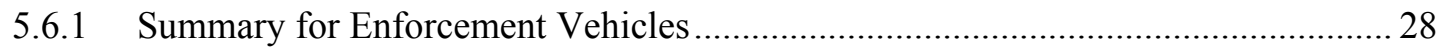

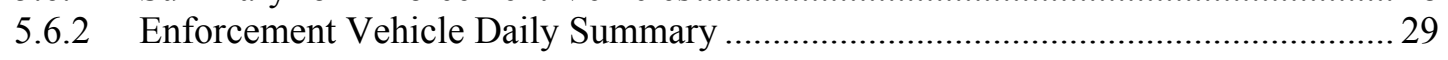

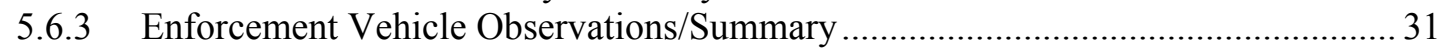

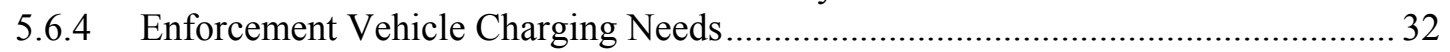

5.7 National Institute of Health Transport Vehicles Evaluation ............................................. 32

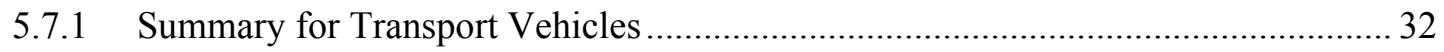

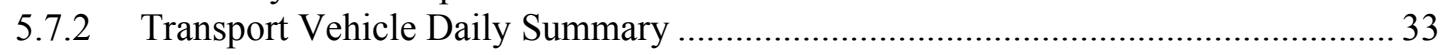

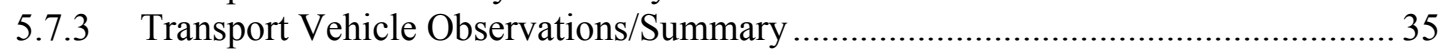

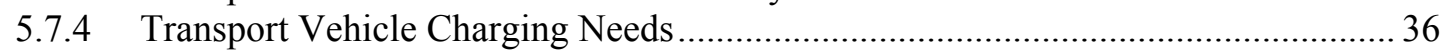

5.8 Balance of Fleet Vehicles ............................................................................................ 36

\section{GREENHOUSE GAS EMISSIONS AVOIDED AND FUEL COST REDUCTION}

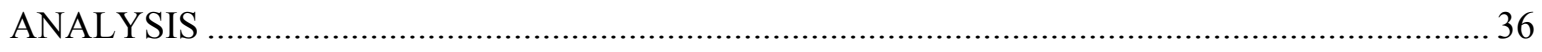

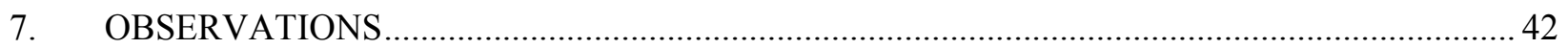

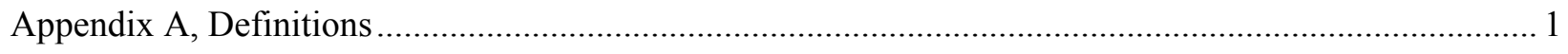

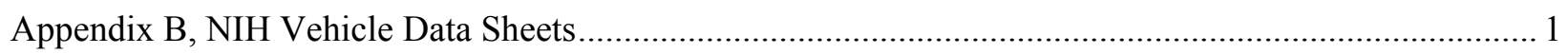

Appendix C, National Fuel Cost and GHG Savings ................................................................... 1

\section{FIGURES}

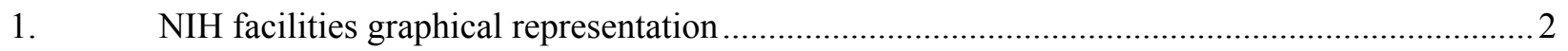

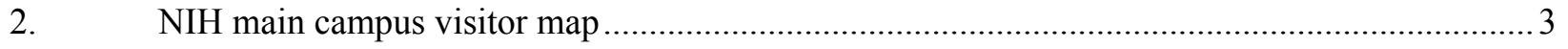




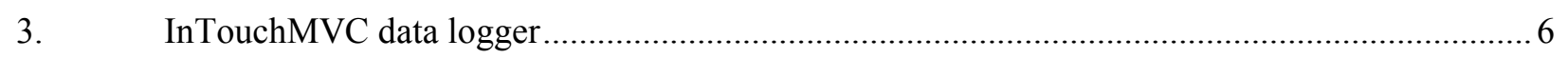

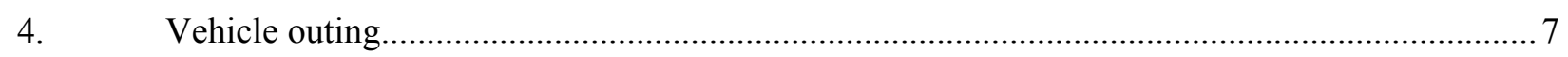

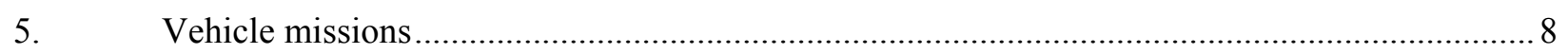

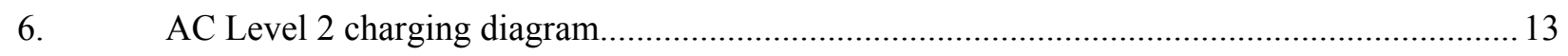

7. Society of Automotive Engineers charging configurations and ratings terminology ................ 13

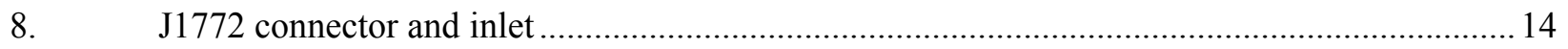

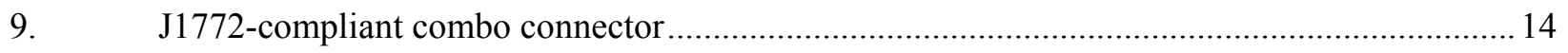

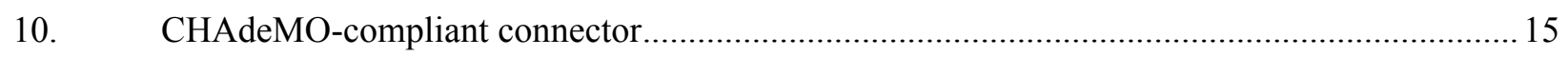

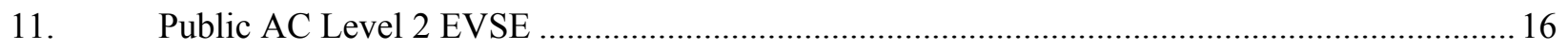

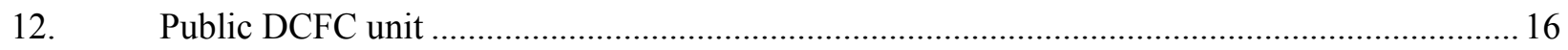

13. NIH pool vehicle daily travel miles and time (all vehicles) ................................................ 19

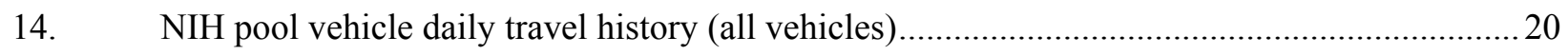

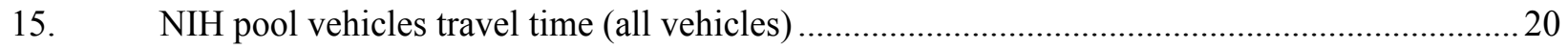

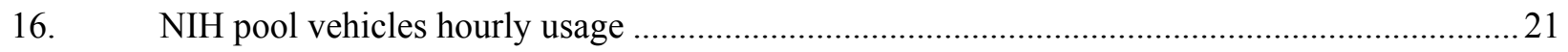

17. NIH pool vehicle outings. For clarity, the single peak outing of 750.2 miles is not

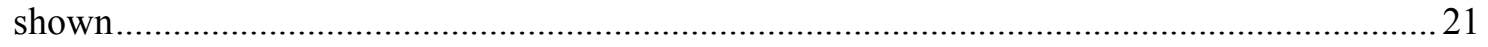

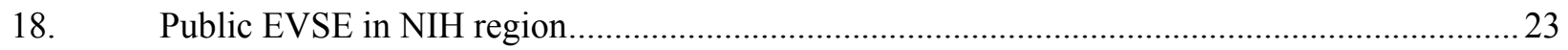

19. NIH support vehicle daily travel miles and time (all vehicles) .............................................2

20. NIH support vehicle daily travel history (all vehicles) .......................................................2

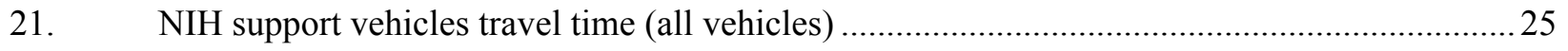

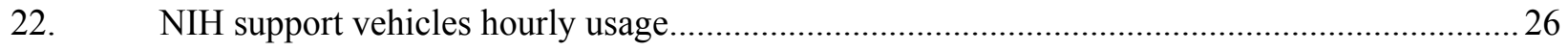

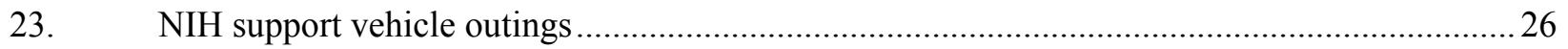

24. Enforcement vehicles percentage of daily use versus daily travel miles and time (all

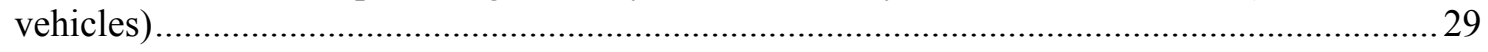

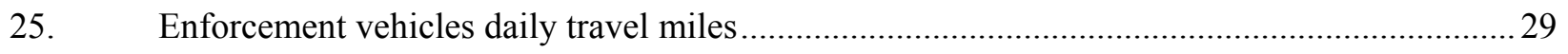

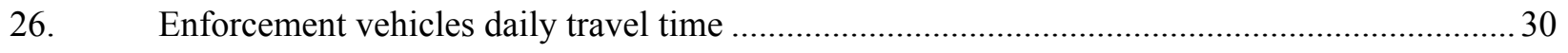

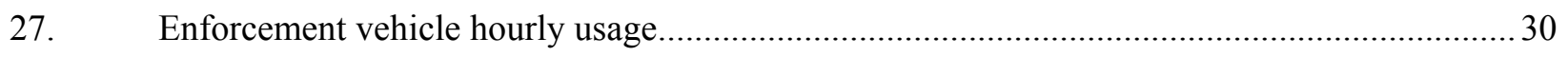




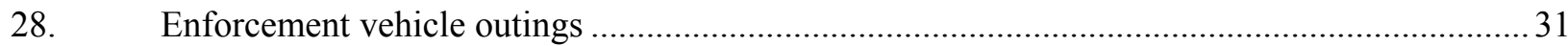

29. Transport vehicles percentage of daily use versus daily travel miles and time (all vehicles)

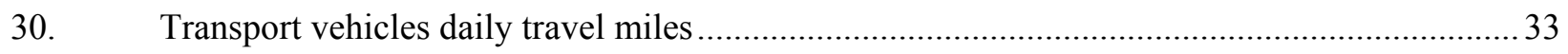

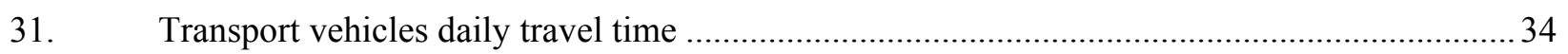

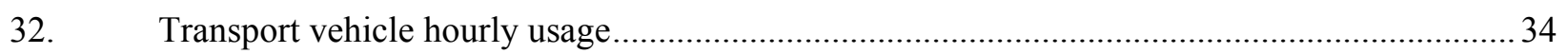

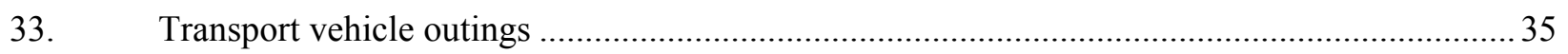

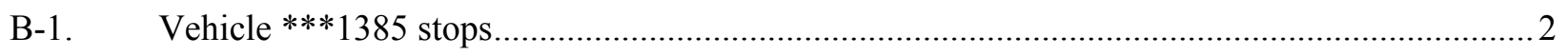

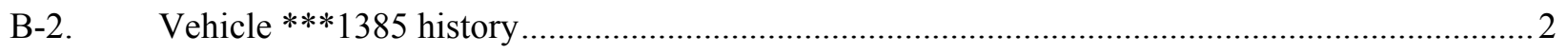

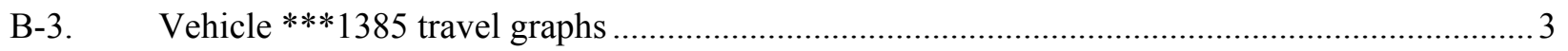

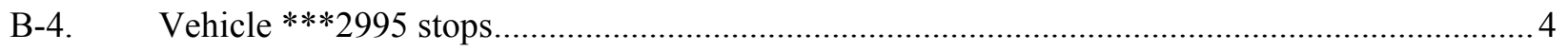

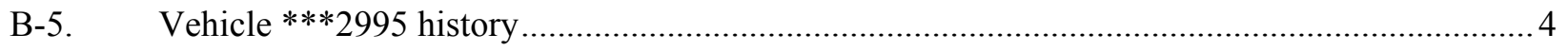

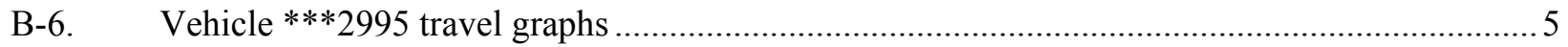

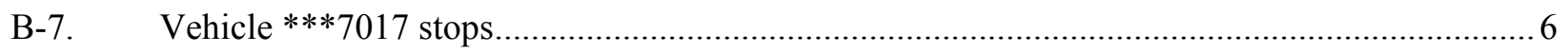

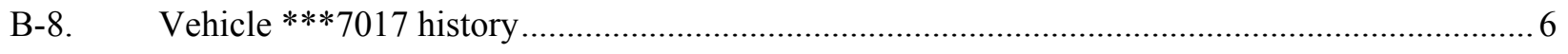

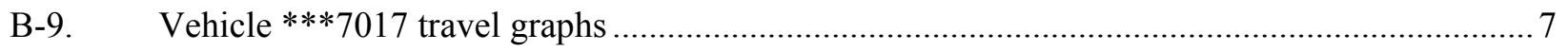

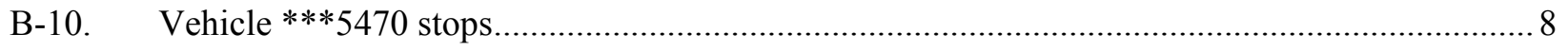

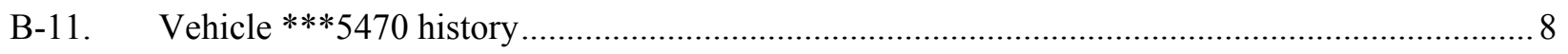

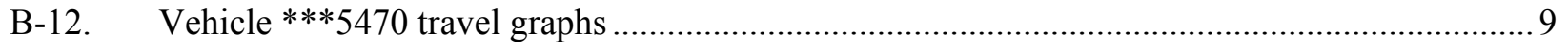

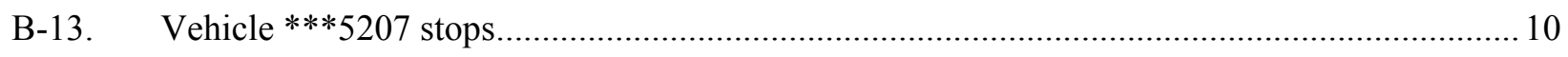

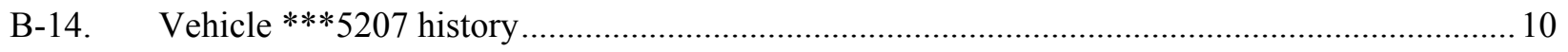

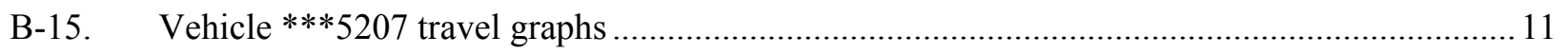

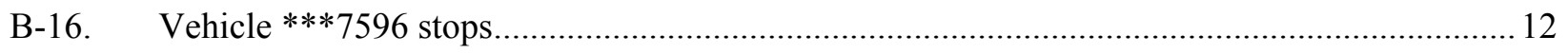

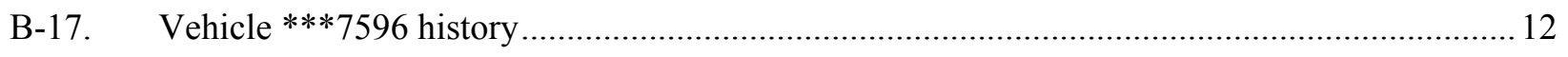

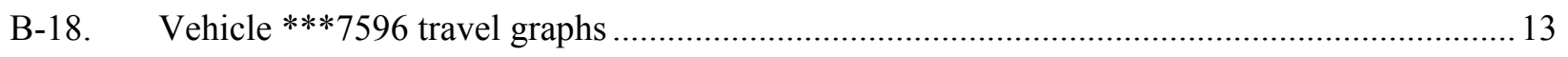

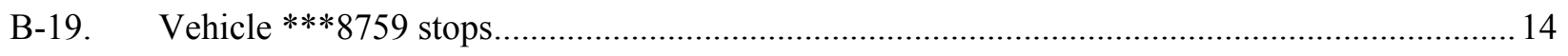

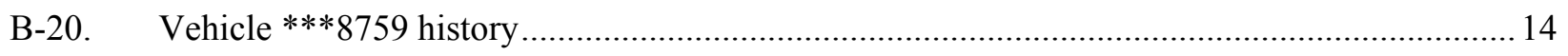




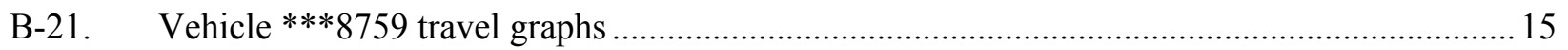

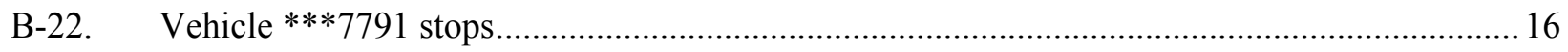

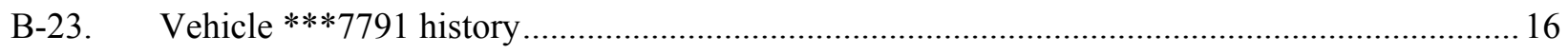

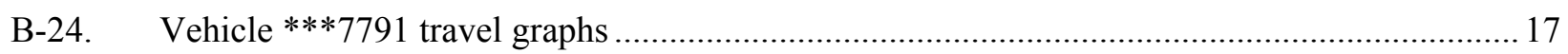

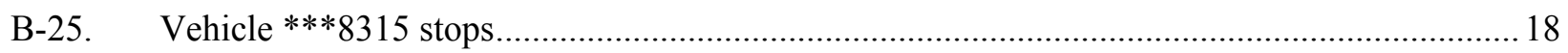

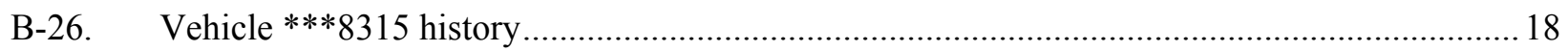

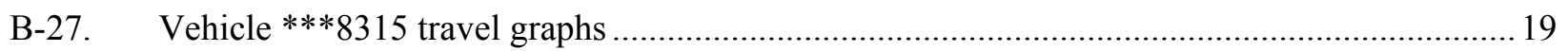

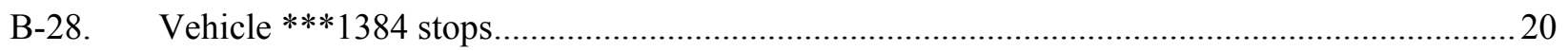

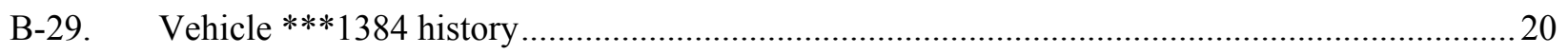

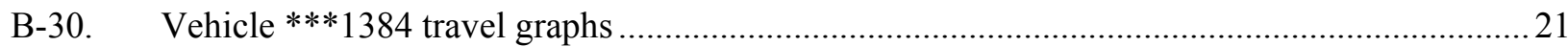

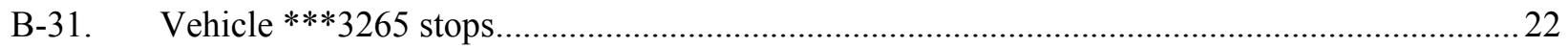

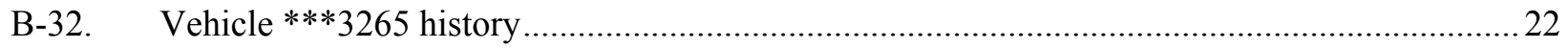

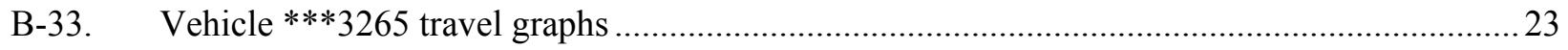

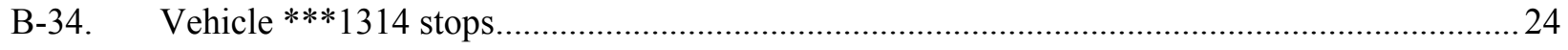

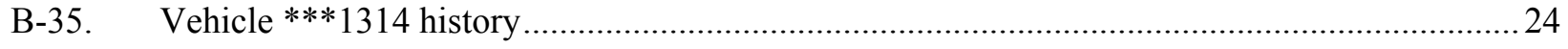

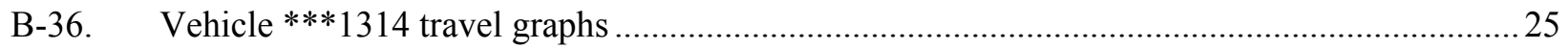

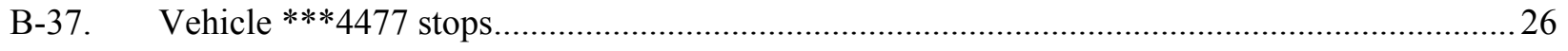

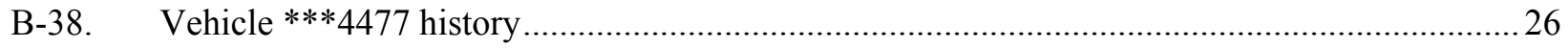

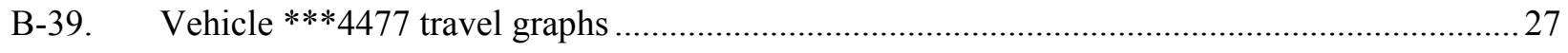

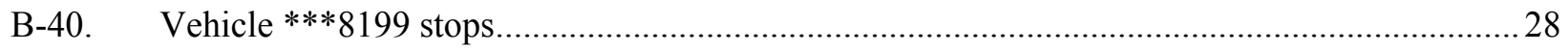

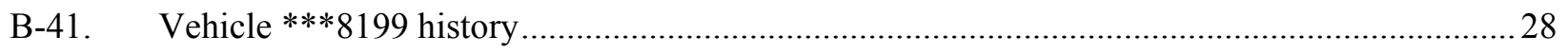

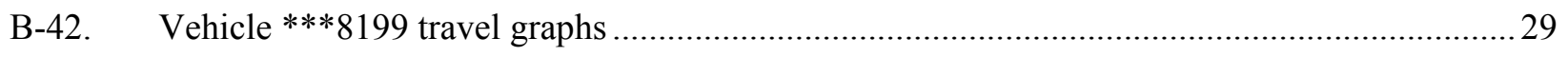

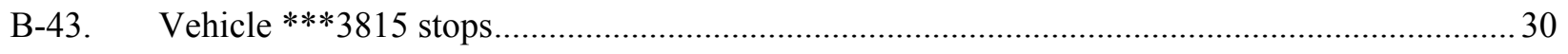

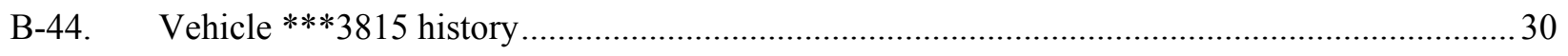

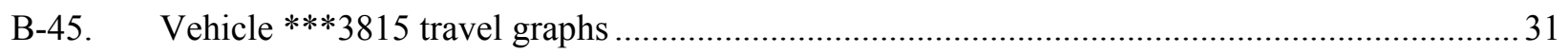

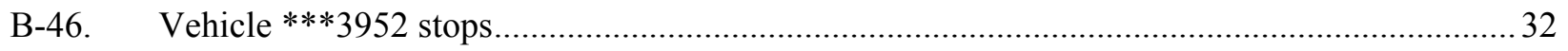




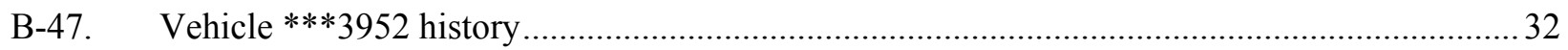

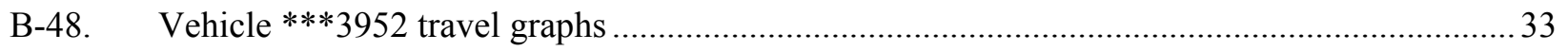

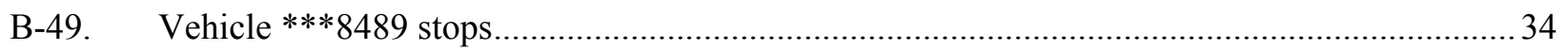

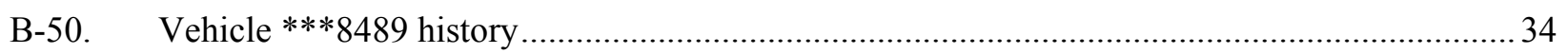

B-51. Vehicle $* * * 8489$ travel graphs. Peak outing of 750.2 miles not shown for clarity of

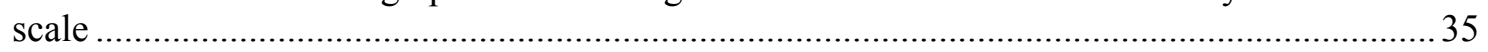

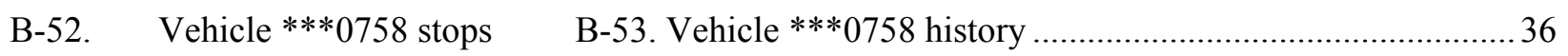

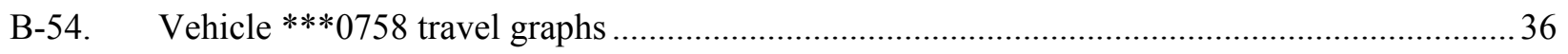

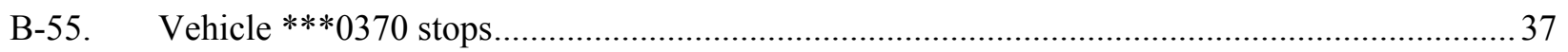

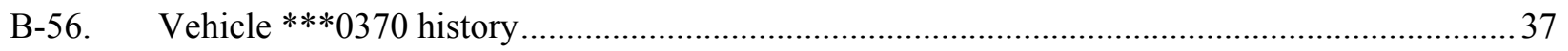

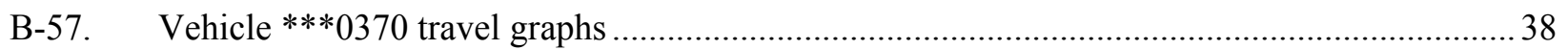

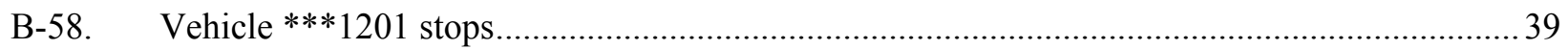

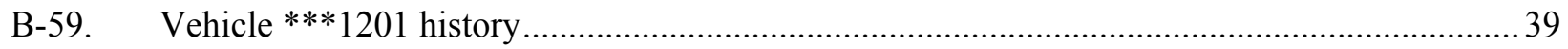

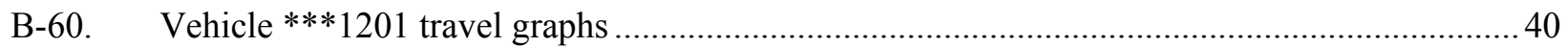

TABLES

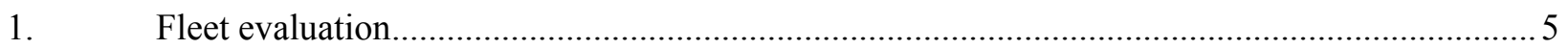

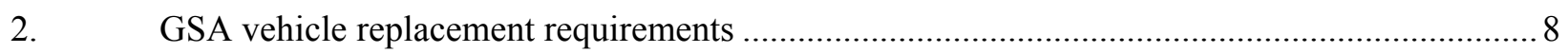

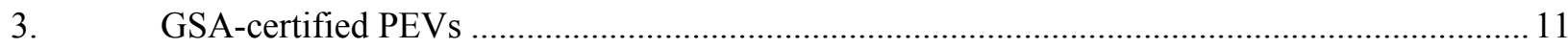

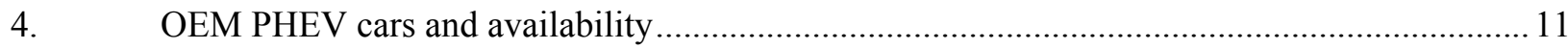

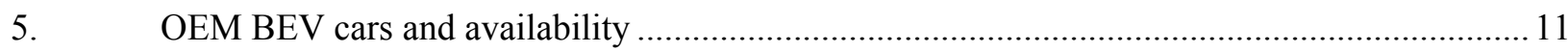

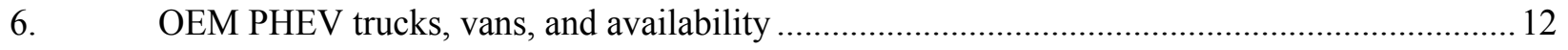

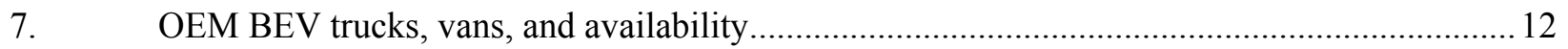

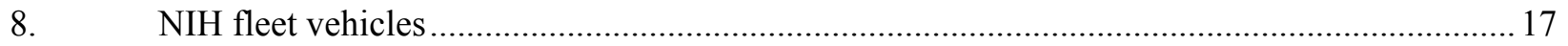

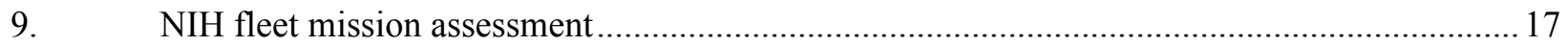

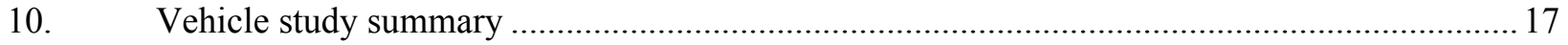

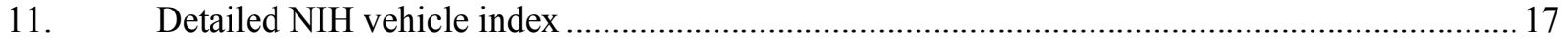

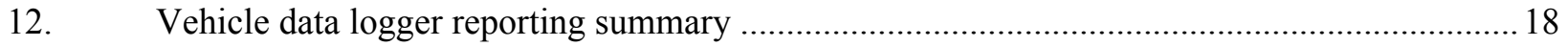




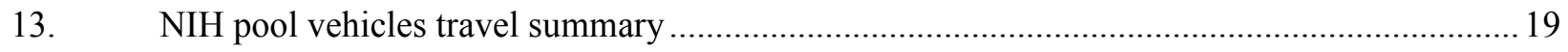

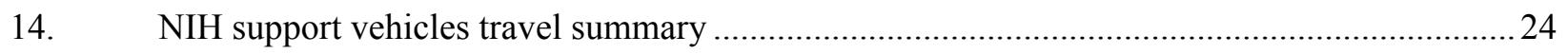

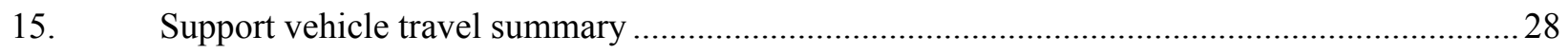

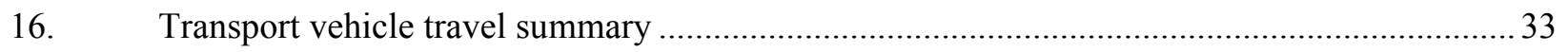

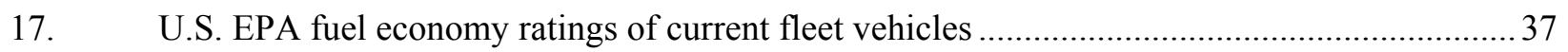

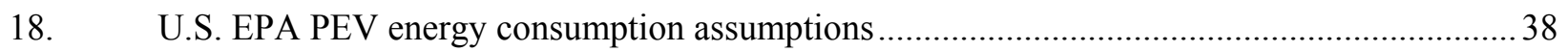

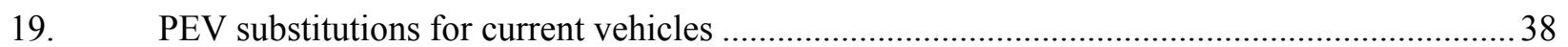

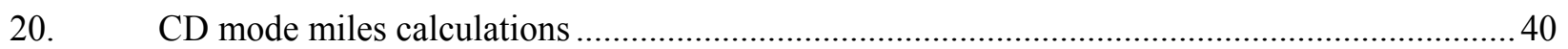

21. GHG emissions avoidance and fuel cost reduction analysis summary.................................... 41

22. Extrapolated greenhouse gas emissions avoided and fuel cost savings for the entire fleet ........42

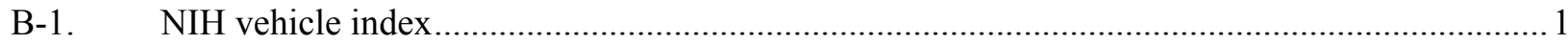

C-1. Fuel cost and GHG savings on a national basis............................................................... 1

C-2. Extrapolated GHG emissions avoided and fuel cost savings for the entire fleet ......................2 


\section{ACRONYMS}

AC alternating current

BEV battery electric vehicle

CD charge depleting

CS charge sustaining

DC direct current

DCFC DC fast charger

EPA U.S. Environmental Protection Agency

EVSE electric vehicle supply equipment

GHG greenhouse gas emissions

GSA General Services Administration

ICE internal combustion engine

Intertek Intertek Testing Services, North America

NIH National Institute of Health

OEM original equipment manufacturers

PEV plug-in electric vehicle (includes BEVs and PHEVs, but not hybrid electric vehicles)

PHEV plug-in hybrid electric vehicle

SUV sport utility vehicle

VIN vehicle identification number 


\section{INTRODUCTION}

Federal agencies are mandated by the Energy Policy Act of $1992,{ }^{3}$ Energy Policy Act of 2005, ${ }^{4}$ Executive Order 13423 (President Bush 2007), ${ }^{5}$ Executive Order 13514 (President Obama), ${ }^{6}$ and the Energy Independence and Security Act of $2007^{7}$ to purchase alternative fuel vehicles, increase consumption of alternative fuels, reduce petroleum consumption, and reduce greenhouse gas (GHG) emissions.

Battelle Energy Alliance, LLC, managing and operating contractor for Idaho National Laboratory, is the lead laboratory for the U.S. Department of Energy's advanced vehicle testing and manages the Advanced Vehicle Testing Activity Federal Fleet Vehicle Data Logging and Characterization Study, which promotes utilization of advanced electric drive vehicle transportation technologies. The Advanced Vehicle Testing Activity focuses its testing activities on emerging and newly commercialized plug-in electric vehicle (PEV) technologies because of the high-energy efficiencies and reduced consumption of petroleum through use of electric-drive vehicles. Battelle Energy Alliance, LLC selected Intertek Testing Services, North America (Intertek) to collect data on federal fleet operations and report the findings on vehicle and mission characterizations to support successful introduction of PEVs into federal fleets.

It is likely that more fuel efficient internal combustion engine (ICE) vehicles, including hybrid electric vehicles, exist that may provide improvements for the current fleet; however, these vehicles are not the focus of this study.

Because of the large number of vehicles in federal fleets in the United States, these fleets provide a substantial opportunity for introduction of battery electric vehicles (BEVs) and plug-in hybrid electric vehicles (PHEVs) (collectively referred to as PEVs). However, to assess the scale of this opportunity, additional data are required to characterize the various missions performed by each fleet and to determine which existing vehicles are most suitable for replacement by a PEV.

The National Institute of Health (NIH), located in Bethesda, Maryland (Figures 1and 2), employs approximately 6,000 scientists as part of the total onsite workforce. NIH consists of 27 institutes and centers, each with a specific research agenda often focusing on particular diseases or body systems. NIH leadership plays an active role in shaping the agency's research planning, activities, and outlook. NIH's mission is to seek fundamental knowledge about the nature and behavior of living systems and the application of that knowledge to enhance health, lengthen life, and reduce illness and disability. ${ }^{8}$

$\mathrm{NIH}$ is an excellent site for fleet evaluation because of its size, location, and travel between the site, Rockville, and other local destinations and travel within the NIH perimeter. NIH has an opportunity to be a leader in the adoption of BEVs and PHEVs for its fleet. Visitor entrance requirements exist; therefore, electric vehicle charging stations that may be installed at NIH may not be generally available for public use.

\footnotetext{
${ }^{3}$ http://thomas.loc.gov/cgi-bin/query/z?c102:h.r.776.enr [accessed January 10, 2014].

${ }^{4}$ http://www.gpo.gov/fdsys/pkg/BILLS-109hr6enr/pdf/BILLS-109hr6enr.pdf [accessed January 10, 2014 ].

${ }^{5}$ http://www.gsa.gov/portal/content/102452 [accessed January 10, 2014].

${ }^{6}$ https://www.fedcenter.gov/programs/eo13514/ [accessed September 1, 2014].

${ }^{7}$ http://www.gpo.gov/fdsys/pkg/PLAW-110publ140/pdf/PLAW-110publ140.pdf [accessed January 10, 2014].

${ }^{8}$ http://nih.gov/about/ [accessed October 2, 2014].
} 


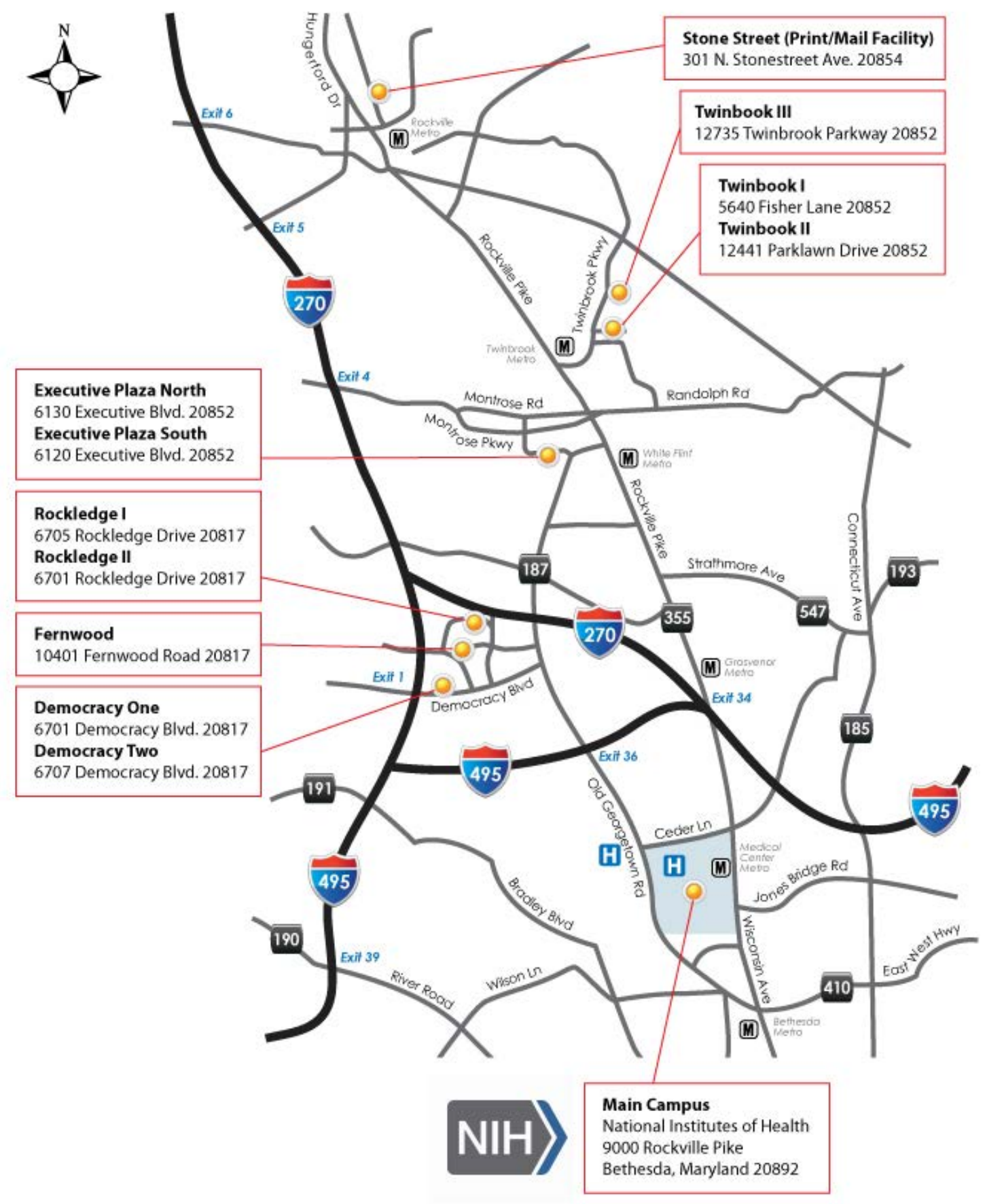

Figure 1. NIH facilities graphical representation. ${ }^{9}$

${ }^{9}$ https://nih.gov [accessed September 16, 2014]. 


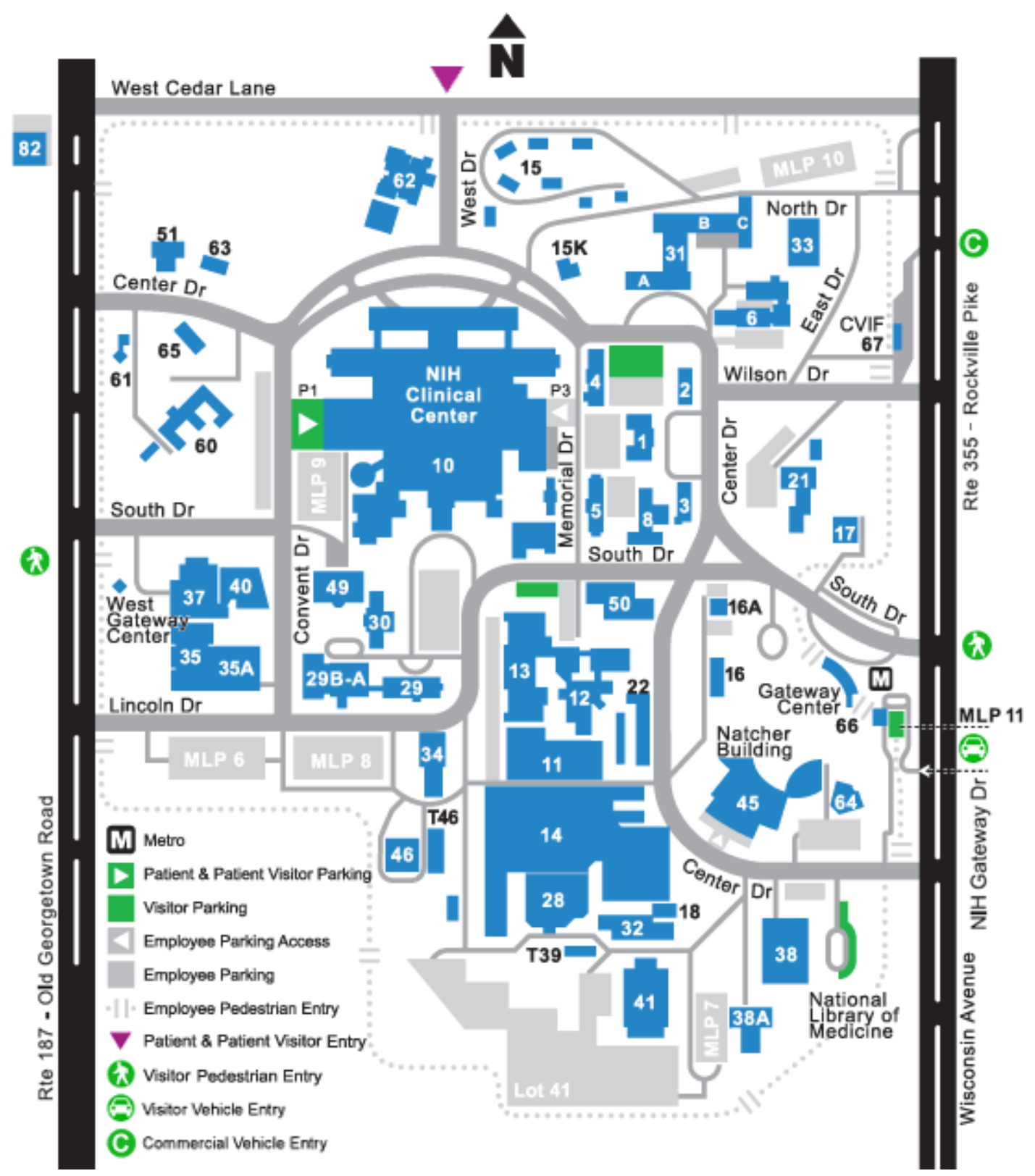

Figure 2. NIH main campus visitor map. ${ }^{10}$

\section{PROJECT OBJECTIVE}

This study explores federal fleet vehicles and their usage characteristics, with a primary goal of supporting the goals of Presidential Executive Order 13514, which includes the following:

- Pursuing opportunities with vendors and contractors to address and incentivize GHG emission reductions and petroleum use reductions

- Implementing strategies and accommodations for transit, travel, training, and conferences that actively reduce carbon emissions associated with commuting and travel by agency staff

\footnotetext{
${ }^{10}$ http://www.ors.od.nih.gov/maps/Pages/NIH-Visitor-Map.aspx [accessed October 2, 2014].
} 
- Meeting GHG emissions reductions associated with other federal government sustainability goals

- Implementing innovative policies and practices that address agency-specific Scope 3 GHG emissions. ${ }^{11}$

Because of the large number of vehicles in the federal fleets, there is a substantial opportunity for PHEV and BEV adoption. Federal fleets offer an opportunity as a first market replacement for alternative fuels due to their scale, refueling patterns, and regular vehicle turnover. ${ }^{12}$

This project has the following four defined tasks:

1. Data collection: Coordinate with the fleet manager to collect data on agency fleet vehicles. This includes collecting information on the fleet vehicle and installing data loggers on a representative sample of the fleet vehicles to characterize their missions.

2. Data analysis and review: Examine the data collected by the loggers and fleet vehicle characteristics to describe typical fleet activity. Incorporate fleet manager's input on introducing PEVs to the agency's fleet.

3. PEV implementation feedback: Provide feedback to fleet personnel and BEA on the selection criteria for replacement PEVs in their specific fleet vehicle missions.

4. Observations and recommendations: Provide actionable information to introduce PEVs into agency fleet operations and assess any related impacts for the facility.

Data collected from vehicles include trip distance, idle time, time between uses, and stop locations. Data collection continues for 30 to 60 days using a non-intrusive data logger, which gathers and transmits information using global positioning satellites and cellular service. The loggers collect data at 1-minute intervals and transmit when an active signal is present.

Extrapolating the results of this analysis to the larger fleet provides estimates of potential savings in gasoline consumption and GHG emissions. This report also provides recommendations relating to fleet management of BEVs and PHEVs for additional consideration.

Fleet managers may use the information supplied in this report to help them to identify which vehicles are candidates for replacement by BEV or PHEV based on their use. BEVs are preferred because of the greater potential reduction of GHG emissions, fuel cost, and petroleum usage, but they are not likely to be suitable for all vehicle missions.

The information in this report supports a final report to Battelle Energy Alliance, LLC/Idaho National Laboratory and the U.S. Department of Energy. The aggregated results for all agencies' fleets will provide an overview of federal fleets, vehicle missions, vehicle uses, and agencies needs to plan and establish a more systematic method for the adoption of BEVs and PHEVs.

\section{METHODS}

\subsection{Fleet Vehicle Survey}

Agency fleet managers selected fleet vehicles for this study and provided basic information for each vehicle, including its managing agency, home base for the vehicle, contact information, primary vehicle mission, vehicle ownership, fuel type, and odometer reading.

\footnotetext{
${ }^{11} \mathrm{http}: / /$ energy.gov/sites/prod/files/2013/10/f3/eo13514.pdf [accessed February 5, 2014].

${ }^{12}$ Fleet Purchase Behavior: Decision Processes and Implications for New Vehicle Technologies and Fuel, Nesbitt, Sperling, University of California, Davis 2001.
} 
NIH identified 243 fleet vehicles in their fleet. Vehicle missions were identified by NIH input (Table 1). (Note that Section 4 provides descriptions of the vehicle mission types.) Intertek coordinated with the NIH fleet manager to identify the specific vehicles for data collection for inclusion in the study. The fleet manager assessed their wide range of vehicles and made selections of high-interest, representative vehicles based on vehicle missions and vehicle type/class. Selection also favored vehicles used at least twice a week. Because data loggers rely on the vehicle's battery power, non-use of the vehicle can result in the vehicle having a depleted battery. Intertek received no reports of depleted batteries during the study at NIH. Twenty vehicles were selected: seven pool, six support, four enforcement, and three transport vehicles.

Table 1. Fleet evaluation.

\begin{tabular}{cccc}
\hline Vehicle Mission & Study Vehicles & $\begin{array}{c}\text { Total Fleet } \\
\text { Reported }\end{array}$ & $\begin{array}{c}\text { Percentage } \\
\text { Studied }\end{array}$ \\
\hline Pool Vehicles & 7 & 19 & $37 \%$ \\
Support Vehicles & 6 & 131 & $5 \%$ \\
Enforcement Vehicles & 4 & 53 & $7 \%$ \\
Transport & 3 & 29 & $100 \%$ \\
Bus & 0 & 4 & $0 \%$ \\
Specialty Vehicles & 0 & 7 & $0 \%$ \\
Total Fleet Vehicles & 20 & 243 & $8 \%$ \\
\hline
\end{tabular}

\subsection{Data Collection}

Individual privacy concerns exist when monitoring vehicle movement with data loggers. Data collection occurs by vehicle identification as identified by Intertek, data logger number, and vehicle identification number (VIN) or agency-assigned vehicle number. Intertek receives no information related to the vehicle operator and provides no raw data to the fleet managers. In this manner, Intertek does not collect, analyze, or report on individual driving habits.

\subsubsection{Data Logger}

Non-intrusive data loggers, produced by InTouchMVC ${ }^{13}$ and depicted in Figure 3, were inserted into the vehicle's onboard diagnostic port to collect and transmit the relevant data. The installation of the data logger and the manual recording of information about the vehicle that ties the logger and vehicle together in the data, typically takes less than 5 minutes. Once installed and activated (during vehicle use), the data loggers collect vehicle information once every minute during vehicle operation and transmit by cellular communication to the data center.

Intertek maintains the data logger's connectivity and verifies data transmission weekly. Missing data (reported as "null" values) are frequently the result of lost global positioning system reception, logger device removal, or extended periods in regions with insufficient cellular reception. Intertek filters the vehicle and data logger information if these null values present a significant impact on the data collected and no resolution is possible. This report also identifies the statistics on this validation process.

NIH requested and installed ten data loggers into the selected fleet vehicles. The agency removed and shipped the data loggers to Intertek at the conclusion of the data collection period.

\footnotetext{
${ }^{13}$ www.intouchmvc.com [accessed January 10, 2014].
} 


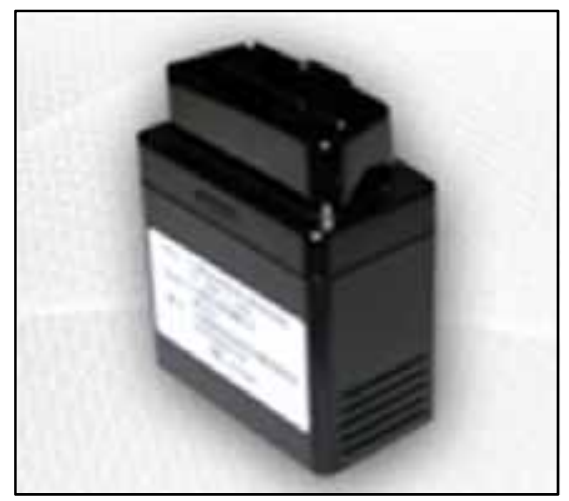

Figure 3. InTouchMVC data logger.

\subsubsection{Data Captured}

Data consist of key-on events, key-off events, and position updates logged every minute while the vehicle is keyed-on. InTouchMVC converted these data points into records of trip events, stop events, and idle events.

From these data points, the following information was available for evaluation:

- Trip start and stop time and location

- Trip distance and duration

- Idle start time, location, and duration

- Stop start time, location, and duration.

\subsection{Data Analysis}

\subsubsection{Definitions}

Figure 4 illustrates a vehicle outing, which is comprised of trips, stops, and idle events, that may occur during 1 day or over several days. The following list provides a definition of these terms:

1. Outing: An outing is the combination of trips and stops that begin at the home base and includes all travel until the vehicle returns home.

2. Trip: A trip begins with a key-on event and ends with the next key-off event.

3. Vehicle stop: A vehicle stop includes a key-off/key-on event pair.

4. Idle time: Idle time is the amount of time a vehicle spends stationary after a key-on event when the vehicle is not moving for a period of 3 minutes or longer.

5. Trip travel time: Trip travel time is the amount of time required to complete a trip, excluding stops, but including idle time.

Definitions of additional analysis and survey terms are as follows:

1. Operating shift: Fleet manager-defined period worked.

2. Study days: Days during which the data loggers are connected.

3. Vehicle days: Study days during which a vehicle is used.

4. Null values: Data record unusable for analysis for various reasons. 


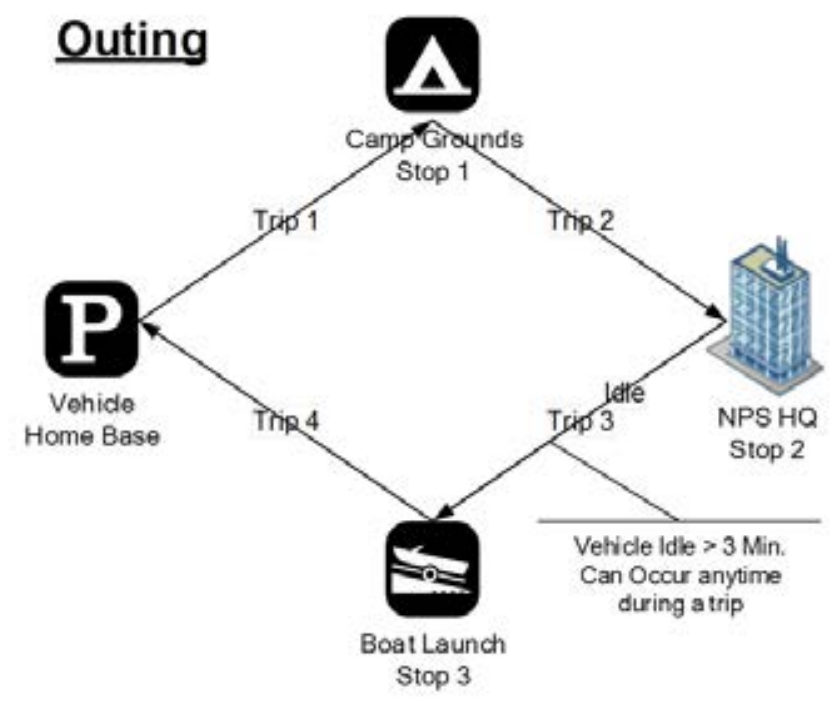

Figure 4. Vehicle outing.

\subsubsection{Data Evaluation}

Processing the data involves removal of null values and aggregation by different spatial and temporal scales. Aggregation was by day, by trip, and by outing to produce figures showing the patterns of use. Aggregation by vehicle mission followed to characterize use for the agency fleet. Section 5 presents these results. Data were extrapolated to provide the overall fleet usage and benefit analysis when fleet information was provided. Section 6 presents these benefits. Intertek observations are included in Section 7.

Statistical data analysis uses Microsoft ${ }^{\circledR}$ Excel and Tableau ${ }^{\circledR}$ software. Frequency distributions summarize the travel behavior of each vehicle and vehicle mission during the study period. Rounding of the tables and figures are to three significant digits.

\section{VEHICLES}

\subsection{Vehicle Missions}

The vehicle mission is an important characteristic in the fleet study. Information used to define the vehicle mission includes the vehicle's configuration, vehicle use, classification per 40 CFR Part 600.31582 and the Environmental Protection Agency (EPA), the participating agency use, and generally assumed vehicle use. Based on fleet information gathered, Intertek has established the following seven mission/vehicle categories for analysis. They are listed as follows and examples are depicted in Figure 5:

1. Pool vehicles: A pool vehicle is any automobile (other than the low-speed vehicles identified below) manufactured primarily for use in passenger transportation, with not more than 10 passengers.

2. Enforcement vehicles: Vehicles specifically approved in an agency's appropriation act for use in apprehension, surveillance, police, or other law enforcement work. This category also includes site security vehicles, parking enforcement, and general use, but the vehicles are capable of requirements to support enforcement activities. Appendix C provides further definition.

3. Support vehicles: Vehicles assigned to a specific work function or group to support the mission of that group. Vehicles are generally passenger vehicles or light-duty pickup trucks and may contain after-market modifications to support the mission. 
4. Transport vehicles: Light, medium, or heavy-duty trucks used to transport an operator and tools or equipment of a non-specific design or nature. The vehicle's uses include repair, maintenance, or delivery.

5. Specialty vehicles: Vehicles designed to accommodate a specific purpose or mission (such as ambulances, mobile cranes, and handicap controls).

6. Shuttles/buses: Vehicles designed to carry more than 12 passengers and further outlined in 49 CFR 532.2.

7. Low-speed vehicle: Vehicles that are legally limited to roads with posted speed limits up to $45 \mathrm{mph}$ and that have a limited load-carrying capability.

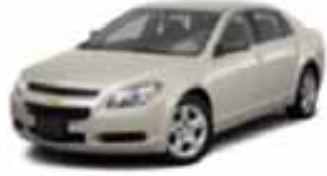

Pool Vehicle

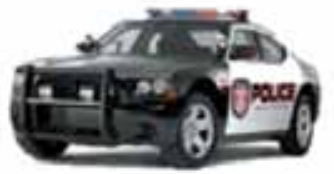

Enforcement Vehicle

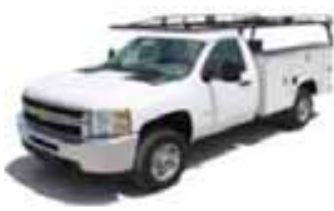

Support Vehicle

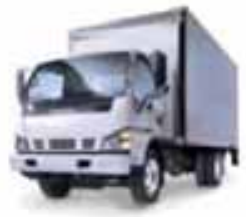

Transport Vehicle

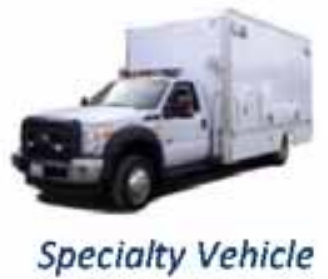

Specialty Vehicle

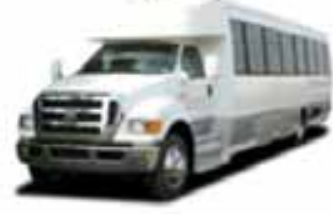

Shuttle / Bus

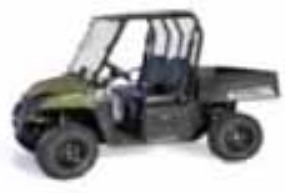

Low Speed

Vehicles

Figure 5. Vehicle missions.

\subsection{Alternative Fuel Vehicles}

As the operating agency, NIH has a unique opportunity to plan for adoption of BEVs and PHEVs, along with planning for the supporting infrastructure. The adoption of PHEVs and BEVs is a primary goal of the General Services Administration (GSA) and supports the directives previously referenced.

As GSA increases its certification of PHEVs and BEVs, agencies can plan for vehicle replacement through GSA for passenger vehicles and trucks. Table 2 presents the replacement requirements for fleet vehicles. Note that both the age and mileage requirements need to be met in order for the vehicle to qualify for replacement, except where noted as "or."

Table 2. GSA vehicle replacement requirements.

\begin{tabular}{cccc}
\hline \multicolumn{4}{c}{ GSA Vehicle Replacement Requirements ${ }^{14}$} \\
& Fuel Type & Years & Miles \\
\hline Passenger vehicles & Gasoline or & 3 & 36,000 \\
& Alternative Fuel & 4 & 24,000 \\
& Vehicle & 5 & Any mileage \\
& & Any age & 75,000
\end{tabular}

\footnotetext{
${ }^{14}$ http://www.gsa.gov/graphics/fas/VehicleReplacementStandardsJune2011Redux.pdf [accessed January 10, 2014].
} 


\begin{tabular}{cccc}
\hline & \multicolumn{3}{c}{ GSA Vehicle Replacement Requirements } \\
& Fuel Type & Years & Miles \\
\hline & Hybrid & 5 & Any miles \\
Low Speed BEV & 6 & Any miles \\
Light trucks 4 x 2 & Non-diesel & 7 & 65,000 \\
& Diesel & 8 or & 150,000 \\
Light trucks 4 x 4 & Hybrid & 7 & Any mileage \\
& Non-diesel & 7 or & 60,000 \\
& Diesel & 8 or & 150,000 \\
& Hybrid & 7 & Any mileage \\
\hline
\end{tabular}

\subsection{Battery Electric Vehicle and Plug-In Hybrid Electric Vehicle Benefits/Challenges}

BEVs are fully powered by the battery energy storage system available onboard the vehicle. The Nissan Leaf is an example of a BEV. Because the BEV has no other energy source for propulsion, the range, power requirements, and mission of the needed vehicle factor greatly in purchasing decisions. Maximizing BEV capabilities typically requires batteries more than an order of magnitude larger in capacity than the batteries in hybrid electric vehicles.

PHEVs obtain their power from at least two energy sources. The typical PHEV configuration uses a battery and an ICE, powered by either gasoline or diesel. PHEV designs differ between manufacturers. All have a charge-depleting (CD) mode in which the battery is depleted of its stored energy to propel the vehicle and a charge-sustaining (CS) mode (or extended range mode), which is entered after CD mode is complete and in which the battery and the ICE work together to provide propulsion while the state of charge of the battery is maintained between set limits. Some PHEVs' operation in CD modes is purely electric, while others employ the engine to supplement battery power during the initial battery depletion to a set state of charge (usually below $50 \%$ ).

\subsubsection{Battery Electric Vehicle Benefits/Challenges}

EPA identifies the following benefits of BEVs: ${ }^{15}$

- Energy efficient: Electric vehicles convert about 59 to $62 \%$ of the electrical energy from the grid to power at the wheels, whereas conventional gasoline vehicles only convert about 17 to $21 \%$ of the energy stored in gasoline to power at the wheels.

- Environmentally friendly: PEVs emit no tailpipe pollutants, although the power plant producing the electricity may emit them. Electricity from nuclear, hydro, solar, or wind-powered plants causes no air pollutants.

- Performance benefits: Electric motors provide quiet, smooth operation and exhibit maximum torque at zero and low speeds, while also requiring less maintenance than ICEs.

- Reduce energy dependence: Electricity is a domestic energy source.

EPA also identifies challenges associated with BEVs, including the following:

\footnotetext{
${ }^{15}$ http://www.fueleconomy.gov/feg/evtech.shtml [accessed December 27, 2013].
} 
- Driving range: Most BEVs can only travel about 100 to 200 miles (or less) before recharging, whereas gasoline vehicles can often travel over 300 miles before refueling and some much further.

- Recharge time: Fully recharging the battery pack can take 4 to 8 hours. With a high-power DC fast charger, restoration from a depleted state to $80 \%$ capacity can take approximately 30 minutes.

- Battery cost: The large battery packs are expensive and may need to be replaced one or more times.

- Bulk and weight: Battery packs are heavy and take up considerable vehicle space.

\subsubsection{Plug-in Hybrid Electric Vehicle Benefits/Challenges}

EPA identifies the following benefits of PHEVs: ${ }^{16}$

- Less petroleum use: PHEVs are expected to use about 40 to $60 \%$ less petroleum than conventional vehicles. Because electricity is produced primarily from domestic resources, PHEVs reduce dependence on oil.

- Fewer emissions: PHEVs are expected to emit fewer GHG emissions than conventional vehicles, but as with BEVs, the difference depends largely on the type of power plant supplying the electricity.

- Higher vehicle costs, lower fuel costs: PHEVs will likely cost $\$ 1,000$ to $\$ 7,000$ more than comparable non-PHEVs. Fuel will cost less because electricity is much cheaper than gasoline, but the fuel savings depends on how much of the driving is done on the off-board electrical energy.

- Recharging takes time: Recharging the battery typically takes several hours. However, PHEVs do not have to be plugged in to be driven. They can be fueled solely with gasoline, but will not achieve maximum range, fuel economy, or fuel savings without charging.

- Measuring fuel economy: Because a PHEV can operate on electricity alone, gasoline alone, or a mixture of the two, EPA provides a fuel economy estimate for gasoline-only operation (CS mode), electric-only operation (all-electric CD mode), or combined gasoline and electric operation (blended CD mode).

In most cases, the PEV retail cost is higher than a non-PEV model. This incremental purchase cost may be a fleet budget challenge; however, many original equipment manufacturers (OEMs) have offered incentives to encourage the use and adoption of BEVs and PHEVs. Some OEMs have recently reduced the vehicle cost, while also increasing vehicle range. Additionally, federal and state incentives have increased the attractiveness of purchasing a PEV. A common assumption is that increasing PEV sales will result in a reduction in this incremental purchase cost and a positive feedback loop will ensue.

\subsection{Plug-In Electric Vehicle Availability}

GSA provides a summary of light] and medium-duty passenger vehicles available for lease or purchase through the GSA portal, ${ }^{17}$ although not all BEVs and PHEVs currently on the market are 'certified' to be GSA replacements. Vehicles not on the GSA list of 'certified' vehicles require an agency to self-certify a functional need or provide alternative measures for exemptions. Table 3 summarizes the vehicles that may be suitable replacements and are certified replacements through GSA. Note that the "CD/CS" column provides the EPA fuel economy values for CD and CS modes. The fuel economy of CD mode is provided in units of miles-per-gallon-of-gasoline-equivalent (MPGe). This metric allows for electricity consumption during CD mode to be compared with fuel consumption during CS mode (or against conventional vehicles). The Nissan Leaf and Mitsubishi i-MiEV are not included in the alternative fuel guide for 2014, but they have appeared in previous guides.

\footnotetext{
${ }^{16} \mathrm{http}: / /$ www.fueleconomy.gov/feg/phevtech.shtml [accessed July 19, 2013].

${ }^{17}$ http://www.gsa.gov/portal/content/104224 [accessed March 6, 2014].
} 
Replacement is dependent on vehicle configuration characteristics and the vehicle mission. Further evaluation related to vehicle purpose and mission follows in Section 5.

Tables 4 through 7 provide summaries of PHEVs and BEVs either currently available or near commercialization in both passenger cars and pickup trucks, but do not appear on the GSA 'certified' vehicle list. These vehicles may qualify for use by the agency through demonstrating a functional need.

Table 3. GSA-certified PEVs.

\begin{tabular}{llccc}
\hline \multicolumn{1}{c}{ Make/Model } & \multicolumn{1}{c}{ GSA Class } & Type & CD/CS & GSA Incremental Price \\
\hline Chevrolet Volt & Sedan, subcompact & PHEV & $98 \mathrm{MPGe} / 37 \mathrm{mpg}$ & $\$ 17,087.18$ \\
Ford C-MAX Energi & Sedan, subcompact & PHEV & $100 \mathrm{MPGe} / 38 \mathrm{mpg}$ & $\$ 14,899.52$ \\
Ford Focus Electric & Sedan, subcompact & BEV & $110 \mathrm{MPGe} / 99 \mathrm{mpg}$ & $\$ 16,573.09$ \\
Ford Fusion Energi & Sedan, compact & PHEV & $100 \mathrm{MPGe} / 38 \mathrm{mpg}$ & $\$ 19,289.99$ \\
\hline
\end{tabular}

Note that EPA differs in vehicle class. EPA identifies the Volt as a compact, the C_MAX Energi as a midsize, the Fusion Energi as a midsize, and the Focus as a compact. ${ }^{18}$

Table 4. OEM PHEV cars and availability.

\begin{tabular}{llc}
\multicolumn{1}{c}{ Make } & \multicolumn{1}{c}{ Model } & Model Year \\
\hline Audi & A3 eTron PHEV & 2015 (estimate) \\
Chevrolet & Volt & 2011 \\
Honda & Accord PHEV & 2014 \\
Toyota & Prius PHEV & 2012 \\
Volvo & V60 Plug-in & 2016 (estimate) \\
BMW & i3 with range extender & 2014 \\
\hline
\end{tabular}

Table 5. OEM BEV cars and availability.

\begin{tabular}{llc}
\multicolumn{1}{c}{ Make } & \multicolumn{1}{c}{ Model } & Model Year \\
\hline BMW & i3 & 2014 \\
Chevrolet & Spark EV & 2014 \\
Fiat & 500e & 2013(California only) \\
Ford & Focus Electric & 2012 \\
Honda & Fit EV & 2013 \\
Kia & Soul EV & 2014 (estimate) \\
Mercedes-Benz & B-Class ED & 2015 (estimate) \\
Nissan & Leaf & 2011 \\
smart & ED & 2014 \\
Tesla & Model S & 2012 \\
Tesla & Model X & 2015 (estimate) \\
Volkswagen & Golf & 2015 (estimate) \\
Volvo & C30 Electric & 2016 (estimate) \\
\hline
\end{tabular}

\footnotetext{
${ }^{18} \mathrm{http}: / /$ www.fueleconomy.gov/feg/Find.do?action=sbs\&id=34130 [accessed August 1, 2014].
} 
Table 6. OEM PHEV trucks, vans, and availability.

\begin{tabular}{llc}
\multicolumn{1}{c}{ Make } & \multicolumn{1}{c}{ Model } & Model Year \\
\hline Land Rover & Range Rover Sport & 2016 (estimate) \\
Mitsubishi & Outlander PHEV & 2015 (estimate) \\
Via & VTRUX VR300 & 2013 \\
\hline
\end{tabular}

Table 7. OEM BEV trucks, vans, and availability.

\begin{tabular}{llc} 
Make & \multicolumn{1}{c}{ Model } & Model Year \\
\hline Nissan & eNV200 & 2015 (estimate) \\
Toyota & RAV4 EV & 2013 (California only - elsewhere 2015 estimate) \\
\hline
\end{tabular}

As further indication of the expanding market for PEVs, companies are offering after-market vehicle upgrades involving the addition of plug-in capabilities to OEM vehicles. For example, Echo Automotive headquartered in Scottsdale, Arizona offers a "...low-cost, bolt-on, plug-in hybrid system that can quickly be installed on new or existing fleet vehicles to increase fuel efficiency and decrease operating costs - all without affecting the OEM power train or requiring costly infrastructure." ${ }^{\prime 19}$ Options such as this company's conversions might be of benefit to NIH fleet vehicles for which no replacement PEV is currently available.

\subsection{Plug-In Electric Vehicle Charging}

Refueling electric vehicles presents some challenges and some opportunities not encountered when refueling petroleum-fueled vehicles. Recharging the battery of a PHEV follows the same methodology as that for BEVs. This section provides basic information on recharging PEVs.

\subsubsection{Electric Vehicle Supply Equipment Design}

4.5.1.1 Charging Components. Electric vehicle supply equipment (EVSE) stations deliver electric power from the utility to the applicable charge port on the vehicle. Figure 6 illustrates the primary components of a typical alternating current (AC) Level 2 EVSE unit.

The electric utility delivers AC current to the charging location. The conversion from AC to direct current (DC) electricity necessary for battery charging can occur either on or off board the vehicle. Section 4.5.1.2 provides further explanation of the different EVSE configurations. For onboard conversion, AC current flows through the PEV inlet to the onboard charger. The charger converts AC to the DC current required to charge the battery. A connector attached to the EVSE inserts into a PEV inlet to establish an electrical connection to the PEV for charging and information/data exchange. Off-board conversion, also known as DC charging, proceeds in a similar manner except that the AC to DC conversion occurs in a charger that is off board the vehicle and, thus, bypasses any onboard charger. For both AC and DC charging, the PEV's battery management system on board the vehicle controls the battery rate of charge, among other functions. All current PEVs have an onboard charger; some BEVs (but no PHEVs currently) accommodate DC charging.

4.5.1.2 Charging Configurations and Ratings. The Society of Automotive Engineers standardized the requirements, configurations, and equipment followed by most PEV suppliers in the United States in the J1772 Standard. Figure 7 summarizes these attributes and the estimated recharge times. Actual recharge times depend on the onboard equipment, including the charger, battery, and battery management system.

\footnotetext{
${ }^{19}$ http://www.echoautomotive.com/index.php?option=com_content\&view=article\&id=8 [accessed July 14, 2014].
} 
Most PEV manufacturers supply an AC Level 1 cord set with the vehicle, which provides sufficient capabilities for some drivers, but often provides an emergency backup capability because of the long recharge times. AC recharging capabilities found in the public arena more typically are AC Level 2. Figure 8 depicts a typical J1772-compliant inlet and connector for both AC Levels 1 and 2.

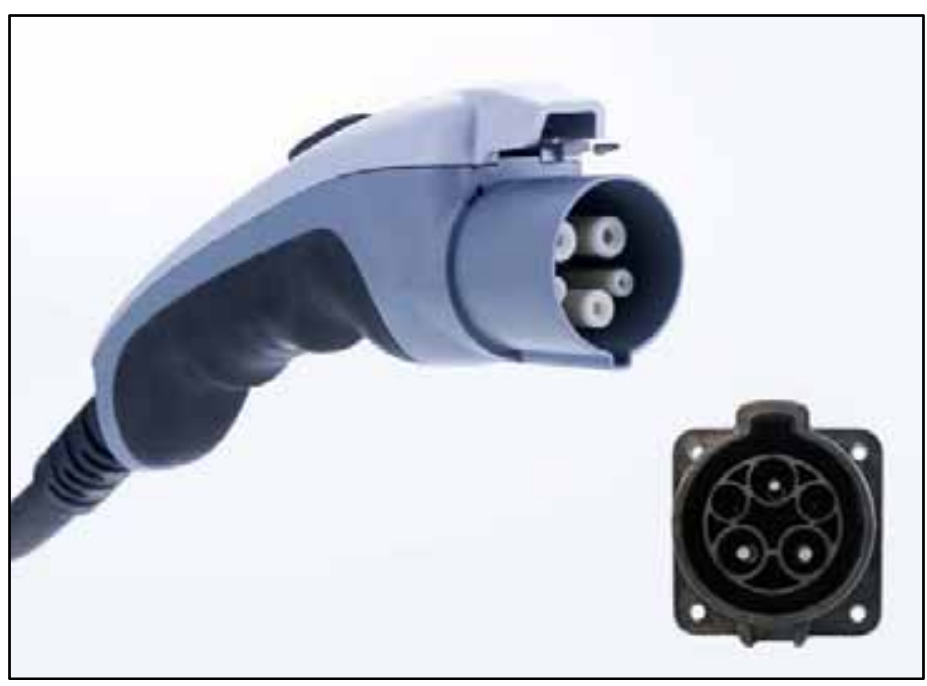

Figure 8. J1772 connector and inlet. ${ }^{22}$

The J1772 standard also identifies requirements for DC charging. For PEVs that accept both AC and DC inputs, the Society of Automotive Engineers approved a single connector and inlet design. Figure 9 shows this connector, which is colloquially known as the J1772 "combo connector."
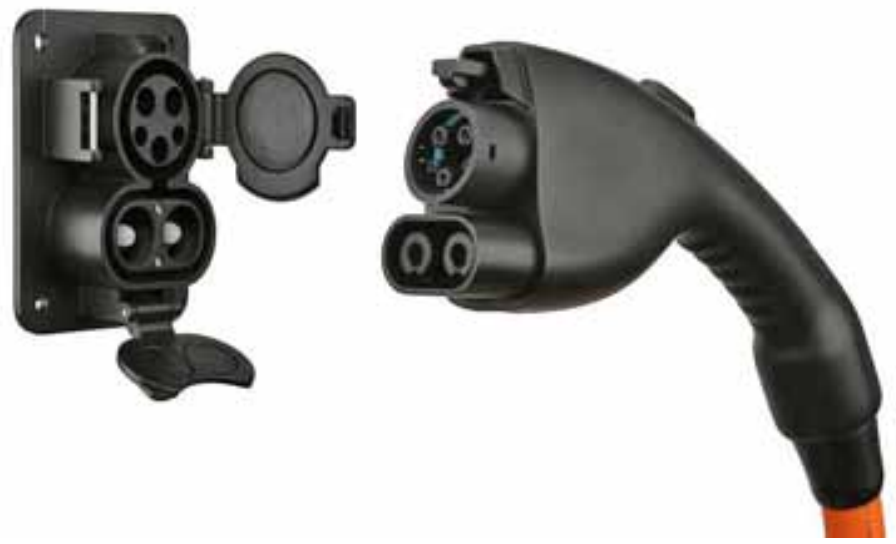

Figure 9. J1772-compliant combo connector. ${ }^{23}$

Some BEVs introduced in the United States prior to approval of the J1772 standard for DC charging employ the CHAdeMO (designed in Japan) standard for connector and inlet design. Figure 10 shows this connector. EVSE units that are either J1772-compliant or CHAdeMO-compliant are both known as DC fast chargers (DCFCs).

${ }^{22}$ http://carstations.com/types/j09 [accessed January 15, 2014]

${ }^{23} \mathrm{http}$ ://www.zemotoring.com/news/2012/10/sae-standardizes-j1772-fast-dc-charging-up-to-100-kw [accessed January 15, 2014] 
The presence of the two separate standards for DC charging presents challenges for vehicle owners to ensure that the EVSE accessed provides the appropriate connector for their vehicle inlet. Not all PEV suppliers include DC charging options. BEV suppliers have provided DC inlets where PHEV suppliers have not, because the rapid recharging provides opportunities for expanded vehicle range with minimal operator wait times. PHEV operators can rely on the gasoline drive in the event they deplete the vehicle's battery; at present, no PHEV on the market or near commercialization has DC charging capability (although the Mitsubishi Outlander PHEV is rumored to be offering DC charging capability as an option). It is noted that DC Level 1 and DC Level 2 charging are commonly combined and labeled DCFC.

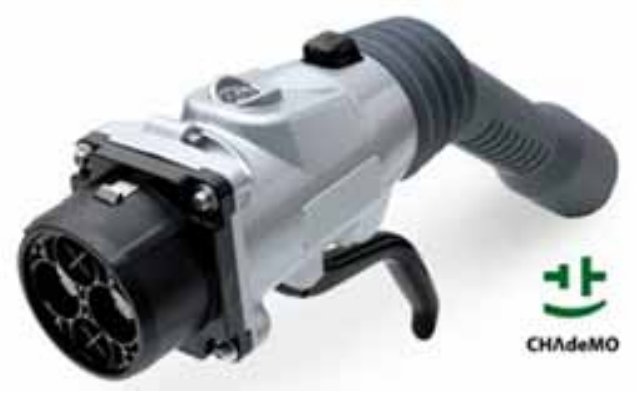

Figure 10. CHAdeMO-compliant connector. ${ }^{24}$

Because the battery of a BEV is typically much larger than that of a PHEV, recharge times are longer (see Figure 7). BEVs that see daily mileage near the limits of the advertised range do better when recharged using AC Level 2 EVSE or DCFCs, because AC Level 1 recharge times are usually extensive. PHEVs, on the other hand, generally can use AC Level 1 EVSE for overnight charging to ensure a fully charged battery at the start of daily use. AC Level 2 EVSE units provide greater range in the shortest amount of time when intermediate or opportunity charging. DCFCs provide the fastest recharge capability for those vehicles equipped with DCFC.

\subsubsection{Electric Vehicle Supply Equipment Stations}

AC Level 2 charging is the predominant rating of publicly accessible EVSE because of its wide acceptance by auto manufacturers and recharge times that are faster than AC Level 1 charging. Purchase and installation costs are more manageable than DCFCs and less space is required. There are several manufacturers of AC Level 2 equipment and the agency should review brands for comparison purposes. Figure 10 provides an example of a public AC Level 2 EVSE unit. ${ }^{25}$

DCFCs also are available from several manufacturers. Figure 12 illustrates one such charger. ${ }^{26}$ This particular charger uses the CHAdeMO connector standard.

In general, installation costs are higher for DCFCs because of the higher voltage requirements and the inclusion of the AC to DC converter and other safety and design features. Costs for both types are highly dependent on site characteristics such as distance to the nearest power source, asphalt or concrete cutting and repair, conduit requirements, and payment systems if any.

Payment and equipment control systems included by some suppliers provide the potential for use by privately owned vehicles for a fee, but can allow agency fleet vehicle use without direct payment. These systems also allow for accurate record keeping of vehicle charging requirements.

\footnotetext{
${ }^{24}$ https://radio.azpm.org/p/azspot/2012/5/10/1632-electric-cars/ [accessed January 15, 2014].

${ }^{25}$ www.eaton.com/ [accessed January 29, 2014].

${ }^{26} \mathrm{http}$ ://evsolutions.avinc.com/products/public_charging/public_charging_b [Accessed April 16, 2014].
} 


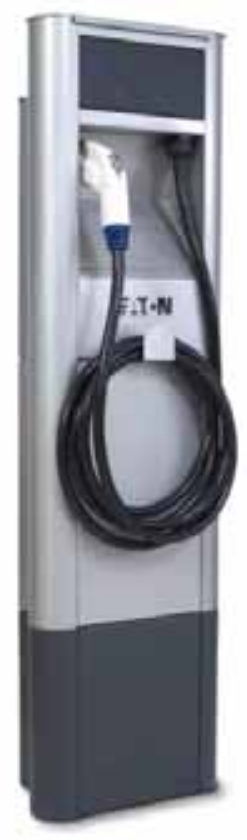

Figure 11. Public AC Level 2 EVSE.

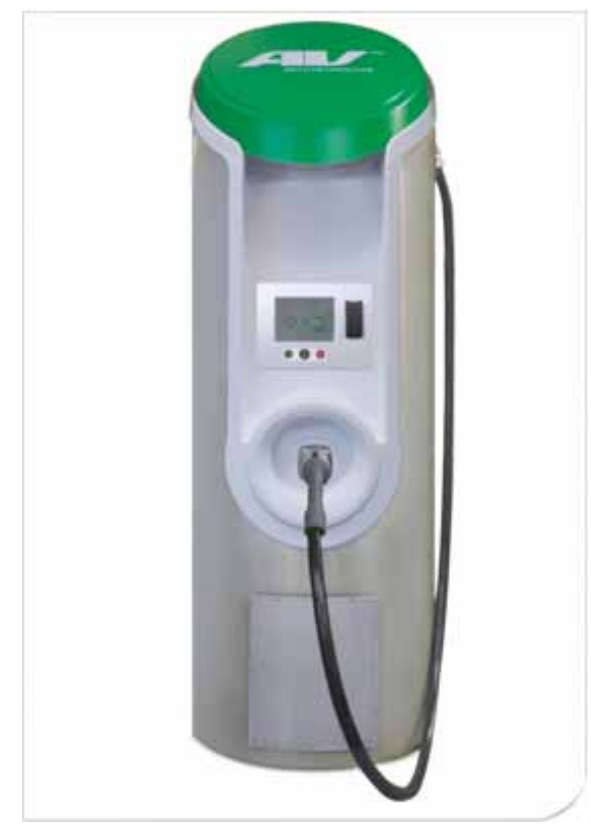

Figure 12. Public DCFC unit.

\section{NATIONAL INSTITUTE OF HEALTH ANALYSIS \\ 5.1 National Institute of Health Fleet}

NIH reports 319 vehicles in their complete fleet for all institutes. Table 8 shows the breakdown of EPA vehicle class. Based on NIH input on fleet vehicles, an assessment of mission by vehicle type was completed. Table 9 shows the results of that assessment. 
Table 8. NIH fleet vehicles.

\begin{tabular}{|c|c|c|c|c|c|c|c|c|c|c|c|c|}
\hline & $\begin{array}{c}\text { Sedan } \\
\text { Compact } \\
\end{array}$ & $\begin{array}{c}\text { Sedan } \\
\text { Midsize } \\
\end{array}$ & $\begin{array}{l}\text { Sedan } \\
\text { Large }\end{array}$ & SUV & $\begin{array}{l}\text { Mini } \\
\text {-van } \\
\end{array}$ & $\begin{array}{c}\text { Cargo } \\
\text { Van } \\
\end{array}$ & $\begin{array}{l}\text { Pass } \\
\text { Van } \\
\end{array}$ & $\begin{array}{l}\text { Pickup } \\
\text { or LD } \\
\text { Truck } \\
\end{array}$ & $\begin{array}{c}\text { MD } \\
\text { HD } \\
\text { Truck } \\
\end{array}$ & Bus & Specialty & Total \\
\hline NIH & 2 & 6 & 60 & 49 & 19 & 10 & 7 & 54 & 25 & 4 & 7 & 243 \\
\hline Other Inst. & 1 & 6 & 15 & 4 & 18 & 9 & 5 & 11 & 7 & & & 76 \\
\hline Total & 3 & 12 & 75 & 53 & 37 & 19 & 12 & 65 & 32 & 4 & 7 & 319 \\
\hline
\end{tabular}

Table 9. NIH fleet mission assessment.

\begin{tabular}{|c|c|c|c|c|c|c|c|c|c|c|c|c|}
\hline Mission & $\begin{array}{c}\text { Sedan } \\
\text { Compact } \\
\end{array}$ & $\begin{array}{c}\text { Sedan } \\
\text { Midsize } \\
\end{array}$ & $\begin{array}{l}\text { Sedan } \\
\text { Large }\end{array}$ & SUV & $\begin{array}{l}\text { Mini } \\
\text {-van } \\
\end{array}$ & $\begin{array}{c}\text { Cargo } \\
\text { Van } \\
\end{array}$ & $\begin{array}{l}\text { Pass } \\
\text { Van } \\
\end{array}$ & $\begin{array}{c}\text { Pickup } \\
\text { or LD } \\
\text { Truck } \\
\end{array}$ & $\begin{array}{c}\text { Heavy } \\
\text { Duty } \\
\text { Truck } \\
\end{array}$ & Bus & Specialty & Total \\
\hline Pool & 1 & 2 & 6 & 4 & & & 3 & 3 & & & & 19 \\
\hline Support & 2 & 10 & 38 & 30 & 35 & 19 & 9 & 56 & 1 & & & 200 \\
\hline $\begin{array}{l}\text { Law } \\
\text { Enforce. }\end{array}$ & & & 31 & 18 & 1 & & & 3 & & & & 53 \\
\hline Transport & & & & 1 & 1 & & & 3 & 31 & & & 36 \\
\hline Specialty & & & & & & & & & & & 7 & 7 \\
\hline Bus & & & & & & & & & & 4 & & 4 \\
\hline Total & 3 & 12 & 75 & 53 & 37 & 19 & 12 & 65 & 32 & 4 & 7 & 319 \\
\hline
\end{tabular}

\subsection{Survey Results}

Twenty vehicles were included in the study at NIH. Seven vehicles have pool missions, six have support missions, four have law enforcement missions, and three have transport missions. Table 10 presents a summary of these vehicles and Table 11 provides details about the monitored vehicles.

Table 10 . Vehicle study summary.

\begin{tabular}{|c|c|c|c|c|c|c|c|c|c|}
\hline Mission & $\begin{array}{c}\text { Sedan } \\
\text { Compact }\end{array}$ & $\begin{array}{c}\text { Sedan } \\
\text { Midsize }\end{array}$ & $\begin{array}{l}\text { Sedan } \\
\text { Large }\end{array}$ & SUV & $\begin{array}{l}\text { Mini- } \\
\text { van }\end{array}$ & $\begin{array}{c}\text { Cargo } \\
\text { Van }\end{array}$ & $\begin{array}{l}\text { Pass } \\
\text { Van }\end{array}$ & $\begin{array}{l}\text { Pickup } \\
\text { of LD } \\
\text { Truck }\end{array}$ & Total \\
\hline Pool & & & 2 & 3 & 2 & & & & 7 \\
\hline Support & & & 1 & 2 & & 1 & & 2 & 6 \\
\hline Law Enforce. & & & 4 & & & & & & 4 \\
\hline Transport & & & & 1 & 1 & & & 1 & 3 \\
\hline Total & & & 7 & 6 & 3 & 1 & & 3 & 20 \\
\hline
\end{tabular}

Table 11. Detailed NIH vehicle index.

\begin{tabular}{|c|c|c|c|c|c|c|}
\hline \multicolumn{7}{|c|}{ Vehicle Index } \\
\hline Log & Fleet Vehicle Id & Make & Model & Year & EPA Class & Mission \\
\hline 41 & $* * * 1385$ & Ford & Crown Victoria & 2009 & Sedan - Large & Enforcement \\
\hline 42 & $* * * 2995$ & Chevrolet & Impala & 2010 & Sedan - Large & Pool \\
\hline 43 & $* * * 7017$ & Ford & Escape Hybrid & 2009 & SUV & Pool \\
\hline 44 & $* * * 5470$ & Ford & F-150 & 2010 & Pickup & Support \\
\hline
\end{tabular}




\begin{tabular}{|c|c|c|c|c|c|c|}
\hline \multicolumn{7}{|c|}{ Vehicle Index } \\
\hline Log & Fleet Vehicle Id & Make & Model & Year & EPA Class & Mission \\
\hline 45 & $* * * 5207$ & Dodge & Sprinter & 2002 & Van - Cargo & Support \\
\hline 46 & $* * * 7596$ & Dodge & Durango & 2001 & SUV & Pool \\
\hline 47 & $* * * 8759$ & Chevrolet & Uplander & 2008 & Minivan & Pool \\
\hline 48 & $* * * 7791$ & Dodge & Caravan & 2009 & Minivan & Pool \\
\hline 49 & $* * * 8315$ & Chevrolet & Impala & 2010 & Sedan - Large & Support \\
\hline 50 & $* * * 1384$ & Ford & Crown Victoria & 2009 & Sedan - Large & Enforcement \\
\hline 51 & $* * * 3265$ & Chevrolet & Silverado & 2005 & Pickup & Support \\
\hline 52 & $* * * 1314$ & Chevrolet & HHR & 2010 & SUV & Transport \\
\hline 53 & $* * * 4477$ & Chevrolet & Colorado & 2010 & Pickup & Transport \\
\hline 54 & $* * * 8199$ & Dodge & Caravan & 1999 & Minivan & Transport \\
\hline 55 & $* * * 3815$ & Jeep & Grand Cherokee & 2009 & SUV & Support \\
\hline 56 & $* * * 3952$ & Ford & Expedition & 2006 & SUV & Support \\
\hline 57 & $* * * 8489$ & Chevrolet & Impala & 2010 & Sedan - Large & Pool \\
\hline 58 & $* * * 0758$ & Chevrolet & Impala & 2005 & Sedan - Large & Enforcement \\
\hline 59 & $* * * 0370$ & Chevrolet & Impala & 2005 & Sedan - Large & Enforcement \\
\hline 60 & $* * * 1201$ & Chevrolet & HHR & 2010 & SUV & Pool \\
\hline
\end{tabular}

The vehicle ID is the last four digits of the VIN. Specific vehicle references may be made to the vehicle ID or logger ID in this report.

Appendix B provides the analysis of each individual vehicle included in this study. Grouping the vehicles by mission creates an aggregated view of mission requirements to provide observations related to PEV replacement. The missions of these five categories vary considerably; therefore, these missions are evaluated separately.

\subsection{Data Validity}

NIH data collection took place from January through March 2012. Vehicle data sheets (presented in Appendix B) detail the collected data for each vehicle, including the specific dates the logger provided data.

Of the data collected, validation occurred for $97.9 \%$, while null values exist for the balance. Table 12 shows this information by mission type.

Table 12. Vehicle data logger reporting summary.

\begin{tabular}{cccc}
\hline \multicolumn{4}{c}{ Vehicle Data Logger Reporting Summary } \\
Mission & 96.3 & 3.7 & $100 \%$ \\
Pool & 98.9 & 1.1 & $100 \%$ \\
Support & 97.7 & 2.3 & $100 \%$ \\
Law Enforcement & 99.3 & 0.7 & $100 \%$ \\
Transport & 97.9 & 2.1 & $100 \%$ \\
All Vehicles & &
\end{tabular}




\subsection{National Institute of Health Pool Vehicles Evaluation}

\subsubsection{Survey and Site Information}

Pool vehicles are typically light-duty motor vehicles for use in passenger transportation, with not more than 10 passengers. Pool missions can vary by agency, location, and jurisdiction; however, they typically utilize sedans, minivans, SUVs, vans, or small pickup trucks and typically do not carry specific cargo or equipment. Table 9 identifies the seven vehicles (i.e., two large sedans, two minivans, and three SUVs).

Incorporation of BEVs and/or PHEVs into the pool mission is a definite possibility. Pool vehicles used for shorter trips or outings qualify for BEV or PHEV replacement, while other pool vehicle activities that are associated with longer trips may require PHEV capabilities.

\subsubsection{Summary for Pool Vehicles}

Appendix B provides the vehicle data sheets for each of the pool vehicles monitored. This section aggregates data for all pool vehicles for NIH. Table 13 summarizes pool travel during the study period for those days in which the vehicle was driven. Vehicle use occurred primarily between 0700 and 1500 hours daily. The vehicles were driven 2,702 miles, logged 155 hours of operation and idled 18 hours during the study period.

Table 13. NIH pool vehicles travel summary.

\begin{tabular}{lcccc}
\hline & Pool Vehicles Travel Summary & & \\
& $\begin{array}{c}\text { Per Day } \\
\text { Average/Peak }\end{array}$ & $\begin{array}{c}\text { Per Outing } \\
\text { Average/Peak }\end{array}$ & $\begin{array}{c}\text { Per Trip } \\
\text { Average/Peak }\end{array}$ & Total \\
\hline Travel Distance (Miles) & $20.8 / 317.1$ & $15.7 / 750.2$ & $3.0 / 186.1$ & 2,702 \\
Travel Time (Minutes) & $53.3 / 423$ & $40.3 / 1,175$ & $7.6 / 167.0$ & 6,932 \\
Idle Time (Minutes) & $8.6 / \mathrm{NA}$ & $6.5 / \mathrm{NA}$ & $1.2 / \mathrm{NA}$ & 1,112 \\
\hline
\end{tabular}

\subsubsection{Pool Vehicles Daily Summary}

Figure 13 identifies daily travel distance and time for all pool vehicles. The green line and bars indicate typical electric range on a single charge for a PHEV, while the blue line and bars (including the green bars) indicate the same for a BEV. Figures 14 and 15 show the composite history in distance and time traveled for the pool vehicles. In the stacked bar charts of Figures 14 and 15, the contribution of each vehicle is indicated by a different color.
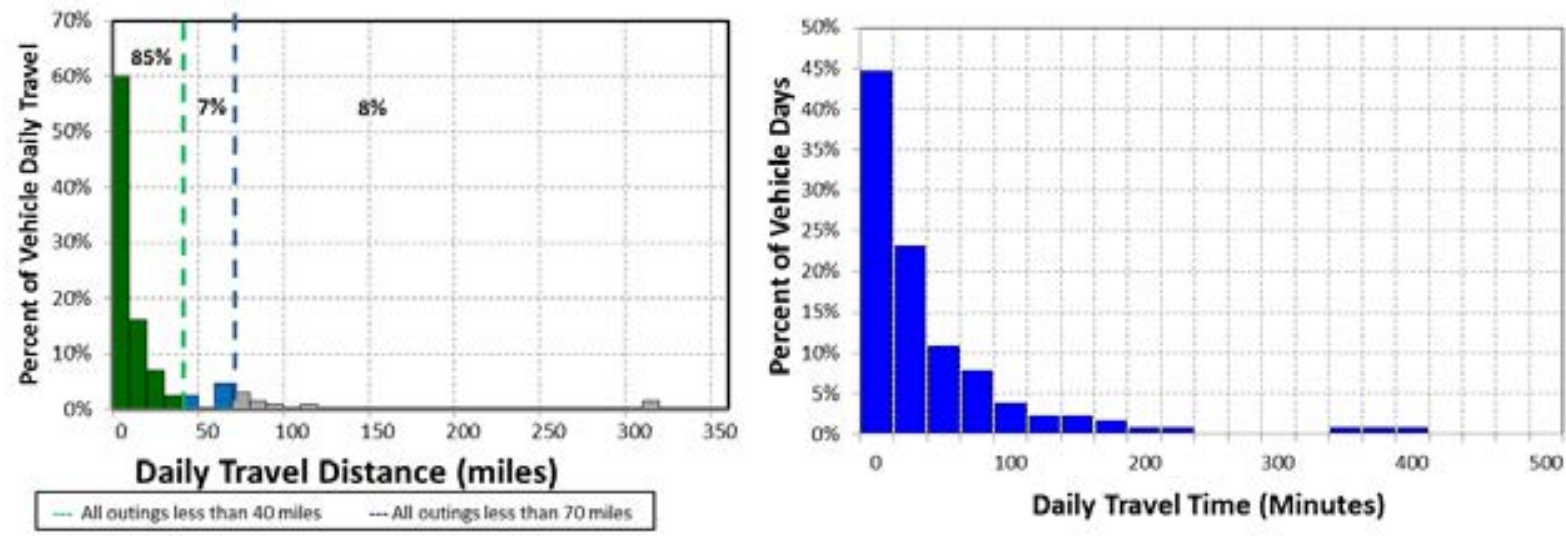

Figure 13. NIH pool vehicle daily travel miles and time (all vehicles). 


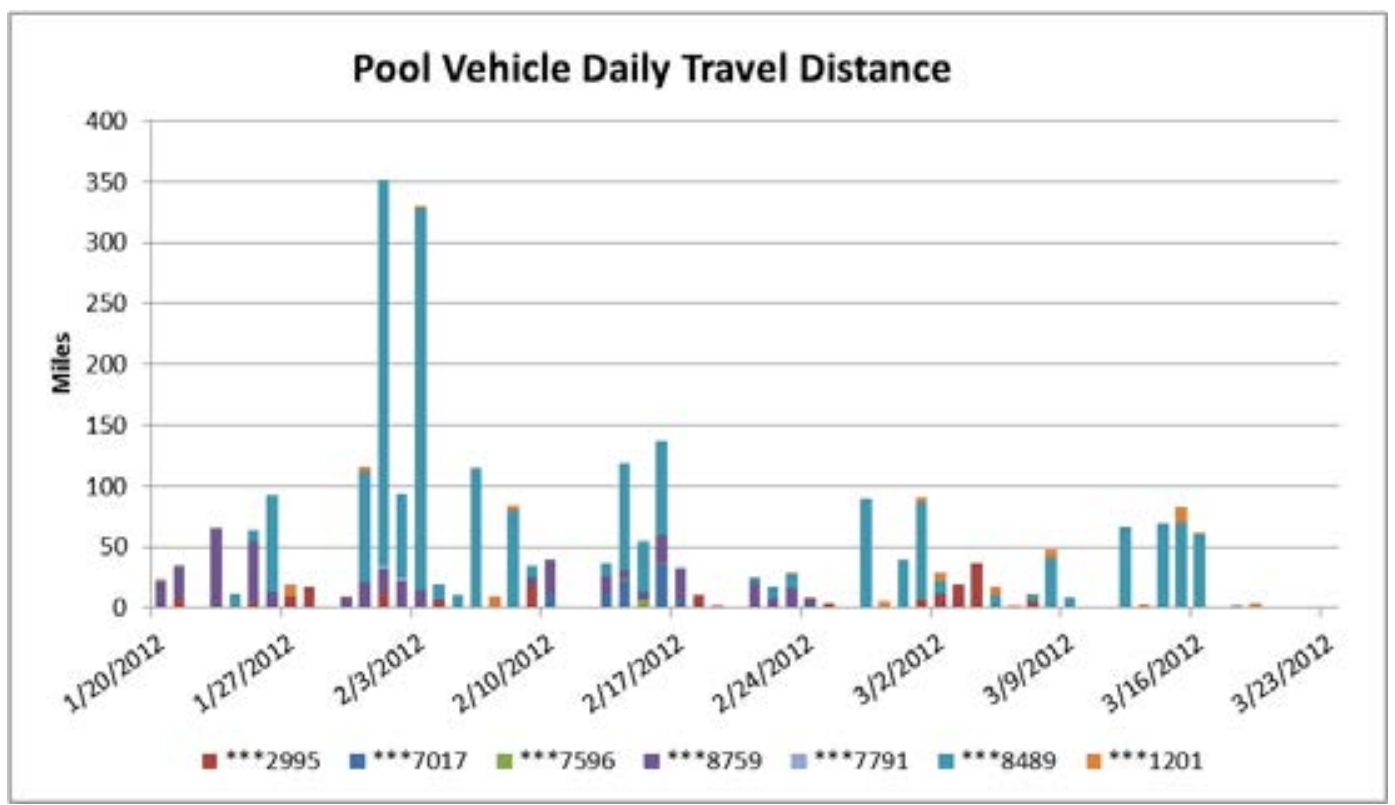

Figure 14. NIH pool vehicle daily travel history (all vehicles).

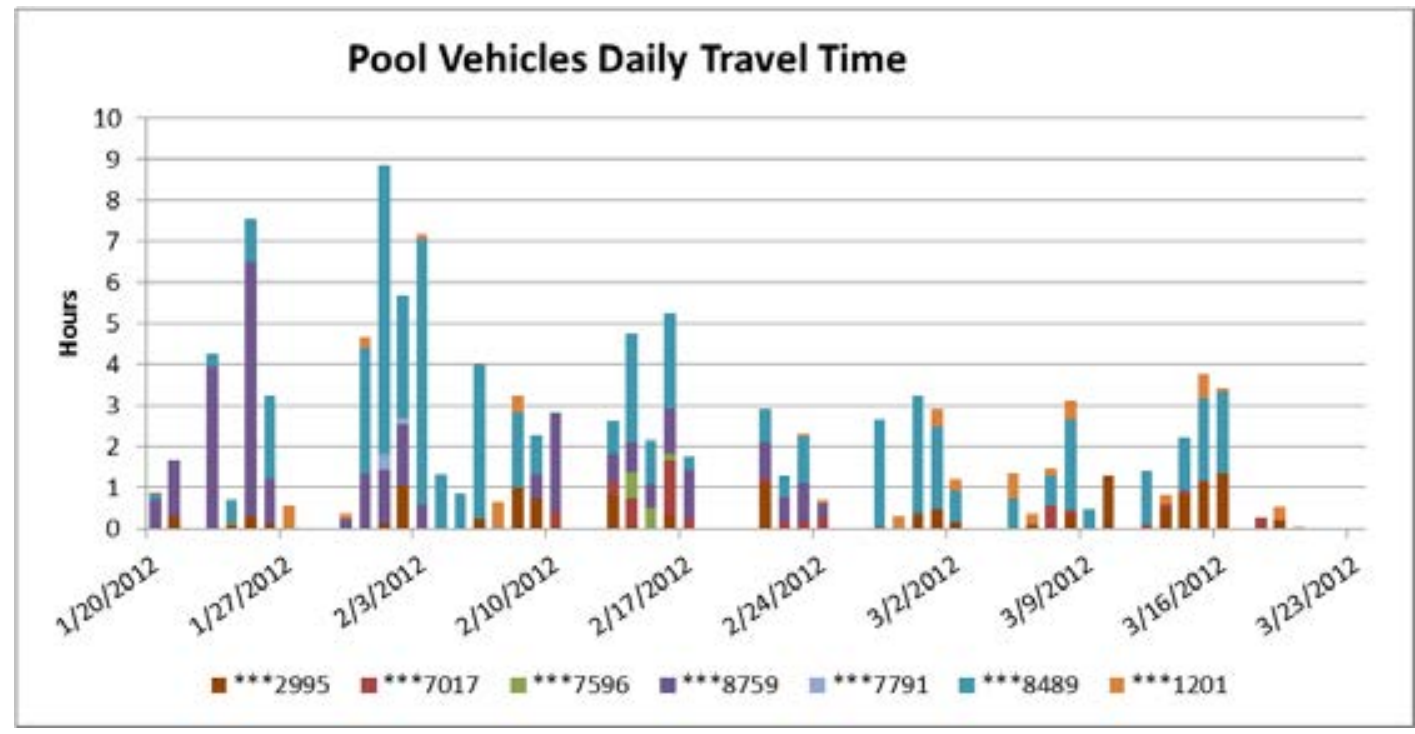

Figure 15. NIH pool vehicles travel time (all vehicles).

Vehicles $* * * 8759$ and $* * * 8489$ experienced the longest travel days. When driven, the average travel distance per day for pool vehicles was 20.8 miles. On $92 \%$ of these vehicle days, the daily travel was less than the 70 miles considered to be within the BEV safe range (i.e., while BEV range can vary based on several factors, most BEVs provide at least 70 miles of vehicle range on a single battery charge), and $8 \%$ percent of pool daily travel was greater than 70 miles. Further, $85 \%$ of vehicle travel days were less than 40 miles considered to be within the CD range of a PHEV.

Figures 14 and 15 show that the vehicles are not used every day, although there are many days when many of the vehicles are in use. Vehicles $* * * 2995$ and $* * * 8489$ had the highest percentage of use in travel days, while vehicles $* * * 7596$ and $* * * 7791$ had the least. Both of the latter vehicles had insufficient data from which to draw general conclusions. Figure 16 displays the summary of use by time of day for all pool vehicles. Figure 17 shows the outing distances traveled, including data for all pool vehicles. 


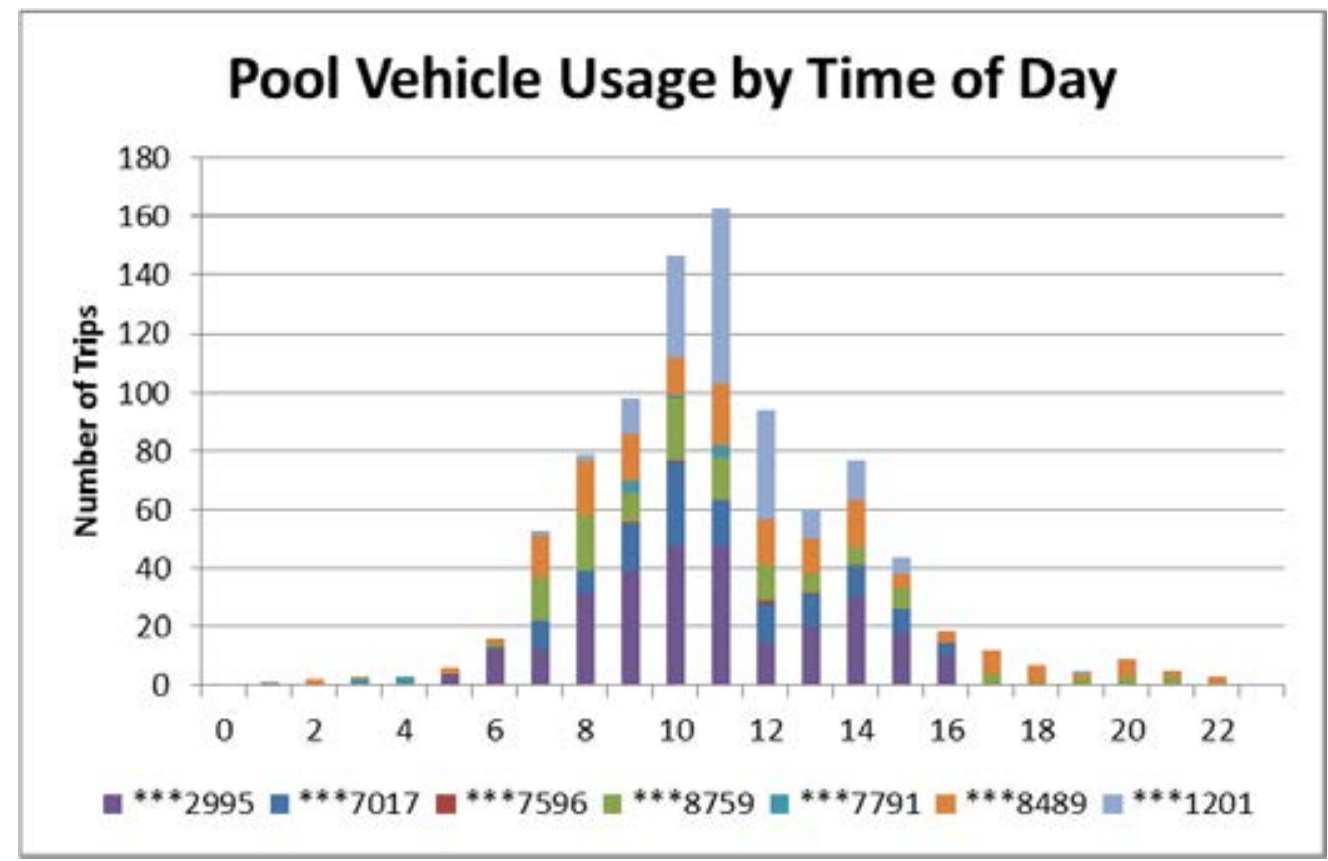

Figure 16. NIH pool vehicles hourly usage.

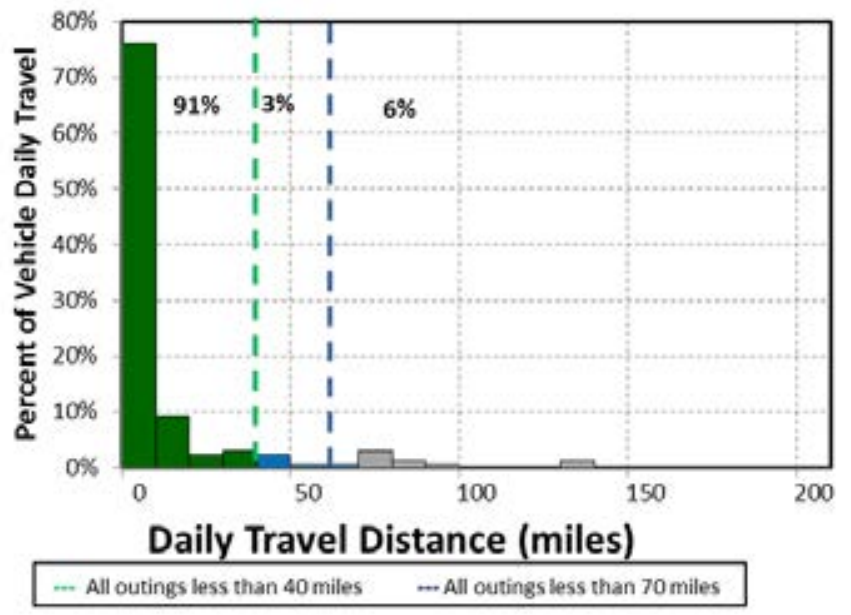

Figure 17. NIH pool vehicle outings. For clarity, the single peak outing of 750.2 miles is not shown.

Appendix B provides the details of each of the pool vehicle's outing travel. The average travel outing for pool vehicles was 15.7 miles. On $94 \%$ of these vehicle outings, the distance traveled was less than the 70 miles considered to be within the BEV safe range. Only $6 \%$ percent of pool outing travel was greater than 70 miles. Further, $91 \%$ of vehicle travel outings were less than 40 miles considered to be within the $\mathrm{CD}$ range of a PHEV. In summary, these vehicles can be characterized by low daily travel and outing distances (the average numbers are quite low) with a few days of travel that exceed the typical BEV range.

\subsubsection{National Institute of Health Pool Vehicle Observations/Summary}

There appears to be three choices for NIH in implementing PEVs into the pool fleet at NIH. It should be noted that the objective would be to incorporate as many BEVs as possible to realize the advantages of reduced petroleum usage and reduced emissions of GHGs. 
1. All BEV fleet: While some BEV manufacturers report vehicle range exceeding 70 miles, Intertek recommends careful evaluation of experienced range to ensure vehicle missions are accomplished. Nevertheless, assuming the 70-mile safe range for a BEV, an all-BEV fleet does not appear to be possible due to the length of some of the daily travel.

2. Mixed BEV/PHEV fleet: Certainly, PHEVs can accomplish the same mission as the current fleet when only considering travel times and distances because the PHEV's gasoline engine can provide motive power when the battery has been depleted. Figure 13 shows that on $85 \%$ of all vehicle travel days, the total daily travel is less than 40 miles, which typically is the maximum distance a PHEV will travel in CD mode. This represents a significant operating cost savings opportunity while retaining the ability to go longer distances when needed. In addition, $91 \%$ of the outings are less than 40 miles and could be completed in CD mode for certain PHEVs if the battery is fully charged prior to the outing.

Meanwhile, $94 \%$ of the outings are within the typical capability of a BEV and the EVSE at the home base could provide recharge energy for another outing. A mixed fleet requires fleet manager attention to appropriately assign vehicles for the anticipated use on that day.

Figure 13 also shows $92 \%$ of daily travel is within the typical range of a BEV. This would suggest that $8 \%$ of the fleet could be PHEVs to handle travel greater than 70 miles per day without requiring additional opportunity charging during daytime stops and $92 \%$ of the fleet could be BEVs. However, this does not allow for use of several vehicles at the same time and would require a greater level of fleet management, with the daily assignment of vehicles based on anticipated driving distance. Allowing more conservatism in assigning vehicles, five BEVs and two PHEVs could conservatively meet the demand for these seven pool vehicles. All monitored pool vehicles have PEV models currently available for potential replacement.

3. All PHEV fleet: As noted above, PHEVs can accomplish the same mission as the current fleet when only considering travel times and distances. Replacing all current vehicles with PHEVs only requires an evaluation of the individual vehicle's capabilities of currently available PHEVs to meet current pool requirements. These seven pool vehicles have replacement PEVs available. Data show that for a significant number of days, the PHEV will operate in CD mode. The first 40 miles of longer travel days would also be powered by (at least mostly) electricity so that $85 \%$ of all pool vehicle travel would be (again, at least mostly) battery powered with only one charge per day. As above, this represents an opportunity for significant operating cost savings while retaining the ability to go longer distances when needed. Intermediate charging opportunities provide additional benefit, enhancing CD mode. Data show significant charging opportunities throughout the day during stop times.

The vehicle summary shows sufficient time for charging at the base location during the course of the day and additional opportunities at intermediate charging stations are not required. These stations also provide charging opportunities for the visiting public, whose fees may assist in offsetting operating costs. Given the availability of daytime changing, with experience, NIH may find a greater fraction of BEVs within the pool vehicle fleet may meet their needs.

Considering a full complement of 19 pool vehicles in the total fleet, Intertek notes that all, except the three passenger vans, have PEVs currently available as a potential replacement. While the remaining vehicles were not monitored, using the same ratio as above suggests a fleet of $11 \mathrm{BEVs}$ and five PHEVs conservatively meets vehicle travel requirements. Typically, additional EVSE at frequently visited locations provide recharging for both the BEV and PHEV that may be of benefit.

\subsubsection{National Institute of Health Pool Vehicle Charging Needs}

Upon review of these data, Intertek suggests replacement of the studied pool fleet with five BEVs and two PHEVs. No available PHEVs at this writing provide for DCFC "nor do the data suggest that this would be a significant benefit for PHEVs in the pool fleet. A DCFC at the home base will provide a more 
rapid recharge for BEVs but appears to be unnecessary, given that the data show that $94 \%$ of outings are less than a typical BEV's driving range.

As noted above, AC Level 2 overnight charging of BEVs is typical, whereas overnight charging of PHEVs can usually be accomplished with AC Level 1 charging.

Intertek's experience suggests that each vehicle should have an assigned charging parking space at its home base. Assigned stations require less management attention to ensure completion of overnight charging. BEVs and PHEVs not assigned to these stations also benefit during visits to the location as part of their normal operation. For the entire fleet of pool vehicles, the 11 BEVs require 11 AC Level 2 EVSE units for overnight charging and the five PHEVs require five AC Level 1 outlets at each vehicles overnight parking location. Intertek recommends a minimum of two EVSE at each location to maximize charge capability without a significant increase in installation costs. The PHEVs can utilize the AC Level 2 EVSE at the home base during the day to increase the amount of vehicle miles traveled in CD mode.

At times, fleet vehicles obtain benefit from using public charging infrastructure. Figure 18 displays the availability of public charging at the time of this writing for the NIH area. All indicated stations are available to the public and provide AC Level 2 or Level 1 EVSE. Some of these may be located along the traffic routes used by NIH vehicles.

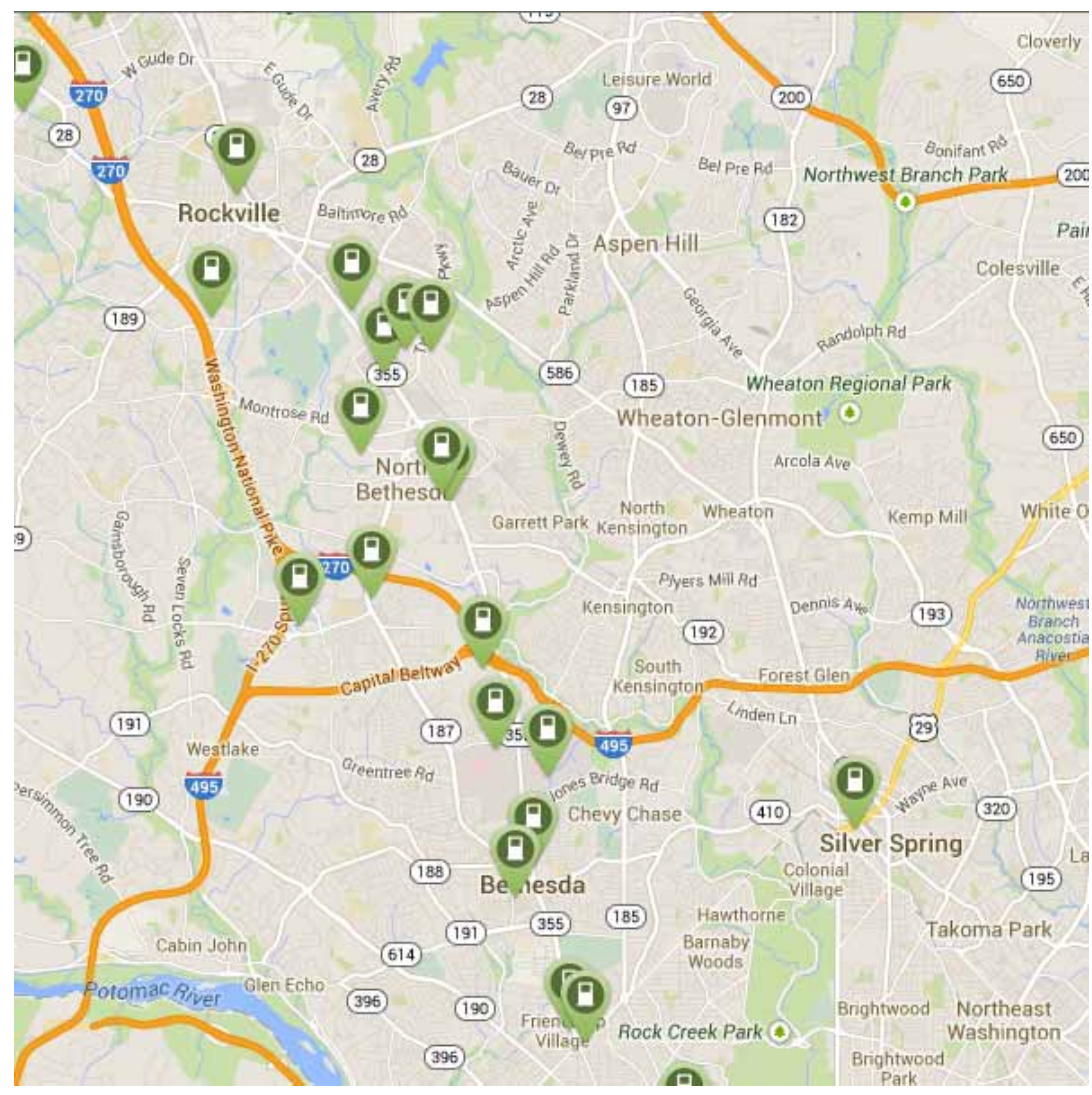

Figure 18. Public EVSE in NIH region. ${ }^{27}$

${ }^{27}$ http://www.plugshare.com/ [accessed October 2, 2014]. 


\subsection{National Institute of Health Support Vehicles Evaluation \\ 5.5.1 Survey and Site Information}

Support vehicles provide a specific work function, facilitating the mission of a particular group. The vehicles are generally passenger or light-duty pickup trucks and may contain after-market modifications to support the mission. While assigned to maintenance and service areas, missions may vary depending on agency needs.

Incorporation of BEVs and/or PHEVs into the support mission is a definite possibility. Support vehicles used for shorter trips or outings qualify for BEV or PHEV replacement, while other support vehicle activities that are associated with longer trips may require PHEV capabilities.

\subsubsection{Summary for Support Vehicles}

Appendix B provides the vehicle data sheets for each of the support vehicles monitored. This section aggregates data for all support vehicles for NIH. Table 14 summarizes support travel during the study period for those days in which the vehicle was driven. Vehicle use occurred primarily between 0600 and 1700 hours daily. The vehicles were driven 1,536 miles, logged 265 hours, and idled 132 hours during the study period.

Table 14. NIH support vehicles travel summary.

\begin{tabular}{|c|c|c|c|c|}
\hline \multicolumn{5}{|c|}{ Support Vehicles Travel Summary } \\
\hline & $\begin{array}{c}\text { Per Day } \\
\text { Average/Peak }\end{array}$ & $\begin{array}{c}\text { Per Outing } \\
\text { Average/Peak }\end{array}$ & $\begin{array}{c}\text { Per Trip } \\
\text { Average/Peak }\end{array}$ & Total \\
\hline Travel Distance (Miles) & $9.6 / 63.5$ & $4.4 / 63.0$ & $0.8 / 33.2$ & 1,536 \\
\hline Travel Time (Minutes) & $99.5 / 425.0$ & $45.6 / 771.0$ & $8.0 / 184.0$ & 15,916 \\
\hline Idle Time (Minutes) & 49.4/NA & 22.6/NA & $4.0 / \mathrm{NA}$ & 7,902 \\
\hline
\end{tabular}

\subsubsection{Support Vehicles Daily Summary}

Figure 19 identifies daily travel distance and time for all support vehicles. The green line and bars indicate typical electric range on a single charge for a PHEV, while the blue line and bars (including the green bars) indicate the same for a BEV. Figures 20 and 21 show the composite history in distance and time traveled for the support vehicles. In the stacked bar charts of Figures 20 and 21, the contribution of each vehicle is indicated by a different color.
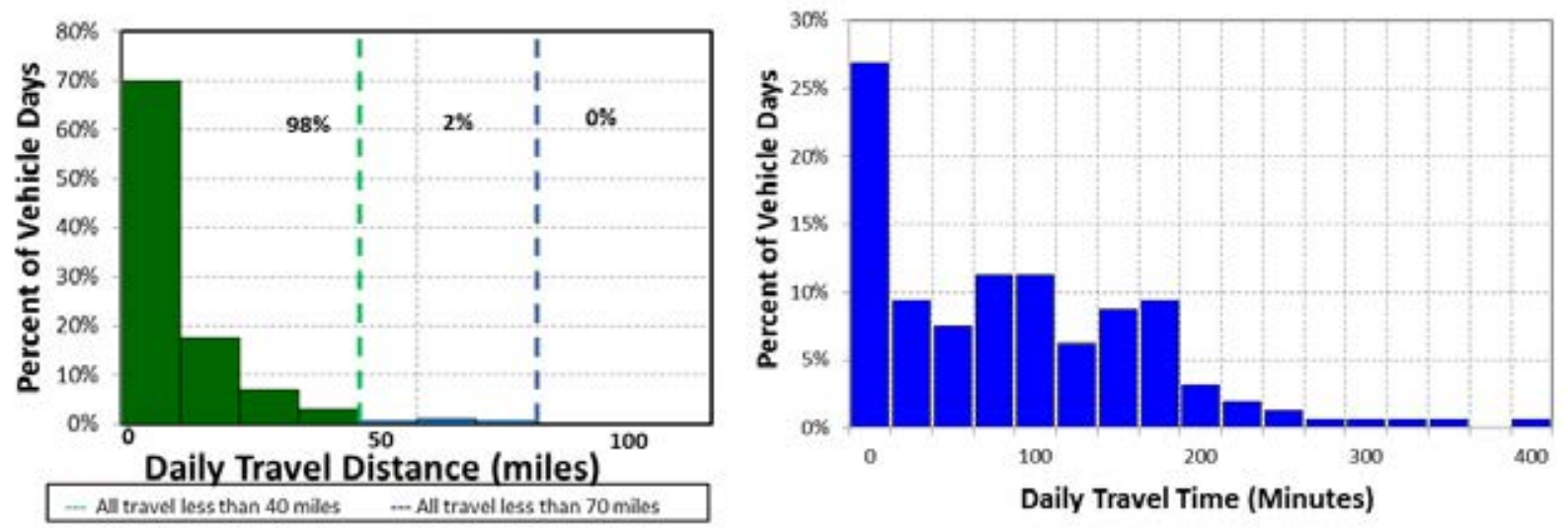

Figure 19. NIH support vehicle daily travel miles and time (all vehicles). 


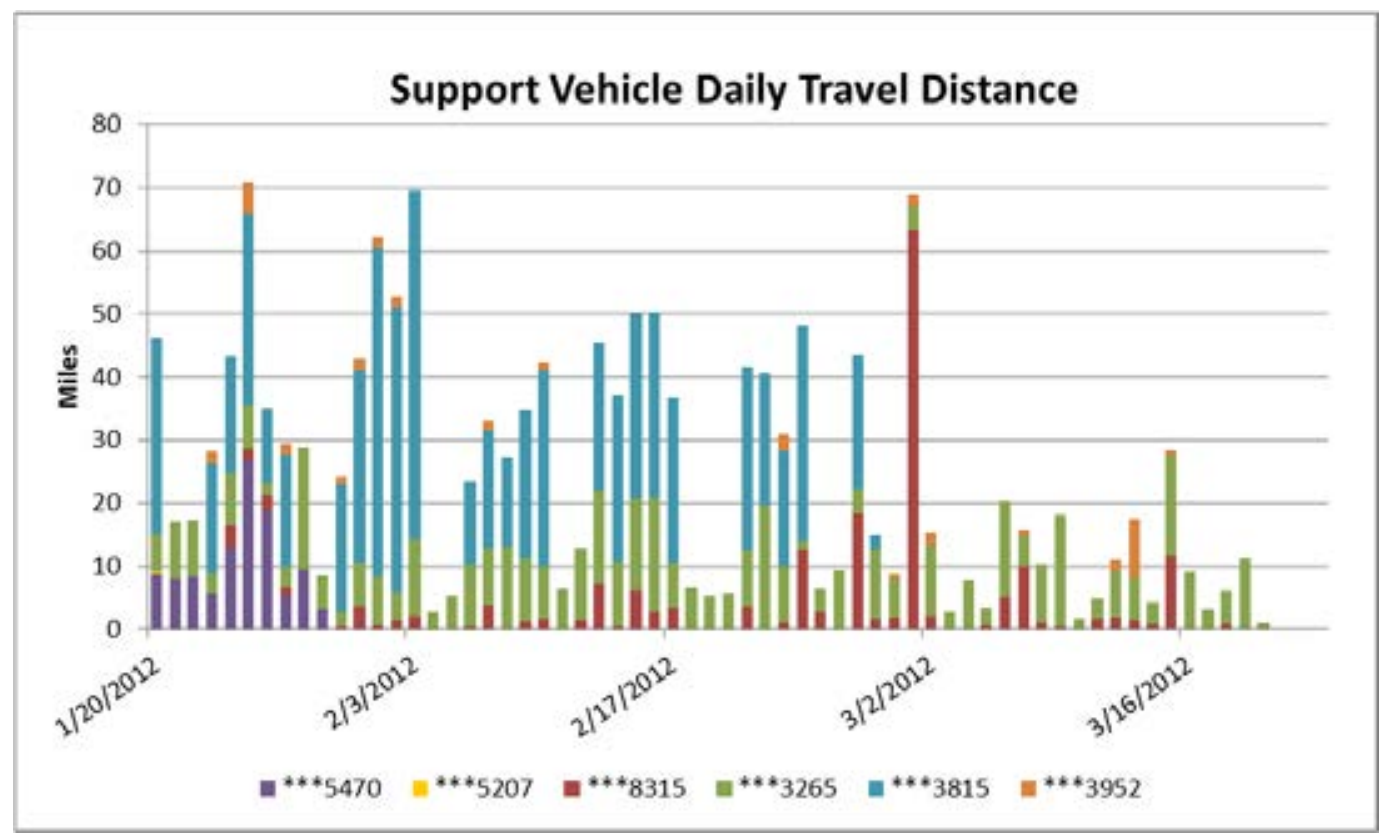

Figure 20. NIH support vehicle daily travel history (all vehicles).

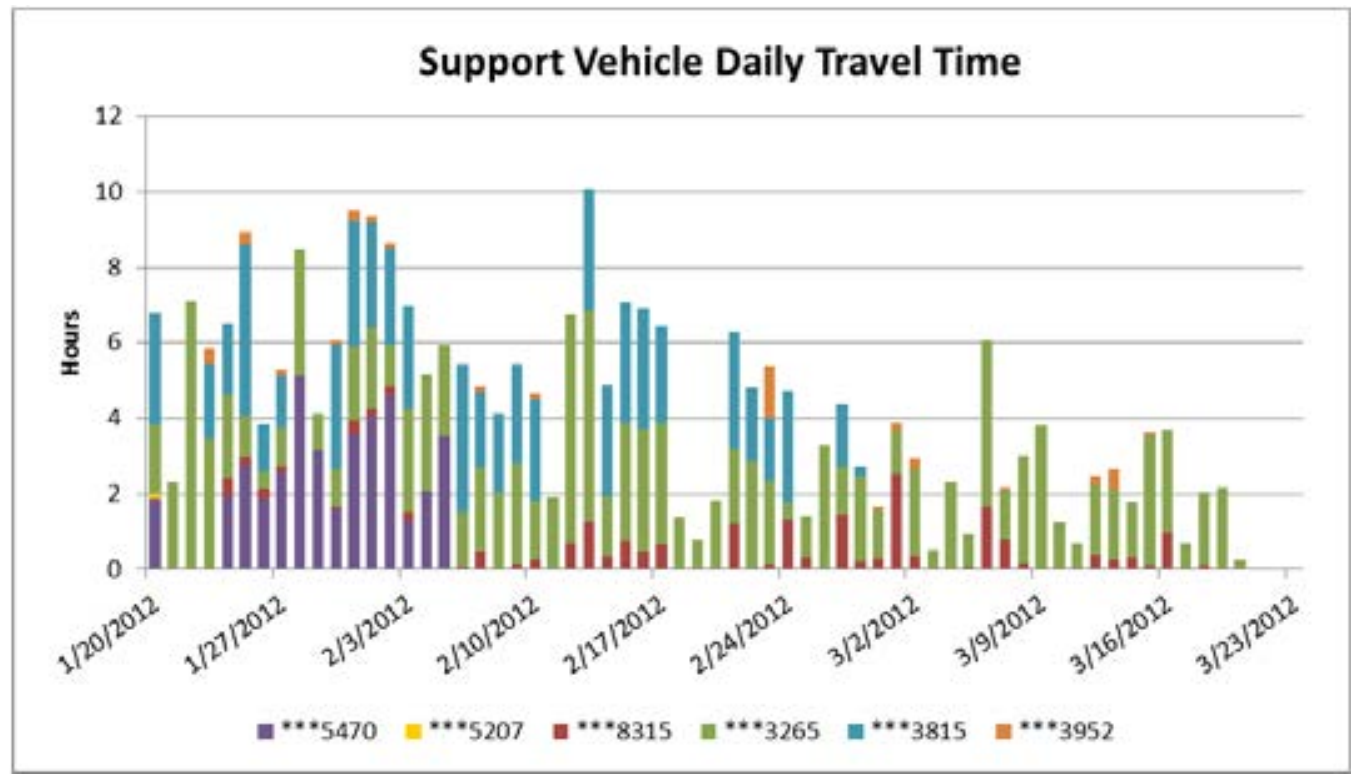

Figure 21. NIH support vehicles travel time (all vehicles).

When driven, the average travel distance per day for support vehicles was 9.6 miles. On all of these vehicle days, the daily travel was less than the 70 miles considered to be within the BEV safe range (i.e., while BEV range can vary based on several factors, most BEVs provide at least 70 miles of vehicle range on a single battery charge). None of the support daily travel was greater than 70 miles. In addition, $98 \%$ of the vehicle travel days were less than the 40 miles considered to be within the CD range of a PHEV.

Figures 20 and 21 show that the vehicles were not used every day, although there were many days when many of the vehicles were in use. Vehicles $* * * 3265$ and $* * * 5470$ had the highest percentage of 
usage days, while vehicles $* * * 5207$ and $* * * 3952$ had the least. Figure 22 displays the summary of use by time of day for all support vehicles. Figure 23 shows the outing distances traveled for all support vehicles.

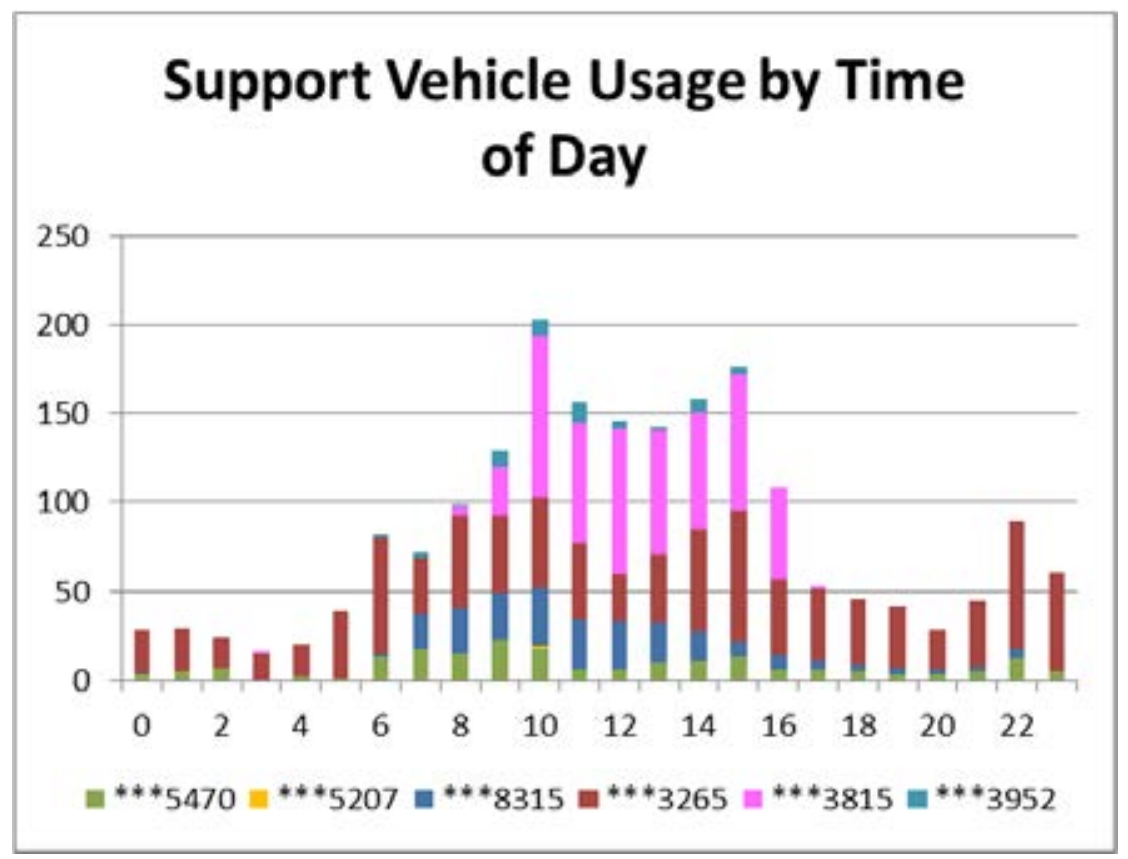

Figure 22. NIH support vehicles hourly usage.

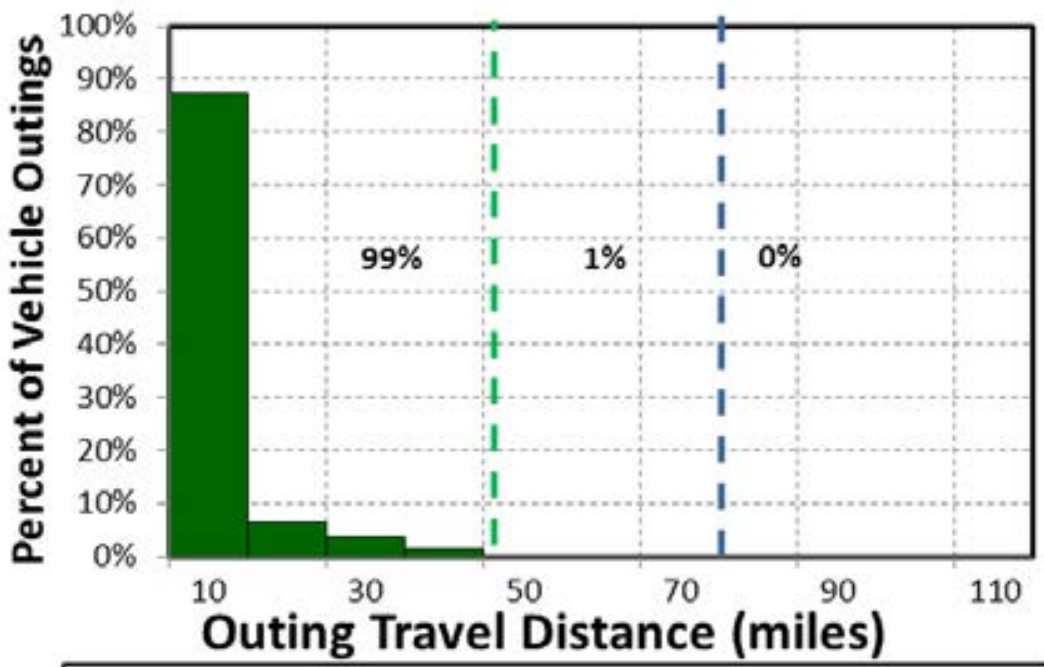

... All outings less than 40 miles ... All outings less than 70 miles

Figure 23. NIH support vehicle outings.

Appendix B provides the details of each of the support vehicle's outing travel. The average travel outing for support vehicles was 4.4 miles. On all of these vehicle outings, the distance traveled was less than the 70 miles considered to be within the BEV safe range. None of the support outing travel was greater than 70 miles. Further, $99 \%$ of the vehicle travel outings were less than the 40 miles considered to be within the CD range of a PHEV. In summary, these vehicles can be characterized by low daily travel and outing distances. 


\subsubsection{National Institute of Health Support Vehicle Observations/Summary}

There appears to be three choices for NIH in implementing PEVs into the support fleet at NIH. It should be noted that the objective would be to incorporate as many BEVs as possible to realize the advantages of reduced petroleum usage and reduced emissions of GHGs.

1. All BEV fleet: While some BEV manufacturers report vehicle range exceeding 70 miles, Intertek recommends careful evaluation of experienced range to ensure vehicle missions are accomplished. Nevertheless, assuming the 70-mile safe range for a BEV, an all-BEV fleet does appear to be feasible. Nevertheless, a conservative approach would suggest at least one PHEV might be desirable.

2. Mixed BEV/PHEV fleet: Certainly, PHEVs can accomplish the same mission as the current fleet when only considering travel times and distances because the PHEV's gasoline engine can provide motive power when the battery has been depleted. Figure 19 shows that on $98 \%$ of all vehicle travel days, the total daily travel is less than 40 miles, which typically is the maximum distance a PHEV will travel in CD mode. This represents a significant operating cost savings opportunity while retaining the ability to go longer distances when needed. In addition, $99 \%$ of the outings are less than 40 miles and could be completed in CD mode for certain PHEVs if the battery is fully charged prior to the outing.

Meanwhile, all of the outings are within the typical capability of a BEV and the EVSE at the home base could provide recharge energy for another outing. A mixed fleet requires fleet manager attention to assign vehicles appropriately for the anticipated use on that day.

Figure 19 also shows all daily travel is within the typical range of a BEV. This would suggest that all of the fleet could be BEVs. However, this does not allow for the use of several vehicles at the same time and would require a greater level of fleet management, with the daily assignment of vehicles based on anticipated driving distance. Allowing more conservatism in assigning vehicles, one PHEV and five BEVs could conservatively meet the demand for these six support vehicles. All monitored support vehicles have potential replacement PEVs available.

3. All PHEV fleet: As noted above, PHEVs can accomplish the same mission as the current fleet when only considering travel times and distances. Replacing all current vehicles with PHEVs only requires an evaluation of the individual vehicle capabilities of currently available PHEVs to meet current support requirements. These six support vehicles have replacement PEVs available. Data show that for a significant number of days, the PHEV will operate in a CD mode. The first 40 miles of longer travel days would also be powered by (at least mostly) electricity, so that $98 \%$ of all support vehicle travel would be (again, at least mostly) battery powered with only one charge per day. As above, this represents an opportunity for significant operating cost savings while retaining the ability to go longer distances when needed. Intermediate charging opportunities provide additional benefit, enhancing the CD mode. Data show significant charging opportunities throughout the day during stop times.

The vehicle summary shows sufficient time for charging at the base location during the course of the day, and additional opportunities at intermediate charging stations are not required. Given the availability of daytime changing, with experience, NIH may find that a greater fraction of BEVs within the support vehicle fleet may meet their needs.

Considering a full complement of 200 support vehicles in the total fleet, 69 were in use by other institutes and were not monitored in this study. However, it is likely that they have similar travel characteristics for the area. Nine of these vehicles are passenger vans and one is a large truck for which no PEVs are currently available for replacement. Thus, using the analysis for the monitored support vehicles and extrapolating to the 190 vehicles (with some additional conservatism added for the other institutes), Intertek suggests that $75 \%$ could be replaced by BEVs for a complement of nine ICE passenger vans, one ICE heavy duty truck, 142 BEVs, and 48 PHEVs. 


\subsubsection{National Institute of Health Support Vehicle Charging Needs}

Upon review of these data, Intertek suggests replacement of the studied support fleet with five BEVs and one PHEV. No available PHEVs at this writing provide for DCFC nor do the data suggest that this would be a significant benefit for PHEVs in the support fleet. A DCFC at the home base will provide a more rapid recharge for BEVs but appears to be unnecessary, given that the data show that all of outings are less than a typical BEV's driving range.

As noted above, AC Level 2 overnight charging of BEVs is typical, whereas overnight charging of PHEVs can usually be accomplished with AC Level 1 charging.

Intertek's experience suggests that each vehicle should have an assigned charging parking space at its home base. Assigned stations require less management attention to ensure completion of overnight charging. BEVs and PHEVs not assigned to these stations also benefit during visits to the location as part of their normal operation. For the entire fleet of support vehicles, the 142 BEVs require 142 AC Level 2 EVSE units for overnight charging and the 48 PHEVs require 48 AC Level 1 outlets at each vehicle's overnight parking location. Intertek recommends a minimum of two EVSE at each location to maximize charge capability without a significant increase in installation costs. The PHEVs can utilize the AC Level 2 EVSE at the home base during the day to increase the amount of vehicle miles traveled in CD mode.

At times, fleet vehicles obtain benefit from using public charging infrastructure. Figure 18 displays the availability of public charging at the time of this writing for the NIH area; however, data indicate it typically would not be necessary to support these vehicles.

\subsection{National Institute of Health Law Enforcement Vehicles Evaluation}

Enforcement vehicles are typically light-duty motor vehicles specifically approved in an agency's appropriation act for use in apprehension, surveillance, police, or other law enforcement work. Enforcement missions can vary by agency, location, and jurisdiction; however, they typically utilize sedans, minivans, vans, or small pickup trucks and typically do not carry specific cargo or equipment. Four enforcement vehicles were selected to be monitored, but one vehicle (***0758) failed to report any data throughout the study period for unknown reasons.

Incorporation of BEVs and/or PHEVs into the enforcement mission is a definite possibility. Enforcement vehicles used to patrol small areas and for parking enforcement activities qualify for BEV or PHEV replacement, while other law enforcement vehicle activities that are associated with longer trips may require PHEV capabilities.

\subsubsection{Summary for Enforcement Vehicles}

Appendix B provides the vehicle data sheets for the enforcement vehicles monitored.

Table 15 summarizes the enforcement vehicles' travel during the study period. Vehicle use occurred during all hours of the day. The enforcement vehicle traveled 4,371 miles, logged 788 hours, and idled 511 hours during the study period.

Table 15. Support vehicle travel summary.

\begin{tabular}{lcccc}
\hline \multicolumn{4}{c}{ Enforcement Vehicle Travel Summary } & \\
& $\begin{array}{c}\text { Per Day } \\
\text { Average/Peak }\end{array}$ & $\begin{array}{c}\text { Per Outing } \\
\text { Average/Peak }\end{array}$ & $\begin{array}{c}\text { Per Trip } \\
\text { Average/Peak }\end{array}$ & Total \\
\hline Travel Distance (Miles) & $26.0 / 132.2$ & $17.6 / 363.2$ & $1.9 / 66.1$ & 4,371 \\
Travel Time (Minutes) & $281.5 / 764.0$ & $189.9 / 1381.0$ & $20.6 / 335.0$ & 47,293 \\
\hline
\end{tabular}




\begin{tabular}{lcccc}
\hline & \multicolumn{2}{c}{ Enforcement Vehicle Travel Summary } & & \\
& $\begin{array}{c}\text { Per Day } \\
\text { Average/Peak }\end{array}$ & $\begin{array}{c}\text { Per Outing } \\
\text { Average/Peak }\end{array}$ & $\begin{array}{c}\text { Per Trip } \\
\text { Average/Peak }\end{array}$ & Total \\
\hline Idle Time (Minutes) & $182.5 / \mathrm{NA}$ & $123.1 / \mathrm{NA}$ & $13.3 / \mathrm{NA}$ & 30,661 \\
\hline
\end{tabular}

\subsubsection{Enforcement Vehicle Daily Summary}

Figure 24 identifies daily travel distance and time for the enforcement vehicles. The green line and bars indicate typical electric range on a single charge for a PHEV, while the blue line and bars indicate the same for a BEV. Figures 25 and 26 show the composite history in distance and time traveled for the enforcement vehicles.
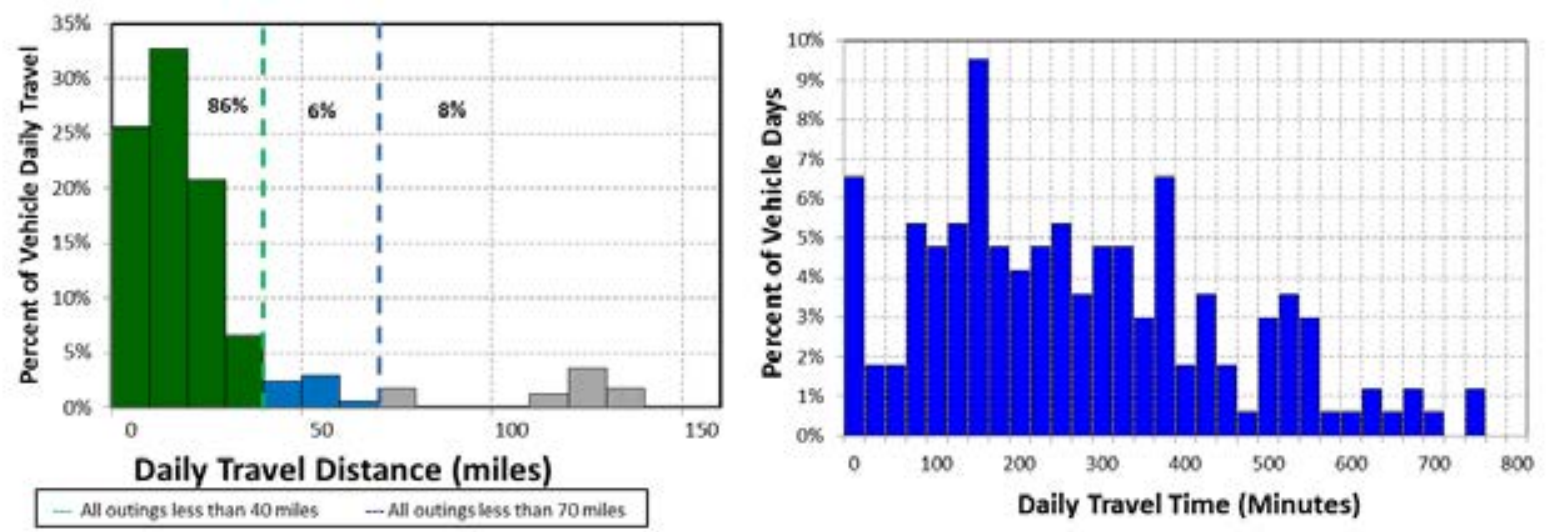

Figure 24. Enforcement vehicles percentage of daily use versus daily travel miles and time (all vehicles).

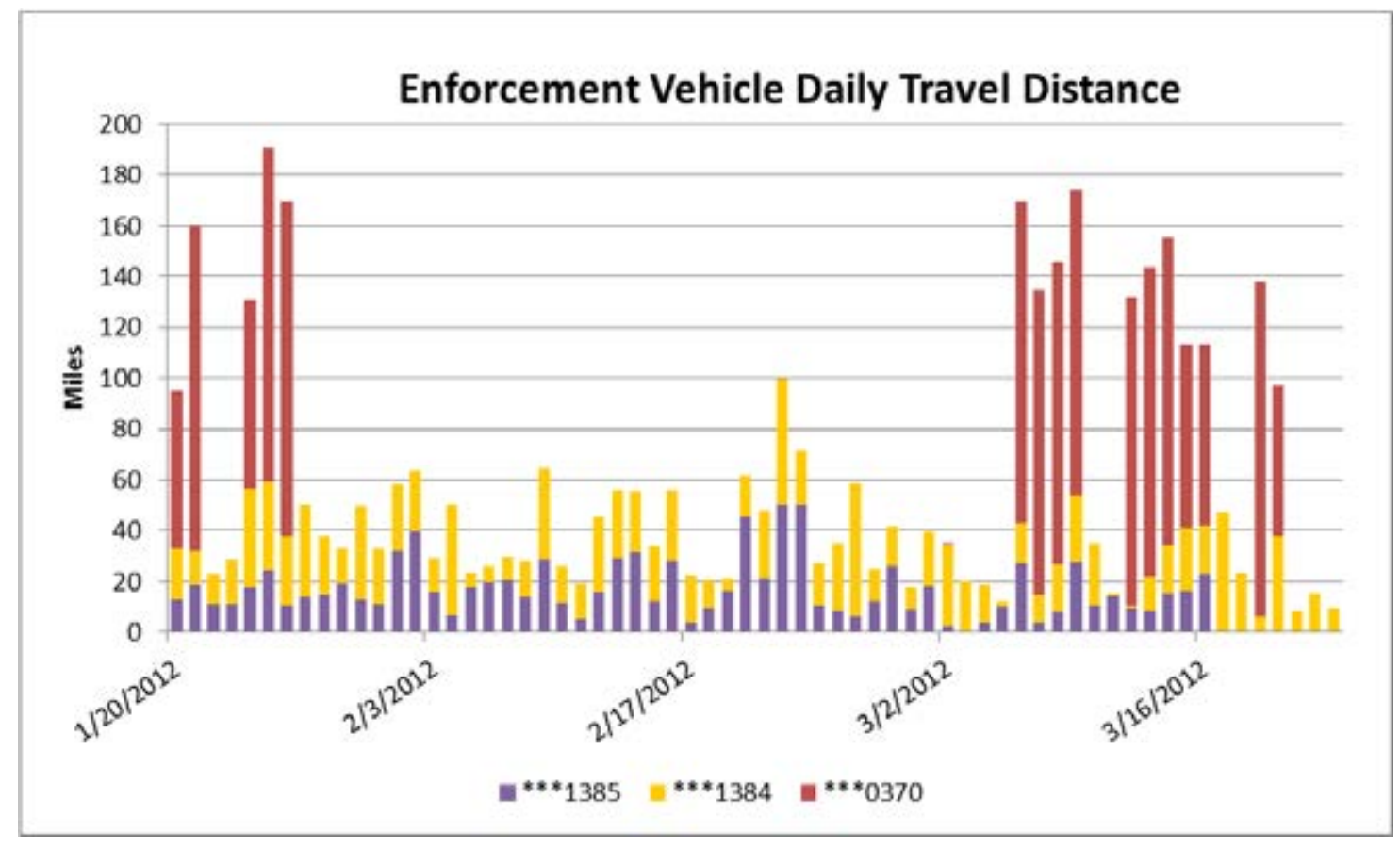

Figure 25. Enforcement vehicles daily travel miles. 


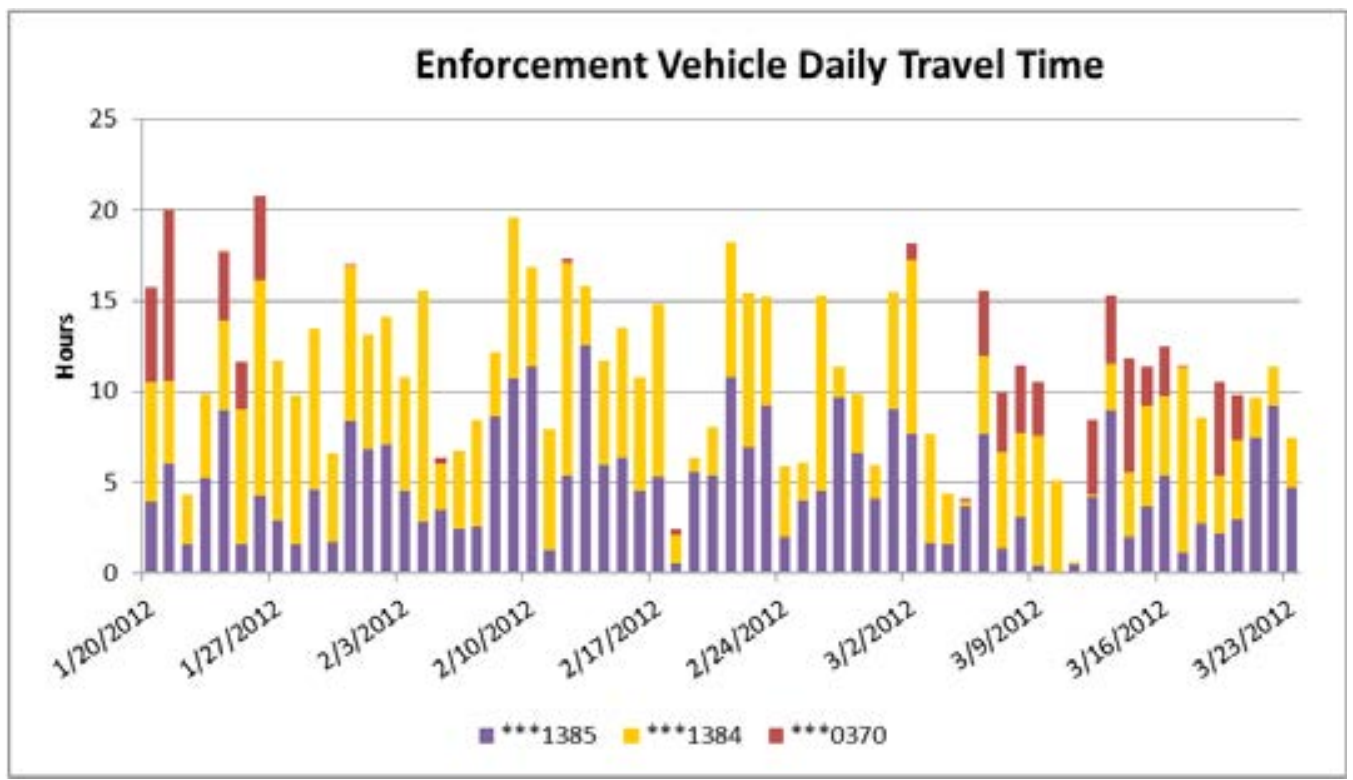

Figure 26. Enforcement vehicles daily travel time.

During the study period, the average travel distance per day, when driven, by the enforcement vehicles was 26.0 miles. On $92 \%$ of these vehicle days, the daily travel was less than the 70 miles considered to be within the BEV safe range, and $8 \%$ percent of enforcement vehicle daily travel was greater than 70 miles. Eighty-six percent of vehicle travel days were less than the 40 miles considered to be within the CD mode range of a PHEV. Most of the high distance travel was accomplished by vehicle ***0370. See the data sheets in Appendix B for details. The other two vehicles primarily restricted travel to the main campus or short trips to Rockville.

Figures 25 and 26 show that the vehicles are used often. Figure 27 shows the time of day during which trips start. Figure 28 shows the outing distances for the enforcement vehicles.

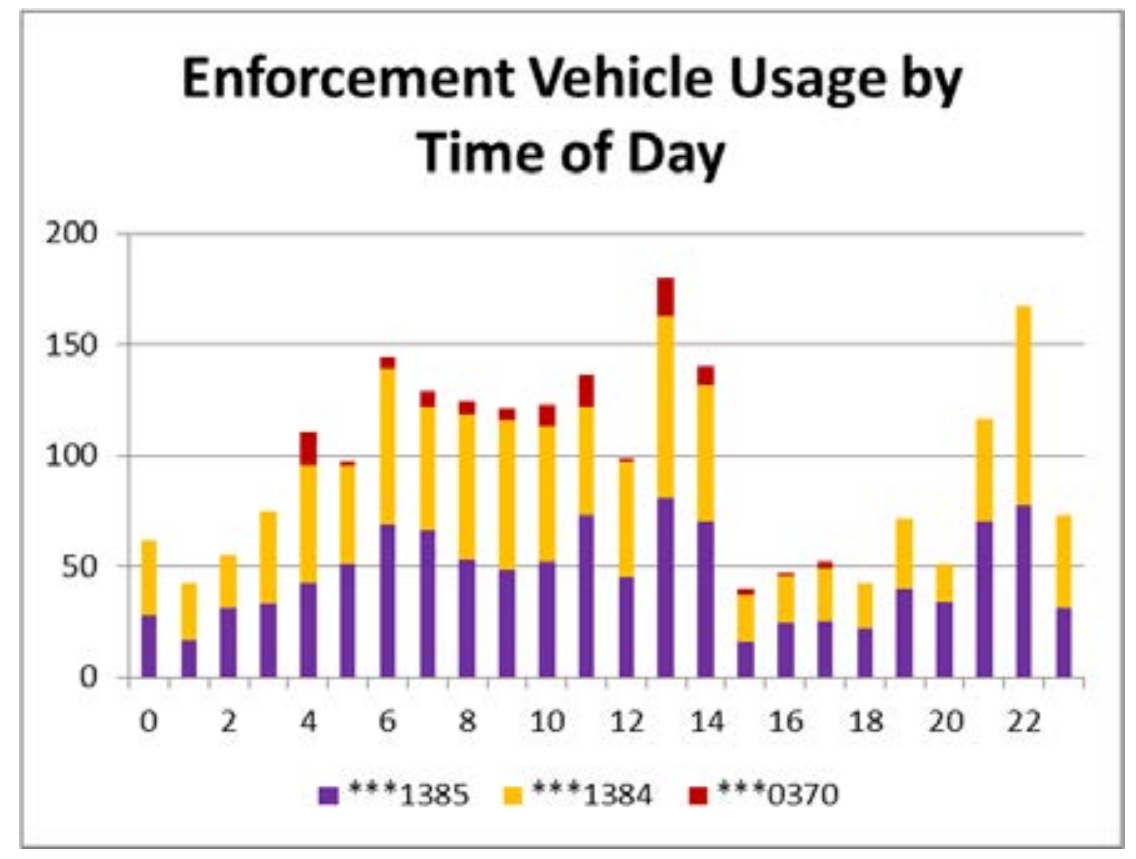

Figure 27. Enforcement vehicle hourly usage. 


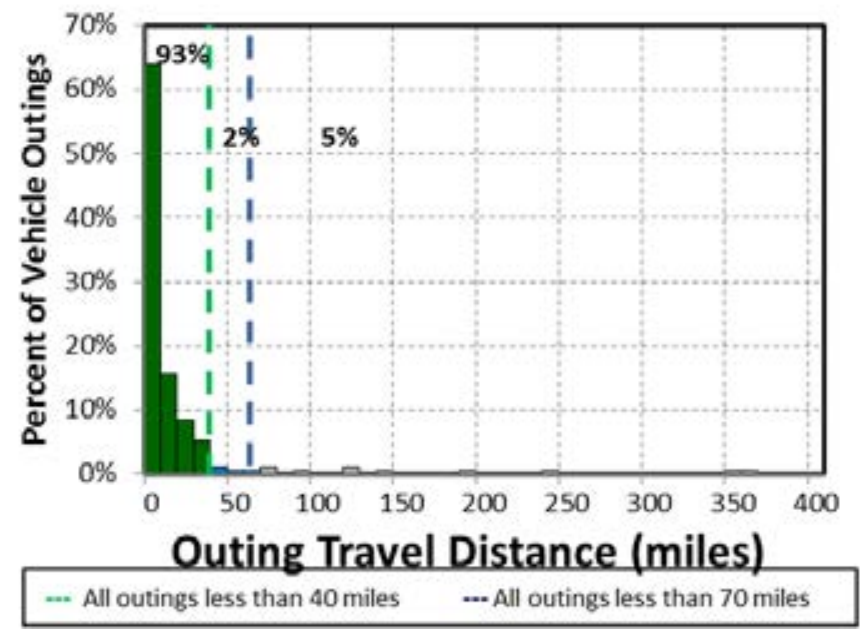

Figure 28. Enforcement vehicle outings.

Appendix B provides the details of the enforcement vehicles' daily travel. The average travel outing for the enforcement vehicles was 17.6 miles, with $93 \%$ of vehicle travel outings being less than the 40 miles considered to be within the CD mode range of a PHEV.

\subsubsection{Enforcement Vehicle Observations/Summary}

The enforcement vehicles are large sedans. This is a popular choice for enforcement vehicles because they are versatile to support various types of enforcement activities needed.

As before, consideration of three possible options for NIH in introducing PEVs into the enforcement vehicle fleet was evaluated. It should be noted that the objective would be to incorporate as many BEVs as possible to realize the advantages of reduced petroleum usage and reduced emissions of GHGs.

1. All BEV fleet: While some BEV manufacturers report vehicle ranges exceeding 70 miles, Intertek recommends careful evaluation of experienced range to ensure vehicle missions are accomplished. Nevertheless, assuming the 70-mile safe range for a BEV, an all-BEV fleet is not possible for enforcement vehicles due to the occasional long distances experienced by one of the vehicles. In addition, the mission of enforcement vehicles does not typically lend itself to range limitations.

2. Mixed BEV/PHEV fleet: Certainly, PHEVs can accomplish the same mission as the current fleet when only considering travel times and distances because the PEV's gasoline engine can provide motive power when the battery has been depleted. Figure 24 shows that on $86 \%$ of all vehicle travel days, the total daily travel was less than 40 miles, which typically is the maximum distance a PHEV will travel in CD mode. This represents a significant operating cost savings opportunity while retaining the ability to go longer distances when needed. In addition, $93 \%$ of the outings were less than 40 miles and could be completed in CD mode for certain PHEVs if the battery was fully charged prior to the outing.

Ninety-five percent of the outings were within the typical capability of a BEV; therefore, EVSE at the home base could provide recharge energy for another outing. A mixed fleet requires fleet manager attention to assign vehicles appropriately for the anticipated use on that day.

The data suggest that $8 \%$ of the fleet could be PHEVs to handle the travel greater than 70 miles per day without requiring additional opportunity charging during daytime stops; $92 \%$ of the fleet could be BEVs. A more conservative approach for enforcement vehicles, for which range limitations may not be desirable, is to replace vehicles with more PHEVs. Thus, using one BEV and one PHEV for police patrol and one BEV and one PHEV for K-9 patrol is possible. 
3. All PHEV fleet: As noted above, PHEVs can accomplish the same mission as the current fleet when only considering travel times and distances. Replacing all current vehicles with PHEVs only requires an evaluation of the individual vehicle capabilities of currently available PHEVs to meet current support vehicle requirements.

The vehicle summary shows sufficient time for charging at the base location during the course of the day. These stations also provide charging opportunities for the visiting public, whose fees may assist in offsetting operating costs, although it is recognized that visitation by the public is limited due to NIH operations.

The current fleet contains 53 enforcement vehicles, all of which have PEV replacement models currently available. While the above analysis suggests that a 50\% split between BEVs and PHEVs would meet mission requirements, it is recognized that additional PHEVs may provide greater confidence in meeting all mission needs. Thus, Intertek suggests that 23 BEVs and 30 PHEVs could replace these vehicles and continue to carry out the same mission.

\subsubsection{Enforcement Vehicle Charging Needs}

Upon review of these data, Intertek suggests replacement of the studied enforcement fleet with two BEVs and two PHEVs. No available PHEVs at this writing provide for DCFC nor do the data suggest that this would be a significant benefit for PHEVs in the support fleet. A DCFC at the home base will provide a more rapid recharge for BEVs but appears to be unnecessary, given that the data show that $95 \%$ of the outings were less than a typical BEV's driving range.

As noted above, AC Level 2 overnight charging of BEVs is typical, whereas overnight charging of PHEVs can usually be accomplished with AC Level 1 charging.

For the entire fleet of enforcement vehicles, the $23 \mathrm{BEVs}$ require $23 \mathrm{AC}$ Level 2 EVSE units for overnight charging and the $30 \mathrm{PHEV}$ s require $30 \mathrm{AC}$ Level 1 outlets for home base charging. Intertek recommends a minimum of two EVSE at each location to maximize charge capability without a significant increase in installation costs. As noted above, there are no publicly accessible EVSE in the vicinity to provide significant backup charging resources.

At times, fleet vehicles obtain benefit from using public charging infrastructure. Figure 18 displays the availability of public charging (at the time of this writing) for the NIH area, but data indicate it typically would not be necessary to support these vehicles. They may provide a backup function for enforcement vehicles that leave the main campus.

\subsection{National Institute of Health Transport Vehicles Evaluation}

Transport vehicles are typically light or heavy-duty motor vehicles for use in cargo transportation and typically not for personnel transport. Transport missions can vary by agency, location, and jurisdiction and for NIH the transport vehicles monitored included a pickup truck, a minivan, and an SUV.

Incorporation of BEVs and/or PHEVs into the transport mission is a definite possibility. Transport vehicles used for shorter trips or outings qualify for BEV or PHEV replacement, while other transport vehicle activities that are associated with longer trips may require PHEV capabilities.

\subsubsection{Summary for Transport Vehicles}

Appendix B provides the vehicle data sheets for the transport vehicles monitored.

Table 16 summarizes the transport vehicles' travel during the study period. Vehicle use occurred during typical day shift hours. The transport vehicle traveled 638 miles, logged 65 hours, and idled 13 hours during the study period. 
Table 16. Transport vehicle travel summary.

\begin{tabular}{|c|c|c|c|c|}
\hline \multicolumn{5}{|c|}{ Transport Vehicle Travel Summary } \\
\hline & $\begin{array}{c}\text { Per Day } \\
\text { Average/Peak }\end{array}$ & $\begin{array}{c}\text { Per Outing } \\
\text { Average/Peak }\end{array}$ & $\begin{array}{c}\text { Per Trip } \\
\text { Average/Peak }\end{array}$ & Total \\
\hline Travel Distance (Miles) & $9.8 / 25.5$ & $2.7 / 26.0$ & $0.7 / 14.5$ & 638 \\
\hline Travel Time (Minutes) & $59.9 / 158.0$ & $16.6 / 147.0$ & $4.2 / 135.0$ & 3,893 \\
\hline Idle Time (Minutes) & $12.7 / \mathrm{NA}$ & $3.5 / \mathrm{NA}$ & $0.9 / \mathrm{NA}$ & 824 \\
\hline
\end{tabular}

\subsubsection{Transport Vehicle Daily Summary}

Figure 29 identifies daily travel distance and time for the transport vehicle. The green line and bars indicate typical the electric range on a single charge for a PHEV, while the blue line and bars indicate the same for a BEV. Figures 30 and 31 show the composite history in distance and time traveled for the transport vehicles.
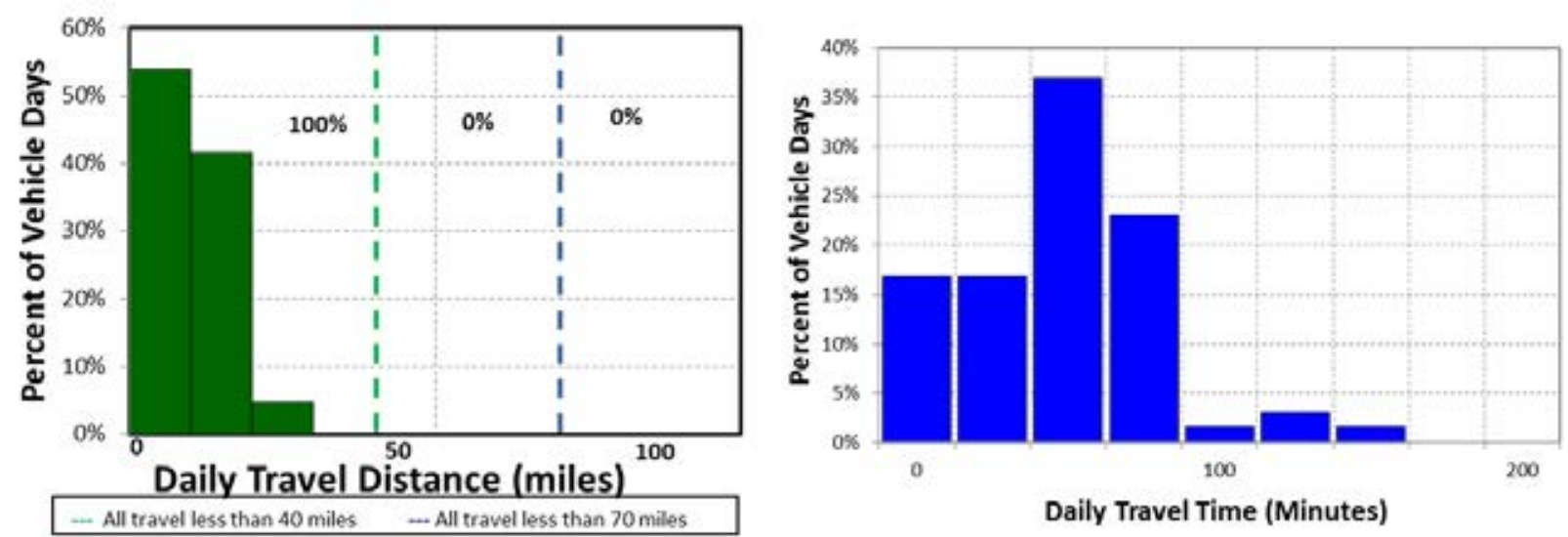

Figure 29. Transport vehicles percentage of daily use versus daily travel miles and time (all vehicles).

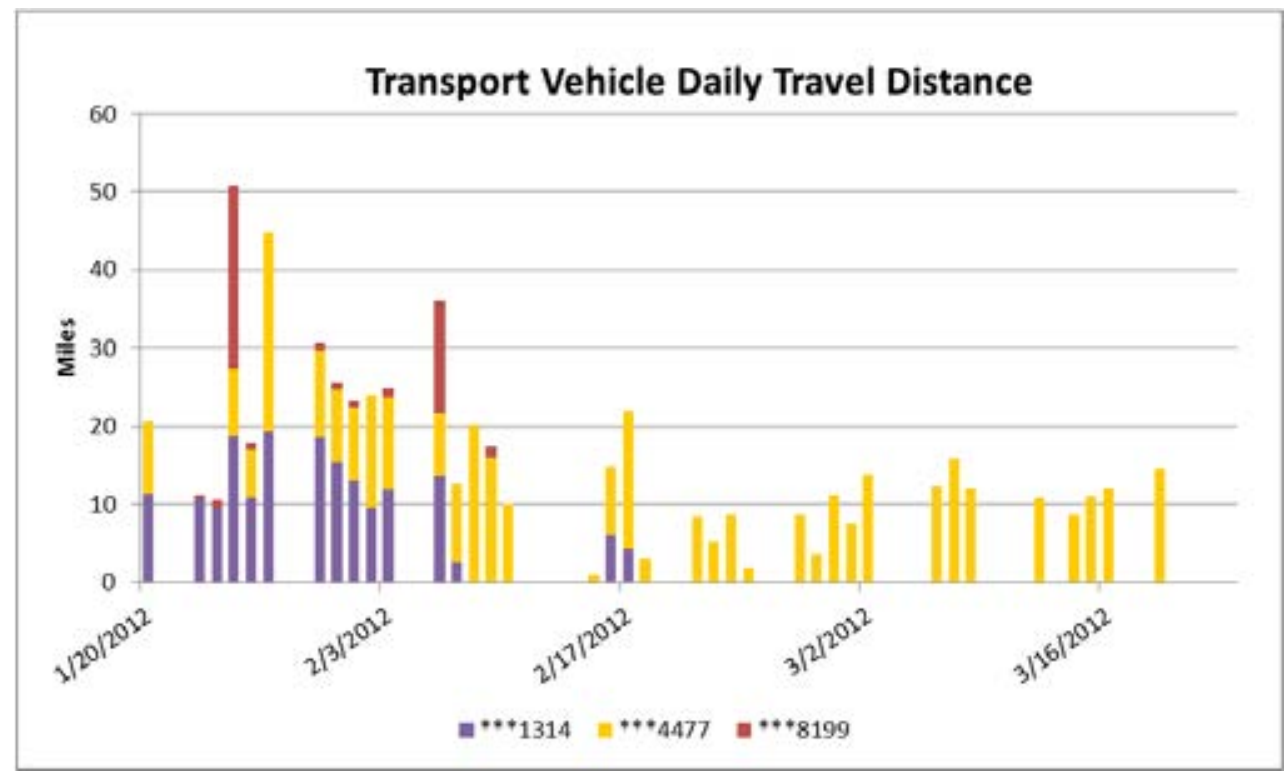

Figure 30. Transport vehicles daily travel miles. 


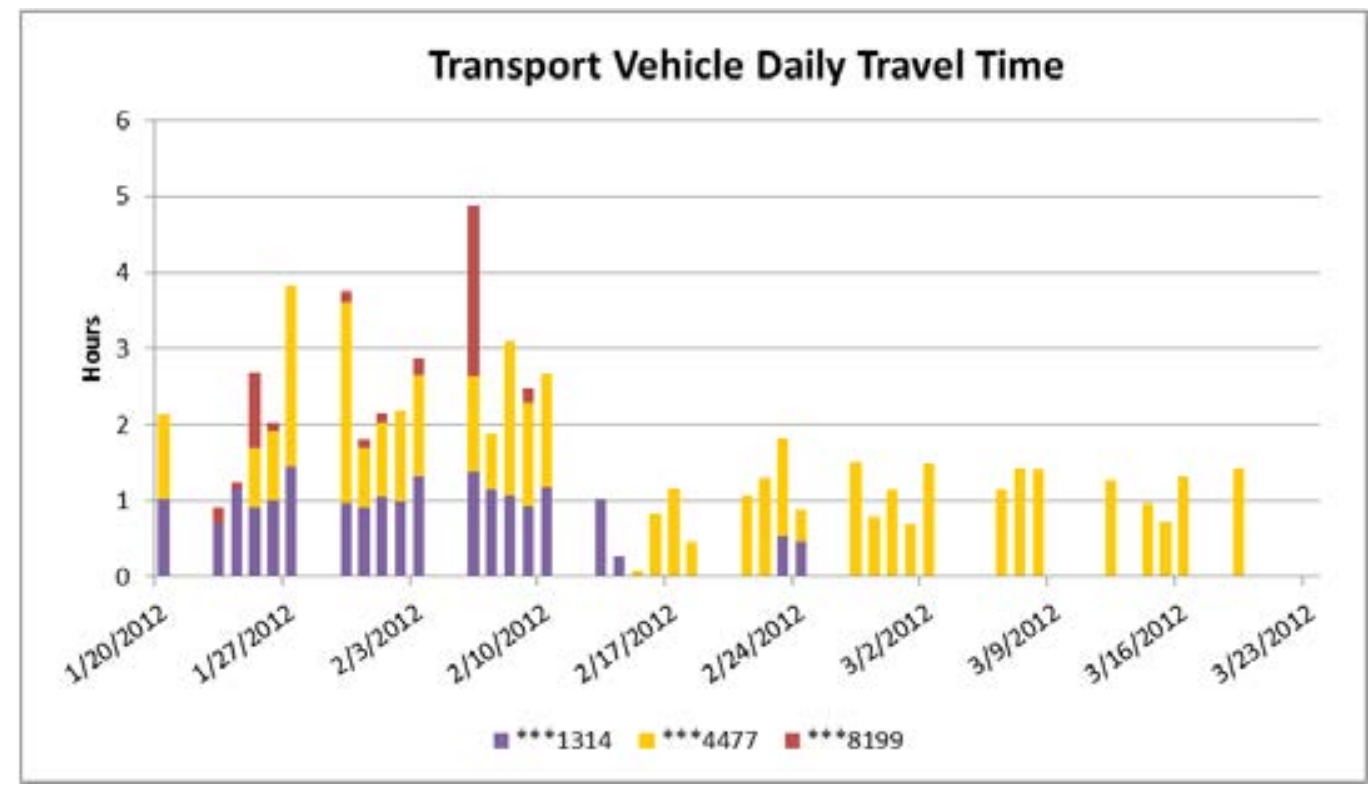

Figure 31. Transport vehicles daily travel time.

During the study period, the average travel distance per day, when driven, by the transport vehicle was 9.8 miles. On all of these vehicle days, the daily travel was less than the 70 miles considered to be within the BEV safe range. In addition, all vehicle travel days were less than the 40 miles considered to be within the CD mode range of a PHEV. See the data sheets in Appendix B for details. Figure 32 shows the time of day during which trips started. Figure 33 shows the outing distances for the transport vehicle.

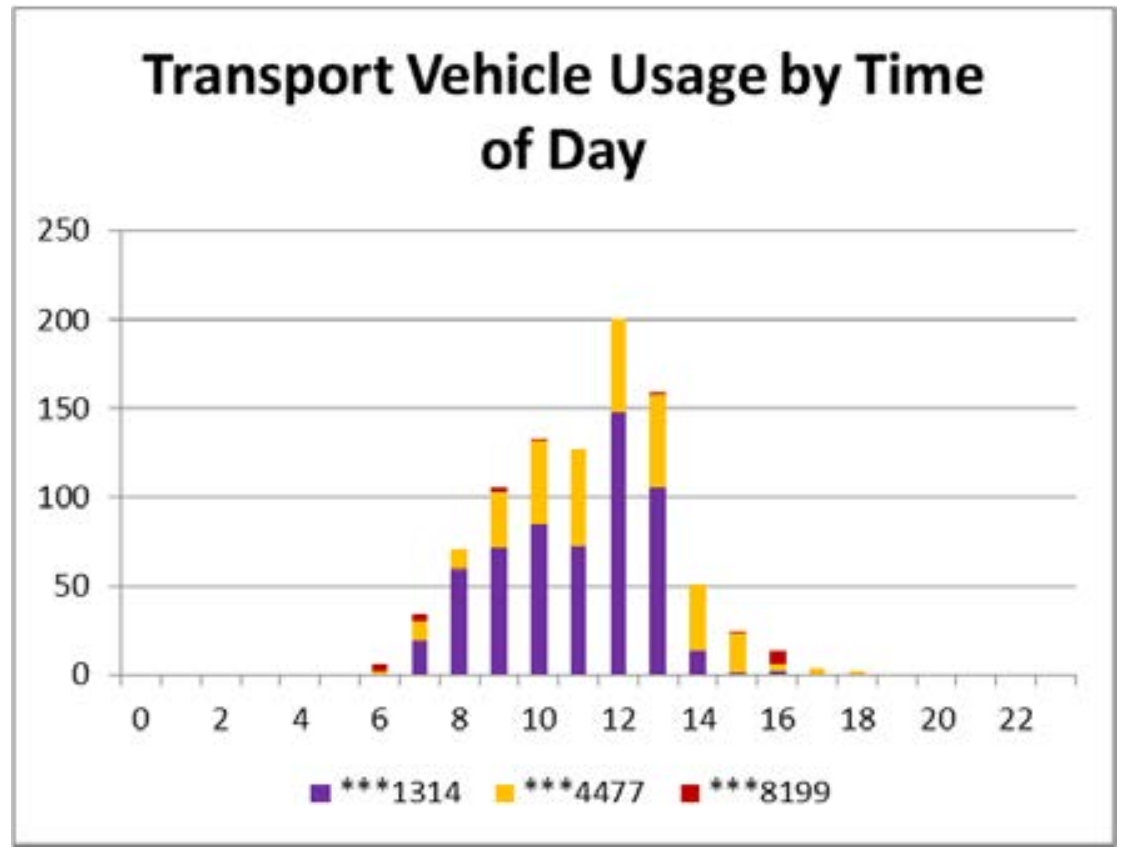

Figure 32. Transport vehicle hourly usage. 


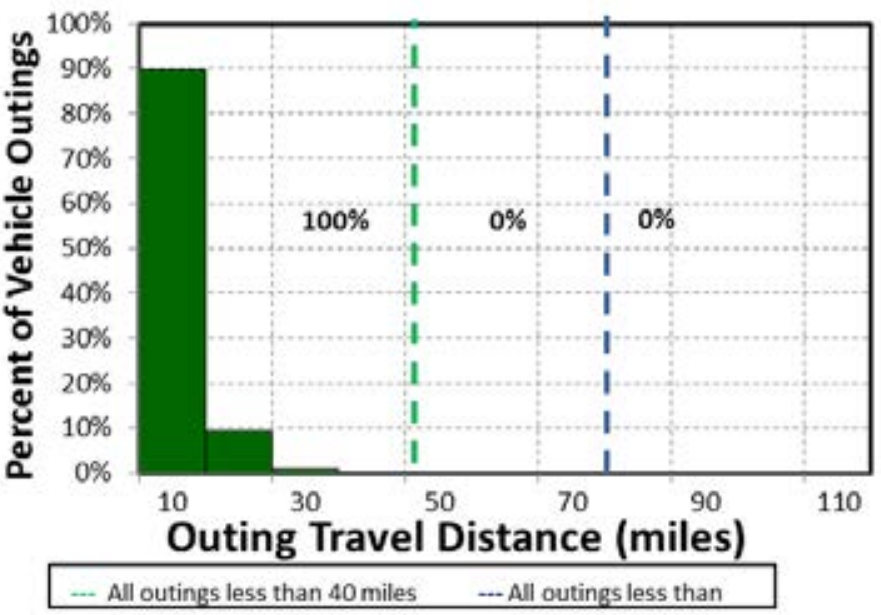

Figure 33. Transport vehicle outings.

Appendix B provides the details of the transport vehicle's daily travel. The average travel outing for the transport vehicles was 2.7 miles. All vehicle travel outings were less than 40 miles considered to be within the CD mode range of a PHEV.

\subsubsection{Transport Vehicle Observations/Summary}

The transport vehicles include a pickup truck, a minivan, and an SUV. These are popular choices for transport vehicles because they are versatile to support various types of transport activities needed.

As before, consideration of three possible options for NIH in introducing PEVs into the transport vehicle fleet was evaluated. It should be noted that the objective would be to incorporate as many BEVs as possible to realize the advantages of reduced petroleum usage and reduced emissions of GHGs.

1. All BEV fleet: While some BEV manufacturers report vehicle ranges exceeding 70 miles, Intertek recommends careful evaluation of experienced range to ensure vehicle missions are accomplished. Nevertheless, assuming the 70-mile safe range for a BEV, an all-BEV fleet is possible for transport vehicles due to the short distances experienced by these vehicles. In addition, the types of duties performed by these vehicles involve delivery of store materials for which these vehicles are appropriate.

2. Mixed BEV/PHEV fleet: Certainly, PHEVs can accomplish the same mission as the current fleet when only considering travel times and distances because the PEV's gasoline engine can provide motive power when the battery has been depleted. Figure 29 shows that on all vehicle travel days, the total daily travel was less than 40 miles, which typically is the maximum distance a PHEV will travel in CD mode. This represents a significant operating cost savings opportunity while retaining the ability to go longer distances when needed. In addition, all outings were less than 40 miles and could be completed in CD mode for certain PHEVs if the battery is fully charged prior to the outing.

All of the outings are within the typical capability of a BEV; therefore, the EVSE at the home base could provide recharge energy for another outing. A mixed fleet requires fleet manager attention to assign vehicles appropriately for the anticipated use on that day.

The data suggest that all of the fleet could be BEVs to handle all daily travel without requiring additional opportunity charging during daytime stops. A more conservative approach for transport vehicles, for which range limitations may not be desirable, is to utilize some PHEVs. However, considering the short distances to be traveled within the main campus or the short trips to remote facilities, substitutions of PHEVs are not required. 
3. All PHEV fleet: As noted above, PHEVs can accomplish the same mission as the current fleet when only considering travel times and distances. Replacing all current vehicles with PHEVs only requires an evaluation of the individual vehicle capabilities of currently available PHEVs to meet current support vehicle requirements. Available PHEVs can meet these requirements.

The vehicle summary shows sufficient time for charging at the base location during the course of the day. These stations also provide charging opportunities for the visiting public, whose fees may assist in offsetting operating costs, although it is recognized that visitation by the public is limited due to NIH operations.

The current fleet contains 36 transport vehicles, of which 31 are heavy-duty trucks for which no PEV is currently available as a replacement. Of the five remaining transport vehicles, Intertek suggests that four BEVs and one PHEV could replace these vehicles and continue to carry out the same mission.

\subsubsection{Transport Vehicle Charging Needs}

Upon review of these data, Intertek suggests replacement of the studied transport fleet with four BEVs. A DCFC at the home base will provide a more rapid recharge for BEVs but appears to be unnecessary, given that the data show that all of outings were less than a typical BEV's driving range.

As noted above, AC Level 2 overnight charging of BEVs is typical.

For the entire fleet of transport vehicles, five BEVs require five AC Level 2 EVSE units for overnight charging and the one PHEV requires one AC Level 1 outlets for home base charging. Intertek recommends a minimum of two EVSE at each location to maximize charge capability without a significant increase in installation costs.

At times, fleet vehicles obtain benefit from using public charging infrastructure. Figure 18 displays the availability of public charging (at the time of this writing) for the NIH area; however, data indicate it typically would not be necessary to support these vehicles because their travel off-campus is minimal.

\subsection{Balance of Fleet Vehicles}

The balance of the NIH fleet consists of seven specialty vehicles and four buses. Certain select PEVs are being demonstrated for various specialty applications but none is listed in the GSA schedule. In addition, plug-in electric buses have been available for some time. They are not considered here because they typically require special charging equipment not available for use by other PEVs. NIH may wish to monitor PEV developments for vehicles that may provide sufficient mission support.

\section{GREENHOUSE GAS EMISSIONS AVOIDED AND FUEL COST REDUCTION ANALYSIS}

PEV substitution for an existing conventional vehicle avoids GHG emissions and reduces fuel costs. The GHG emissions avoided occur due to the difference in emissions associated with power plant electricity generation versus fuel combustion that occurs in the engine of a conventional vehicle. This analysis does not account for life-cycle emissions that occur outside of the electricity generation and fuel combustion phases (i.e., materials and resource extraction, production supply-chains, and decommissioning are not accounted for). These phases are beyond the scope of this report due to the significant effort required to conduct an accurate environmental life-cycle assessment for a transportation system in a very specific setting. The analysis used is known as a "tank-to-wheel" analysis rather than a "well-to-wheel" analysis that would include the aforementioned phases. Cost reduction also occurs because the cost of electricity is comparable to the cost of gasoline on a unit of energy basis; however, PEVs are more efficient than conventional ICE vehicles. Because fuel logs were not kept, the mileage accumulated by each vehicle and the extrapolation to annual miles provide one source of annual miles estimates. NIH also provided information related to anticipated annual miles. These are compared to that calculated during the study to identify the source of fuel consumption estimates for the study vehicles. 
In order to perform the analysis, EPA fuel economy ratings were used. ${ }^{28}$ Tables 17 and 18 provide these ratings. Ratings for the PHEVs in Table 18 include CD operation. Because these data are estimates, assumptions include the following:

1. PHEVs operate in CD mode only for the percentage of travel less than 40 miles per day. This is reasonable for most daily operations, as described in Section 5. This is conservative since there exists additional charge time between most outings. It is also conservative in that the replacement PEV typically will have greater fuel economy when operating in CS mode. BEVs operate in electric mode for $100 \%$ of travel.

2. The energy consumption for the Mitsubishi Outlander was assigned the same value as the RAV4 EV and the Via Motors VTRUX PU was estimated because EPA has not yet created ratings for these vehicles.

3. Figure 18 suggests the PEVs for replacing existing monitored vehicles. See Section 4.4 for vehicle availability.

4. Annual miles were calculated from the actual miles identified in the study and extrapolated to a full 365-day year. This was compared to the annual miles reported by NIH for information. The NIH annual miles were used for the reduction calculations if available. Miles in CD mode were the NIH annual miles times percent of daily travel less than 40 miles for the PHEV replacement and full annual miles for the BEV replacement.

Table 17. U.S. EPA fuel economy ratings of current fleet vehicles.

\begin{tabular}{|c|c|c|c|c|c|}
\hline Vehicle & Logger & Mission & Make and Model & Model Year & $\begin{array}{l}\text { Fuel Economy-Combined } \\
\text { (miles/gallon) }\end{array}$ \\
\hline$* * * 1385$ & 41 & Enforcement & Ford Crown Victoria & 2009 & 19 \\
\hline$* * * 2995$ & 42 & Pool & Chevrolet Impala & 2010 & 22 \\
\hline$* * * 7017$ & 43 & Pool & Ford Escape Hybrid & 2009 & 32 \\
\hline$* * * 5470$ & 44 & Support & Ford F-150 & 2010 & 16 \\
\hline$* * * 5207$ & 45 & Support & Dodge Sprinter & 2002 & 14 \\
\hline$* * * 7596$ & 46 & Pool & Dodge Durango & 2001 & 14 \\
\hline$* * * 8759$ & 47 & Pool & Chevrolet Uplander & 2008 & 19 \\
\hline ***7791 & 48 & Pool & Dodge Caravan & 2009 & 19 \\
\hline$* * * 8315$ & 49 & Support & Chevrolet Impala & 2010 & 22 \\
\hline$* * * 1384$ & 50 & Enforcement & Ford Crown Victoria & 2009 & 19 \\
\hline$* * * 3265$ & 51 & Support & Chevrolet Silverado & 2005 & 16 \\
\hline$* * * 1314$ & 52 & Transport & Chevrolet HHR & 2010 & 26 \\
\hline$* * * 4477$ & 53 & Transport & Chevrolet Colorado & 2010 & 21 \\
\hline$* * * 8199$ & 54 & Transport & Dodge Caravan & 1999 & 20 \\
\hline$* * * 3815$ & 55 & Support & Jeep Grand Cherokee & 2009 & 15 \\
\hline$* * * 3952$ & 56 & Support & Ford Expedition & 2006 & 14 \\
\hline$* * * 8489$ & 57 & Pool & Chevrolet Impala & 2010 & 22 \\
\hline$* * * 0758$ & 58 & Enforcement & Chevrolet Impala & 2005 & 21 \\
\hline$* * * 0370$ & 59 & Enforcement & Chevrolet Impala & 2005 & 21 \\
\hline$* * * 1201$ & 60 & Pool & Chevrolet HHR & 2010 & 26 \\
\hline
\end{tabular}

${ }^{28} \mathrm{http}: / /$ www.fueleconomy.gov/feg/Find.do?action=sbs\&id=33558 [accessed August 27, 2014]. 
Table 18. U.S. EPA PEV energy consumption assumptions.

\begin{tabular}{lccc}
\hline Vehicle & Mission & Replacement PEV & Wh/mile \\
\hline$* * * 1385$ & Enforcement & Ford C-Max Energi PHEV & 370 \\
$* * * 2995$ & Pool & Nissan Leaf BEV & 300 \\
$* * * 7017$ & Pool & Toyota Rav4 BEV & 440 \\
$* * * 5470$ & Support & VTRUX PU PHEV & 475 \\
$* * * 5207$ & Support & Nissan eNV200 BEV & 400 \\
$* * * 7596$ & Pool & Toyota Rav4 BEV & 440 \\
$* * * 8759$ & Pool & Mitsubishi Outlander PHEV & 440 \\
$* * * 7791$ & Pool & Toyota Rav4 BEV & 440 \\
$* * * 8315$ & Support & Nissan Leaf BEV & 300 \\
$* * * 1384$ & Enforcement & Nissan Leaf BEV & 300 \\
$* * * 3265$ & Support & Toyota Rav4 BEV & 440 \\
$* * * 1314$ & Transport & Toyota Rav4 BEV & 440 \\
$* * * 4477$ & Transport & Nissan eNV200 BEV & 400 \\
$* * * 8199$ & Transport & Toyota Rav4 BEV & 440 \\
$* * * 3815$ & Support & Toyota Rav4 BEV & 440 \\
$* * * 3952$ & Support & Nissan eNV200 BEV & 400 \\
$* * * 8489$ & Pool & Ford Fusion PHEV & 370 \\
$* * * 0758$ & Enforcement & Nissan Leaf BEV & 300 \\
$* * * 0370$ & Enforcement & Ford C-Max Energi PHEV & 370 \\
$* * * 1201$ & Pool & Toyota Rav4 BEV & 440 \\
\hline
\end{tabular}

Table 19 provides a pictorial view of potential replacement PEVs.

Table 19. PEV substitutions for current vehicles.

\begin{tabular}{|c|c|c|c|}
\hline Vehicle Class & $\begin{array}{c}\text { Current Vehicle } \\
\text { Example }\end{array}$ & Replacement PHEV & Replacement BEV \\
\hline \multicolumn{4}{|c|}{ Sedan - Midsize/Large } \\
\hline & Chevrolet Impala & $\begin{array}{l}\text { Ford Fusion Energi } \\
370 \mathrm{Wh} / \mathrm{mi}\end{array}$ & $\begin{array}{l}\text { Nissan Leaf } \\
300 \mathrm{Wh} / \mathrm{mi}\end{array}$ \\
\hline \multicolumn{4}{|l|}{ SUV and Minivan } \\
\hline & Dodge Grand Caravan & $\begin{array}{l}\text { Mitsubishi Outlander } \\
440 \mathrm{wh} / \mathrm{mi}\end{array}$ & $\begin{array}{c}\text { Toyota RAV4 } \\
440 \mathrm{wh} / \mathrm{mi}\end{array}$ \\
\hline
\end{tabular}




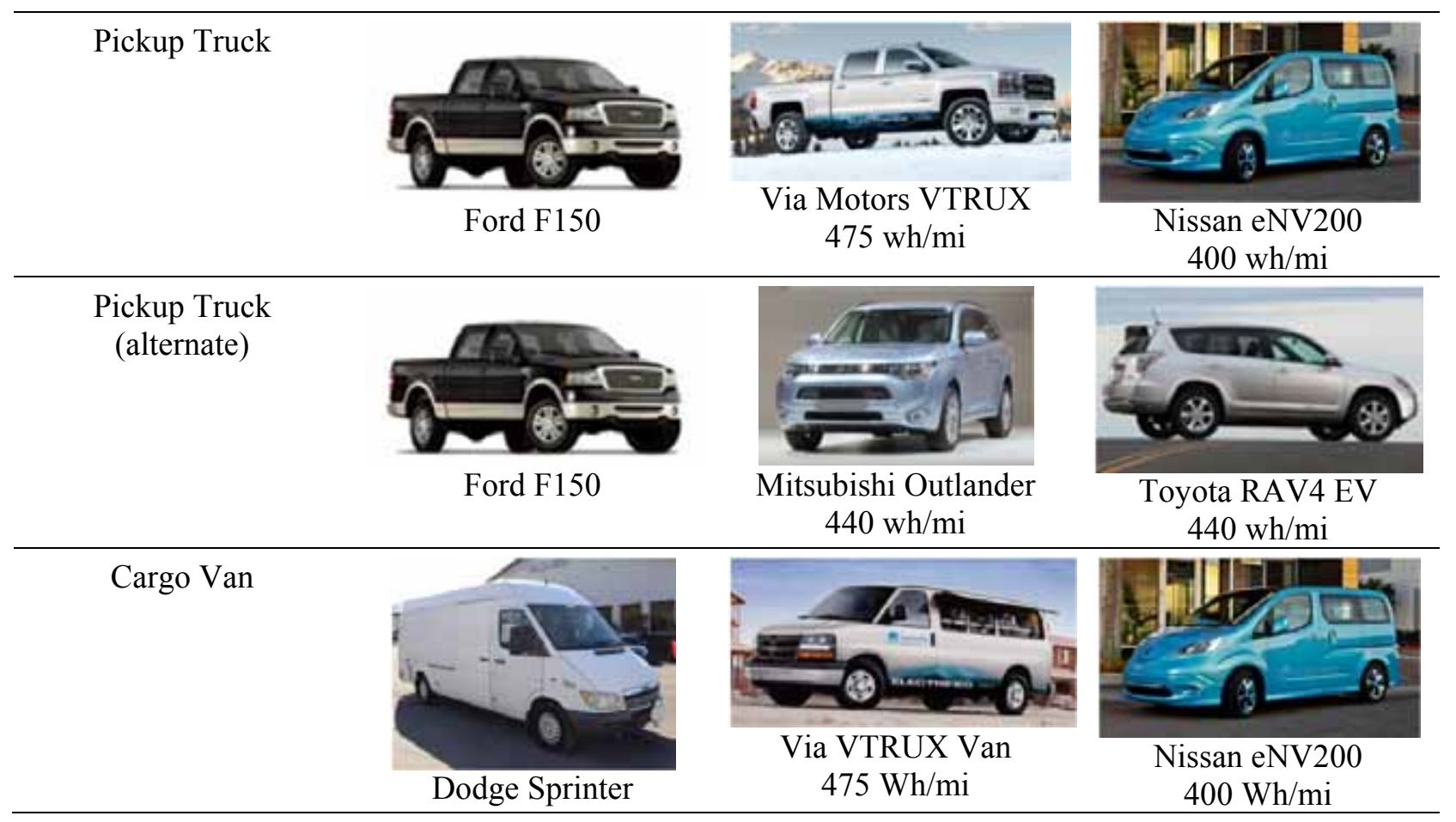

Calculations provided for GHG emissions and fuel savings include both a total U.S. perspective and for the local area. The electricity generation mix of power plants for the total United States is different from the local mix of generation in the NIH area. Likewise, the national average cost for petroleum fuel is different from the local cost for fuel. This analysis includes both approaches in order to allow for local evaluation and to provide the potential benefit for fleet vehicles in other locations of the United States that may be of interest. The final report summarizing results from all sites studied across the Unites States from Intertek to Idaho National Laboratory primarily will consider the national figures. For clarity, only the local figures are shown here. The national figures are included in Appendix C.

For the GHG emissions avoided portion of the analysis, the GHG emissions (in pounds of carbon dioxide equivalent (which also accounts for other GHGs such as methane and nitrous oxide), $\left(\mathrm{lb}-\mathrm{CO}_{2} e\right.$ ) from combustion of gasoline is $20.1 \mathrm{lb}-\mathrm{CO}_{2} \mathrm{e} /$ gallon. ${ }^{29}$ The United States averages for GHG emissions for the production of electricity is $1.53 \mathrm{lb}-\mathrm{CO}_{2} \mathrm{e} / \mathrm{kWh}^{30}$

Pepco, a subsidiary of Pepco Holdings, Inc. completed construction of the NIH cogeneration facility. It is a 23-MW gas-fired plant providing electric power to NIH. ${ }^{31}$ EPA reports GHG emissions from the production of electricity. The annual report is available in the Emissions and Generation Resource Integrated Database. The most recent publication is for $2010 .^{32} \mathrm{Using}$ the information provided for the NIH cogeneration plant, emissions for 2010 for the production of electricity were $1.391 \mathrm{lb}-\mathrm{CO}_{2} \mathrm{e} / \mathrm{kWh}$.

GHG emissions avoided are the GHGs emitted by the current vehicle (total annual gallons gasoline $\times$ GHG emissions/gallon) minus the annual GHG emitted by the replacement PEV (total annual $\mathrm{kWh} \times$ GHG emissions/kWh). For PHEVs, the percentages of outings less than 40 miles are counted for the annual miles saved in CD mode, with the balance of the miles accounted as fueled with gasoline.

\footnotetext{
${ }^{29} \mathrm{http}: / /$ www.theevproject.com/cms-assets/documents/106077-891082.ghg.pdf [accessed 19 July 2013].

${ }^{30} \mathrm{http}: / /$ www.theevproject.com/cms-assets/documents/106077-891082.ghg.pdf [accessed July 19, 2013].

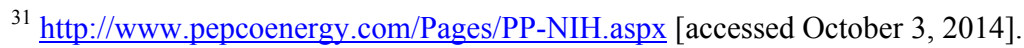

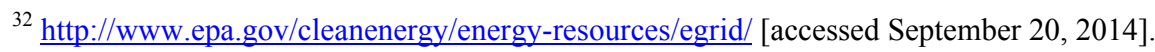


Table 20 shows the calculation of annual miles based on the recorded and extrapolated miles in this study. The NIH reported annual miles are also shown for comparison. A replacement vehicle is identified for each vehicle. It is important to note that the analysis conducted above suggests replacement vehicles for the fleet of vehicles rather than necessarily replacing the exact vehicle monitored. The percent of miles in CD mode is $100 \%$ for BEVs because all travel is battery powered. The percent of miles in CD mode for PHEVs was obtained from the daily travel shown in Appendix B. Miles in CD mode are the percentage of NIH reported annual miles.

Table 20. CD mode miles calculations.

\begin{tabular}{|c|c|c|c|c|c|}
\hline Vehicle & Replacement Vehicle & $\begin{array}{c}\text { Study } \\
\text { Calculated } \\
\text { Annual Miles }\end{array}$ & $\begin{array}{l}\text { NIH Reported } \\
\text { Annual Miles }\end{array}$ & $\begin{array}{l}\text { Percent of } \\
\text { Miles CD } \\
\text { Mode }\end{array}$ & $\begin{array}{l}\text { CD Mode } \\
\text { Miles }\end{array}$ \\
\hline $\begin{array}{l}\text { Crown } \\
\text { Victoria }\end{array}$ & Ford C-Max Energi & 5,999 & 10,889 & $95 \%$ & 10,345 \\
\hline Impala & Nissan Leaf BEV & 1,103 & 9,917 & $100 \%$ & 9,917 \\
\hline Escape Hybrid & Toyota Rav4 BEV & 860 & 3,728 & $100 \%$ & 3,728 \\
\hline F-150 & VTRUX PU PHEV & 3,109 & 1,268 & $100 \%$ & 1,268 \\
\hline Sprinter & Nissan eNV200 BEV & 3,255 & 1,000 & $100 \%$ & 1,000 \\
\hline Durango & Toyota Rav4 BEV & 3,273 & 2,821 & $100 \%$ & 2,821 \\
\hline Uplander & Mitsubishi Outlander & 2,550 & 16,629 & $90 \%$ & 14,966 \\
\hline Caravan & Toyota Rav4 BEV & 3,273 & 2,936 & $100 \%$ & 2,936 \\
\hline Impala & Nissan Leaf BEV & 1,150 & 1,908 & $100 \%$ & 1,908 \\
\hline $\begin{array}{l}\text { Crown } \\
\text { Victoria }\end{array}$ & Nissan Leaf BEV & 7,690 & 11,929 & $100 \%$ & 11,929 \\
\hline Silverado & Toyota Rav4 BEV & 2,929 & 2,759 & $100 \%$ & 2,759 \\
\hline HHR & Toyota Rav4 BEV & 1,377 & 8,690 & $100 \%$ & 8,690 \\
\hline Colorado & Nissan eNV200 BEV & 2,229 & 6,110 & $100 \%$ & 6,110 \\
\hline Caravan & Toyota Rav4 BEV & 277 & 3,255 & $100 \%$ & 3,255 \\
\hline Gr Cherokee & Toyota Rav4 BEV & 4,208 & 8,809 & $100 \%$ & 8,809 \\
\hline Expedition & Nissan eNV200 BEV & 225 & 1,042 & $100 \%$ & 1,042 \\
\hline Impala & Ford Fusion PHEV & 11,620 & 6,929 & $54 \%$ & 3,742 \\
\hline Impala & Nissan Leaf BEV & 8,864 & 9,892 & $100 \%$ & 9,892 \\
\hline Impala & Ford C-Max Energi & 10,418 & 10,175 & $30 \%$ & 3,053 \\
\hline HHR & Toyota Rav4 BEV & 497 & 1,183 & $100 \%$ & 1,183 \\
\hline
\end{tabular}

For the cost-avoided piece of the analysis, fuel cost assumptions are $\$ 3.322 /$ gallon of regular gasoline for the United States and \$3.584 gallon in Bethesda, Maryland. ${ }^{33}$ Electrical costs are $0.0984 \$ / \mathrm{kWh}$ for the United States and $0.113 \$ / \mathrm{kWh}$ in Maryland. ${ }^{34}$ Therefore, fuel costs savings are the current vehicle's calculated annual gasoline cost (total annual gallons gasoline $\times$ cost/gallon) minus the electricity cost (total annual $\mathrm{kWh} \times \operatorname{cost} / \mathrm{kWh}$ ) of the replacement PEV traveling the same distance.

\footnotetext{
${ }^{33} \mathrm{http}: / /$ www.marylandgasprices.com/Bethesda/index.aspx[accessed [October 3, 2014].

${ }^{34} \mathrm{http} / / / \mathrm{www}$. eia.gov/electricity/state/ [Accessed October 3, 2014].
} 
The miles calculated above for CD mode yield estimates for yearly GHG emissions avoided and fuel cost reductions. The results of this analysis (shown in Table 21) demonstrate that the substitution of a conventional ICE vehicle with a PEV can reduce the GHG emissions and fuel costs dramatically. The table also shows the percentage reduction in GHG emissions and fuel costs for ease of comparison. For example, if the Mitsubishi Outlander replaces the Chevrolet Uplander pool vehicle ***8759, a 42\% reduction in GHG emissions in Maryland occurs. The Uplander traveling 14,966 miles per year produces $15,833 \mathrm{lb}-\mathrm{CO}_{2} \mathrm{e} /$ year, whereas the Outlander produces $9,160 \mathrm{lb}-\mathrm{CO}_{2} \mathrm{e} /$ year for that same distance for a reduction of $6,673 \mathrm{lb}-\mathrm{CO}_{2} \mathrm{e} /$ year.

Table 21. GHG emissions avoidance and fuel cost reduction analysis summary.

\begin{tabular}{|c|c|c|c|c|c|}
\hline Mission & $\begin{array}{c}\text { Replacement } \\
\text { Model }\end{array}$ & $\begin{array}{l}\text { Extrapolated } \\
\text { Local. Yearly } \\
\mathrm{CO}_{2} \mathrm{e} \mathrm{Avoided} \\
\left(\mathrm{lb}_{-} \mathrm{CO}_{2} \mathrm{e} / \text { year) }\right.\end{array}$ & $\%$ reduction & $\begin{array}{l}\text { Extrapolated } \\
\text { Local Yearly } \\
\text { Fuel Cost } \\
\text { Reduction }\end{array}$ & $\%$ reduction \\
\hline Enforcement & C-Max & 5,619 & $51 \%$ & $\$ 1,519$ & $78 \%$ \\
\hline Pool & Leaf & 4,922 & $54 \%$ & $\$ 1,279$ & $79 \%$ \\
\hline Pool & Rav4 EV & 60 & $3 \%$ & $\$ 232$ & $56 \%$ \\
\hline Support & VTRUX PU & 755 & $47 \%$ & $\$ 216$ & $76 \%$ \\
\hline Support & eNV200 & 879 & $61 \%$ & $\$ 211$ & $82 \%$ \\
\hline Pool & Rav4 EV & 2,324 & $57 \%$ & $\$ 582$ & $81 \%$ \\
\hline Pool & Outlander & 6,673 & $42 \%$ & $\$ 2,079$ & $74 \%$ \\
\hline Pool & Rav4 EV & 1,309 & $42 \%$ & $\$ 408$ & $74 \%$ \\
\hline Support & Leaf & 947 & $54 \%$ & $\$ 246$ & $79 \%$ \\
\hline Enforcement & Leaf & 7,642 & $61 \%$ & $\$ 1,846$ & $82 \%$ \\
\hline Support & Rav4 EV & 1,777 & $51 \%$ & $\$ 481$ & $78 \%$ \\
\hline Transport & Rav4 EV & 1,399 & $21 \%$ & $\$ 766$ & $64 \%$ \\
\hline Transport & eNV200 & 2,449 & $42 \%$ & $\$ 767$ & $74 \%$ \\
\hline Transport & Rav4 EV & 1,279 & $39 \%$ & $\$ 421$ & $72 \%$ \\
\hline Support & Rav4 EV & 6,413 & $54 \%$ & $\$ 1,667$ & $79 \%$ \\
\hline Support & eNV200 & 916 & $61 \%$ & $\$ 220$ & $82 \%$ \\
\hline Pool & Fusion & 1,493 & $44 \%$ & $\$ 453$ & $74 \%$ \\
\hline Enforcement & Leaf & 5,340 & $56 \%$ & $\$ 1,353$ & $80 \%$ \\
\hline Enforcement & C-Max & 1,351 & $46 \%$ & $\$ 393$ & $76 \%$ \\
\hline Pool & Rav4 EV & 191 & $21 \%$ & $\$ 104$ & $64 \%$ \\
\hline Total & & 53,737 & $48 \%$ & $\$ 15,243$ & $76 \%$ \\
\hline Total Pool & & 16,971 & $44 \%$ & $\$ 5,138$ & $74 \%$ \\
\hline Total Support & & 11,688 & $54 \%$ & $\$ 3,040$ & $79 \%$ \\
\hline Total Enforcement & & 19,952 & $55 \%$ & $\$ 5,111$ & $80 \%$ \\
\hline Total Transport & & 5,127 & $32 \%$ & $\$ 1,954$ & $69 \%$ \\
\hline
\end{tabular}

Table 21 shows the high potential benefit in reduction of GHG emissions in the local NIH area. In addition, the fuel cost reduction potential benefit is also significant due to the low cost of power.

As presented in Section 5, three ICE vehicles, $11 \mathrm{BEVs}$, and 5 PHEVs could replace the pool fleet of 19 vehicles. The support fleet of 200 vehicles would retain one heavy-duty pickup and nine passenger 
vans and replace the balance with 142 BEVs and 48 PHEVs. In addition, 23 BEVs and 30 PHEVs are assumed to replace the enforcement fleet of 53 vehicles. The full transport fleet of 36 vehicles would retain the 31 ICE heavy-duty trucks and replace the others with four BEVs and one PHEV. Using an average savings per vehicle, Table 22 provides the avoided GHG and fuel cost savings should these replacements occur. The table also shows the percentage reduction in GHG emissions and fuel costs for ease of comparison. Only local Maryland savings are projected in this table; national figures are presented in Appendix C.

Table 22. Extrapolated greenhouse gas emissions avoided and fuel cost savings for the entire fleet.

\begin{tabular}{ccccc}
\hline & $\begin{array}{c}\text { Extrapolated Local } \\
\text { Yearly } \mathrm{CO}_{2} \mathrm{e} \text { Avoided } \\
\left(\text { lb- } \mathrm{CO}_{2} \mathrm{e} / \text { year) }\right.\end{array}$ & \% reduction & $\begin{array}{c}\text { Extrapolated Local } \\
\text { Yearly Fuel Cost } \\
\text { Reduction (\$/year }\end{array}$ & \% reduction \\
\hline Mission & 43,933 & $48 \%$ & $\$ 12,387$ & $76 \%$ \\
Pool & 425,365 & $50 \%$ & $\$ 117,211$ & $77 \%$ \\
Enforcement & 174,987 & $50 \%$ & $\$ 48,008$ & $77 \%$ \\
Transport & 7,272 & $44 \%$ & $\$ 2,179$ & $75 \%$ \\
Total & 651.557 & $50 \%$ & $\$ 179,786$ & $77 \%$ \\
\hline
\end{tabular}

\section{OBSERVATIONS}

Intertek appreciates the opportunity to present the results of this evaluation. Observations for possible follow-up action include the following:

\section{Observation \#1:}

Implementation: NIH can move forward in the near future with the replacement of pool, support, enforcement, and transport vehicles with PEVs as current budget and vehicle replacement schedules allow. Certainly, the vehicle types studied in this report are candidates for immediate replacement.

\section{Observation \#2:}

Fleet Inventory: A more thorough examination of the quantities and types of fleet vehicles within each usage category may be beneficial to quantify the potential for replacement by PEVs. While Intertek suggests a mix of BEVs and PHEVs, a more refined look may be possible. In addition, this study did not look in detail at the other fleet vehicle categories (such as those with specialty missions) or vehicles assigned to other institutes.

\section{Observation \#3:}

Vehicle Replacement Plan: Development of a detailed vehicle replacement plan could be beneficial. This plan would include the cost and schedule for vehicle replacement. A more detailed survey and calculation of fleet vehicles use (such as vehicle parking locations, age of vehicle, expected replacement time, expected replacement costs, GSA vehicle costs, EVSE cost, total life costs, and EVSE installation costs) provide support to this replacement plan. A more refined estimate for reduced GHG emissions, petroleum usage reduction, and fuel cost savings flow from this detailed plan.

\section{Observation \#4:}

Infrastructure Planning: In conjunction with the replacement plan, evaluation of the NIH sites for placement of PEV charging infrastructure could be beneficial. Intertek has significant experience in this area and these plans will consider fleet vehicle charging needs and the convenience that charging infrastructure provides employees and visitors. This planning also considers the existing facility electrical distribution system. Vehicle home base considerations factor into the ratio of PEVs to EVSE units to maintain all vehicles at operational readiness. 


\section{Appendix A Definitions}

Alternative fuel

City fuel economy (MPG)

Conventional fuel

Daily travel

Diesel fuel

E85

Electric vehicle

Ethanol-fueled vehicle

Federal vehicle standards

Government motor vehicle

Gross vehicle weight rating

GSA fleet
An alternative fuel means any fuel other than gasoline and diesel fuels, such as methanol, ethanol, and gaseous fuels (40 CFR 86.1803-01). A fuel type other than petroleum-based gasoline or diesel as defined by the Energy Policy Act (examples include ethanol, methanol, compressed natural gas, propane, and electrical energy).

City fuel economy means the city fuel economy determined by operating a vehicle (or vehicles) over the driving schedule in the federal emission test procedure or determined according to the vehicle-specific 5-cycle or derived 5-cycle procedures (40 CFR 600.001).

A petroleum-based fuel (examples include gasoline and diesel fuel).

The sum of daily trips and stops in one day.

Diesel means a type of engine with operating characteristics significantly similar to the theoretical diesel combustion cycle. The non-use of a throttle during normal operation is indicative of a diesel engine (49 CFR 86-1803).

Ethanol fuel blend of up to $85 \%$ denatured ethanol fuel and gasoline or other hydrocarbons by volume.

Electric vehicle means a motor vehicle that is powered solely by an electric motor drawing current from a rechargeable energy storage system, such as from storage batteries or other portable electrical energy storage devices, including hydrogen fuel cells, provided that

(1) The vehicle is capable of drawing recharge energy from a source off the vehicle, such as residential electric service

(2) The vehicle must be certified to the emission standards of Bin \#1 of Table S04-1 in § 86.1811-09(c)(6)

(3) The vehicle does not have an onboard combustion engine/generator system as a means of providing electrical energy (40 CFR 86-1803).

Ethanol-fueled vehicle-means any motor vehicle or motor vehicle engine that is engineered and designed to be operated using ethanol fuel (i.e., a fuel that contains at least $50 \%$ ethanol $\left(\mathrm{C}_{2} \mathrm{H}_{5} \mathrm{OH}\right)$ by volume) as fuel (40 CFR 86.1803-01).

The document that establishes classifications for various types and sizes of vehicles, general requirements, and equipment options. It is issued annually by the GSA Vehicle Acquisition and Leasing Service's Automotive Division.

Any motor vehicle that the government owns or leases. This includes motor vehicles obtained through purchase, excess, forfeiture, commercial lease, or GSA fleet lease.

Gross vehicle weight rating (GVWR) means the value specified by the vehicle manufacturer as the maximum design loaded weight of a single vehicle (e.g., vocational vehicle) (US Government Printing Office 2009)

GSA fleet lease means obtaining a motor vehicle from the General Services Administration fleet (GSA fleet) (41 CFR 102-34). 
Heavy light-duty truck

Highway fuel economy (Hwy MPG)

Hybrid electric vehicle

Idle time

Law enforcement

Light-duty motor vehicle Light-duty truck
Heavy light-duty truck means any light-duty truck rated greater than 6,000 lb GVWR. The light-duty truck 3 (LDT3) and LDT4 classifications comprise the heavy light-duty truck category (40 CFR 86.1803-01).

Highway fuel economy means the highway fuel economy determined either by operating a vehicle (or vehicles) over the driving schedule in the federal highway fuel economy test procedure or determined according to either the vehicle-specific, 5-cycle equation, or the derived 5-cycle equation for highway fuel economy (40 CFR 600.001).

Hybrid electric vehicle means a motor vehicle that draws propulsion energy from onboard sources of stored energy that are both an internal combustion engine or heat engine using consumable fuel and a rechargeable energy storage system (such as a battery, capacitor, hydraulic accumulator, or flywheel), where recharge energy for the energy storage system comes solely from sources on board the vehicle.

Idle time is logged whenever a vehicle idles with the engine running for 3 minutes or longer.

Law enforcement motor vehicle means a light-duty motor vehicle that is specifically approved in an agency-s appropriation act for use in apprehension, surveillance, police, or other law enforcement work or specifically designed for use in law enforcement. If not identified in an agency's appropriation language, a motor vehicle qualifies as a law enforcement motor vehicle only in the following cases:

(1) A passenger automobile having heavy-duty components for electrical, cooling, and suspension systems and at least the next higher cubic inch displacement or more powerful engine than is standard for the automobile concerned

(2) A light truck having emergency warning lights and identified with markings such as "police"

(3) An unmarked motor vehicle certified by the agency head as essential for the safe and efficient performance of intelligence, counterintelligence, protective, or other law enforcement duties

(4) A forfeited motor vehicle seized by a federal agency that subsequently is used for performing law enforcement activities (41 CFR Part 102-34.35).

Any motor vehicle with a GVWR of 8,500 pounds or less (41 CFR 102-34). Light-duty truck means any motor vehicle rated at 8,500 pounds GVWR or less, which has a curb weight of 6,000 pounds or less and, which has a basic vehicle frontal area of 45 square feet or less, which is as follows:

(1) Designed primarily for purposes of transportation of property or is a derivation of such a vehicle

(2) Designed primarily for transportation of persons and has a capacity of more than 12 persons

(3) Available with special features, enabling off-street or off-highway operation and use.

LDT1 means any light light-duty truck up through 3,750-lb loaded vehicle weight.

LDT2 means any light light-duty truck greater than 3,750-lb loaded vehicle weight. 


\section{Light-duty vehicle \\ Low-speed vehicle \\ Light-duty vehicle means a passenger car or passenger car derivative capable of seating 12 passengers or less. \\ Low-speed vehicle means a motor vehicle \\ (1) That is 4-wheeled \\ (2) Whose speed attainable in $1.6 \mathrm{~km}$ (1 mile) is more than 32 kilometers per hour (20 miles per hour) and not more than 40 kilometers per hour (25 miles per hour) on a paved level surface \\ (3) Whose GVWR is less than 1,361 kilograms (3,000 pounds) (49 CFR 571.3 - Definitions).}

Medium-duty passenger vehicle

Model year

$M P G$

$M P G e$

Non-passenger automobile
LDT3 means any heavy light-duty truck up through 5,750-lb adjusted loaded vehicle weight.

LDT4 means any heavy light-duty truck greater than 5,750-lb adjusted loaded vehicle weight (US Government Printing Office 2009)

Medium-duty passenger vehicle means any heavy-duty vehicle (as defined in this subpart) with a GVWR of less than 10,000 pounds that is designed primarily for transportation of persons. The medium-duty passenger vehicle definition does not include any vehicle which

(1) Is an "incomplete truck" as defined in this subpart

(2) Has a seating capacity of more than 12 persons

(3) Is designed for more than 9 persons in seating rearward of the driver's seat

(4) Is equipped with an open cargo area (for example, a pick-up truck box or bed) of 72.0 inches in interior length or more. A covered box not readily accessible from the passenger compartment will be considered an open cargo area for purposes of this definition (US Government Printing Office 2009)

Model year means the manufacturer's annual production period (as determined by the administrator), which includes January 1 of such calendar year; provided that if the manufacturer has no annual production period, the term "model year" shall mean the calendar year (40 CFR 86-1803.01).

"MPG" or "mpg" means miles per gallon. This generally may be used to describe fuel economy as a quantity or it may be used as the units associated with a particular value.

MPGe means miles per gallon equivalent. This generally is used to quantify a fuel economy value for vehicles that use a fuel other than gasoline. The value represents miles the vehicle can drive with the energy equivalent of one gallon of gasoline:

(c) SCF means standard cubic feet

(d) SUV means sport utility vehicle

(e) CREE means carbon-related exhaust emissions [76 FR 39527, July 6, 2011].

A non-passenger automobile means an automobile that is not a passenger automobile or a work truck and includes vehicles described in paragraphs (a) and (b) of 49 CFR 523.5. 
Owning agency

Passenger automobile

Pickup truck

Plug-in hybrid electric vehicle

Vehicle class

Vehicle configuration

Vehicle days

Vehicle home base

Vehicle study period
Owning agency means the executive agency that holds the vehicle title, manufacturer's Certificate of Origin or is the lessee of a commercial lease. This term does not apply to agencies that lease motor vehicles from the GSA fleet (41 CFR Part 102-34.35).

A passenger automobile is any automobile (other than an automobile capable of off-highway operation) manufactured primarily for use in the transportation of not more than 10 individuals (49 CFR 523.4 - Passenger automobile). A sedan or station wagon designed primarily to transport people (41 CFR 102-34).

Pickup truck means a non-passenger automobile, which has a passenger compartment and an open cargo bed (49 CFR 523.2).

PHEV means a hybrid electric vehicle that has the capability to charge the battery from an off-vehicle electric source, such that the off-vehicle source cannot be connected to the vehicle while the vehicle is in motion (40 CFR 86.1803).

The designation of motor vehicle types that include sedans, station wagons, ambulances, buses, and trucks, or different categories of vehicles according to Federal vehicle standards and further defined in 49 CFR 600.315-82.

Vehicle configuration means a unique combination of basic engine, engine code, inertia weight class, transmission configuration, and axle ratio.

The number of days a vehicle was driven or utilized during the (vehicle) study period.

The primary assigned outing beginning and ending parking location for the vehicle.

The time period the vehicle, within the study, has been equipped with a data logger. 


\section{Appendix B \\ NIH Vehicle Data Sheets}

Table B-1. NIH vehicle index.

\begin{tabular}{ccccccc}
\hline Log & NIH Vehicle Id & Make & Model & Year & EPA Class & Mission \\
\hline 41 & $* * * 1385$ & Ford & Crown Victoria & 2009 & Sedan - Large & Enforcement \\
42 & $* * * 2995$ & Chevrolet & Impala & 2010 & Sedan - Large & Pool \\
43 & $* * * 7017$ & Ford & Escape Hybrid & 2009 & SUV & Pool \\
44 & $* * * 5470$ & Ford & F-150 & 2010 & Pickup & Support \\
45 & $* * * 5207$ & Dodge & Sprinter & 2002 & Van - Cargo & Support \\
46 & $* * * 7596$ & Dodge & Durango & 2001 & SUV & Pool \\
47 & $* * * 8759$ & Chevrolet & Uplander & 2008 & Minivan & Pool \\
48 & $* * * 7791$ & Dodge & Caravan & 2009 & Minivan & Pool \\
49 & $* * * 8315$ & Chevrolet & Impala & 2010 & Sedan - Large & Support \\
50 & $* * * 1384$ & Ford & Crown Victoria & 2009 & Sedan - Large & Enforcement \\
51 & $* * * 3265$ & Chevrolet & Silverado & 2005 & Pickup & Support \\
52 & $* * * 1314$ & Chevrolet & HHR & 2010 & SUV & Transport \\
53 & $* * * 4477$ & Chevrolet & Colorado & 2010 & Pickup & Transport \\
54 & $* * * 8199$ & Dodge & Caravan & 1999 & Minivan & Transport \\
55 & $* * * 3815$ & Jeep & Grand Cherokee & 2009 & SUV & Support \\
56 & $* * * 3952$ & Ford & Expedition & 2006 & SUV & Support \\
57 & $* * * 8489$ & Chevrolet & Impala & 2010 & Sedan - Large & Pool \\
58 & $* * * 0758$ & Chevrolet & Impala & 2005 & Sedan - Large & Enforcement \\
59 & $* * * 0370$ & Chevrolet & Impala & 2005 & Sedan - Large & Enforcement \\
60 & $* * * 1201$ & Chevrolet & HHR & 2010 & SUV & Pool \\
\hline
\end{tabular}




\section{Vehicle $^{* * *} 1385$}

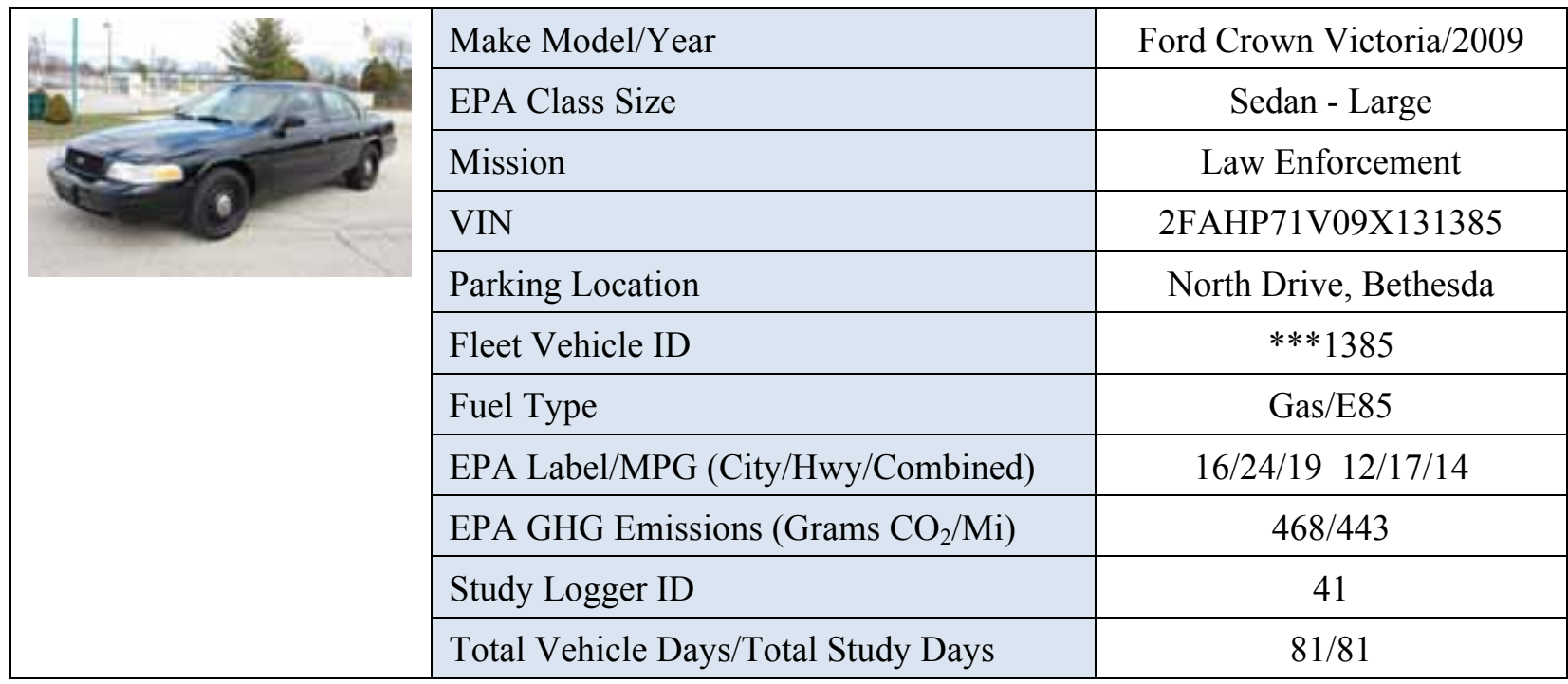

\begin{tabular}{|l|c|c|c|c|}
\hline \multicolumn{5}{|c|}{ Vehicle ***1385 Travel Summary } \\
& Per Day Average/Peak & $\begin{array}{c}\text { Per Outing } \\
\text { Average/Peak }\end{array}$ & $\begin{array}{c}\text { Per Trip } \\
\text { Average/Peak }\end{array}$ & Total \\
\hline Travel Distance (Miles) & $16.4 / 53.5$ & $11.6 / 99.8$ & $1.2 / 38.6$ & 1,331 \\
\hline Travel Time (Minutes) & $278.0 / 752.0$ & $195.8 / 1,381.0$ & $20.5 / 335.0$ & 22,513 \\
\hline Idle Time (Minutes) & $189.5 / \mathrm{NA}$ & $133.5 / \mathrm{NA}$ & $14.0 / \mathrm{NA}$ & 15,348 \\
\hline
\end{tabular}

\begin{tabular}{|c|c|c|c|c|}
\hline \multicolumn{2}{|c|}{ Total Stops } & \multicolumn{2}{c|}{ Stop Duration } \\
\hline $\begin{array}{c}\text { Distance From Home } \\
\text { Base (Miles) }\end{array}$ & Stops & Percentages & $\begin{array}{c}\text { Stop Duration } \\
\text { (Hours) }\end{array}$ & Stops \\
\hline Less than 10 & 929 & $100 \%$ & Less than 2 & 760 \\
\hline 10 to 20 & 0 & $0 \%$ & 2 to 4 & 83 \\
\hline 20 to 40 & 0 & $0 \%$ & 4 to 8 & 47 \\
\hline Greater than 40 & 0 & $0 \%$ & Greater than 8 & 39 \\
\hline
\end{tabular}

\section{Vehicle *1385 Stops}

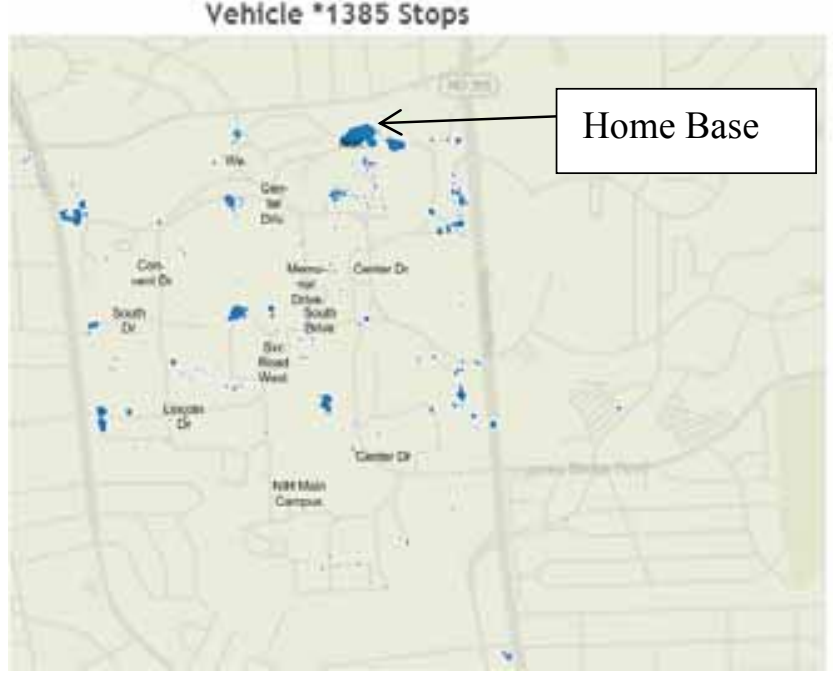

Figure B-1. Vehicle ***1385 stops.

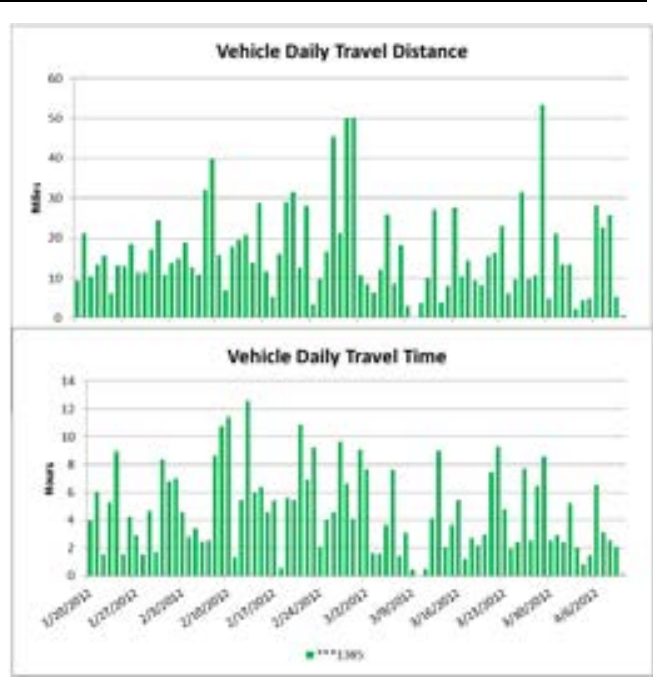

Figure B-2. Vehicle $* * * 1385$ history. 


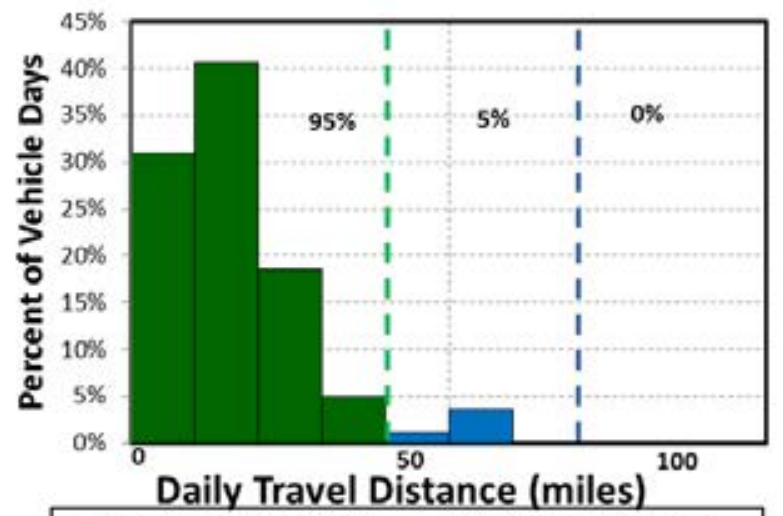

Daily Travel Distance (miles)

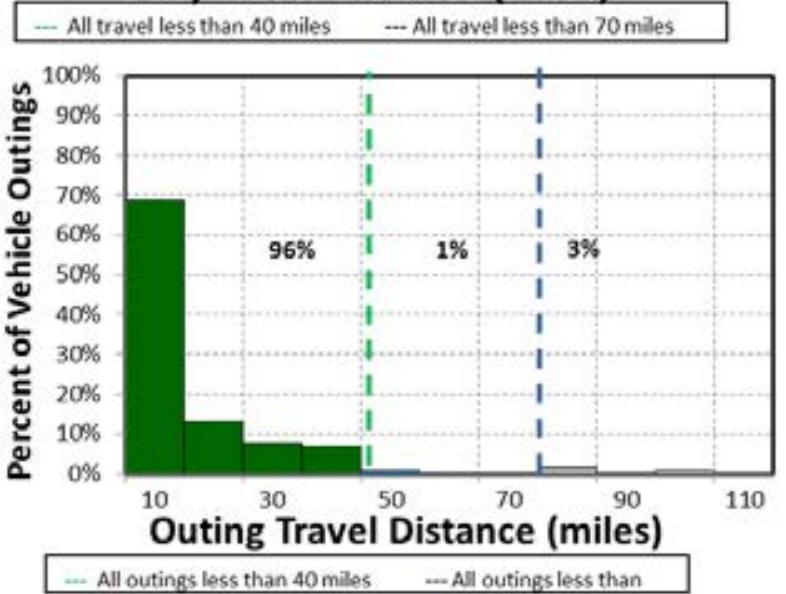

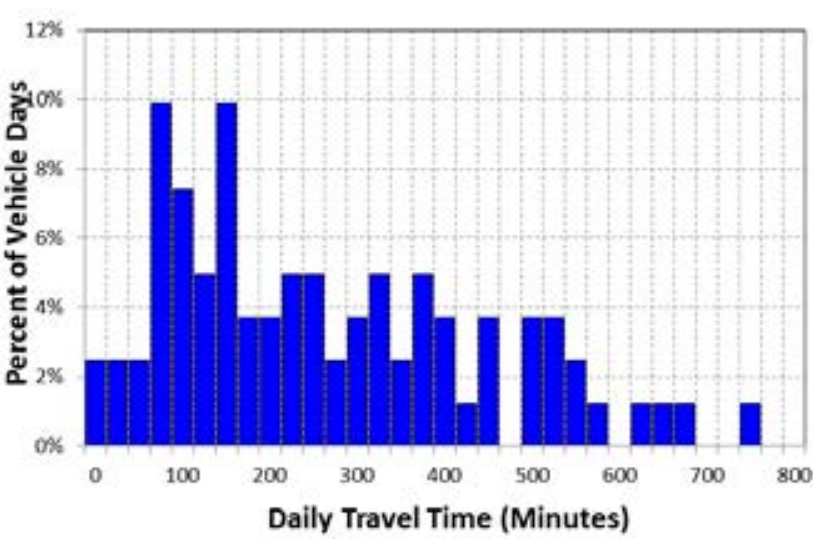

Daily Travel Time (Minutes)

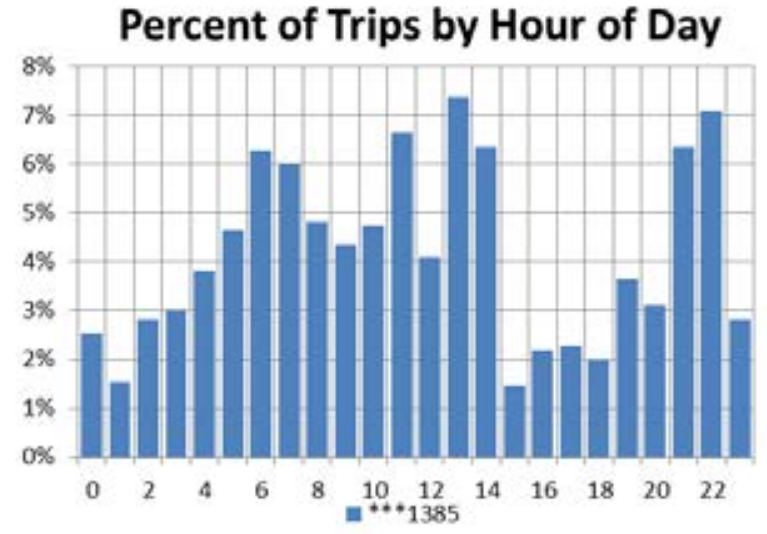

Figure B-3. Vehicle ***1385 travel graphs.

\section{Vehicle ${ }^{* *} 1385$ Observations}

Logger 41 collected data on this vehicle for a period of 81 days of the 81-day study period. Validation occurred on $97.2 \%$ of the input data. NIH reports that this vehicle has a law enforcement mission for police patrol. This vehicle's data indicate it parks in many different locations, but its home base appears to be on North Drive (Figure B-1 and Google Earth figure to the right).

NIH reports that the vehicle odometer indicated 36,298 miles during the study and it travels 10,889 miles per year. The vehicle was used on $100 \%$ of the available days, with an average daily usage of 4.7 hours and a peak daily usage of 12.5 hours on the days it was used. The vehicle was used during all hours of the day.

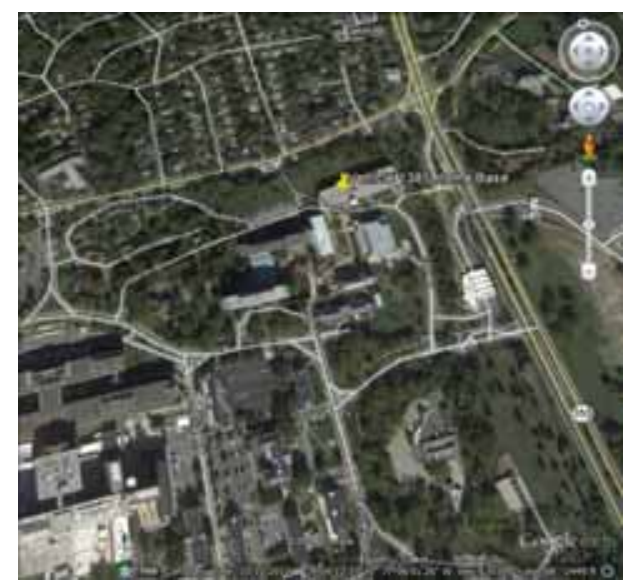

Figure B-3 shows that all daily travel was within the typically advertised range of a BEV of approximately 70 miles; $97 \%$ of the outings were also within this range. Further, $95 \%$ of daily travel and $96 \%$ of outings were within the typically advertised CD mode of 40 miles for PHEVs. The peak outing of 99 miles occurred over a several day period when the vehicle did not return to North Drive, but parked in several other locations on the main campus. Short duration travel to Rockville was also indicated.

A BEV could meet all daily travel without additional charging opportunities assuming the vehicle was assigned a home base. However, fleet managers typically do not prefer enforcement vehicles that contain range limitations. Thus, a fleet of enforcement vehicles would likely contain a mix of BEVs and PHEVs. 


\section{Vehicle $^{* * *} 2995$}

\begin{tabular}{|c|c|c|}
\hline 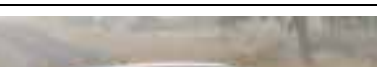 & Make/Model/Year & Chevrolet Impala/2010 \\
\hline $29.42=$ & EPA Class Size & Sedan - Large \\
\hline $6=8-2=$ & Mission & Pool \\
\hline & VIN & 2G1WA5EKXA1112995 \\
\hline & Parking Location & Service Road South \\
\hline & Fleet Vehicle ID & $* * * 2995$ \\
\hline & Fuel Type & Gas/E85 \\
\hline & EPA Label/MPG (City/Hwy/Combined) & $18 / 29 / 22 \quad 14 / 22 / 17$ \\
\hline & EPA GHG Emissions (Grams $\mathrm{CO}_{2} / \mathrm{Mi}$ ) & $404 / 365$ \\
\hline & Study Logger ID & 42 \\
\hline & Total Vehicle Days/Total Study Days & $27 / 60$ \\
\hline
\end{tabular}

\begin{tabular}{|l|c|c|c|c|}
\hline \multicolumn{5}{|c|}{ Vehicle ***2995 Travel Summary } \\
& Per Day Average/Peak & $\begin{array}{c}\text { Per Outing } \\
\text { Average/Peak }\end{array}$ & $\begin{array}{c}\text { Per Trip } \\
\text { Average/Peak }\end{array}$ & Total \\
\hline Travel Distance (Miles) & $6.7 / 36.3$ & $7.0 / 41.6$ & $0.6 / 8.7$ & 181 \\
\hline Travel Time (Minutes) & $29.0 / 80.0$ & $30.3 / 106.0$ & $2.7 / 76.0$ & 787 \\
\hline Idle Time (Minutes) & $4.8 / \mathrm{NA}$ & $5.0 / \mathrm{NA}$ & $0.4 / \mathrm{NA}$ & 129 \\
\hline
\end{tabular}

\begin{tabular}{|c|c|c|c|c|}
\hline \multicolumn{2}{|c|}{ Total Stops } & \multicolumn{2}{c|}{ Stop Duration } & \\
\hline $\begin{array}{c}\text { Distance From Home } \\
\text { Base (Miles) }\end{array}$ & Stops & Percentages & Stop Duration (Hours) & Stops \\
\hline Less than 10 & 130 & $92.9 \%$ & Less than 2 & 108 \\
\hline 10 to 20 & 9 & $6.4 \%$ & 2 to 4 & 6 \\
\hline 20 to 40 & 1 & $0.7 \%$ & 4 to 8 & 2 \\
\hline Greater than 40 & 0 & $0 \%$ & Greater than 8 & 24 \\
\hline
\end{tabular}

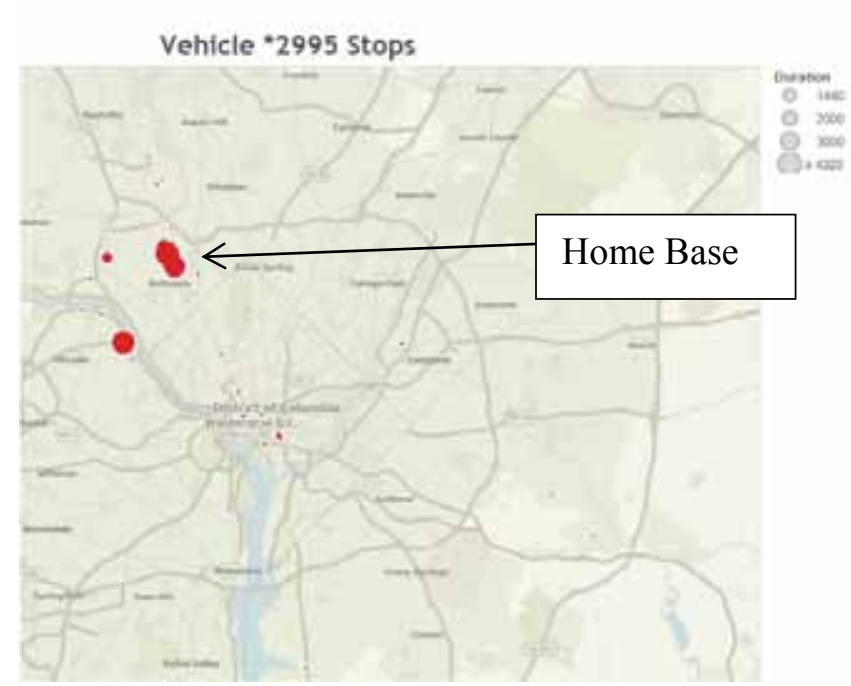

Figure B-4. Vehicle ***2995 stops.

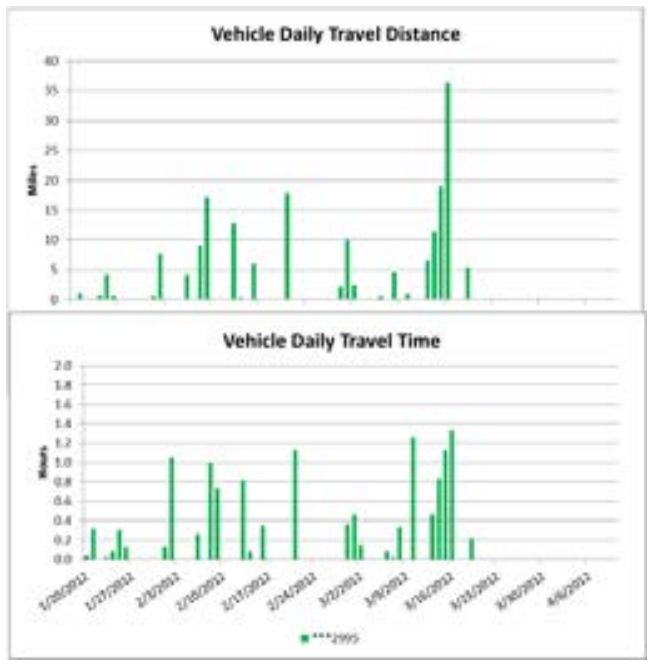

Figure B-5. Vehicle ***2995 history. 


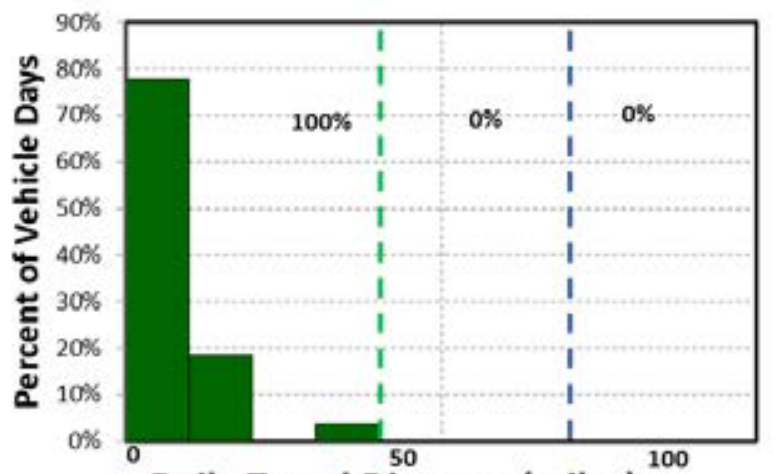

Daily Travel Distance (miles)

- All travel less than 40 miles .... All travel less than 70 miles

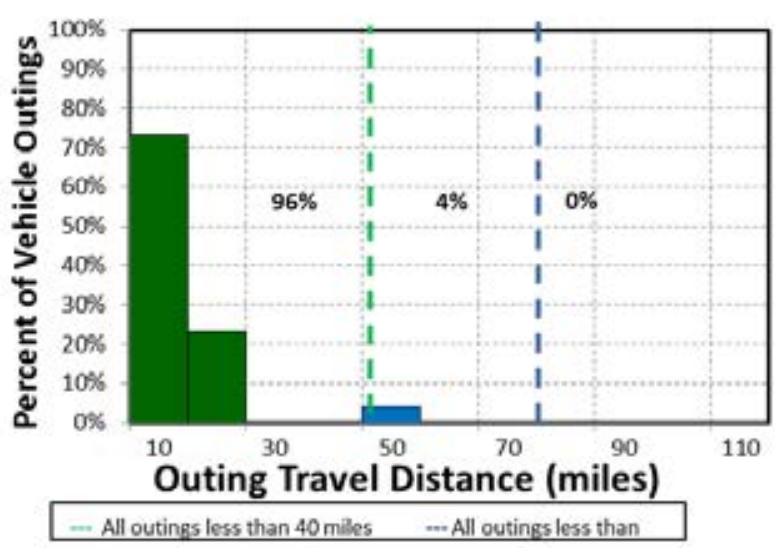

Figure B-6. Vehicle $* * * 2995$ travel graphs.

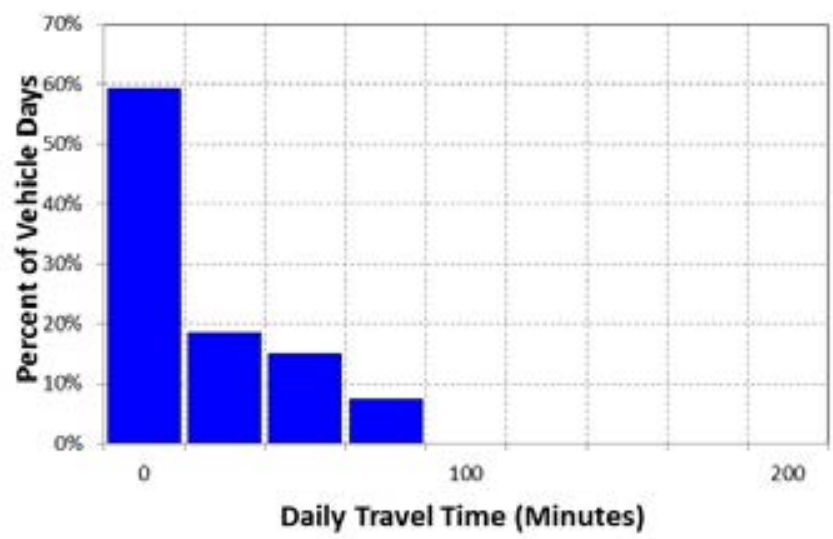

Percent of Trips by Hour of Day

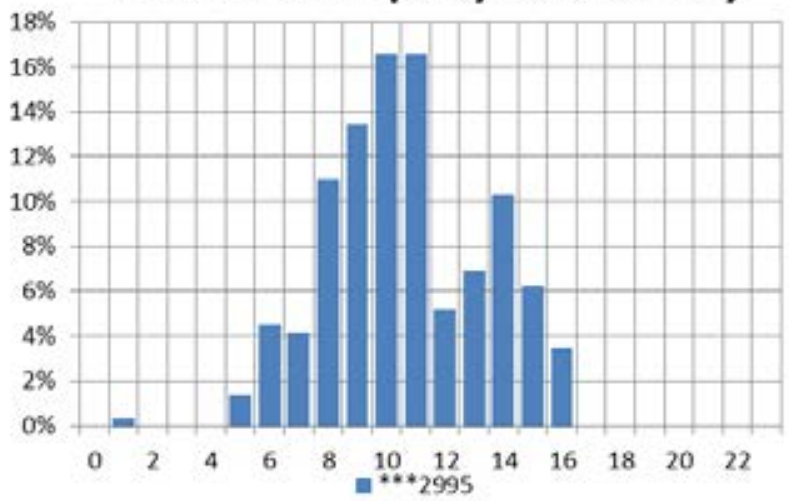

\section{Vehicle ${ }^{* *} 2995$ Observations}

Logger 42 collected data on this vehicle for a period of 27 days of the 60-day study period. Validation occurred on $99.0 \%$ of the input data. NIH reports this vehicle has a pool mission for daily rental and typically parks overnight on Service Road South (Figure B-4 and Google Earth figure to the right).

$\mathrm{NIH}$ reports that the vehicle odometer indicated 9,917 miles during the study and it travels 9,917 miles per year. The vehicle was used on $45 \%$ of the available days, with an average daily usage of 0.5 hours and a peak daily usage of 1.3 hours on the days it was used. The vehicle was used during day shift hours.

Figure B-6 shows that all daily travel and outings were within the typically advertised range of a BEV of approximately 70 miles. Further, all daily travel and $96 \%$ of outings were within the typically advertised CD mode of 40 miles for PHEVs. Short duration travel to Rockville and other cities in the Washington D.C. area were also indicated.

A BEV can meet all daily travel without additional charging opportunities. BEVs are currently available as replacement vehicles for this vehicle. 


\begin{tabular}{|c|c|c|}
\hline & Make/Model/Year & Ford Escape Hybrid/2009 \\
\hline & EPA Class Size & SUV \\
\hline$-2912=$ & Mission & Pool \\
\hline & VIN & 1FMCU49349KC97017 \\
\hline & Parking Location & Service Road South \\
\hline & Fleet Vehicle ID & $* * * 7017$ \\
\hline & Fuel Type & Gas \\
\hline & EPA Label/MPG (City/Hwy/Combined) & $34 / 31 / 32$ \\
\hline & EPA GHG Emissions (Grams $\left.\mathrm{CO}_{2} / \mathrm{Mi}\right)$ & 278 \\
\hline & Study Logger ID & 43 \\
\hline & Total Vehicle Days/Total Study Days & $17 / 41$ \\
\hline
\end{tabular}

\begin{tabular}{|l|c|c|c|c|}
\hline \multicolumn{5}{|c|}{ Vehicle***7017 Travel Summary } \\
& Per Day Average/Peak & $\begin{array}{c}\text { Per Outing } \\
\text { Average/Peak }\end{array}$ & $\begin{array}{c}\text { Per Trip } \\
\text { Average/Peak }\end{array}$ & Total \\
\hline Travel Distance (Miles) & $5.7 / 35.6$ & $2.6 / 52.7$ & $0.8 / 11.6$ & 97 \\
\hline Travel Time (Minutes) & $18.0 / 79.0$ & $8.4 / 92.0$ & $2.5 / 28.0$ & 310 \\
\hline Idle Time (Minutes) & $2.4 / \mathrm{NA}$ & $1.1 / \mathrm{NA}$ & $0.3 / \mathrm{NA}$ & 41 \\
\hline
\end{tabular}

\begin{tabular}{|c|c|c|c|c|}
\hline \multicolumn{2}{|c|}{ Total Stops } & \multicolumn{2}{c|}{ Stop Duration } \\
\hline $\begin{array}{c}\text { Distance From Home } \\
\text { Base (Miles) }\end{array}$ & Stops & Percentages & $\begin{array}{c}\text { Stop Duration } \\
\text { (Hours) }\end{array}$ & Stops \\
\hline Less than 10 & 76 & $100 \%$ & Less than 2 & 56 \\
\hline 10 to 20 & 0 & $0 \%$ & 2 to 4 & 3 \\
\hline 20 to 40 & 0 & $0 \%$ & 4 to 8 & 2 \\
\hline 40 to 60 & 0 & $0 \%$ & Greater than 8 & 15 \\
\hline
\end{tabular}

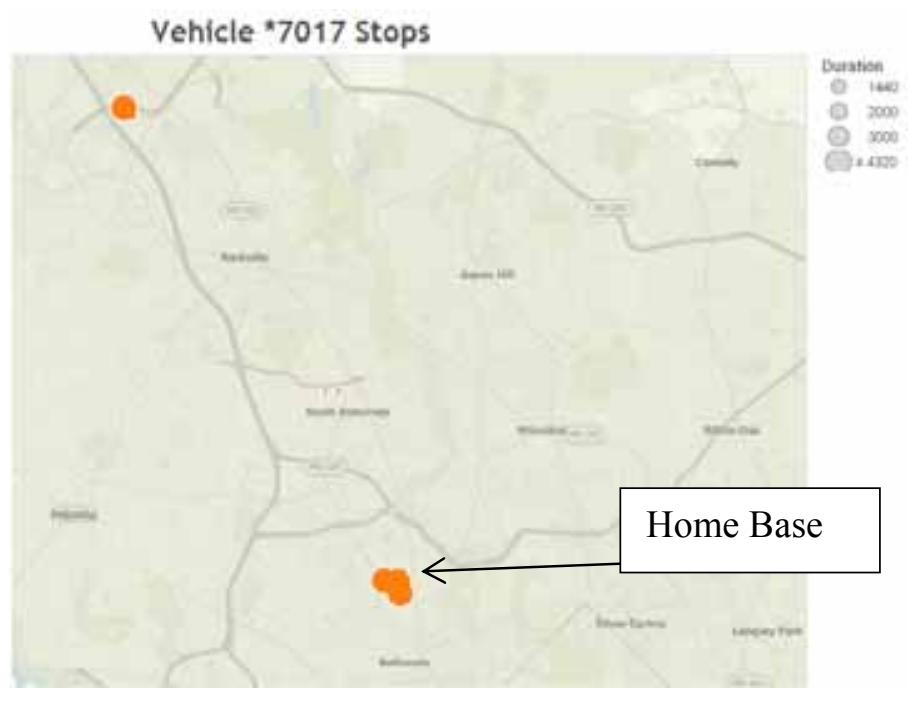

Figure B-7. Vehicle $* * * 7017$ stops.

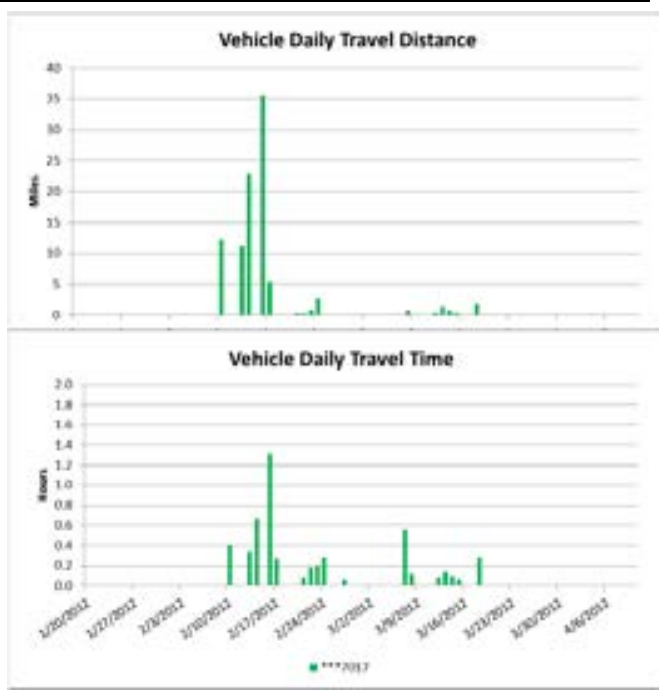

Figure B-8. Vehicle ***7017 history. 


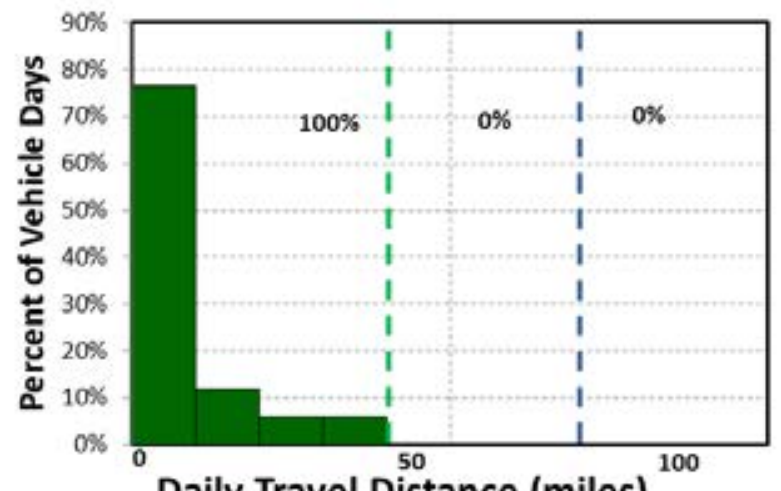

Daily Travel Distance (miles)

-All travel less than 40 miles $\quad$... All travel less than 70 miles

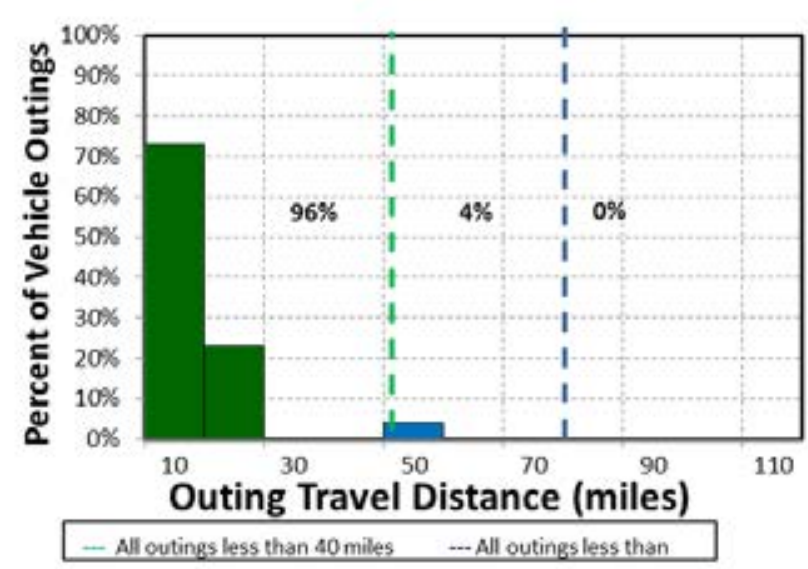

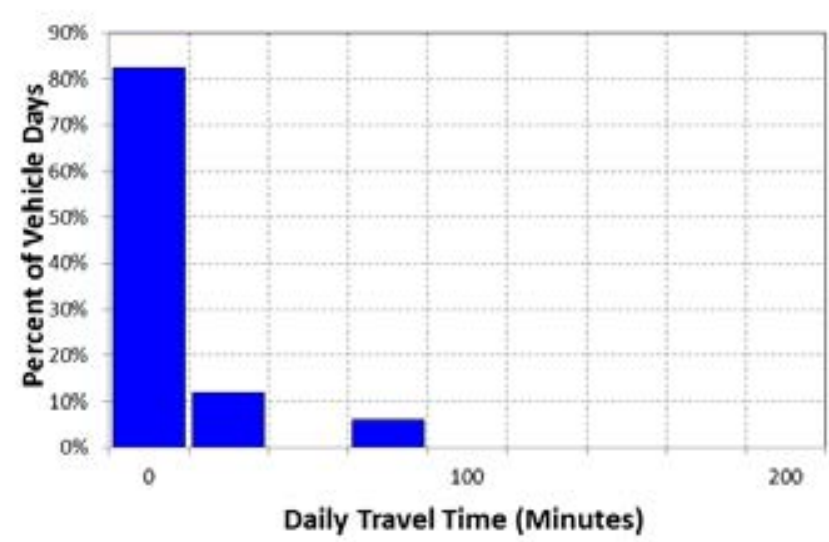

Percent of Trips by Hour of Day

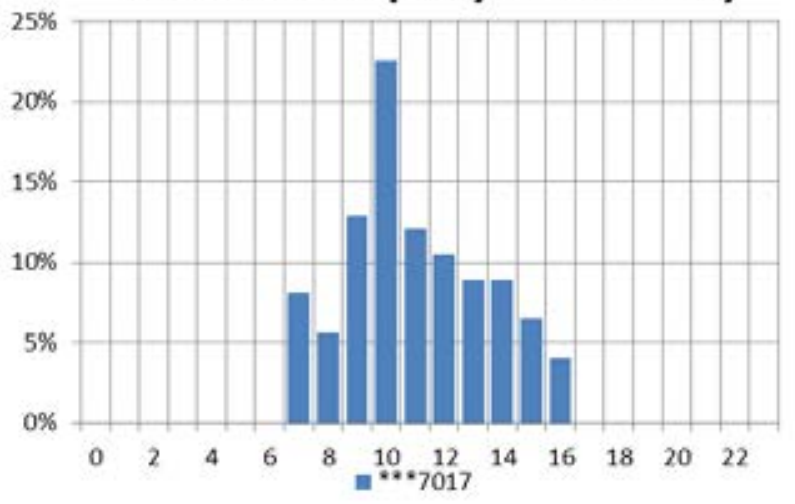

Figure B-9. Vehicle ***7017 travel graphs.

\section{Vehicle ${ }^{* * *} 7017$ Observations}

Logger 43 collected data on this vehicle for a period of 17 days of the 41-day study period. Validation occurred on $91.8 \%$ of the input data. NIH reports that this vehicle has a support mission and is used as a loaner vehicle when other vehicles are in the shop. It typically parks near Service Road South (Figure B-7 and Google Earth figure to the right).

NIH reports that the vehicle odometer indicated 11,185 miles during the study and it travels 3,728 miles per year. The vehicle was used on $41 \%$ of the available days with an average daily usage of 0.3 hours and a peak daily usage of 1.3 hours on the days it was used. The vehicle was used during typical day shift hours.

Figure B-9 shows all daily travel and all outings were within the

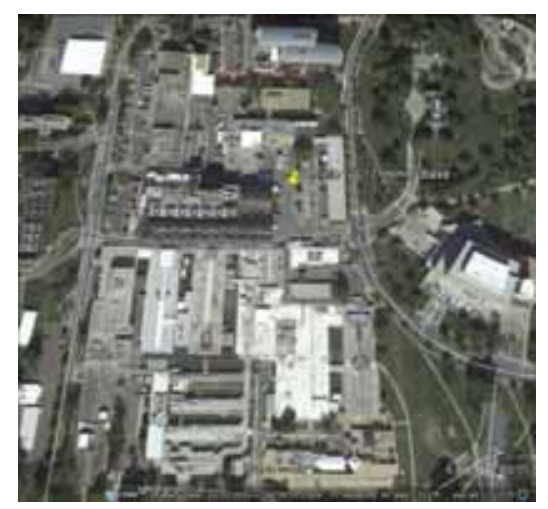
typically advertised range of a BEV of approximately 70 miles. Further, all daily travel and $96 \%$ of outings were within the typically advertised CD mode of 40 miles for PHEVs. The peak outing of 53 miles occurred during a several day excursion away from Bethesda to Rockville, Gaithersburg, and Redland, MD.

A BEV could meet daily travel without additional charging opportunities. Maintenance support may desire a fleet of BEVs and PHEVs to allow daily travel without requiring additional charge times, providing the PEV meets other mission requirements. The survey information suggests no other special requirements exist for this support activity. 


\begin{tabular}{|c|c|c|}
\hline \multirow{11}{*}{$\log ^{2}$} & Make/Model/Year & Ford F150/2010 \\
\hline & EPA Class Size & Pickup \\
\hline & Mission & Support \\
\hline & VIN & 1FTNF1CV9AKB35470 \\
\hline & Parking Location & Service Road South \\
\hline & Fleet Vehicle ID & $* * * 5470$ \\
\hline & Fuel Type & Gas/E85 \\
\hline & EPA Label/MPG (City/Hwy/Combined) & $14 / 20 / 16 \quad 10 / 14 / 12$ \\
\hline & EPA GHG Emissions (Grams $\mathrm{CO}_{2} / \mathrm{Mi}$ ) & $555 / 517$ \\
\hline & Study Logger ID & 44 \\
\hline & Total Vehicle Days/Total Study Days & $14 / 16$ \\
\hline
\end{tabular}

\begin{tabular}{|l|c|c|c|c|}
\hline \multicolumn{5}{|c|}{ Vehicle ***5470 Travel Summary } \\
& Per Day Average/Peak & $\begin{array}{c}\text { Per Outing } \\
\text { Average/Peak }\end{array}$ & $\begin{array}{c}\text { Per Trip } \\
\text { Average/Peak }\end{array}$ & Total \\
\hline Travel Distance (Miles) & $9.7 / 26.9$ & $2.7 / 20.5$ & $0.7 / 9.0$ & 136 \\
\hline Travel Time (Minutes) & $172.0 / 308.0$ & $47.1 / 169.0$ & $12.4 / 147.0$ & 2,401 \\
\hline Idle Time (Minutes) & $111.7 / \mathrm{NA}$ & $30.7 / \mathrm{NA}$ & $8.1 / \mathrm{NA}$ & 1,564 \\
\hline
\end{tabular}

\begin{tabular}{|c|c|c|c|c|}
\hline \multicolumn{2}{|c|}{ Total Stops } & \multicolumn{2}{c|}{ Stop Duration } \\
\hline $\begin{array}{c}\text { Distance From Home } \\
\text { Base (Miles) }\end{array}$ & Stops & Percentages & $\begin{array}{c}\text { Stop Duration } \\
\text { (Hours) }\end{array}$ & Stops \\
\hline Less than 10 & 151 & $100 \%$ & Less than 2 & 113 \\
\hline 10 to 20 & 0 & $0 \%$ & 2 to 4 & 19 \\
\hline 20 to 40 & 0 & $0 \%$ & 4 to 8 & 13 \\
\hline Greater than 40 & 0 & $0 \%$ & Greater than 8 & 6 \\
\hline
\end{tabular}

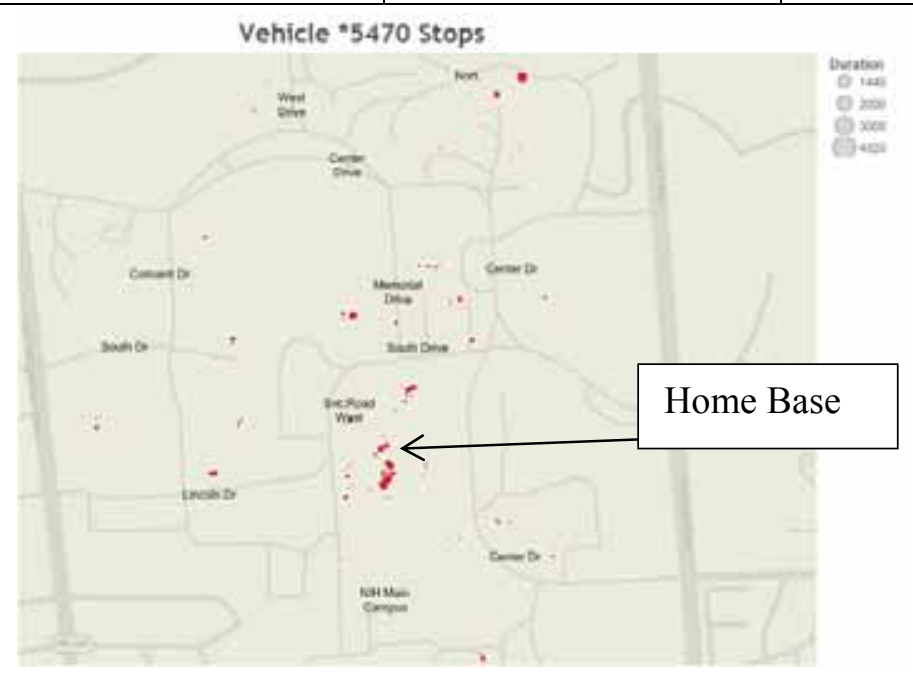

Figure B-10. Vehicle ***5470 stops.

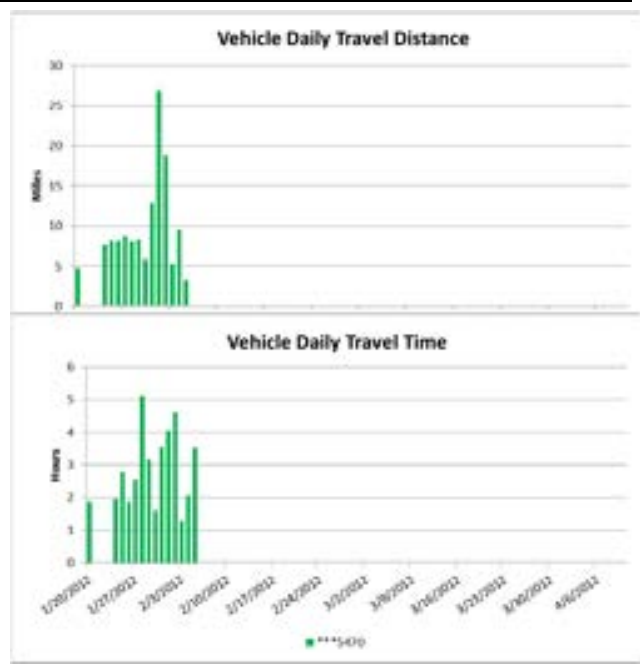

Figure B-11. Vehicle ***5470 history. 

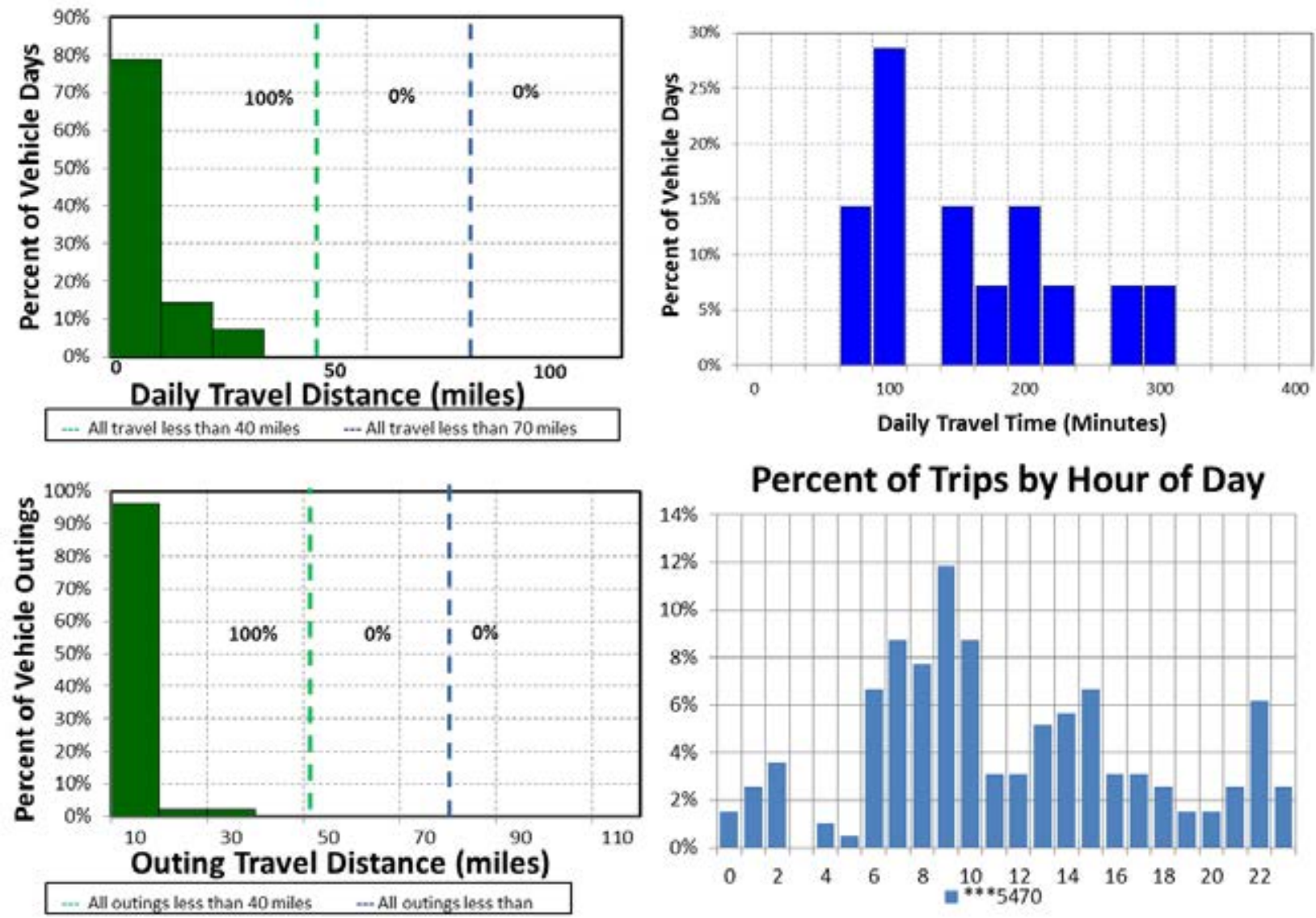

Figure B-12. Vehicle ***5470 travel graphs.

\section{Vehicle ${ }^{* * *} 5470$ Observations}

Logger 44 collected data on this vehicle for a period of 14 days of the 16-day study period. Validation occurred on $97.2 \%$ of the input data. NIH reports this data logger was lost in the maintenance area early in the test period. This vehicle has a support mission for the maintenance department shops; data show it typically parks near Service Road South (Figure B-10 and Google Earth figure to the right).

$\mathrm{NIH}$ reports that the vehicle odometer indicated 2,537 miles during the study and it travels 1,268 miles per year. The vehicle was used on $88 \%$ of the available days prior to loss of the logger, with an average daily usage of 2.9 hour and a peak daily usage of 5.1 hours on the days it was used. The vehicle was used primarily during typical day shift hours.

Figure B-12 shows that all daily travel and outings were

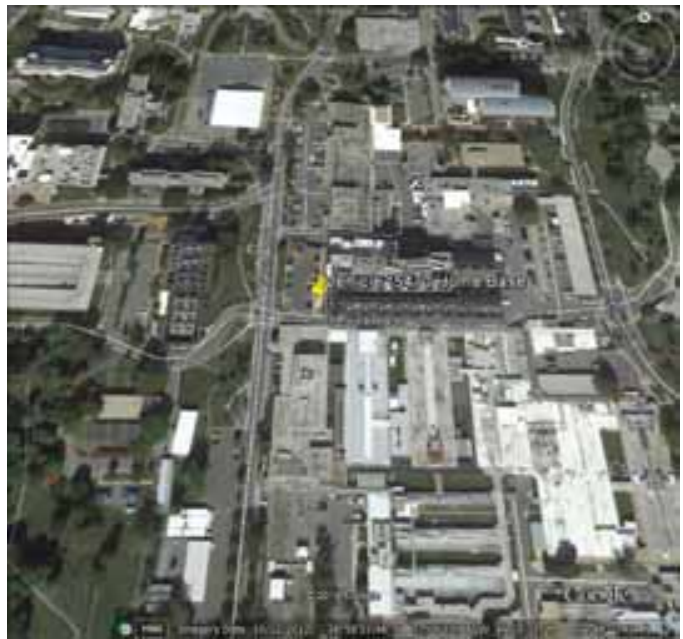
within the typically advertised range of a BEV of approximately 70 miles. Further, all daily travel and outings were within the typically advertised CD mode of 40 miles for PHEVs. Short duration travel to Rockville was also indicated.

A BEV could meet the daily travel noted. Because the vehicle supports maintenance, the ability to carry cargo may be a factor. There are BEVs available that may meet mission requirements. 


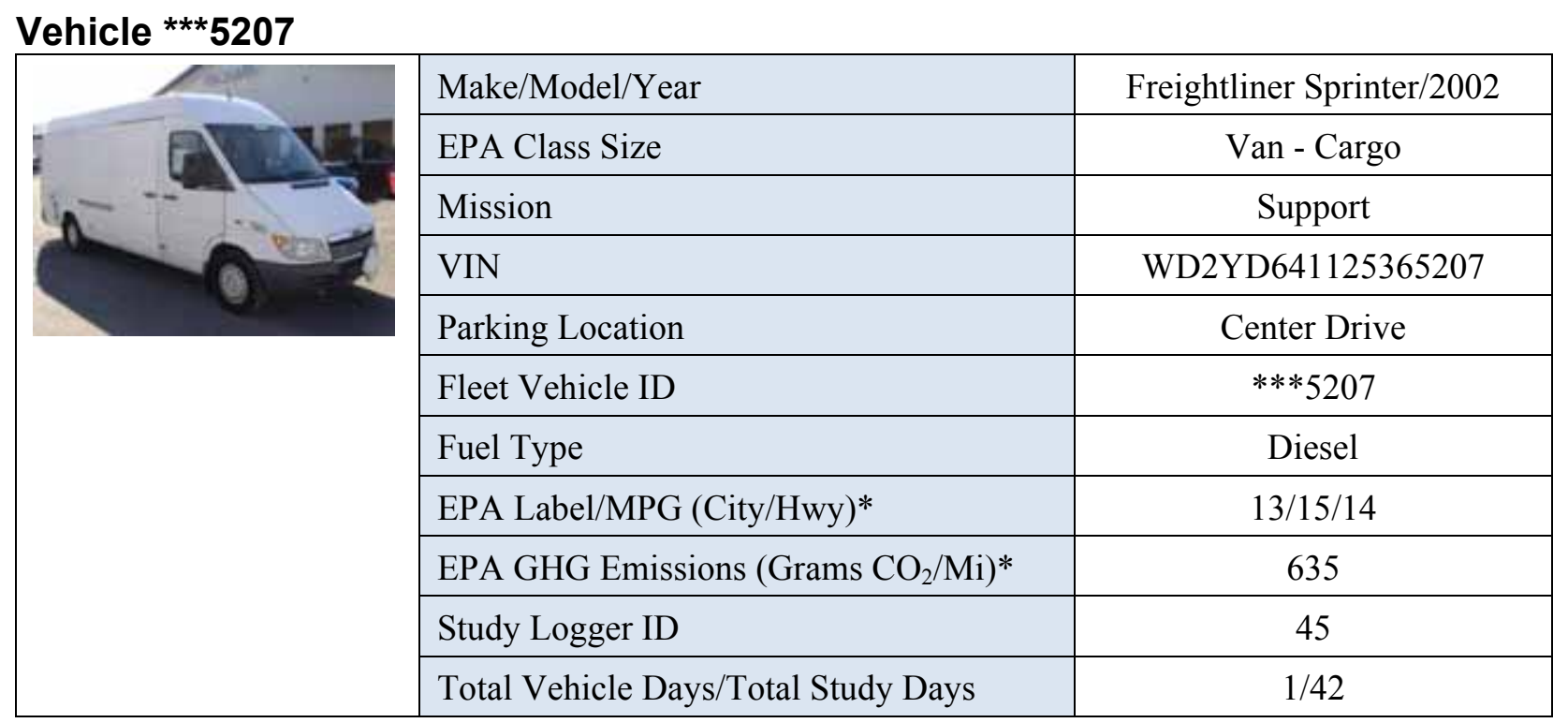

\begin{tabular}{|l|c|c|c|c|}
\hline \multicolumn{7}{|c|}{ Vehicle ***5207 Travel Summary } \\
\hline & $\begin{array}{c}\text { Per Day } \\
\text { Average/Peak }\end{array}$ & $\begin{array}{c}\text { Per Outing } \\
\text { Average/Peak }\end{array}$ & $\begin{array}{c}\text { Per Trip } \\
\text { Average/Peak }\end{array}$ & Total \\
\hline Travel Distance (Miles) & Insufficient data & Insufficient data & Insufficient data & Insufficient data \\
\hline Travel Time (Minutes) & Insufficient data & Insufficient data & Insufficient data & Insufficient data \\
\hline Idle Time (Minutes) & Insufficient data & Insufficient data & Insufficient data & Insufficient data \\
\hline
\end{tabular}

\begin{tabular}{|c|c|c|c|c|}
\hline \multicolumn{2}{|c|}{ Total Stops } & \multicolumn{2}{c|}{ Stop Duration } \\
\hline $\begin{array}{c}\text { Distance From } \\
\text { Home Base (Miles) }\end{array}$ & Stops & Percentages & $\begin{array}{c}\text { Stop Duration } \\
\text { (Hours) }\end{array}$ & Stops \\
\hline Less than 10 & Insufficient data & Insufficient data & Less than 2 & Insufficient data \\
\hline 10 to 20 & Insufficient data & Insufficient data & 2 to 4 & Insufficient data \\
\hline 20 to 40 & Insufficient data & Insufficient data & 4 to 8 & Insufficient data \\
\hline 40 to 60 & Insufficient data & Insufficient data & Greater than 8 & Insufficient data \\
\hline
\end{tabular}

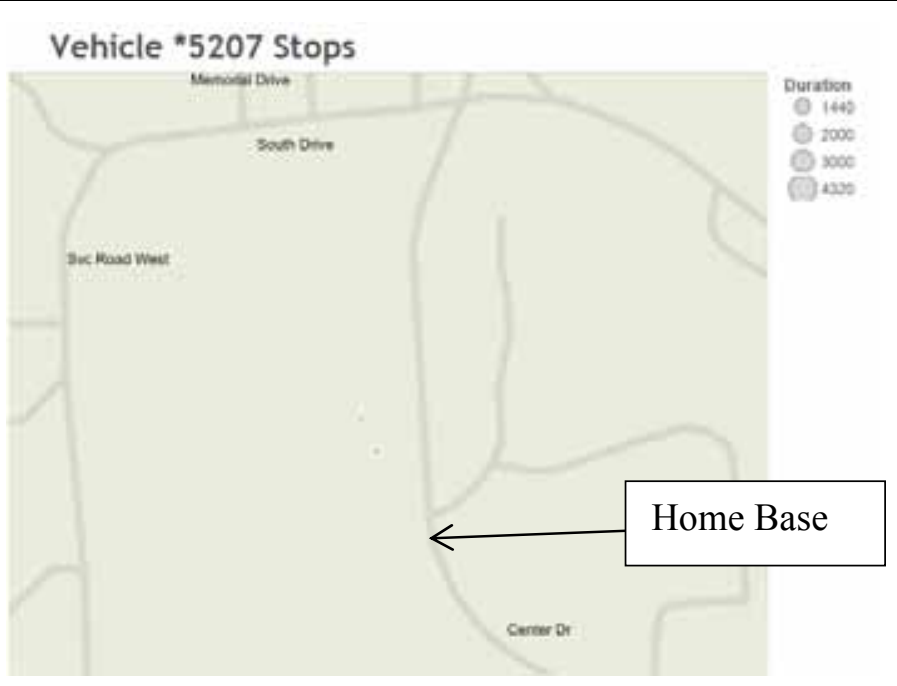

Figure B-13. Vehicle ***5207 stops.

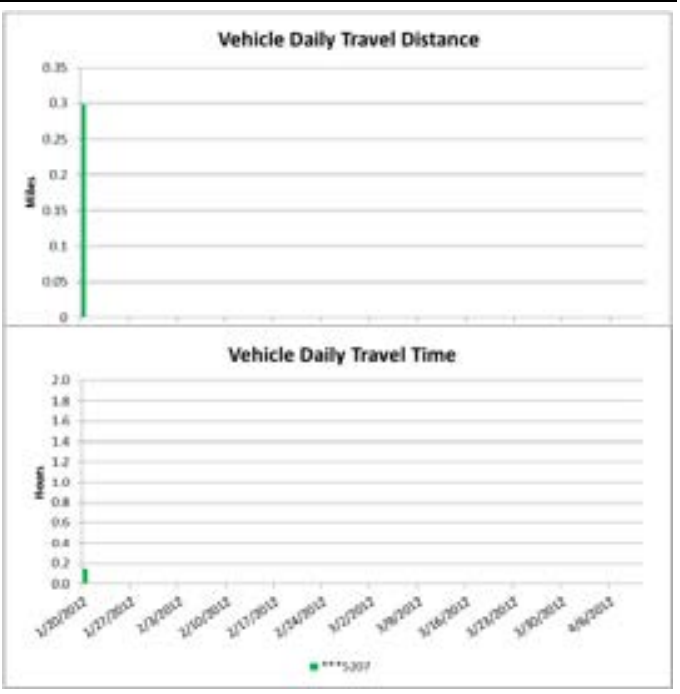

Figure B-14. Vehicle ***5207 history. 
*EPA figures for the diesel Dodge Sprinter are not available. Dodge Ram Van 2500 economy values were used.

\section{Insufficient Data}

Figure B-15. Vehicle ***5207 travel graphs.

\section{Vehicle ${ }^{* *} 5207$ Observations}

Logger 45 was installed on this vehicle for 42 days, but it collected data on this vehicle only 1 day. The vehicle was apparently unused for the remainder of the period. Validation occurred on $100 \%$ of the input data, but the data was insufficient to provide meaningful information. NIH reports that this vehicle has a support mission supporting the on-campus locksmith. Available stop information suggests it typically parks near Center Drive (Figure B-13 and Google Earth figure to the right).

$\mathrm{NIH}$ reports that the vehicle odometer indicated 9,000 miles during the study and it travels approximately 1,000 miles per year. The vehicle was used on $2 \%$ of the available days.

Insufficient data exist for a detailed assessment. However, because this vehicle supports on-campus work, it is suggested that a

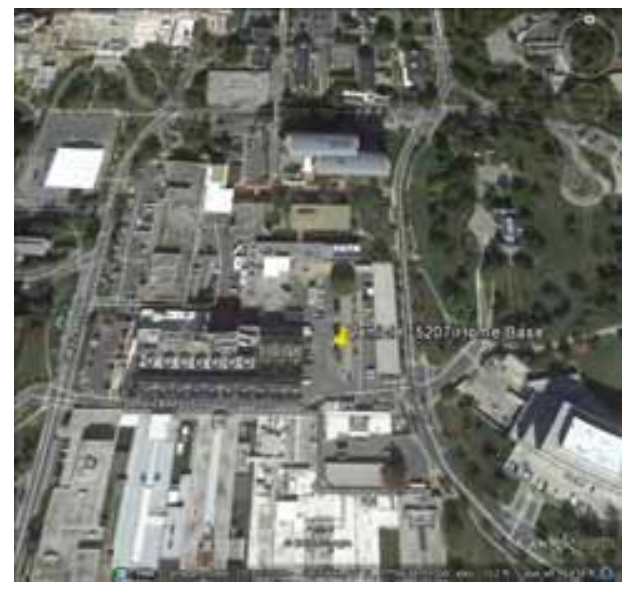
BEV could support this work, assuming the cargo carrying capabilities are supportive. BEVs available to replace this cargo van could carry typical locksmith equipment. 


\begin{tabular}{|l|l|c|}
\hline & Make/Model/Year & Dodge Durango SXT/2006 \\
\hline EPA Class Size & SUV \\
\hline Mission & Pool \\
\hline VIN & 1D4HB38P86F177596 \\
\hline Parking Location & Center Street \\
\hline Fleet Vehicle ID & ***7596 \\
\hline & Fuel Type & Gas/E85 \\
\hline & EPA Label/MPG (City/Hwy/Combined) & $11 / 14 / 128 / 11 / 9$ \\
\hline & EPA GHG Emissions $($ Grams CO $/ \mathrm{Mi})$ & $741 / 689$ \\
\hline & Study Logger ID & 46 \\
\hline & Total Vehicle Days/Total Study Days & $4 / 60$ \\
\hline
\end{tabular}

\begin{tabular}{|l|c|c|c|c|}
\hline \multicolumn{7}{|c|}{ Vehicle ***7596 Travel Summary } \\
\hline & $\begin{array}{c}\text { Per Day } \\
\text { Average/Peak }\end{array}$ & $\begin{array}{c}\text { Per Outing } \\
\text { Average/Peak }\end{array}$ & $\begin{array}{c}\text { Per Trip } \\
\text { Average/Peak }\end{array}$ & Total \\
\hline Travel Distance (Miles) & Insufficient data & Insufficient data & Insufficient data & Insufficient data \\
\hline Travel Time (Minutes) & Insufficient data & Insufficient data & Insufficient data & Insufficient data \\
\hline Idle Time (Minutes) & Insufficient data & Insufficient data & Insufficient data & Insufficient data \\
\hline
\end{tabular}

\begin{tabular}{|c|c|c|c|c|}
\hline \multicolumn{2}{|c|}{ Total Stops } & \multicolumn{2}{c|}{ Stop Duration } \\
\hline $\begin{array}{c}\text { Distance From Home } \\
\text { Base (Miles) }\end{array}$ & Stops & Percentages & $\begin{array}{c}\text { Stop Duration } \\
\text { (Hours) }\end{array}$ & Stops \\
\hline Less than 10 & Insufficient data & Insufficient data & Less than 2 & Insufficient data \\
\hline 10 to 20 & Insufficient data & Insufficient data & 2 to 4 & Insufficient data \\
\hline 20 to 40 & Insufficient data & Insufficient data & 4 to 8 & Insufficient data \\
\hline Greater than 40 & Insufficient data & Insufficient data & Greater than 8 & Insufficient data \\
\hline
\end{tabular}

Vehicle *7596 Stops

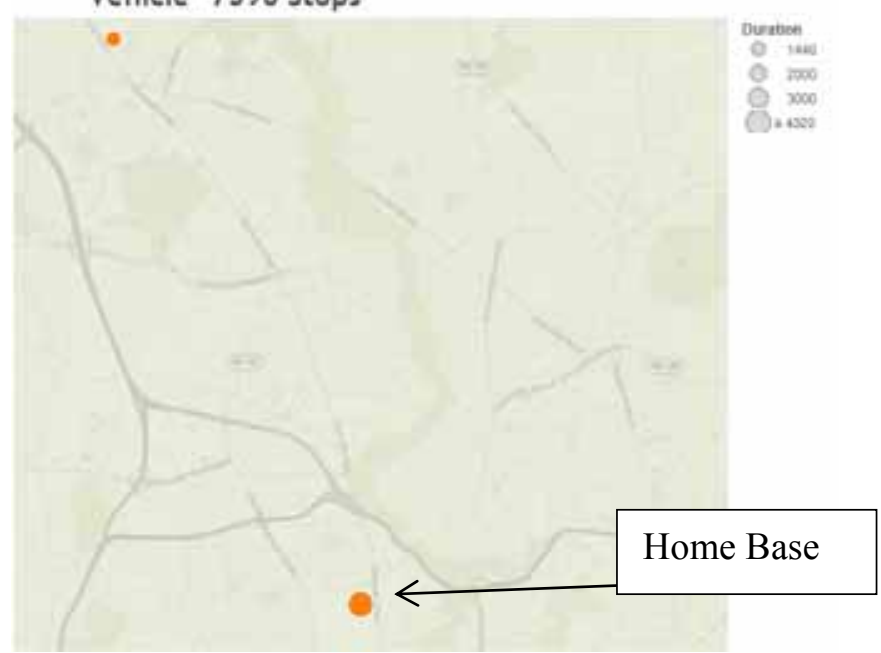

Figure B-16. Vehicle ***7596 stops.

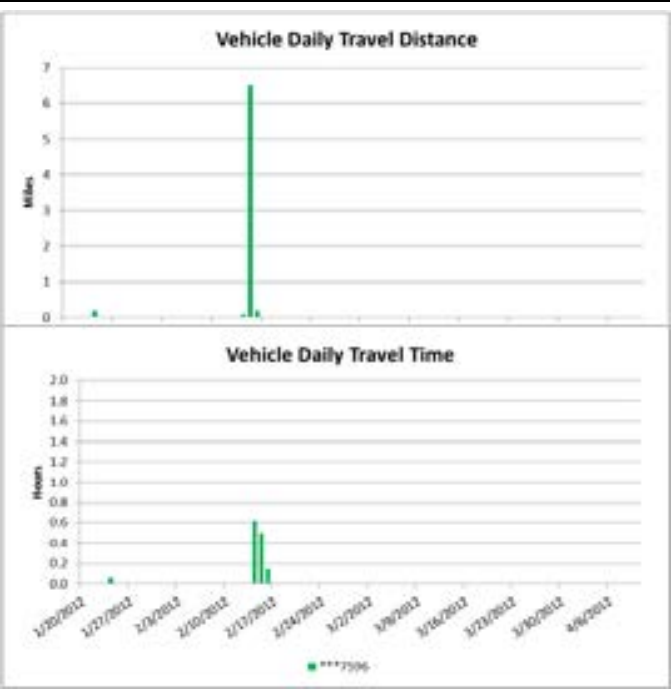

Figure B-17. Vehicle ***7596 history. 


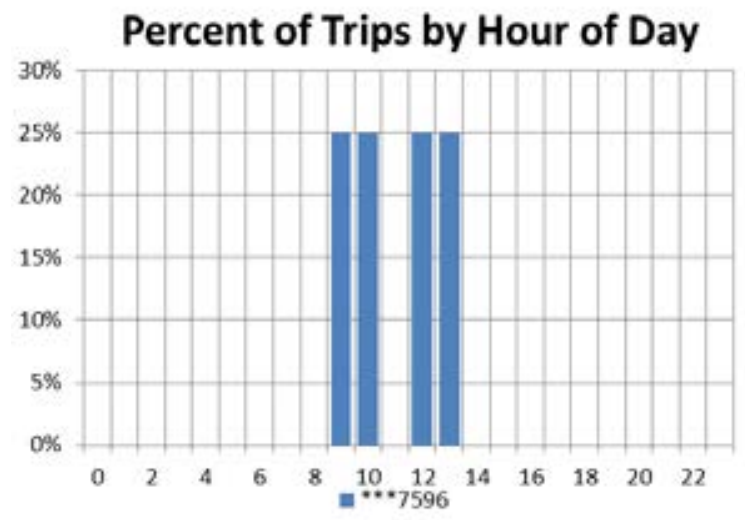

Figure B-18. Vehicle ***7596 travel graphs.

\section{Vehicle ${ }^{* * *} 7596$ Observations}

Logger 46 collected data on this vehicle for a period of 4 days of the 60 -day study period. The logger information shows it was installed for 2 months of this study period but only used on four of these days. Validation occurred on $92.9 \%$ of the input data. NIH reported this vehicle has a pool mission supporting administration. Data suggests it typically parks off Center Street (Figure B-16 and Google Earth figure to the right).

$\mathrm{NIH}$ reports that the vehicle odometer indicated 11,931 miles during the study and it travels 2,821 miles per year. The vehicle was used on $7 \%$ of the available days, with an average daily usage of 0.3 hours and a peak daily usage of 0.6 hours on the days it was used. The vehicle was used during typical day shift hours.

Insufficient data exist to provide detailed

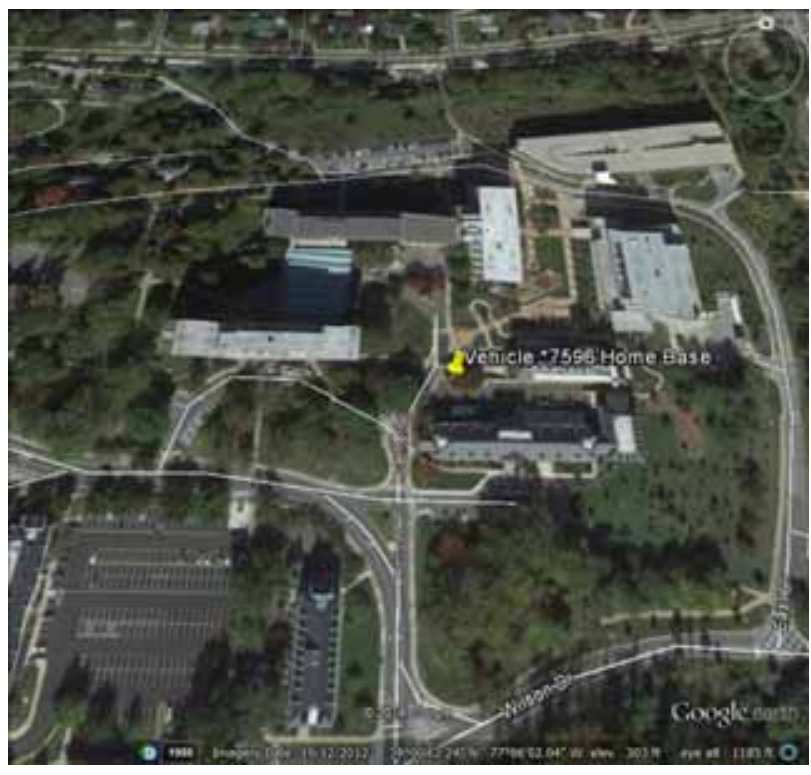
analysis. However, the available data suggest that a BEV could replace this vehicle. BEVs exist in this body style to support the pool mission. 
Vehicle ${ }^{* *} 8759$

\begin{tabular}{|l|l|c|}
\hline Make/Model/Year & Chevrolet Uplander/2008 \\
\hline EPA Class Size & Minivan \\
\hline Mission & Pool \\
\hline VIN & ENDV23W380198759 \\
\hline Parking Location & $* * * 8759$ \\
\hline Fleet Vehicle ID & Gas/E85 \\
\hline Fuel Type & $16 / 23 / 1912 / 17 / 14$ \\
\hline EPA Label/MPG (City/Hwy) & $468 / 443$ \\
\hline & EPA GHG Emissions $\left(\right.$ Grams $\left.\mathrm{CO}_{2} / \mathrm{Mi}\right)$ & 47 \\
\hline & Study Logger ID & $21 / 60$ \\
\hline
\end{tabular}

\begin{tabular}{|l|c|c|c|c|}
\hline \multicolumn{5}{|c|}{ Vehicle $* * * 8759$ Travel Summary } \\
\hline & $\begin{array}{c}\text { Per Day } \\
\text { Average/Peak }\end{array}$ & $\begin{array}{c}\text { Per Outing } \\
\text { Average/Peak }\end{array}$ & $\begin{array}{c}\text { Per Trip } \\
\text { Average/Peak }\end{array}$ & Total \\
\hline Travel Distance (Miles) & $20.0 / 65.2$ & $21.0 / 65.1$ & $3.3 / 25.5$ & 419 \\
\hline Travel Time (Minutes) & $81.0 / 373.0$ & $84.8 / 353.0$ & $13.5 / 127.0$ & 1,696 \\
\hline Idle Time (Minutes) & $10.4 / \mathrm{NA}$ & $10.9 / \mathrm{NA}$ & $1.7 / \mathrm{NA}$ & 218 \\
\hline
\end{tabular}

\begin{tabular}{|c|c|c|c|c|}
\hline \multicolumn{2}{|c|}{ Total Stops } & \multicolumn{2}{c|}{ Stop Duration } \\
\hline $\begin{array}{c}\text { Distance From } \\
\text { Home Base (Miles) }\end{array}$ & Stops & Percentages & Stop Duration (Hours) & Stops \\
\hline Less than 10 & 118 & $99.2 \%$ & Less than 2 & 102 \\
\hline 10 to 20 & 1 & $0.8 \%$ & 2 to 4 & 4 \\
\hline 20 to 40 & 0 & $0 \%$ & 4 to 8 & 3 \\
\hline Greater than 40 & 0 & $0 \%$ & Greater than 8 & 10 \\
\hline
\end{tabular}

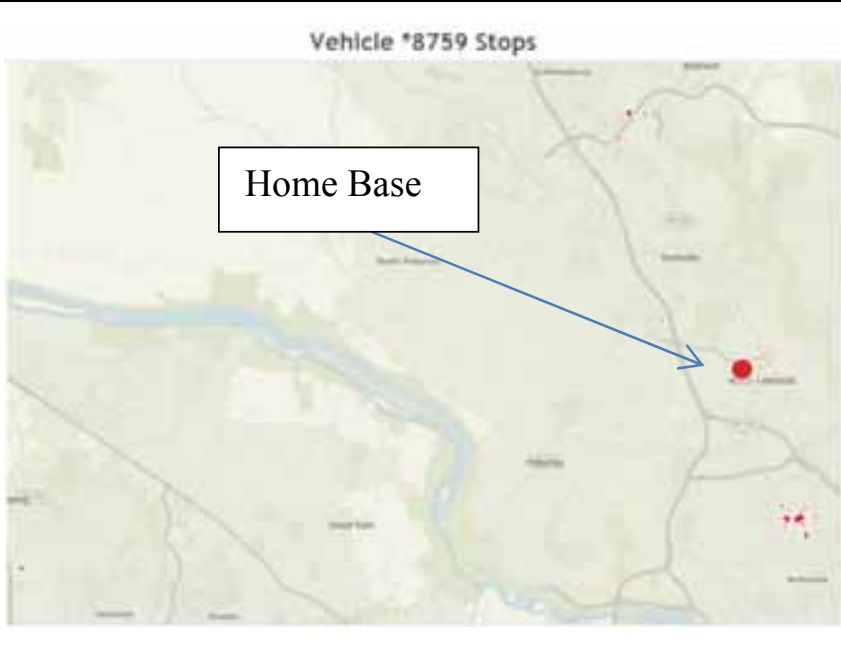

Figure B-19. Vehicle $* * * 8759$ stops.

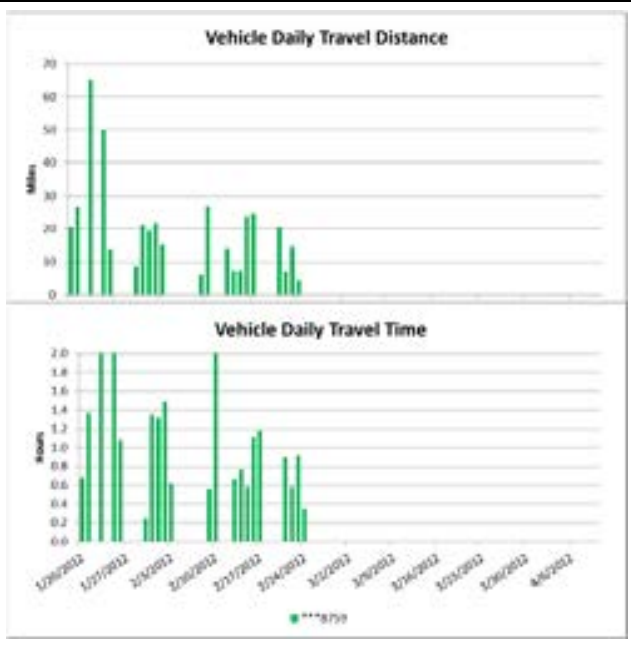

Figure B-20. Vehicle ***8759 history. 

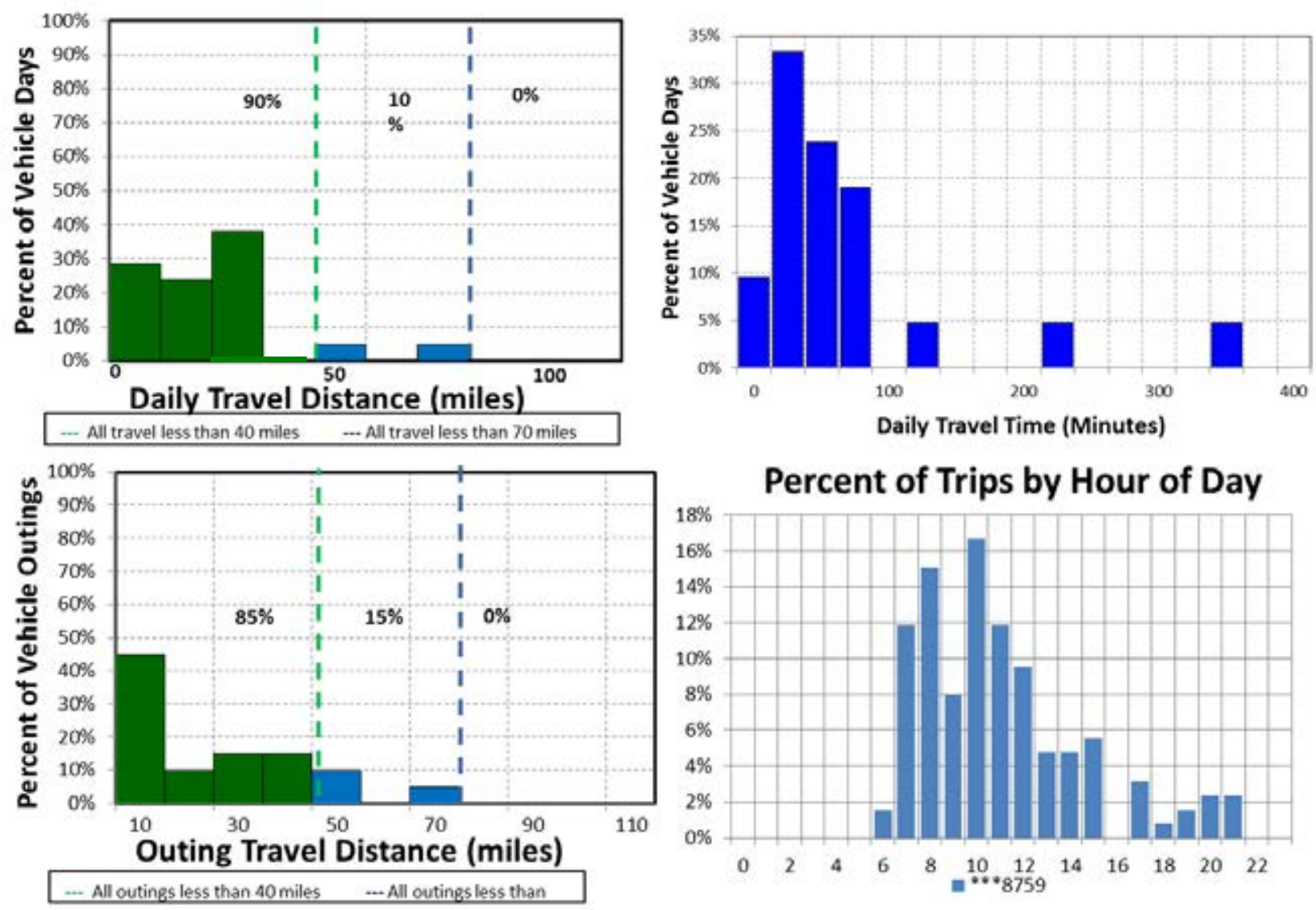

Figure B-21. Vehicle $* * * 8759$ travel graphs.

\section{Vehicle ${ }^{* *} 8759$ Observations}

Logger 47 collected data on this vehicle for a period of 21 days of the 60-day study period. Validation occurred on $94.5 \%$ of the input data. NIH reports that this vehicle has a pool mission in administration. Data indicate it typically parks on E. Jefferson Street in North Bethesda (Figure B-19 and Google Earth figure to the right).

$\mathrm{NIH}$ reports that the vehicle odometer indicated 66,518 miles during the study and it travels 16,629 miles per year. The vehicle was used on $35 \%$ of the available days, with an average daily usage of 1.3 hours and a peak daily usage of 6.2 hours on the days it was used. The vehicle was used during typical day-shift hours.

Figure B-21 shows all daily travel and all outings were within the typically advertised range of a BEV of approximately 70 miles. Further, $90 \%$ of daily travel and

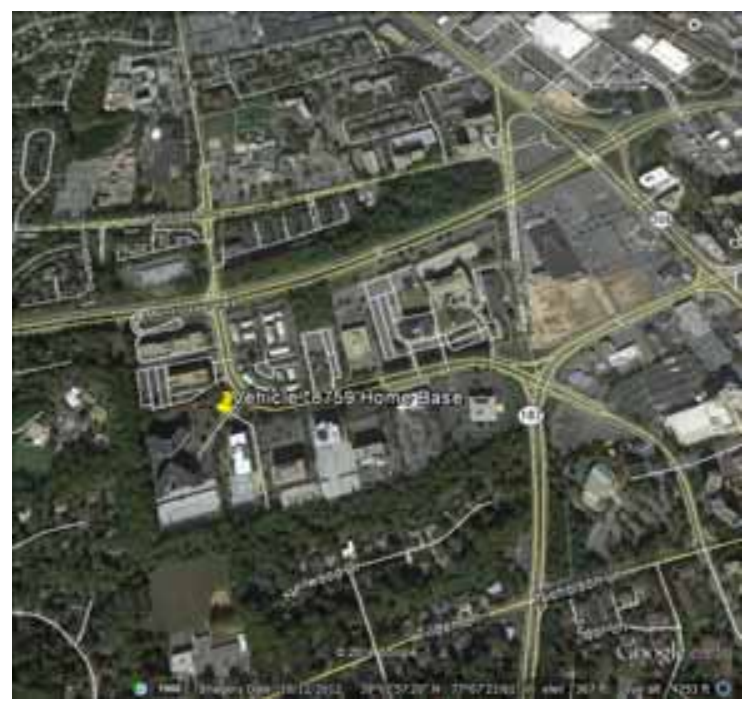
$85 \%$ of all outings were within the typically advertised CD mode of 40 miles for PHEVs. Short duration travel to Rockville and Dulles was also indicated.

A BEV could meet the daily travel requirements identified. In addition, PEV replacements of minivans are available. 
Vehicle ${ }^{* * *} 7791$

\begin{tabular}{|c|c|c|}
\hline & Make/Model/Year & Dodge Caravan/2009 \\
\hline 285 & EPA Class Size & Minivan \\
\hline$=-8=28$ & Mission & Pool \\
\hline & VIN & 2D4RN4DE4AR117791 \\
\hline & Parking Location & Service Road South \\
\hline & Fleet Vehicle ID & $* * * 7791$ \\
\hline & Fuel Type & Gas/E85 \\
\hline & EPA Label/MPG (City/Hwy/Combined) & $17 / 24 / 19 \quad 11 / 16 / 13$ \\
\hline & EPA GHG Emissions (Grams $\mathrm{CO}_{2} / \mathrm{Mi}$ ) & $468 / 477$ \\
\hline & Study Logger ID & 48 \\
\hline & Total Vehicle Days/Total Study Days & $3 / 60$ \\
\hline
\end{tabular}

\begin{tabular}{|l|c|c|c|c|}
\hline \multicolumn{5}{|c|}{ Vehicle $* * * 7791$ Travel Summary } \\
& $\begin{array}{c}\text { Per Day } \\
\text { Average/Peak }\end{array}$ & $\begin{array}{c}\text { Per Outing } \\
\text { Average/Peak }\end{array}$ & $\begin{array}{c}\text { Per Trip } \\
\text { Average/Peak }\end{array}$ & Total \\
\hline Travel Distance (Miles) & Insufficient data & Insufficient data & Insufficient data & Insufficient data \\
\hline Travel Time (Minutes) & Insufficient data & Insufficient data & Insufficient data & Insufficient data \\
\hline Idle Time (Minutes) & Insufficient data & Insufficient data & Insufficient data & Insufficient data \\
\hline
\end{tabular}

\begin{tabular}{|c|c|c|c|c|}
\hline \multicolumn{2}{|c|}{ Total Stops } & \multicolumn{2}{c|}{ Stop Duration } \\
\hline $\begin{array}{c}\text { Distance From Home } \\
\text { Base (Miles) }\end{array}$ & Stops & Percentages & $\begin{array}{c}\text { Stop Duration } \\
\text { (Hours) }\end{array}$ & Stops \\
\hline Less than 10 & Insufficient data & Insufficient data & Less than 2 & Insufficient data \\
\hline 10 to 20 & Insufficient data & Insufficient data & 2 to 4 & Insufficient data \\
\hline 20 to 40 & Insufficient data & Insufficient data & 4 to 8 & Insufficient data \\
\hline 40 to 60 & Insufficient data & Insufficient data & Greater than 8 & Insufficient data \\
\hline
\end{tabular}

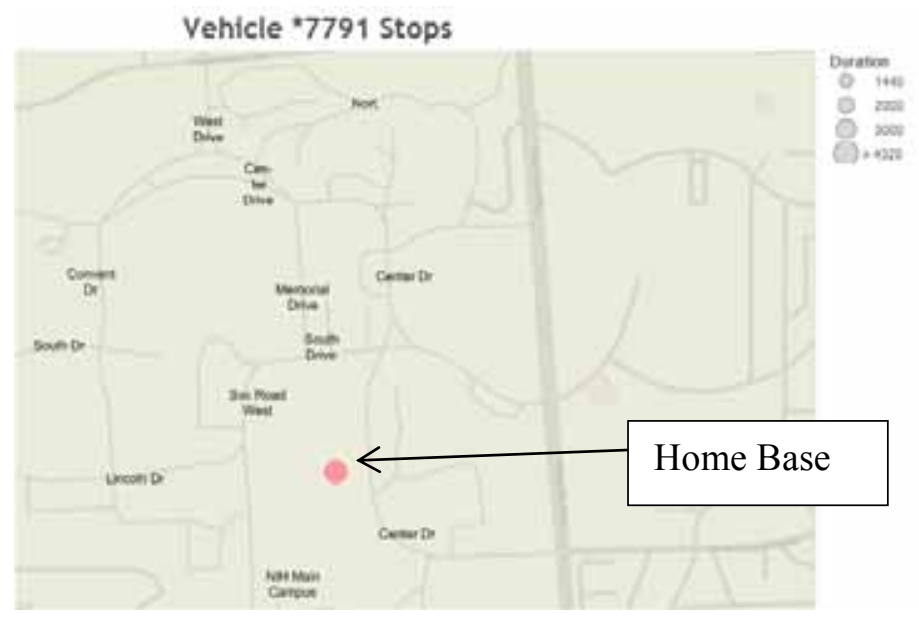

Figure B-22. Vehicle ***7791 stops.

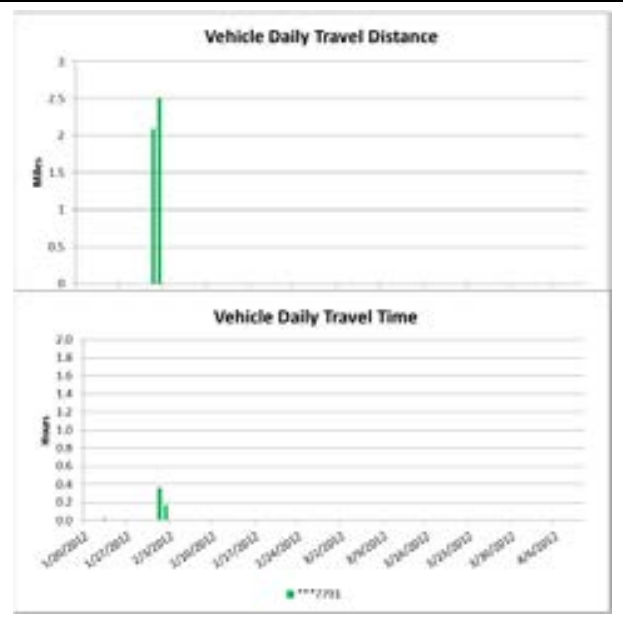

Figure B-23. Vehicle ***7791 history. 


\section{Insufficient Data}

Figure B-24. Vehicle ***7791 travel graphs.

\section{Vehicle $^{* * *} 7791$ Observations}

Logger 48 collected data on this vehicle for a period of 3 days of the 60 -day study period. Validation occurred on $100 \%$ of the input data. NIH reported this vehicle has a pool mission supporting daily rental. Data indicate it parked near Service Road South for the few days monitored (Figure B-22 and Google Earth figure to the right).

$\mathrm{NIH}$ reports the vehicle odometer indicated 8,810 miles during the study and it travels 2,936 miles per year. The vehicle was used on $5 \%$ of the available days, with an average daily usage of 0.2 hours and a peak daily usage of 0.4 hours on the days it was used. The vehicle was used during typical day shift hours. Records indicate that the logger was installed throughout the study period, suggesting the low usage was accurately recorded.

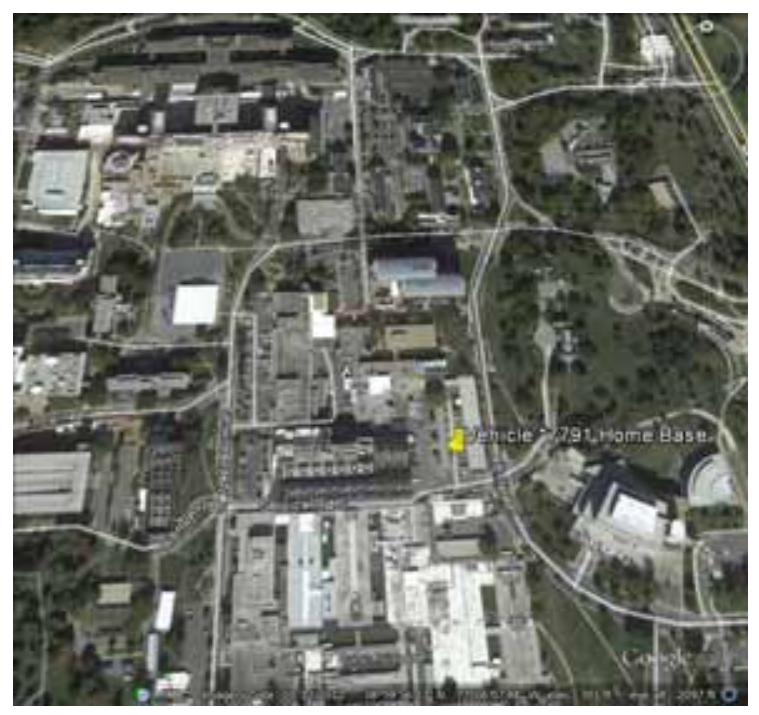

Insufficient data were logged to provide a detailed assessment. Information shows that this is a pool vehicle providing for daily rental and suggests a BEV could be a suitable replacement. BEVs in this body style are available. 


\section{Vehicle $^{* * *} 8315$}

\begin{tabular}{|c|c|c|}
\hline 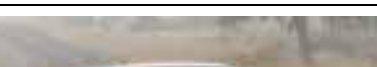 & Make/Model/Year & Chevrolet Impala/2010 \\
\hline $29.42=$ & EPA Class Size & Sedan - Large \\
\hline $6=32-=$ & Mission & Support \\
\hline & VIN & 2G1WA5EK9A1128315 \\
\hline & Parking Location & Service Road South/West \\
\hline & Fleet Vehicle ID & $* * * 8315$ \\
\hline & Fuel Type & Gas/E85 \\
\hline & EPA Label/MPG (City/Hwy) & $18 / 29 / 22 \quad 14 / 22 / 17$ \\
\hline & EPA GHG Emissions (Grams $\mathrm{CO}_{2} / \mathrm{Mi}$ ) & $404 / 365$ \\
\hline & Study Logger ID & 49 \\
\hline & Total Vehicle Days/Total Study Days & $40 / 60$ \\
\hline
\end{tabular}

\begin{tabular}{|l|c|c|c|c|}
\hline \multicolumn{7}{|c|}{ Vehicle ***8315 Travel Summary } \\
\hline & $\begin{array}{c}\text { Per Day } \\
\text { Average/Peak }\end{array}$ & $\begin{array}{c}\text { Per Outing } \\
\text { Average/Peak }\end{array}$ & $\begin{array}{c}\text { Per Trip } \\
\text { Average/Peak }\end{array}$ & Total \\
\hline Travel Distance (Miles) & $4.7 / 63.5$ & $2.7 / 63.0$ & $0.8 / 33.2$ & 189 \\
\hline Travel Time (Minutes) & $30.0 / 152.0$ & $17.0 / 145.0$ & $4.9 / 61.0$ & 1,193 \\
\hline Idle Time (Minutes) & $0 / \mathrm{NA}$ & $0 / \mathrm{NA}$ & $0 / \mathrm{NA}$ & 0 \\
\hline
\end{tabular}

\begin{tabular}{|c|c|c|c|c|}
\hline \multicolumn{2}{|c|}{ Total Stops } & \multicolumn{2}{c|}{ Stop Duration } \\
\hline $\begin{array}{c}\text { Distance From Home } \\
\text { Base (Miles) }\end{array}$ & Stops & Percentages & Stop Duration (Hours) & Stops \\
\hline Less than 10 & 225 & $98.3 \%$ & Less than 2 & 160 \\
\hline 10 to 20 & 1 & $0.4 \%$ & 2 to 4 & 24 \\
\hline 20 to 40 & 3 & $1.3 \%$ & 4 to 8 & 6 \\
\hline Greater than 40 & 0 & $0 \%$ & Greater than 8 & 39 \\
\hline
\end{tabular}

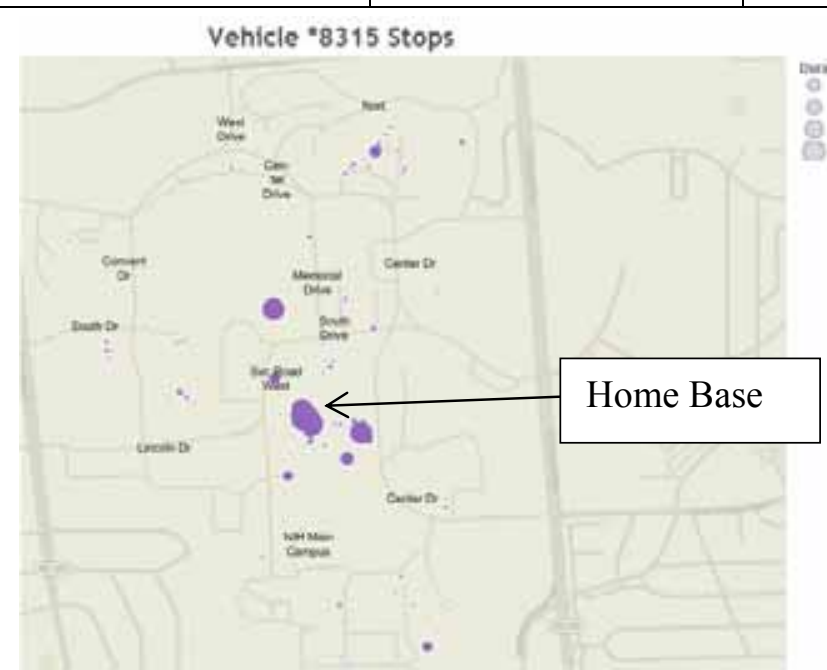

Figure B-25. Vehicle $* * * 8315$ stops.

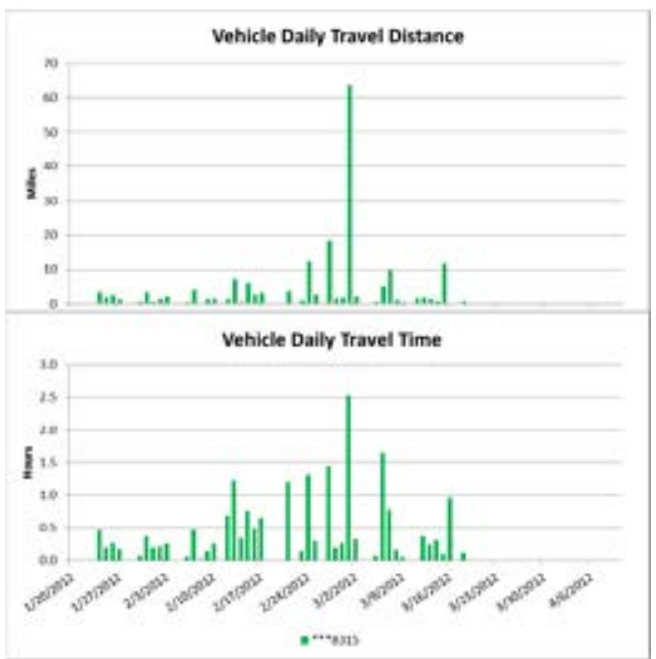

Figure B-26. Vehicle ***8315 history. 

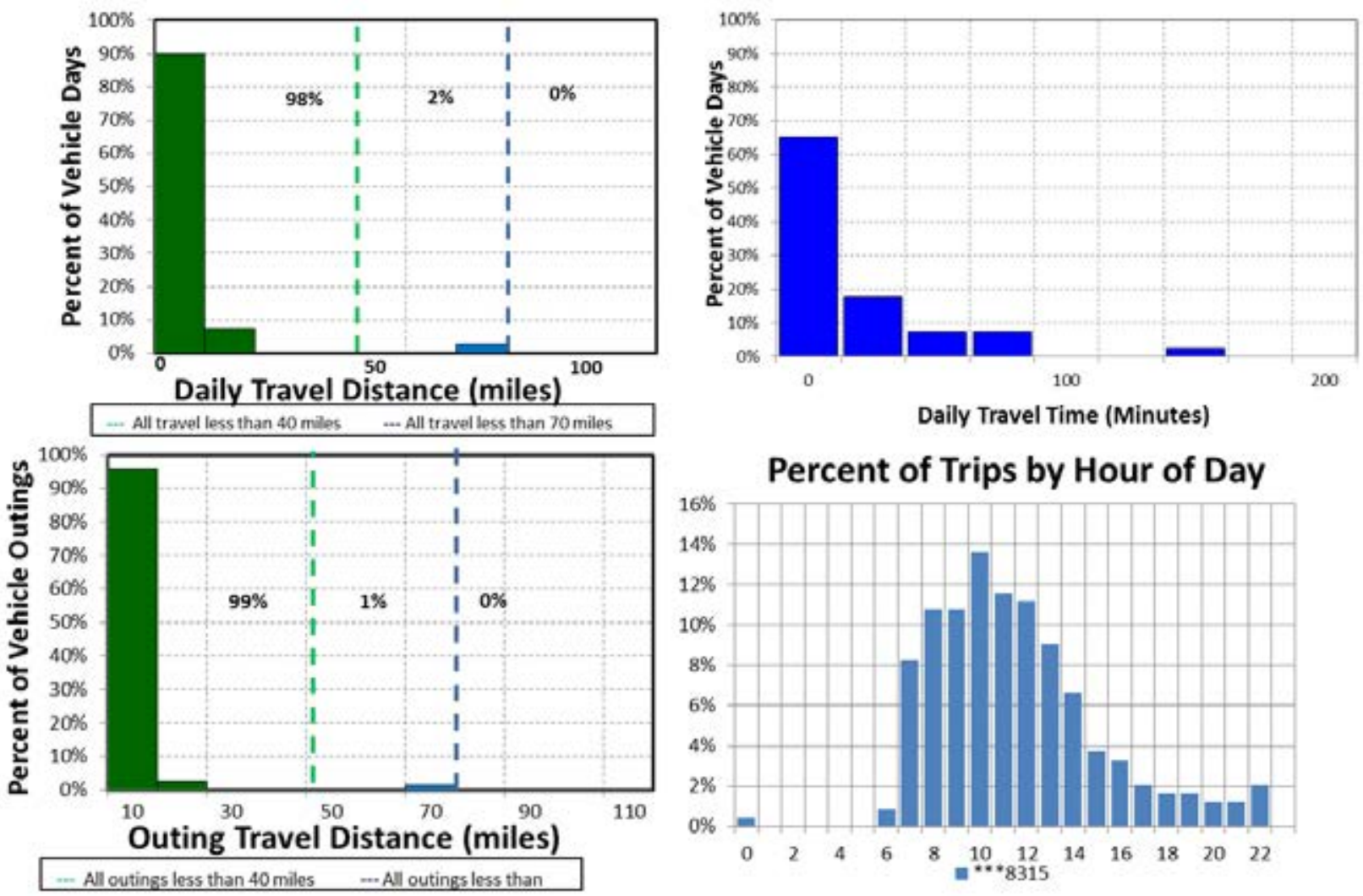

Figure B-27. Vehicle $* * * 8315$ travel graphs.

\section{Vehicle ${ }^{* * *} 8315$ Observations}

Logger 49 collected data on this vehicle for a period of 40 days of the 60-day study period. Validation occurred on $99.4 \%$ of the input data. NIH reports that this vehicle indicated that it has a support mission for maintenance administration. Data indicate it typically parks near Service Road South/West (Figure B-25 and Google Earth figure to the right).

NIH reports that the vehicle odometer indicated 3,791 miles during the study and an annual travel of 1,908 miles. The vehicle was used on $67 \%$ of the available days, with an average daily usage of 0.5 hours and a peak daily usage of 2.5 hours on the days it was used. The vehicle was used during typical day shift hours.

Figure B-27 shows all daily travel and all outings were within the typically advertised range of a BEV of

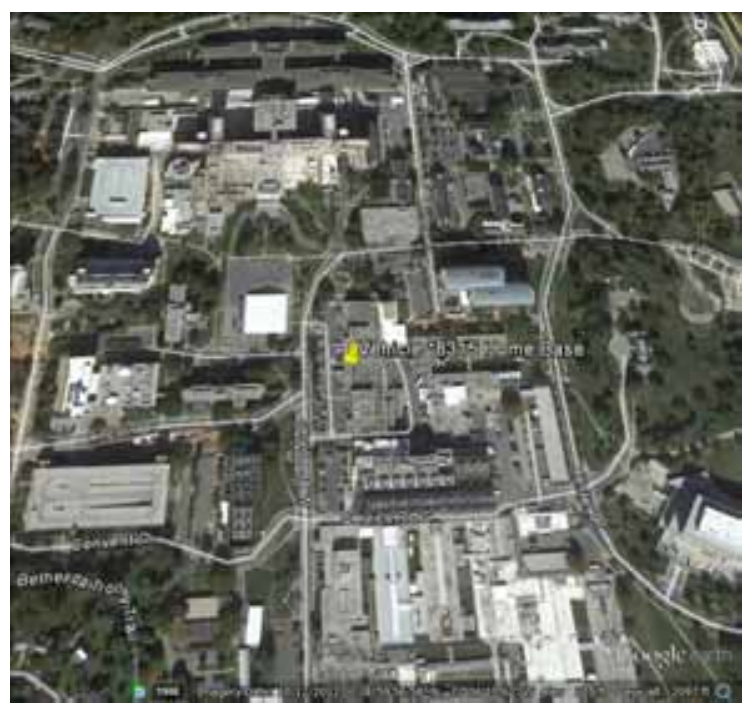
approximately 70 miles. Further, $98 \%$ of daily travel and $99 \%$ of outings were within the typically advertised CD mode of 40 miles for PHEVs.

A BEV could meet all daily travel requirements without additional charging opportunities. PEV replacements for large sedans exist and no further requirements were identified for this support vehicle. 


\begin{tabular}{|l|l|c|}
\hline & Make/Model/Year & Ford Crown Victoria/2009 \\
\cline { 1 - 2 } & EPA Class Size & Sedan - Large \\
\hline & Mission & 2FAHP71V99X131384 \\
\cline { 2 - 3 } & VIN & North Drive \\
\cline { 2 - 3 } & Parking Location & $* * * 1384$ \\
\hline & Fleet Vehicle ID & Gas/E85 \\
\hline & Fuel Type & $16 / 24 / 1912 / 17 / 14$ \\
\cline { 2 - 3 } & EPA Label/MPG (City/Hwy) & $468 / 443$ \\
\cline { 2 - 3 } & EPA GHG Emissions (Grams $\left.\mathrm{CO}_{2} / \mathrm{Mi}\right)$ & 50 \\
\cline { 2 - 3 } & Study Logger ID & $64 / 64$ \\
\cline { 2 - 3 } & Total Vehicle Days/Total Study Days & . \\
\hline
\end{tabular}

\begin{tabular}{|l|c|c|c|c|}
\hline \multicolumn{5}{|c|}{ Vehicle***1384 Travel Summary } \\
\hline & Per Day Average/Peak & $\begin{array}{c}\text { Per Outing } \\
\text { Average/Peak }\end{array}$ & $\begin{array}{c}\text { Per Trip } \\
\text { Average/Peak }\end{array}$ & Total \\
\hline Travel Distance (Miles) & $20.7 / 52.5$ & $11.1 / 78.5$ & $1.2 / 16.5$ & 1,327 \\
\hline Travel Time (Minutes) & $323.0 / 764.0$ & $172.4 / 899.0$ & $18.8 / 249.0$ & 20,694 \\
\hline Idle Time (Minutes) & $207.2 / \mathrm{NA}$ & $110.5 / \mathrm{NA}$ & $12.0 / \mathrm{NA}$ & 13,258 \\
\hline
\end{tabular}

\begin{tabular}{|c|c|c|c|c|}
\hline \multicolumn{2}{|c|}{ Total Stops } & \multicolumn{2}{c|}{ Stop Duration } \\
\hline $\begin{array}{c}\text { Distance From Home } \\
\text { Base (Miles) }\end{array}$ & Stops & Percentages & $\begin{array}{c}\text { Stop Duration } \\
\text { (Hours) }\end{array}$ & Stops \\
\hline Less than 10 & 944 & $100 \%$ & Less than 2 & 833 \\
\hline 10 to 20 & 0 & $0 \%$ & 2 to 4 & 46 \\
\hline 20 to 40 & 0 & $0 \%$ & 4 to 8 & 37 \\
\hline Greater than 40 & 0 & $0 \%$ & Greater than 8 & 28 \\
\hline
\end{tabular}

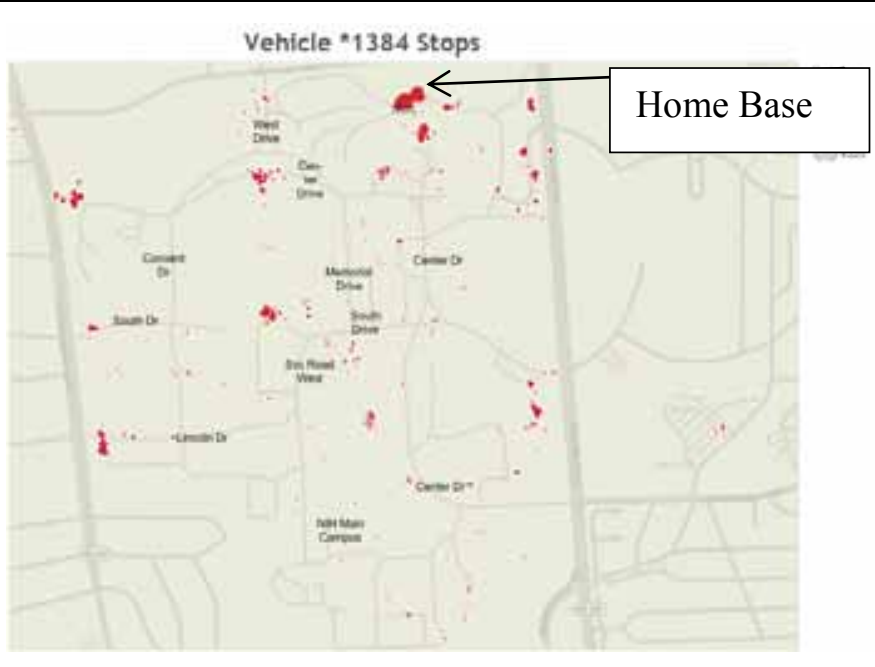

Figure B-28. Vehicle ***1384 stops.

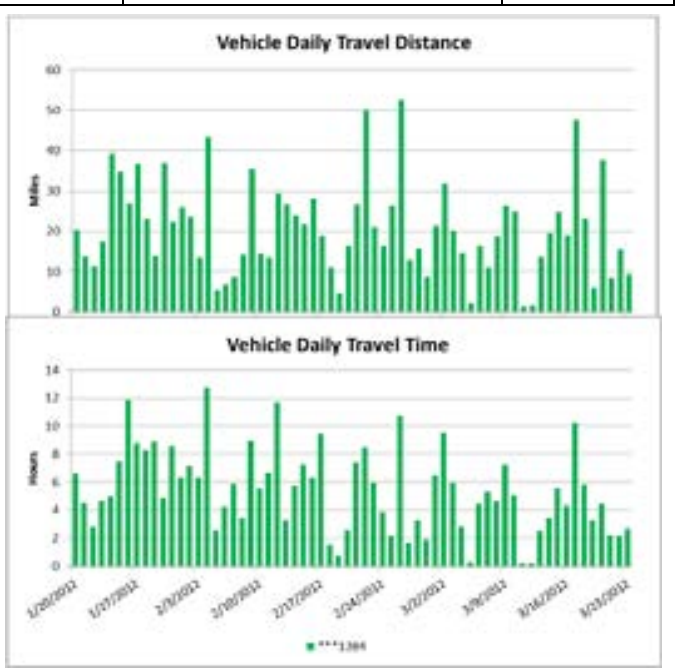

Figure B-29. Vehicle ***1384 history. 

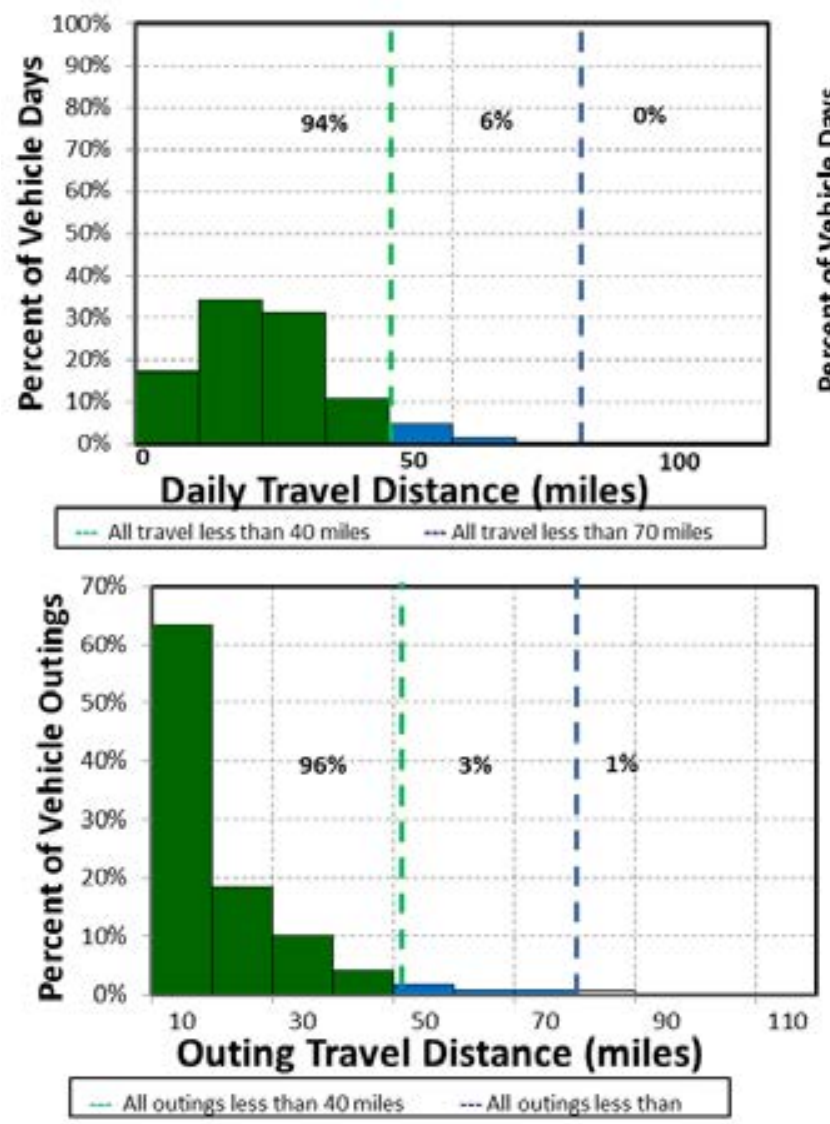
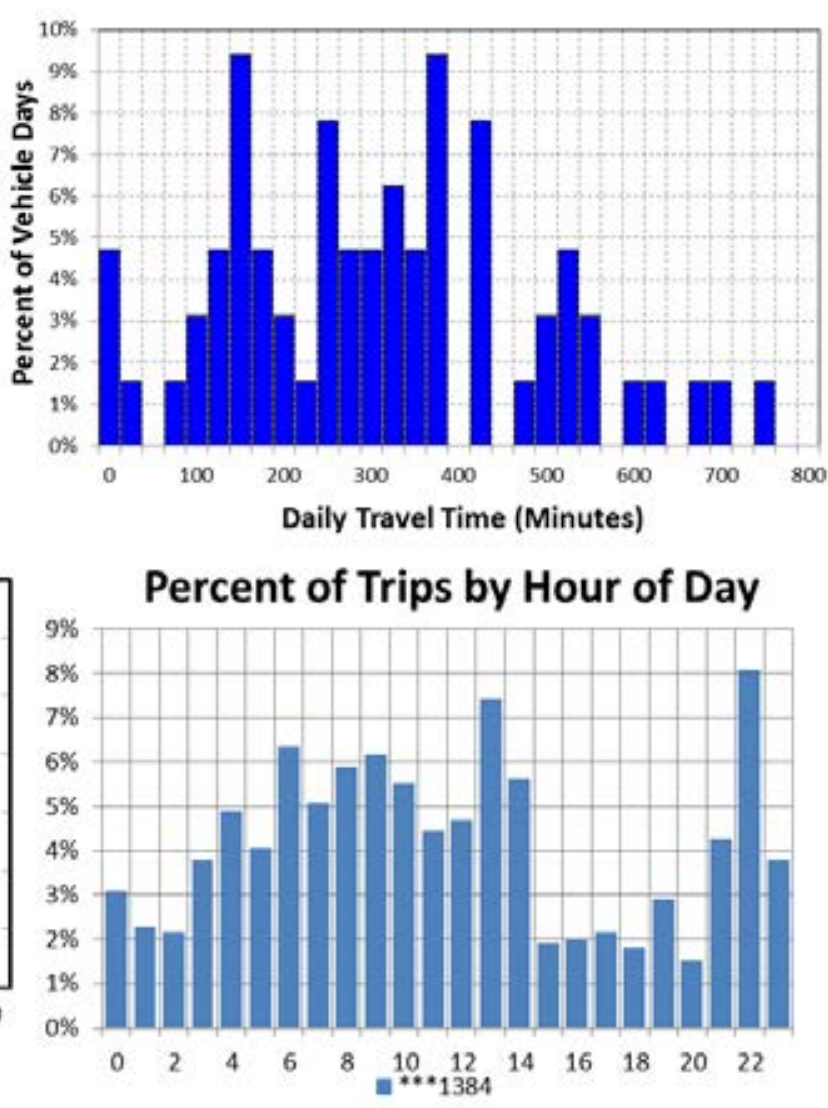

Figure B-30. Vehicle ***1384 travel graphs.

\section{Vehicle ***1384 Observations}

Logger 50 collected data on this vehicle for a period of 64 days of the 64-day study period. Validation occurred on $97.1 \%$ of the input data. NIH reports that this vehicle has a law enforcement mission for police patrol. Data indicate it typically parks near North Drive (Figure B-28 and Google Earth figure to the right).

NIH reports that the vehicle odometer indicated 35,789 miles during the study and projected an annual mileage at 11,929. The vehicle was used on $100 \%$ of available days, with an average daily usage of 5.4 hours and a peak daily usage of 12.7 hours on the days it was used. The vehicle was used during all hours of the day.

Figure B-30 shows all daily travel and $99 \%$ of all outings were within the typically advertised range of a BEV of approximately

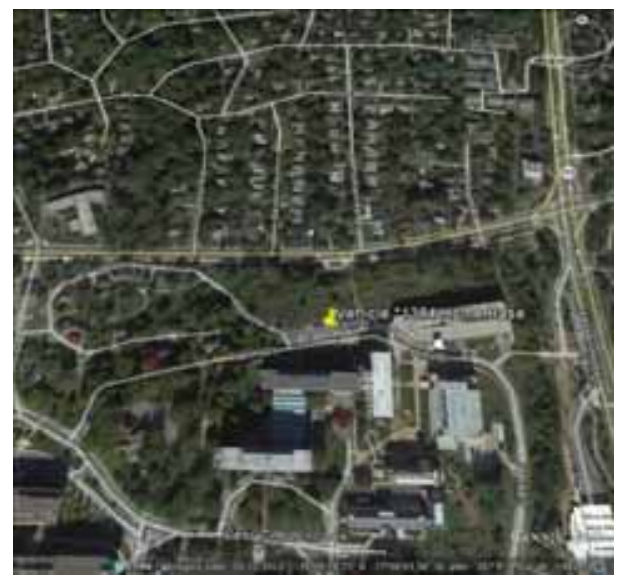
70 miles. Further, $94 \%$ of daily travel and $96 \%$ of outings were within the typically advertised CD mode of 40 miles for PHEVs. The peak outing exceeded the peak daily usage because the vehicle did not return to North Drive on all days, but did stay within the main campus area. Short duration travel to Rockville was also indicated.

A BEV could meet all daily travel without additional charging opportunities, assuming the vehicle was assigned a home base. However, fleet managers typically do not prefer enforcement vehicles that contain range limitations. Thus, a fleet of enforcement vehicles would likely contain a mix of BEVs and PHEVs. 


\begin{tabular}{|l|l|c|}
\hline Make/Model/Year & Chevrolet Silverado/2005 \\
\cline { 2 - 3 } & EPA Class Size & Pickup Truck \\
\hline Mission & Support \\
\hline VIN & Service Road West \\
\cline { 2 - 3 } & Parking Location & $* * * 3265$ \\
\hline Fleet Vehicle ID & Gas/E85 \\
\hline Fuel Type & $14 / 19 / 1611 / 15 / 12$ \\
\hline EPA Label/MPG (City/Hwy) & $555 / 517$ \\
\hline & EPA GHG Emissions (Grams $\left.\mathrm{CO}_{2} / \mathrm{Mi}\right)$ & 51 \\
\hline Study Logger ID & $61 / 61$ \\
\hline & Total Vehicle Days/Total Study Days & . \\
\hline
\end{tabular}

\begin{tabular}{|l|c|c|c|c|}
\hline \multicolumn{5}{|c|}{ Vehicle ***3265 Travel Summary } \\
\hline & $\begin{array}{c}\text { Per Day } \\
\text { Average/Peak }\end{array}$ & $\begin{array}{c}\text { Per Outing } \\
\text { Average/Peak }\end{array}$ & $\begin{array}{c}\text { Per Trip } \\
\text { Average/Peak }\end{array}$ & Total \\
\hline Travel Distance (Miles) & $7.9 / 19.7$ & $3.3 / 21.0$ & $0.5 / 8.0$ & 481 \\
\hline Travel Time (Minutes) & $130 / 425.0$ & $53.5 / 771.0$ & $8.3 / 184.0$ & 7,920 \\
\hline Idle Time (Minutes) & $76.3 / \mathrm{NA}$ & $31.4 / \mathrm{NA}$ & $4.9 / \mathrm{NA}$ & 4,654 \\
\hline
\end{tabular}

\begin{tabular}{|c|c|c|c|c|}
\hline \multicolumn{2}{|c|}{ Total Stops } & \multicolumn{2}{c|}{ Stop Duration } \\
\hline $\begin{array}{c}\text { Distance From } \\
\text { Home Base (Miles) }\end{array}$ & Stops & Percentages & Stop Duration (Hours) & Stops \\
\hline Less than 10 & 671 & $100 \%$ & Less than 2 & 533 \\
\hline 10 to 20 & 0 & $0 \%$ & 2 to 4 & 65 \\
\hline 20 to 40 & 0 & $0 \%$ & 4 to 8 & 55 \\
\hline Greater than 40 & 0 & $0 \%$ & Greater than 8 & 18 \\
\hline
\end{tabular}

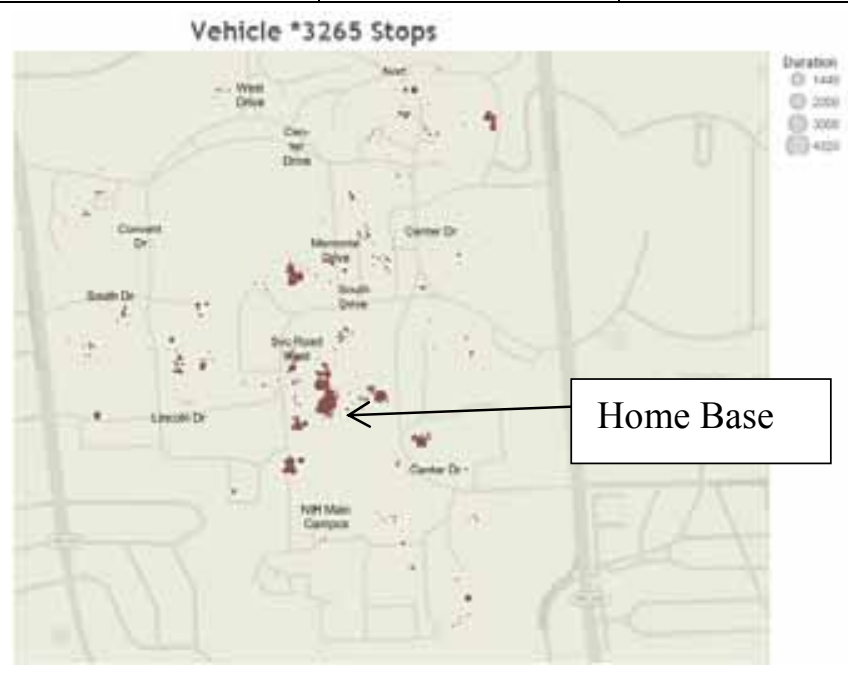

Figure B-31. Vehicle ***3265 stops.

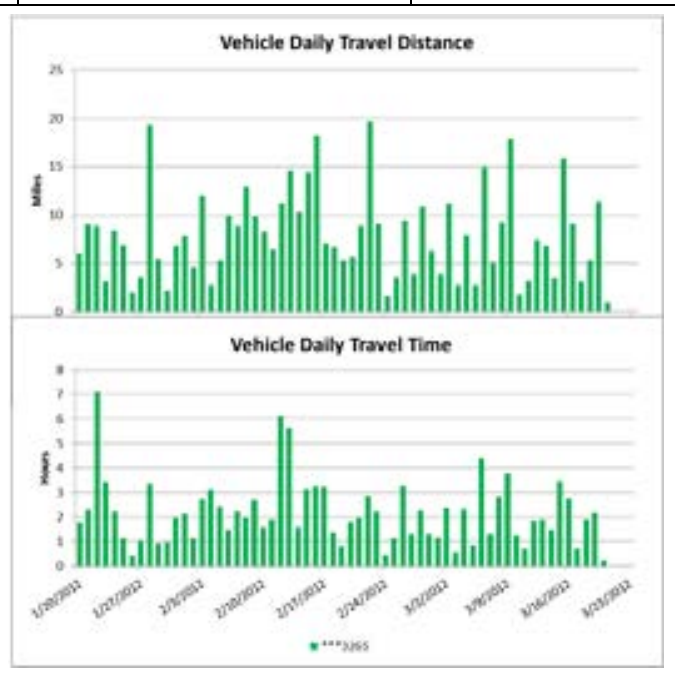

Figure B-32. Vehicle ***3265 history. 

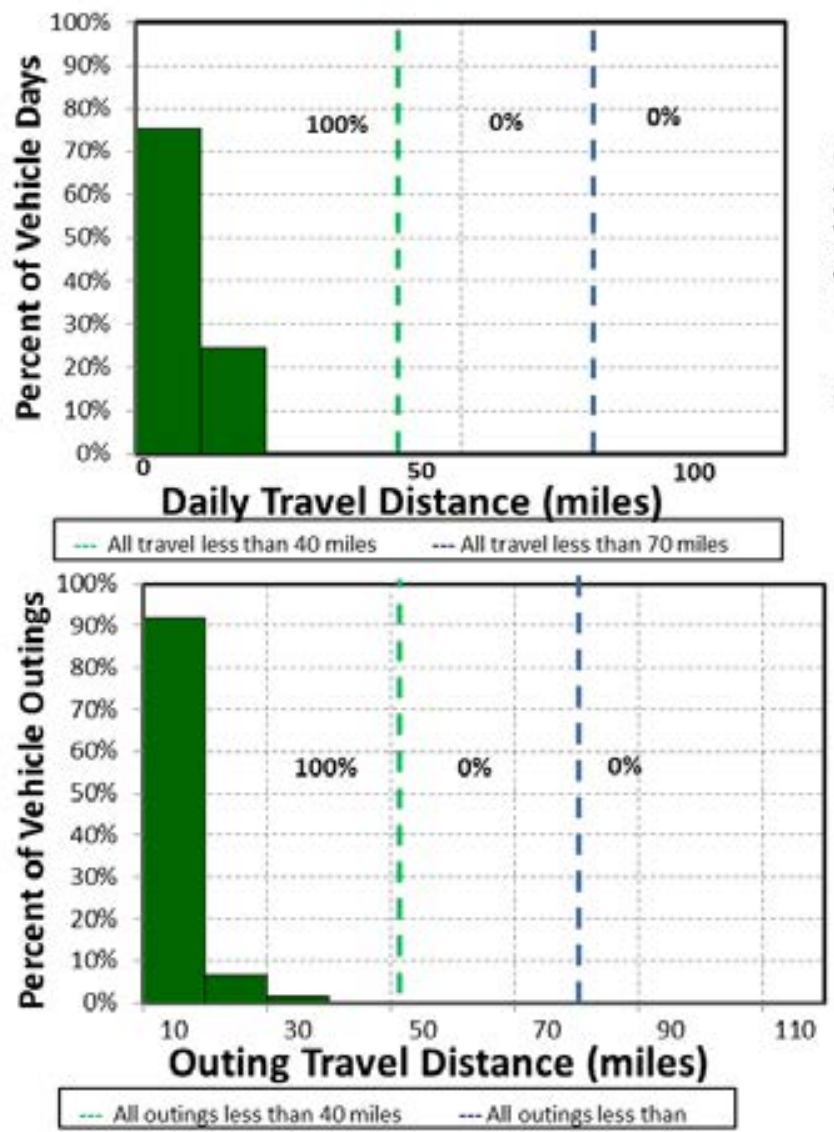
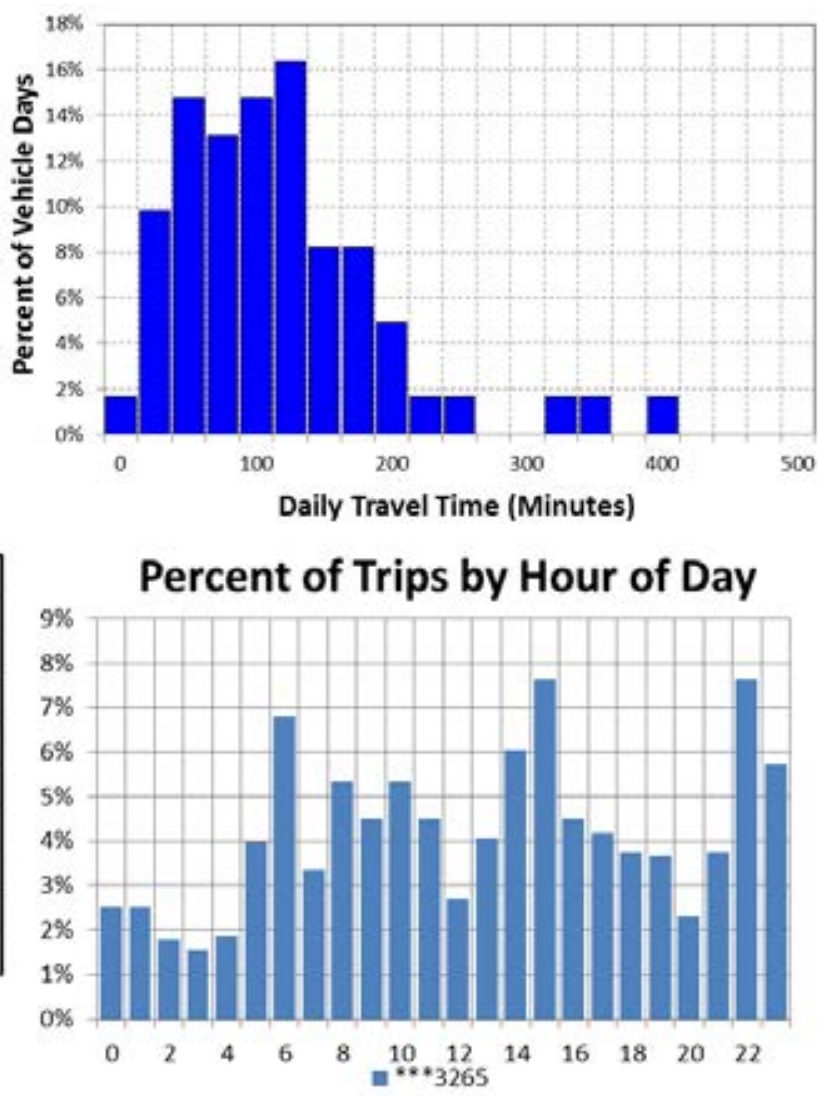

Figure B-33. Vehicle ***3265 travel graphs.

\section{Vehicle ${ }^{* * *} 3265$ Observations}

Logger 51 collected data on this vehicle for a period of 61 days of the 61-day study period. Validation occurred on $98.9 \%$ of the input data. NIH reports that this vehicle has a support mission for maintenance. Data indicate it typically parks near Service Road West (Figure B-31 and Google Earth figure to the right).

$\mathrm{NIH}$ reports that the vehicle odometer indicated 19,317 miles during the study and projected annual mileage at 2,759 . The vehicle was used on $100 \%$ of the available days, with an average daily usage of 2.2 hours and a peak daily usage of 7.1 hours on the days it was used. The vehicle was used during all hours of the day.

Figure B-33 shows all daily travel and all outings were within the typically advertised range of a BEV of

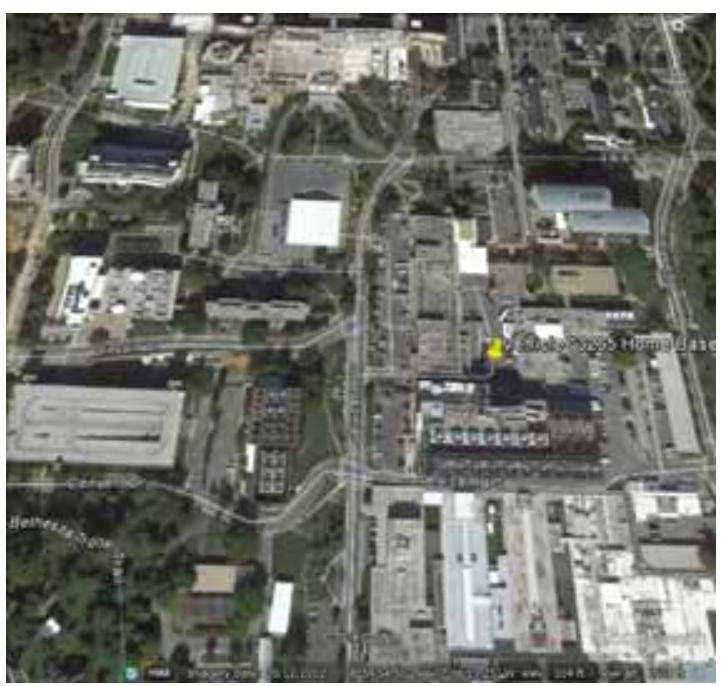
approximately 70 miles. Further, all daily travel and outings were within the typically advertised CD mode of 40 miles for PHEVs.

A BEV could meet all daily travel without additional charging opportunities. PEV replacements for this vehicle type exist and, assuming no other mission requirements exist, a BEV would be suggested. The survey information suggests no other special requirements exist for this support activity. 


\section{Vehicle $^{* * *} 1314$}

\begin{tabular}{|l|l|c|}
\hline & Make/Model/Year & Chevrolet HHR/2010 \\
\cline { 2 - 3 } & EPA Class Size & SUV \\
\hline Mission & Transport \\
\hline VIN & SGNBAADB1AS531314 \\
\cline { 2 - 3 } & Parking Location & $* * * 1314$ \\
\hline Fleet Vehicle ID & Gas/E85 \\
\hline Fuel Type & $22 / 32 / 2616 / 213 / 19$ \\
\hline & EPA Label/MPG (City/Hwy) & $342 / 326$ \\
\hline & EPA GHG Emissions (Grams $\left.\mathrm{CO}_{2} / \mathrm{Mi}\right)$ & 52 \\
\hline & Study Logger ID & $20 / 60$ \\
\hline & Total Vehicle Days/Total Study Days & Sest \\
\hline
\end{tabular}

\begin{tabular}{|l|c|c|c|c|}
\hline \multicolumn{5}{|c|}{ Vehicle ***1314 Travel Summary } \\
& Per Day Average/Peak & $\begin{array}{c}\text { Per Outing } \\
\text { Average/Peak }\end{array}$ & $\begin{array}{c}\text { Per Trip } \\
\text { Average/Peak }\end{array}$ & Total \\
\hline Travel Distance (Miles) & $11.3 / 19.4$ & $2.3 / 13.6$ & $0.4 / 4.3$ & 226 \\
\hline Travel Time (Minutes) & $58.0 / 87.0$ & $11.8 / 64.0$ & $2.0 / 29.0$ & 1,166 \\
\hline Idle Time (Minutes) & $5.0 / \mathrm{NA}$ & $1.0 / \mathrm{NA}$ & $0.2 / \mathrm{NA}$ & 100 \\
\hline
\end{tabular}

\begin{tabular}{|c|c|c|c|c|}
\hline \multicolumn{2}{|c|}{ Total Stops } & \multicolumn{2}{c|}{ Stop Duration } \\
\hline $\begin{array}{c}\text { Distance From Home } \\
\text { Base (Miles) }\end{array}$ & Stops & Percentages & Stop Duration (Hours) & Stops \\
\hline Less than 10 & 359 & $100 \%$ & Less than 2 & 341 \\
\hline 10 to 20 & 0 & $0 \%$ & 2 to 4 & 0 \\
\hline 20 to 40 & 0 & $0 \%$ & 4 to 8 & 0 \\
\hline Greater than 40 & 0 & $0 \%$ & Greater than 8 & 18 \\
\hline
\end{tabular}

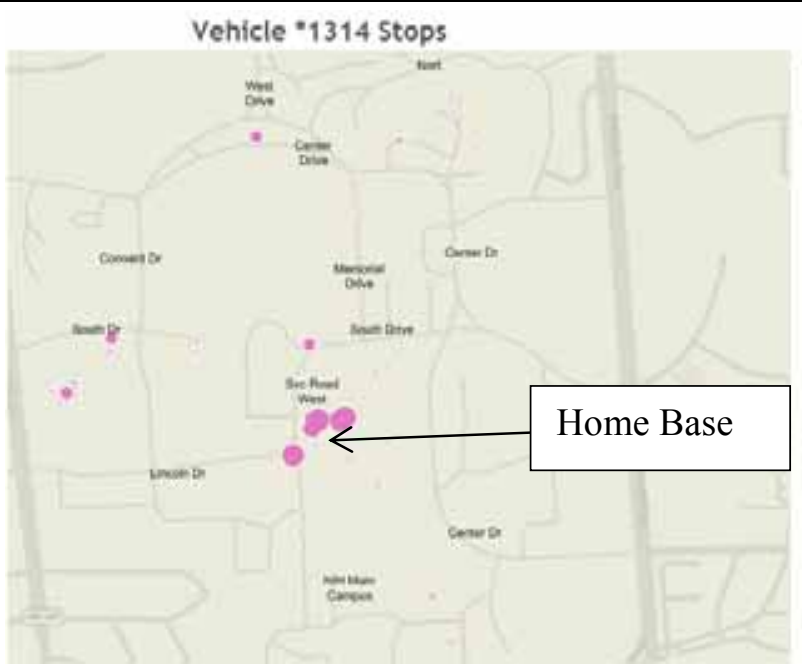

Figure B-34. Vehicle ***1314 stops.

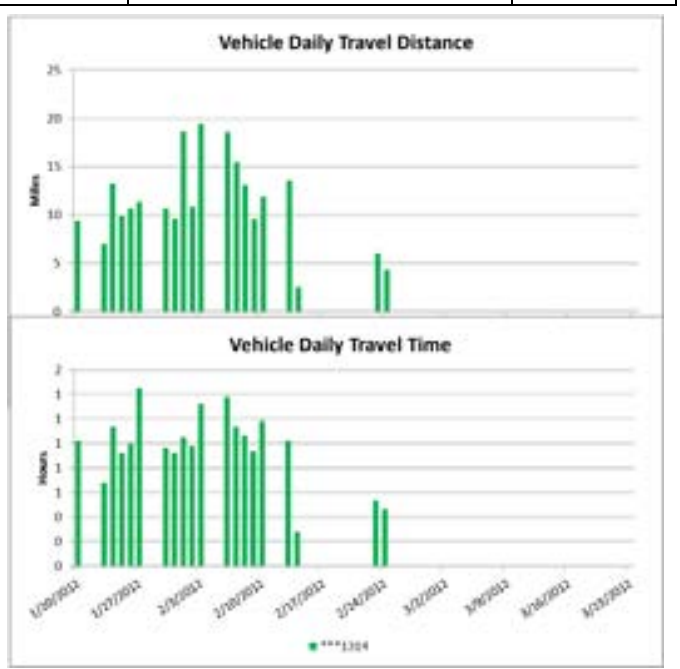

Figure B-35. Vehicle ***1314 history. 

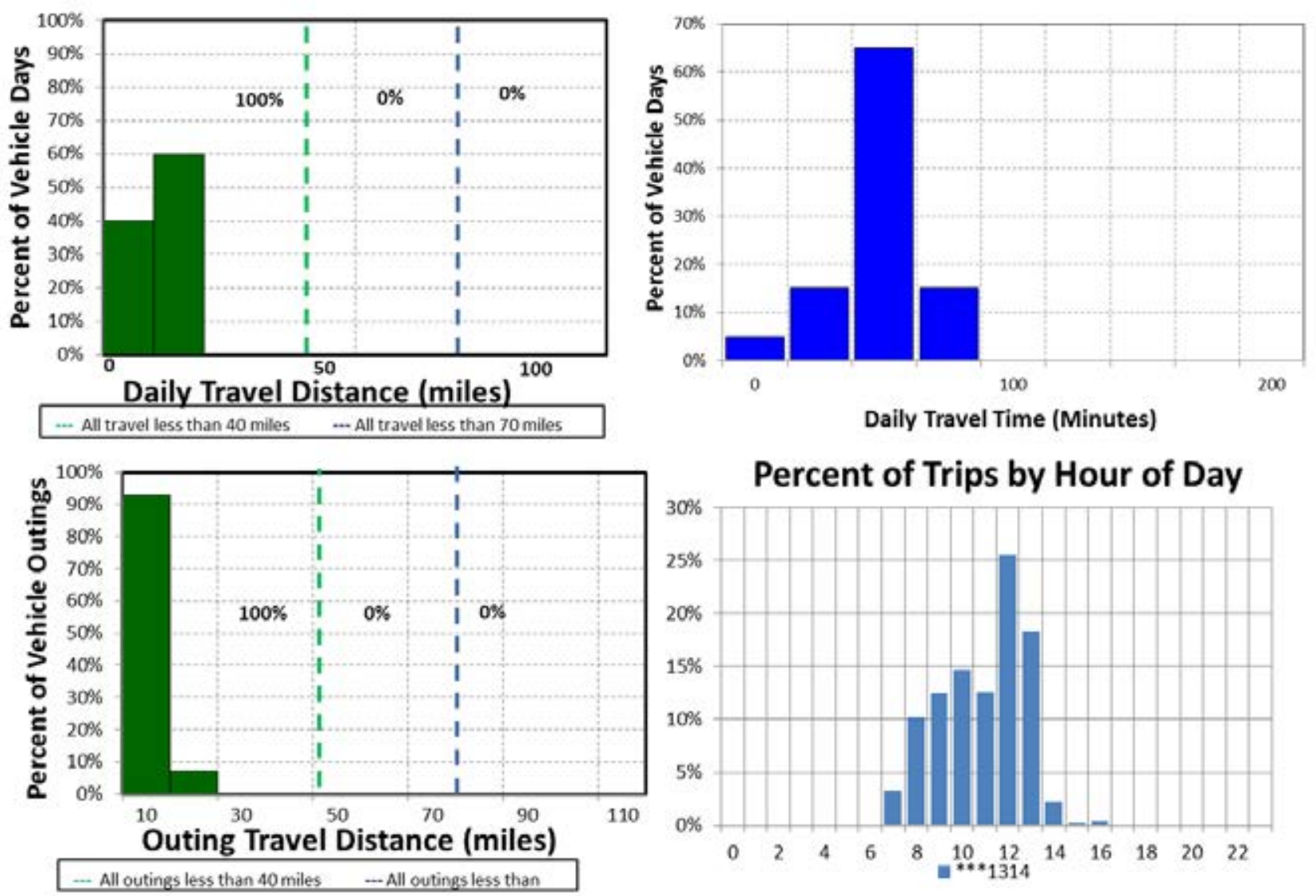

Figure B-36. Vehicle $* * * 1314$ travel graphs.

\section{Vehicle ${ }^{* * *} 1314$ Observations}

Logger 5 collected data on this vehicle for a period of 20 days of the 60 -day study period. Validation occurred on $99.5 \%$ of the input data. NIH reports that this vehicle has a support mission for material transport. Data indicate it typically parks near Service Road West (Figure B-34 and Google Earth figure to the right).

NIH reports the vehicle odometer indicated 17,381 miles during the study and projected an annual mileage of 8,690 . The vehicle was used on $33 \%$ of the available days, with an average daily usage of 1.0 hours and a peak daily usage of 1.5 hours on the days it was used. The vehicle was used during typical day shift hours.

Figure B-36 shows all daily travel and all outings were within the typically advertised range of a BEV of approximately 70 miles. Likewise, all daily travel and all outings were within the typically advertised CD mode of 40 miles for PHEVs. Short duration travel to Rockville was also indicated.

A BEV could meet all daily travel without additional charging opportunities. PEVs are available to replace this vehicle, depending on the type of material to be delivered. The survey information suggests no other special requirements exist for this transport activity. 


\begin{tabular}{|l|l|c|}
\hline Vehicle ***477 & Chevrolet Colorado/2010 \\
\hline & Make/Model/Year & Pransport \\
\cline { 2 - 3 } & EPA Class Size & TrantBDEXA81404477 \\
\cline { 2 - 3 } & Mission & South Dr/Memorial Rd \\
\hline & VIN & $* * * 4477$ \\
\hline & Parking Location & Gas \\
\hline & Fleet Vehicle ID & $18 / 25 / 21$ \\
\cline { 2 - 3 } & Fuel Type & 423 \\
\cline { 2 - 3 } & EPA Label/MPG (City/Hwy) & 53 \\
\cline { 2 - 3 } & EPA GHG Emissions (Grams $\left.\mathrm{CO}_{2} / \mathrm{Mi}\right)$ & $35 / 60$ \\
\cline { 2 - 3 } & Study Logger ID & \\
\cline { 2 - 3 } & Total Vehicle Days/Total Study Days & \\
\hline
\end{tabular}

\begin{tabular}{|l|c|c|c|c|}
\hline \multicolumn{5}{|c|}{ Vehicle ***4477 Travel Summary } \\
\hline & $\begin{array}{c}\text { Per Day } \\
\text { Average/Peak }\end{array}$ & $\begin{array}{c}\text { Per Outing } \\
\text { Average/Peak }\end{array}$ & $\begin{array}{c}\text { Per Trip } \\
\text { Average/Peak }\end{array}$ & Total \\
\hline Travel Distance (Miles) & $10.5 / 25.5$ & $2.9 / 26.0$ & $1.1 / 9.1$ & 366 \\
\hline Travel Time (Minutes) & $70.0 / 158.0$ & $19.4 / 140.0$ & $7.4 / 71.0$ & 2,458 \\
\hline Idle Time (Minutes) & $17.1 / \mathrm{NA}$ & $4.7 / \mathrm{NA}$ & $1.8 / \mathrm{NA}$ & 599 \\
\hline
\end{tabular}

\begin{tabular}{|c|c|c|c|c|}
\hline \multicolumn{2}{|c|}{ Total Stops } & \multicolumn{2}{c|}{ Stop Duration } \\
\hline $\begin{array}{c}\text { Distance From Home } \\
\text { Base (Miles) }\end{array}$ & Stops & Percentages & Stop Duration (Hours) & Stops \\
\hline Less than 10 & 280 & $100 \%$ & Less than 2 & 226 \\
\hline 10 to 20 & 0 & $0 \%$ & 2 to 4 & 15 \\
\hline 20 to 40 & 0 & $0 \%$ & 4 to 8 & 4 \\
\hline Greater than 40 & 0 & $0 \%$ & Greater than 8 & 35 \\
\hline
\end{tabular}

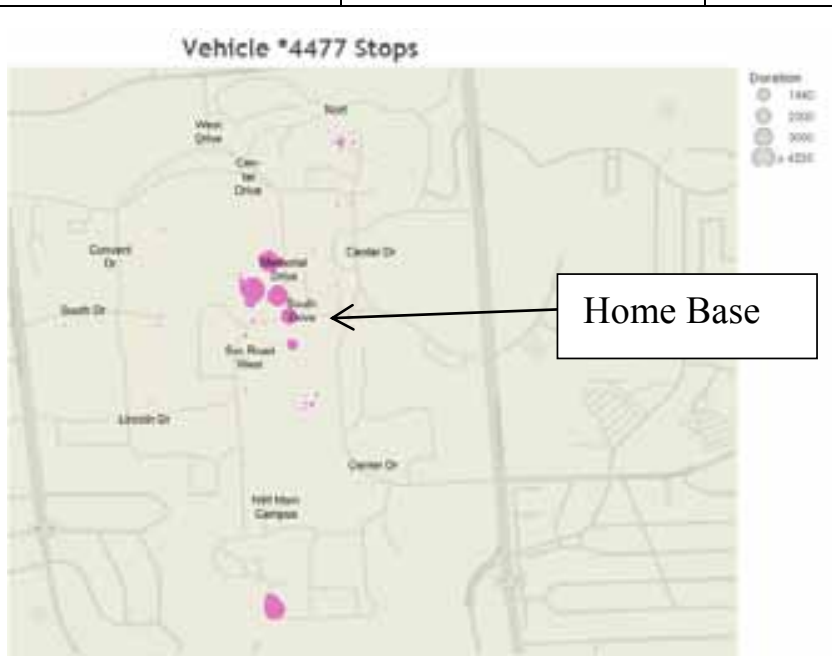

Figure B-37. Vehicle ***4477 stops.

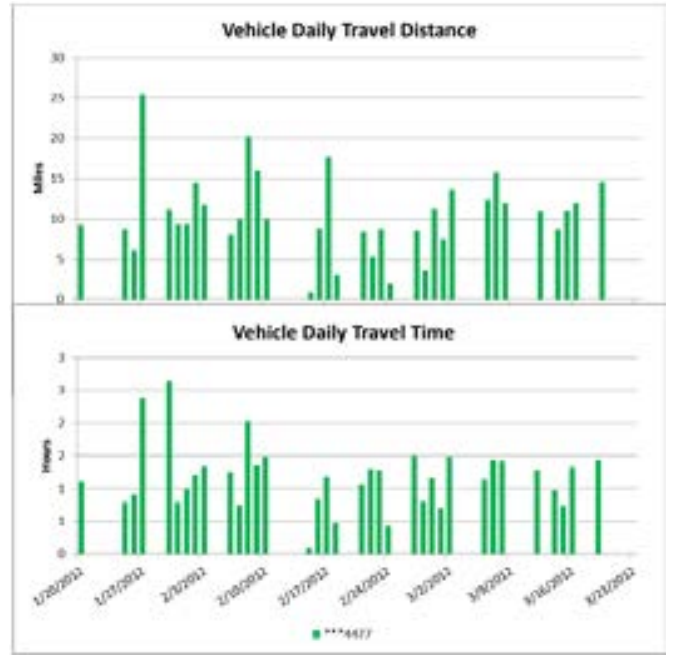

Figure B-38. Vehicle ***4477 history. 

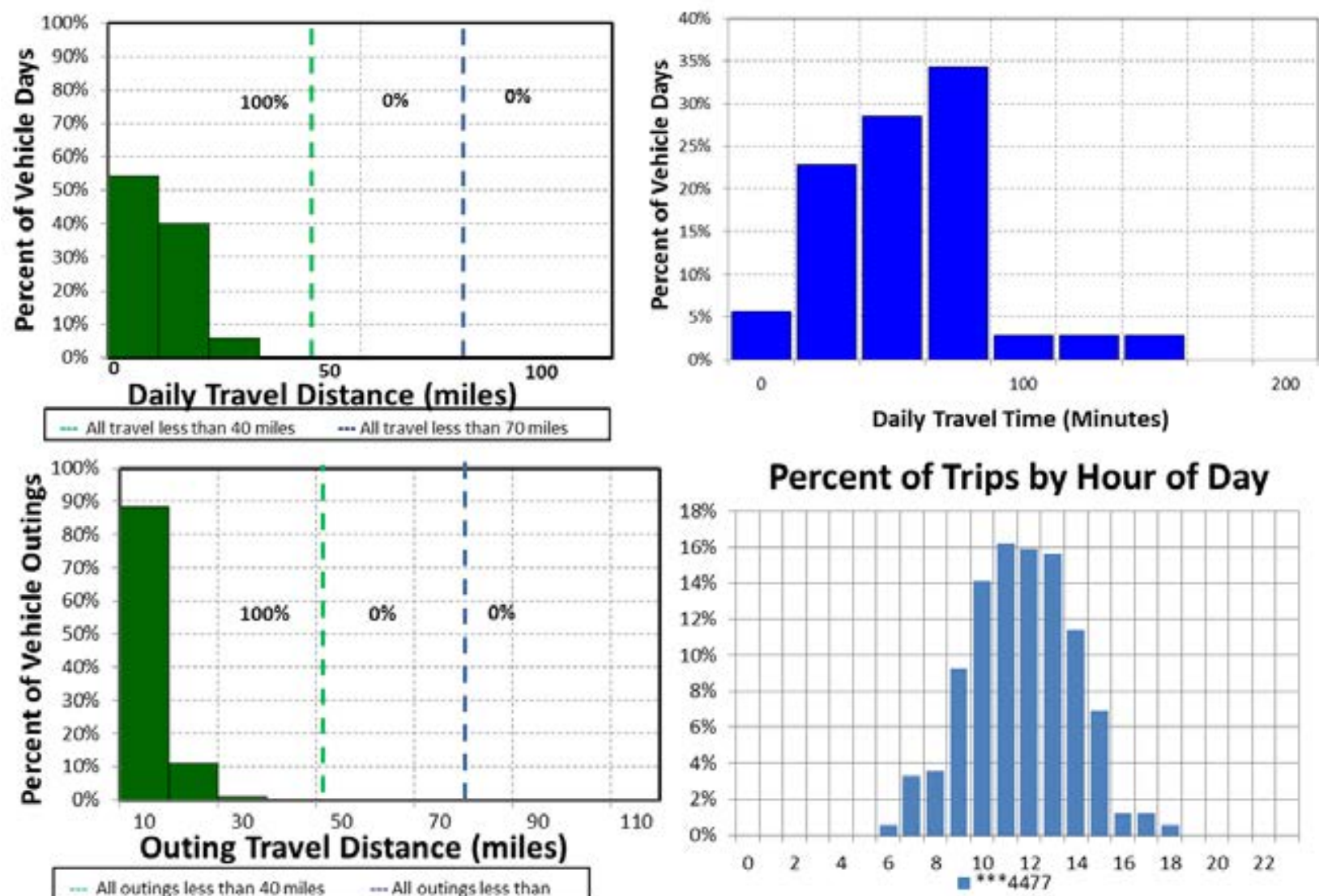

Figure B-39. Vehicle ***4477 travel graphs.

\section{Vehicle ***4477 Observations}

Logger 53 collected data on this vehicle for a period of 35 days of the 60-day study period. Validation occurred on $98.4 \%$ of the input data. NIH reports this vehicle has a transport mission for store delivery. Data indicate it typically parks on South Drive/Memorial Road (Figure B-37 and Google Earth figure to the right).

NIH reports that the vehicle odometer indicated 12,221 miles during the study and projected an annual mileage at 6,110 . The vehicle was used on $58 \%$ of the available days, with an average daily usage of 1.2 hours and a peak daily usage of 2.6 hours on the days it was used. The vehicle was used during typical day shift hours.

Figure B-39 shows all daily travel and all outings were within the typically advertised range of a BEV of

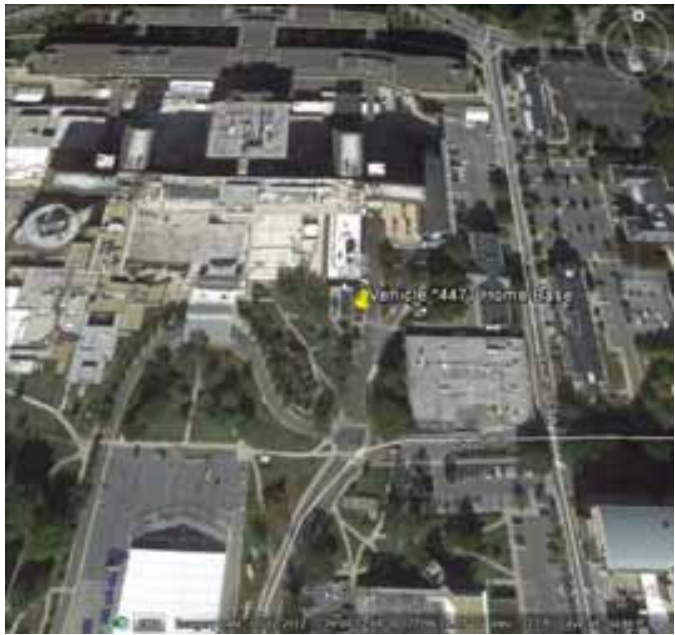
approximately 70 miles. Further, all daily travel and all outings were within the typically advertised CD mode of 40 miles for PHEVs. Short duration travel to Rockville was also indicated.

A BEV could meet all daily travel without additional charging opportunities. PEVs are available to replace this vehicle type, assuming no other mission requirements exist other than store delivery. The survey information suggests no other special requirements exist for this support activity. 


\section{Vehicle ***8199}

\begin{tabular}{|l|l|c|}
\hline & Make/Model/Year & Dodge Caravan/1999 \\
\cline { 2 - 3 } & EPA Class Size & Minivan \\
\hline Mission & Transport \\
\hline VIN & 1B4GT44L7XB618199 \\
\cline { 2 - 3 } & Parking Location & $* * * 8199$ \\
\hline Fleet Vehicle ID & Gas \\
\hline & Fuel Type & $18 / 24 / 20$ \\
\hline & EPA Label/MPG (City/Hwy) & 444 \\
\hline & EPA GHG Emissions (Grams $\left.\mathrm{CO}_{2} / \mathrm{Mi}\right)$ & 54 \\
\cline { 2 - 3 } & Study Logger ID & $10 / 60$ \\
\hline
\end{tabular}

\begin{tabular}{|l|c|c|c|c|}
\hline \multicolumn{5}{|c|}{ Vehicle $* * * 8199$ Travel Summary } \\
\hline & $\begin{array}{c}\text { Per Day } \\
\text { Average/Peak }\end{array}$ & $\begin{array}{c}\text { Per Outing } \\
\text { Average/Peak }\end{array}$ & $\begin{array}{c}\text { Per Trip } \\
\text { Average/Peak }\end{array}$ & Total \\
\hline Travel Distance (Miles) & $4.6 / 23.4$ & $5.7 / 23.4$ & $2.3 / 14.5$ & 46 \\
\hline Travel Time (Minutes) & $27.0 / 135.0$ & $33.6 / 147.0$ & $13.5 / 135.0$ & 269 \\
\hline Idle Time (Minutes) & $12.5 / \mathrm{NA}$ & $15.6 / \mathrm{NA}$ & $6.3 / \mathrm{NA}$ & 125 \\
\hline
\end{tabular}

\begin{tabular}{|c|c|c|c|c|}
\hline \multicolumn{2}{|c|}{ Total Stops } & \multicolumn{2}{c|}{ Stop Duration } \\
\hline $\begin{array}{c}\text { Distance From } \\
\text { Home Base (Miles) }\end{array}$ & Stops & Percentages & Stop Duration (Hours) & Stops \\
\hline Less than 10 & 20 & $95.2 \%$ & Less than 2 & 4 \\
\hline 10 to 20 & 1 & $4.7 \%$ & 2 to 4 & 0 \\
\hline 20 to 40 & 0 & $0 \%$ & 4 to 8 & 1 \\
\hline Greater than 40 & 0 & $0 \%$ & Greater than 8 & 16 \\
\hline
\end{tabular}

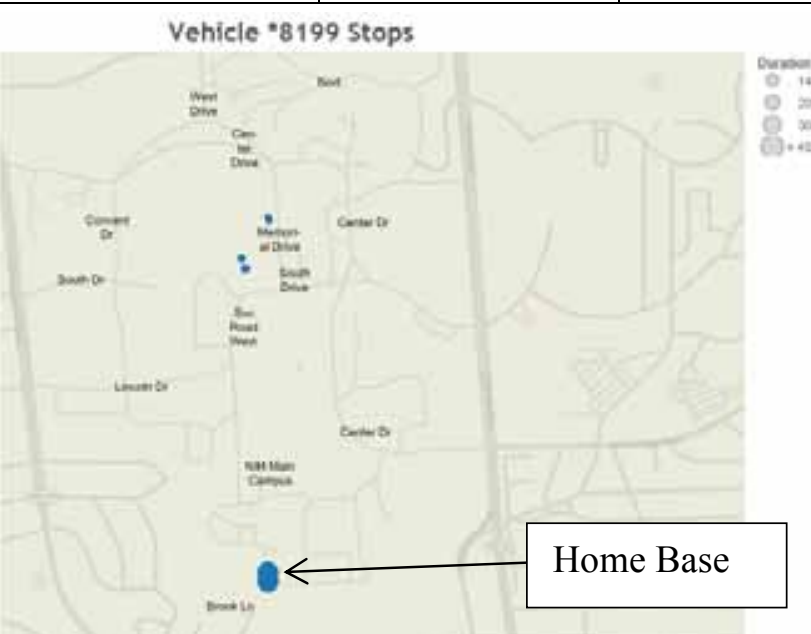

Figure B-40. Vehicle ***8199 stops.

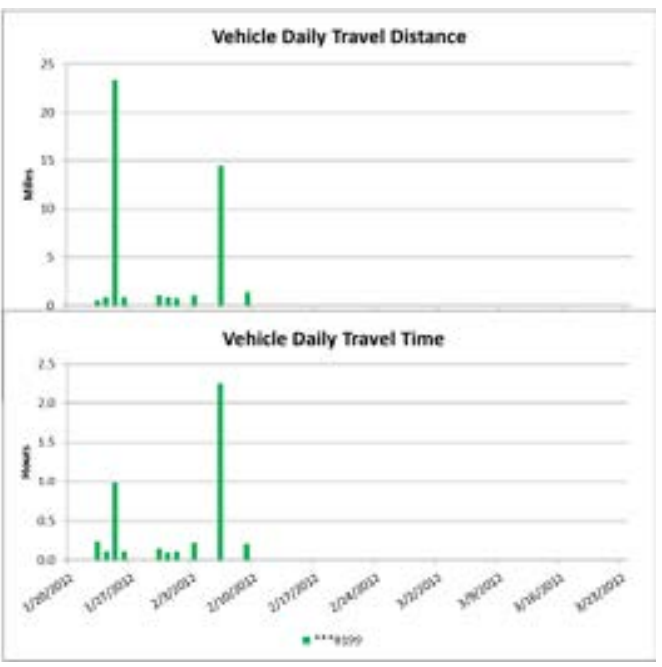

Figure B-41. Vehicle ***8199 history. 


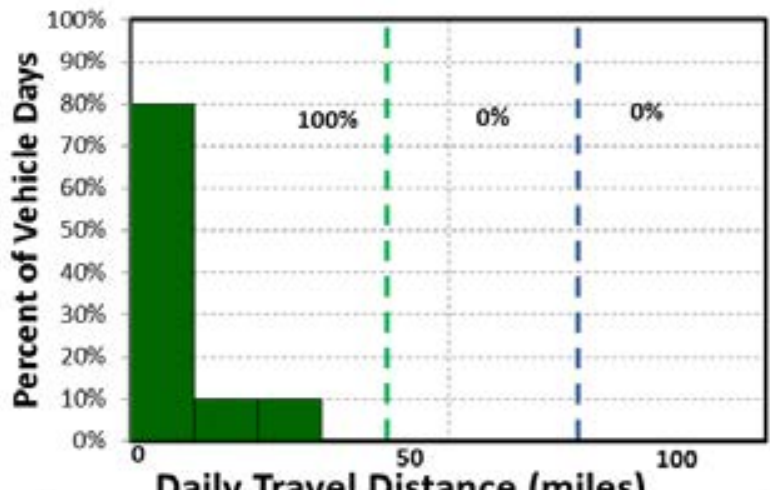

Daily Travel Distance (miles)

- All travel less than 40 miles

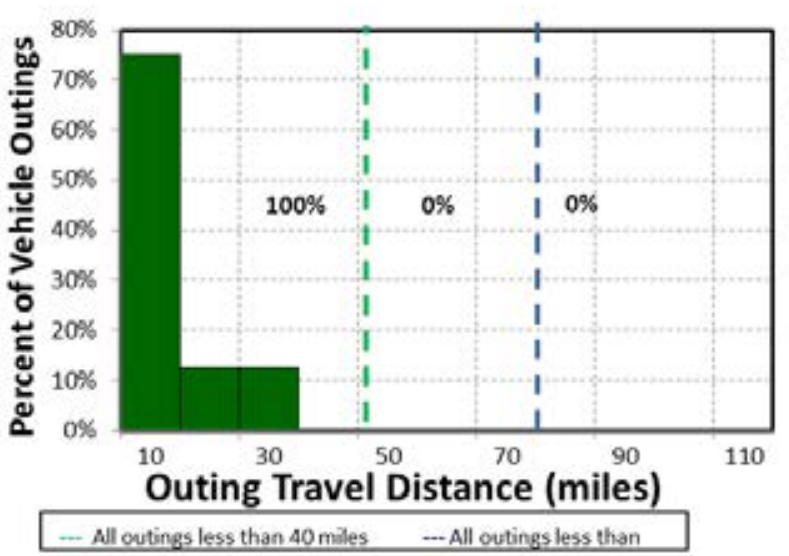

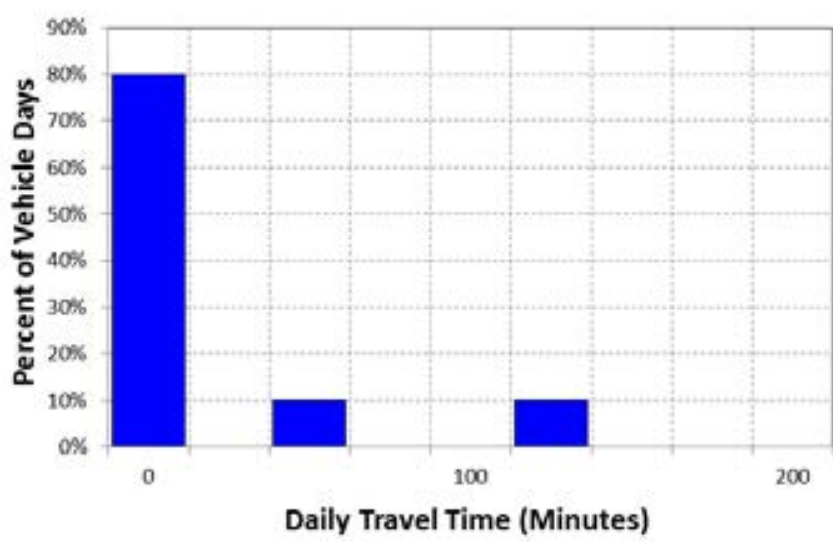

Percent of Trips by Hour of Day

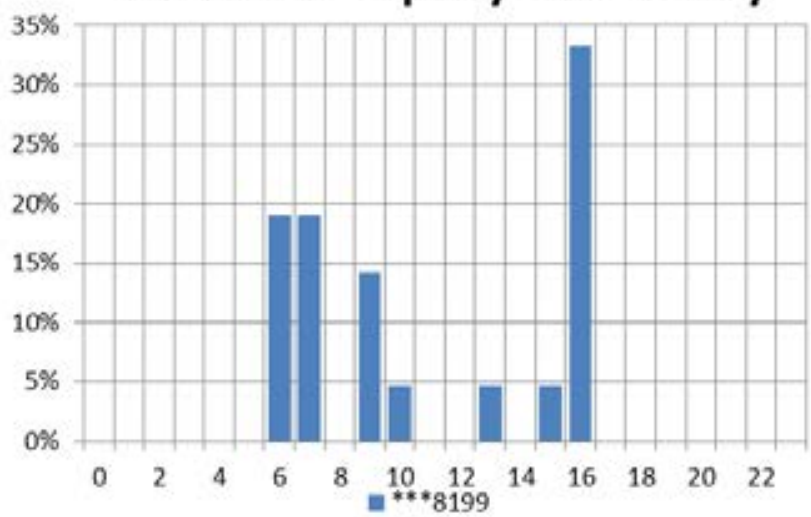

Figure B-42. Vehicle ***8199 travel graphs.

\section{Vehicle ${ }^{* *} 8199$ Observations}

Logger 54 collected data on this vehicle for a period of 10 days of the 60 -day study period. Validation occurred on $100 \%$ of the input data. NIH reports that this vehicle has a transport mission for store delivery. Data indicate it typically parks near Brook Lane (Figure B-40 and Google Earth figure to the right).

$\mathrm{NIH}$ reports that the vehicle odometer indicated 48,826 miles during the study and the projected annual mileage is 3,255 . The vehicle was used on $17 \%$ of the available days, with an average daily usage of 0.4 hours and a peak daily usage of 2.3 hours on the days it was used. The vehicle was used during typical day shift hours.

Figure B-42 shows all daily travel and all outings were within the typically advertised range of a BEV of approximately 70 miles. Further, all daily travel and all outings were within the typically advertised CD mode of 40 miles for PHEVs. Short duration travel to Rockville was also indicated.

A BEV could meet all daily travel without additional charging opportunities. PEVs are available to replace this transport vehicle type, assuming no other mission requirements exist. The survey information suggests no other special requirements exist for this support activity. 


\section{Vehicle $^{* * *} 3815$}

\begin{tabular}{|l|l|c|}
\hline & Make/Model/Year & Jeep Grand Cherokee/2009 \\
\cline { 2 - 3 } & EPA Class Size & SUV \\
\hline & Mission & Support \\
\hline VIN & Service Road S./Center Dr \\
\cline { 2 - 3 } & Parking Location & $* * * 3815$ \\
\hline & Fleet Vehicle ID & Gas/E85 \\
\hline & Fuel Type & $14 / 19 / 159 / 13 / 10$ \\
\cline { 2 - 3 } & EPA Label/MPG (City/Hwy) & $592 / 620$ \\
\cline { 2 - 3 } & EPA GHG Emissions (Grams $\left.\mathrm{CO}_{2} / \mathrm{Mi}\right)$ & 55 \\
\hline & Study Logger ID & $27 / 60$ \\
\hline & Total Vehicle Days/Total Study Days & . \\
\hline
\end{tabular}

\begin{tabular}{|l|c|c|c|c|}
\hline \multicolumn{5}{|c|}{ Vehicle ***3815 Travel Summary } \\
& Per Day Average/Peak & $\begin{array}{c}\text { Per Outing } \\
\text { Average/Peak }\end{array}$ & $\begin{array}{c}\text { Per Trip } \\
\text { Average/Peak }\end{array}$ & Total \\
\hline Travel Distance (Miles) & $25.6 / 55.4$ & $16.1 / 52.1$ & $1.3 / 15.9$ & 692 \\
\hline Travel Time (Minutes) & $152.0 / 272.0$ & $95.7 / 230.0$ & $7.6 / 94.0$ & 4,114 \\
\hline Idle Time (Minutes) & $58.5 / \mathrm{NA}$ & $36.7 / \mathrm{NA}$ & $2.9 / \mathrm{NA}$ & 1,580 \\
\hline
\end{tabular}

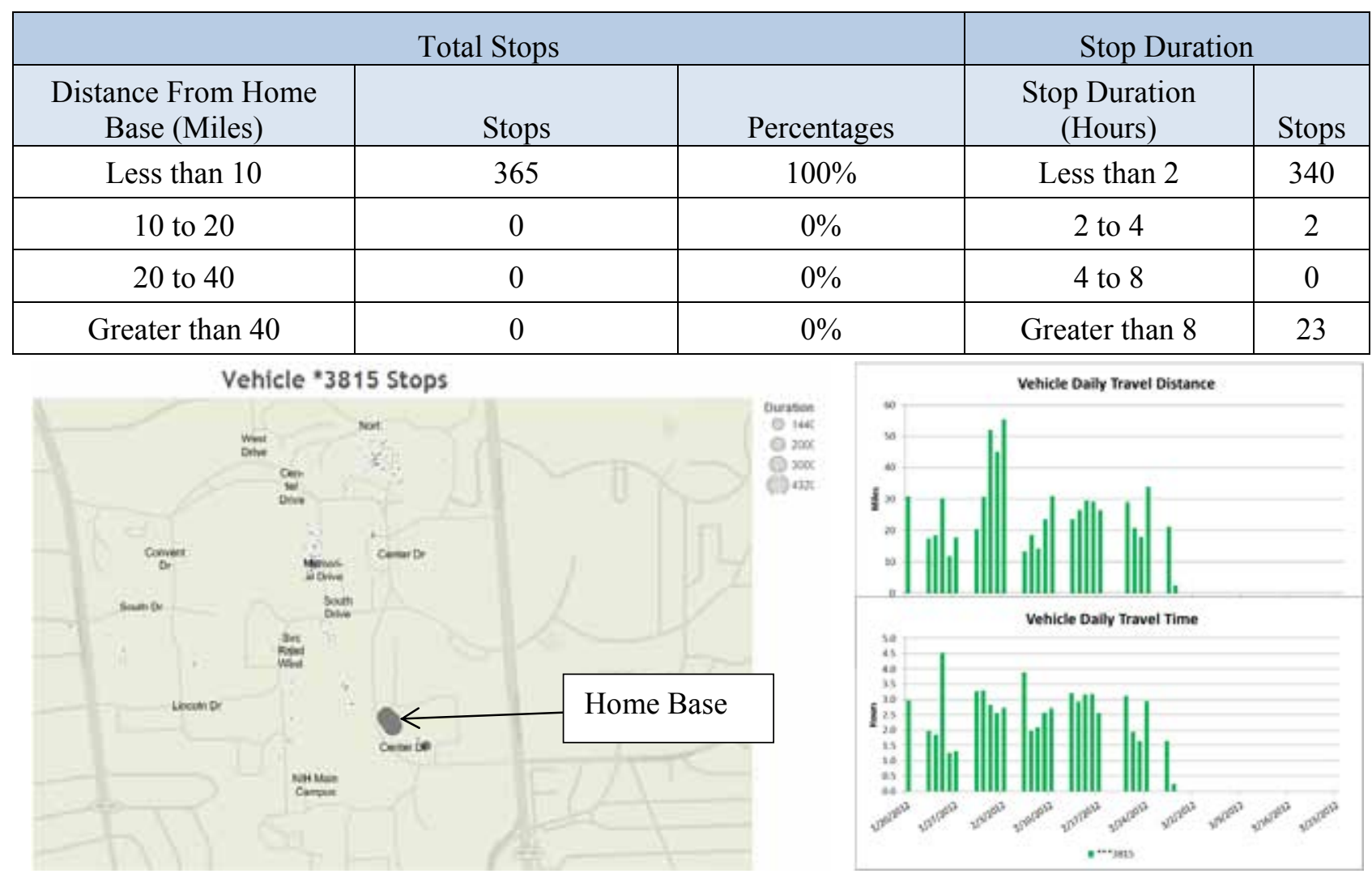

Figure B-43. Vehicle ***3815 stops.

Figure B-44. Vehicle ***3815 history. 


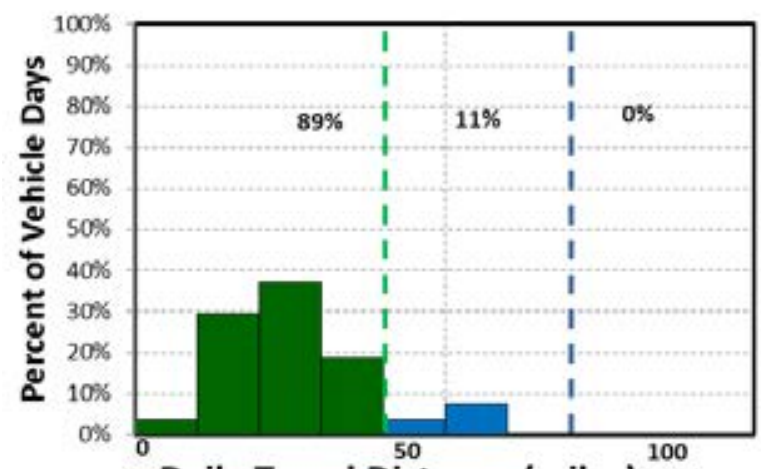

Daily Travel Distance (miles)

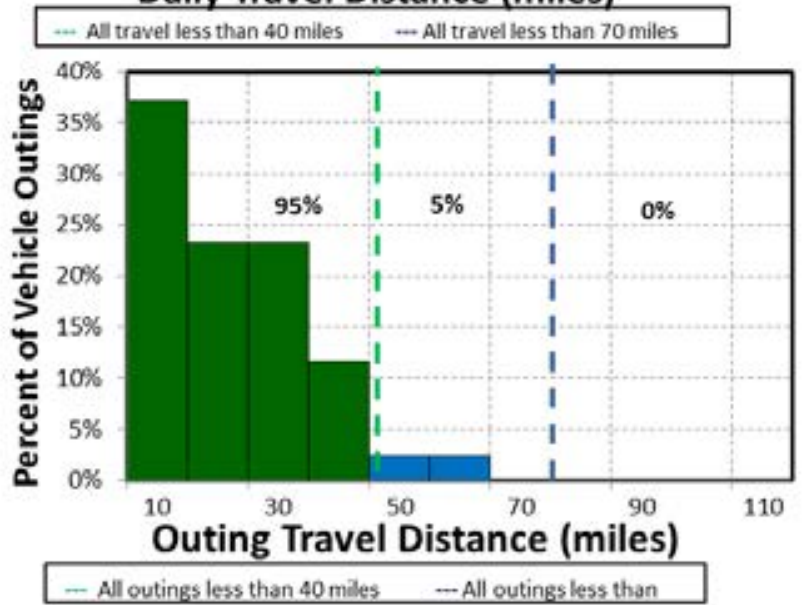

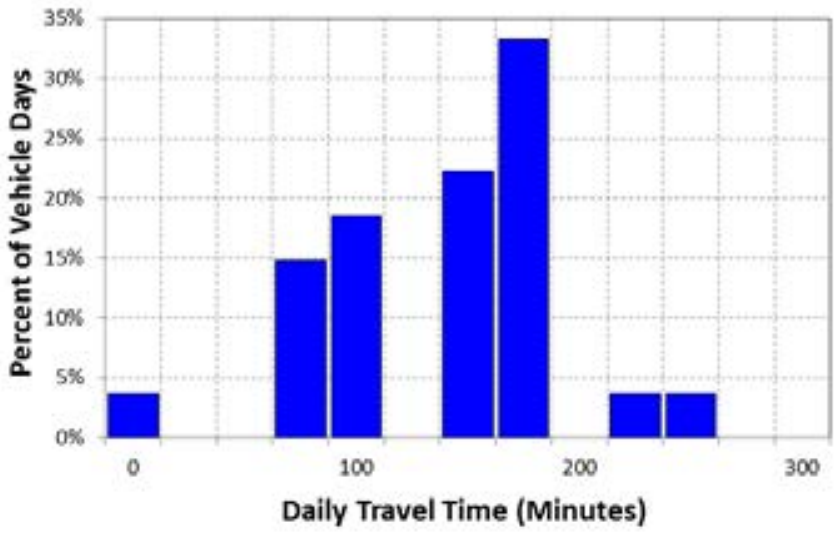

Percent of Trips by Hour of Day

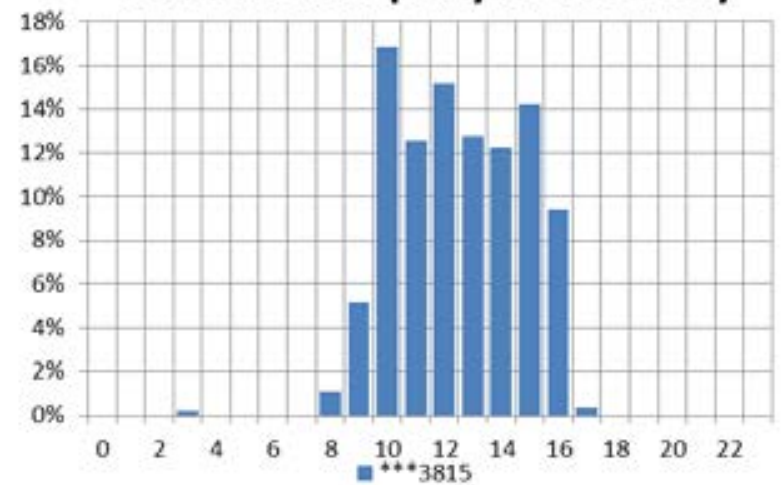

Figure B-45. Vehicle ***3815 travel graphs.

\section{Vehicle ${ }^{* * *} 3815$ Observations}

Logger 55 collected data on this vehicle for a period of 27 days of the 60-day study period. Validation occurred on $99.3 \%$ of the input data. NIH reports that this vehicle has a support mission mail delivery. Data indicate it typically parks near Service Road South and Center Drive (Figure B-43 and Google Earth figure to the right).

$\mathrm{NIH}$ reports that the vehicle odometer indicated 26,429 miles during the study and the projected annual mileage is 8,809 . The vehicle was used on $45 \%$ of the available days, with an average daily usage of 2.5 hours and a peak daily usage of 4.5 hours on the days it was used. The vehicle was used during typical day shift hours.

Figure B-45 shows all daily travel and all outings were within the typically advertised range of a BEV of approximately 70 miles. Further, $89 \%$ of daily travel and $95 \%$ of outings were within the typically advertised CD mode of 40 miles for PHEVs. Short duration travel to Rockville was also indicated.

A BEV could meet all daily travel without additional charging opportunities. PEVs are available to replace this vehicle type, assuming no other mission requirements exist other than mail delivery. The survey information suggests no other special requirements exist for this support activity. 


\begin{tabular}{|c|c|c|}
\hline $5=$ & Make/Model/Year & Ford Expedition XLT/2006 \\
\hline & EPA Class Size & SUV \\
\hline & Mission & Support \\
\hline & VIN & 1FMPU16566LA43952 \\
\hline & Parking Location & Service Road S./Center Dr \\
\hline & Fleet Vehicle ID & $* * * 3952$ \\
\hline & Fuel Type & Gas \\
\hline & EPA Label/MPG (City/Hwy) & $12 / 17 / 14$ \\
\hline & EPA GHG Emissions (Grams $\left.\mathrm{CO}_{2} / \mathrm{Mi}\right)$ & 635 \\
\hline & Study Logger ID & 56 \\
\hline & Total Vehicle Days/Total Study Days & $17 / 60$ \\
\hline
\end{tabular}

\begin{tabular}{|l|c|c|c|c|}
\hline \multicolumn{5}{|c|}{ Vehicle ***3952 Travel Summary } \\
\hline & $\begin{array}{c}\text { Per Day } \\
\text { Average/Peak }\end{array}$ & $\begin{array}{c}\text { Per Outing } \\
\text { Average/Peak }\end{array}$ & $\begin{array}{c}\text { Per Trip } \\
\text { Average/Peak }\end{array}$ & Total \\
\hline Travel Distance (Miles) & $2.2 / 9.3$ & $1.1 / 9.4$ & $0.7 / 8.6$ & 37 \\
\hline Travel Time (Minutes) & $16.0 / 83.0$ & $8.0 / 42.0$ & $5.4 / 30.0$ & 279 \\
\hline Idle Time (Minutes) & $5.9 / \mathrm{NA}$ & $2.9 / \mathrm{NA}$ & $1.9 / \mathrm{NA}$ & 100 \\
\hline
\end{tabular}

\begin{tabular}{|c|c|c|c|c|}
\hline \multicolumn{2}{|c|}{ Total Stops } & \multicolumn{2}{c|}{ Stop Duration } \\
\hline $\begin{array}{c}\text { Distance From } \\
\text { Home Base (Miles) }\end{array}$ & Stops & Percentages & Stop Duration (Hours) & Stops \\
\hline Less than 10 & 43 & $100 \%$ & Less than 2 & 15 \\
\hline 10 to 20 & 0 & $0 \%$ & 2 to 4 & 9 \\
\hline 20 to 40 & 0 & $0 \%$ & 4 to 8 & 2 \\
\hline Greater than 40 & 0 & $0 \%$ & Greater than 8 & 17 \\
\hline
\end{tabular}

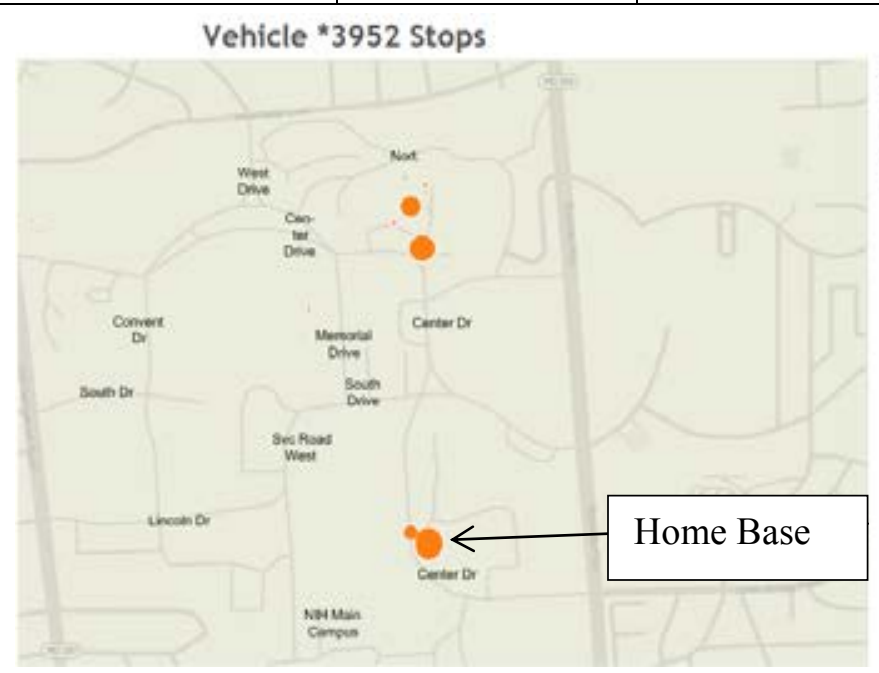

Figure B-46. Vehicle ***3952 stops.

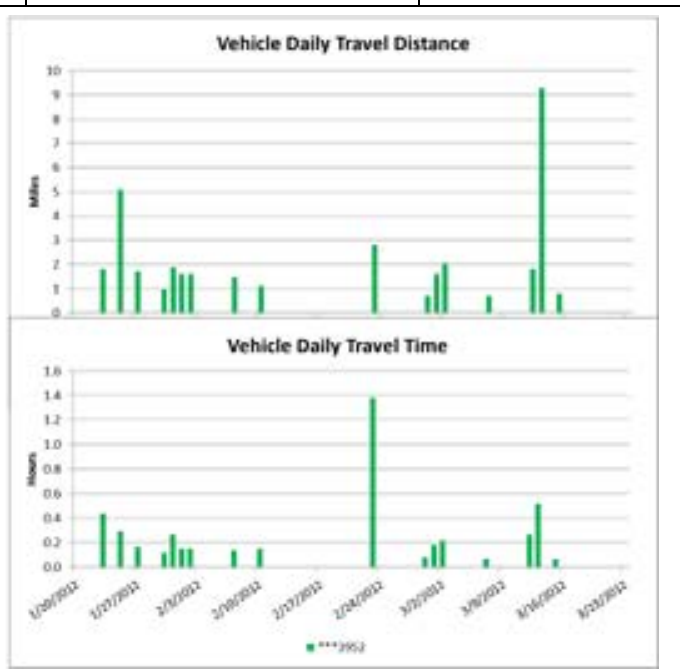

Figure B-47. Vehicle ***3952 history. 


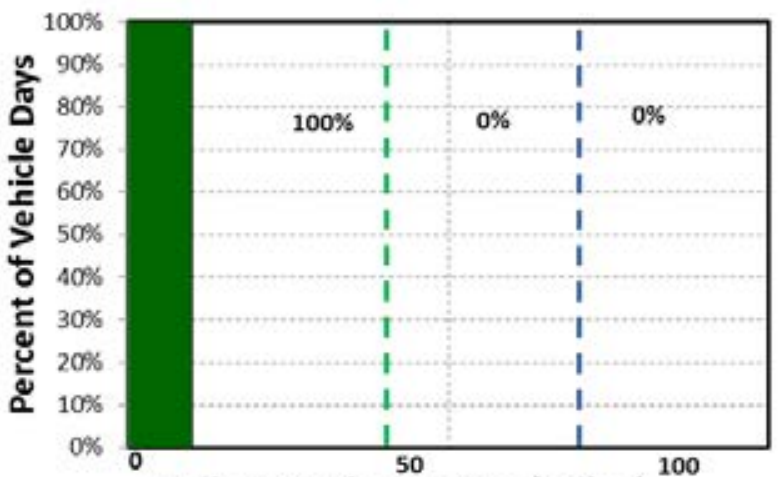

Daily Travel Distance (miles)

. All travel less than 40 miles $\quad \ldots$ All travel less than 70 miles

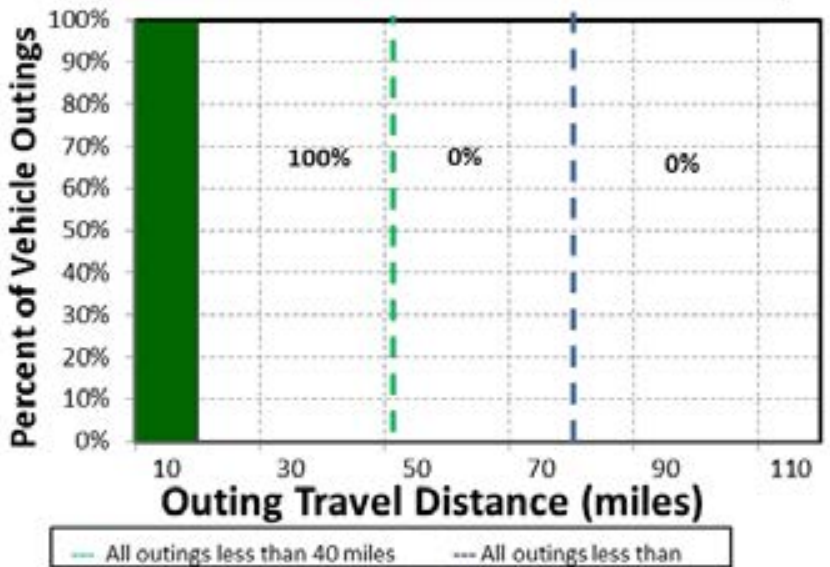

All outings less than 40 miles

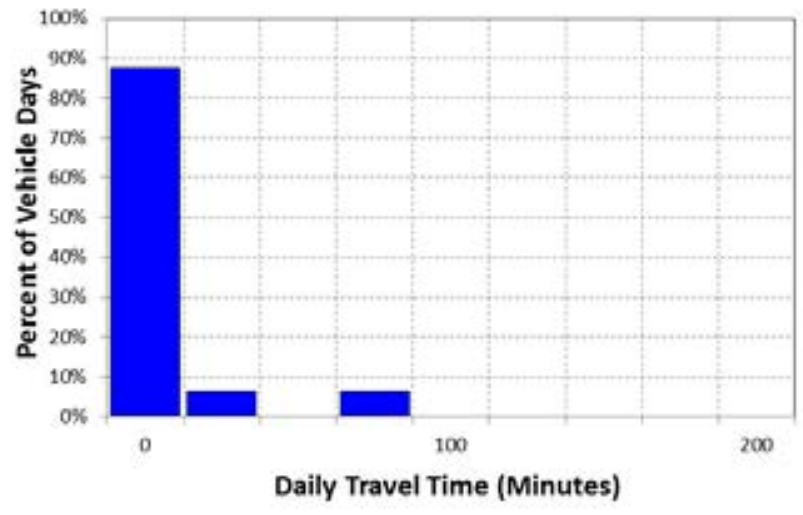

Percent of Trips by Hour of Day

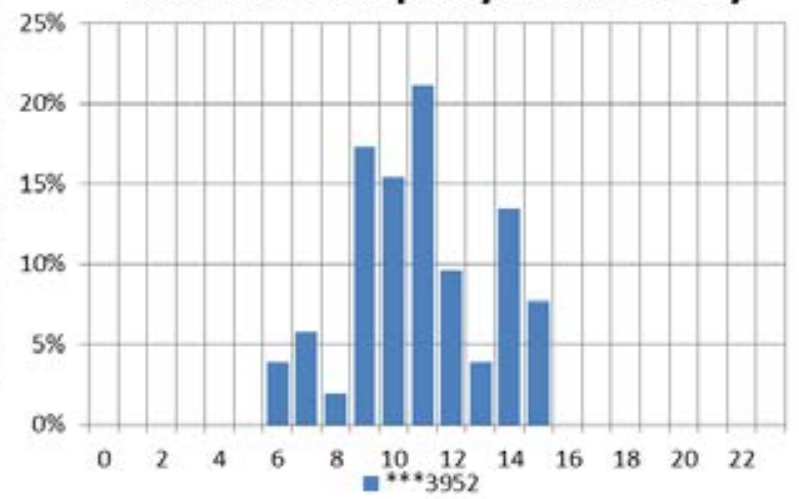

Figure B-48. Vehicle ***3952 travel graphs.

\section{Vehicle ${ }^{* * *} 3952$ Observations}

Logger 56 collected data on this vehicle for a period of 17 days of the 60 -day study period. Validation occurred on $98.3 \%$ of the input data. NIH reports that this vehicle has a support mission as a COOP Emergency vehicle. Data indicate it typically parks near Service Road South/Center Dr (Figure B-46 and Google Earth figure to the right).

NIH reports that the vehicle odometer indicated 6,252 miles during the study and the projected annual mileage is 1,042 . The vehicle was used on $28 \%$ of the available days with an average daily usage of 0.3 hours and a peak daily usage of 1.4 hours on the days it was used. The vehicle was used during typical day shift hours.

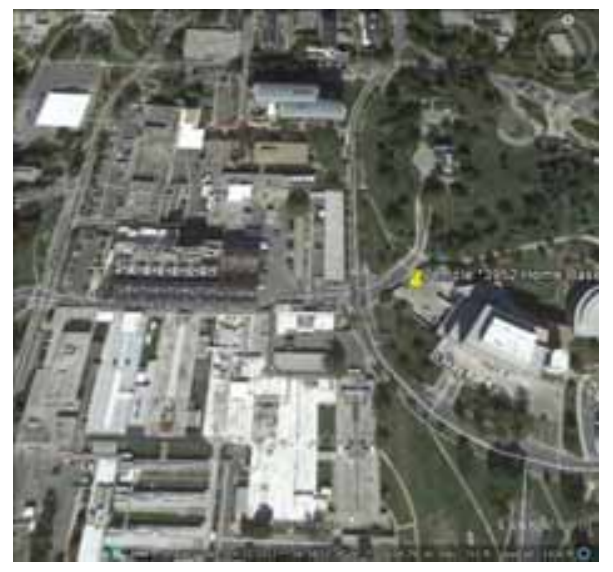

Figure B-48 shows all daily travel and all outings were within the typically advertised range of a BEV of approximately 70 miles. Further, all daily travel and all outings were within the typically advertised CD mode of 40 miles for PHEVs. Short duration travel to Rockville was also indicated.

A BEV could meet all daily travel without additional charging opportunities. PEVs are available to replace SUVs, assuming no other emergency mission requirements exist. 


\section{Vehicle ${ }^{* * *} 8489$}

\begin{tabular}{|c|c|c|}
\hline 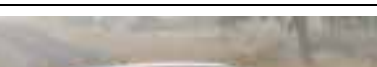 & Make/Model/Year & Chevrolet Impala/2010 \\
\hline 29.52 & EPA Class Size & Sedan - Large \\
\hline $6=8-2=$ & Mission & Pool \\
\hline & VIN & 2G1WA5EK3A1118489 \\
\hline & Parking Location & Service Road South \\
\hline & Fleet Vehicle ID & $* * * 8489$ \\
\hline & Fuel Type & Gas/E85 \\
\hline & EPA Label/MPG (City/Hwy) & $18 / 29 / 22 \quad 14 / 22 / 17$ \\
\hline & EPA GHG Emissions (Grams $\left.\mathrm{CO}_{2} / \mathrm{Mi}\right)$ & $404 / 365$ \\
\hline & Study Logger ID & 57 \\
\hline & Total Vehicle Days/Total Study Days & $37 / 60$ \\
\hline
\end{tabular}

\begin{tabular}{|l|c|c|c|c|}
\hline \multicolumn{5}{|c|}{ Vehicle $* * * 8489$ Travel Summary } \\
\hline & $\begin{array}{c}\text { Per Day } \\
\text { Average/Peak }\end{array}$ & $\begin{array}{c}\text { Per Outing } \\
\text { Average/Peak }\end{array}$ & $\begin{array}{c}\text { Per Trip } \\
\text { Average/Peak }\end{array}$ & Total \\
\hline Travel Distance (Miles) & $51.6 / 317.1$ & $39.0 / 705.2$ & $11.3 / 186.1$ & 1,910 \\
\hline Travel Time (Minutes) & $99.0 / 423.0$ & $74.6 / 1,175.0$ & $21.6 / 167.0$ & 3,653 \\
\hline Idle Time (Minutes) & $16.5 / \mathrm{NA}$ & $12.5 / \mathrm{NA}$ & $3.6 / \mathrm{NA}$ & 611 \\
\hline
\end{tabular}

\begin{tabular}{|c|c|c|c|c|}
\hline \multicolumn{2}{|c|}{ Total Stops } & \multicolumn{2}{c|}{ Stop Duration } \\
\hline $\begin{array}{c}\text { Distance From } \\
\text { Home Base (Miles) }\end{array}$ & Stops & Percentages & Stop Duration (Hours) & Stops \\
\hline Less than 10 & 64 & $53.8 \%$ & Less than 2 & 69 \\
\hline 10 to 20 & 15 & $12.6 \%$ & 2 to 4 & 11 \\
\hline 20 to 40 & 13 & $10.9 \%$ & 4 to 8 & 6 \\
\hline Greater than 40 & 27 & $22.7 \%$ & Greater than 8 & 33 \\
\hline
\end{tabular}

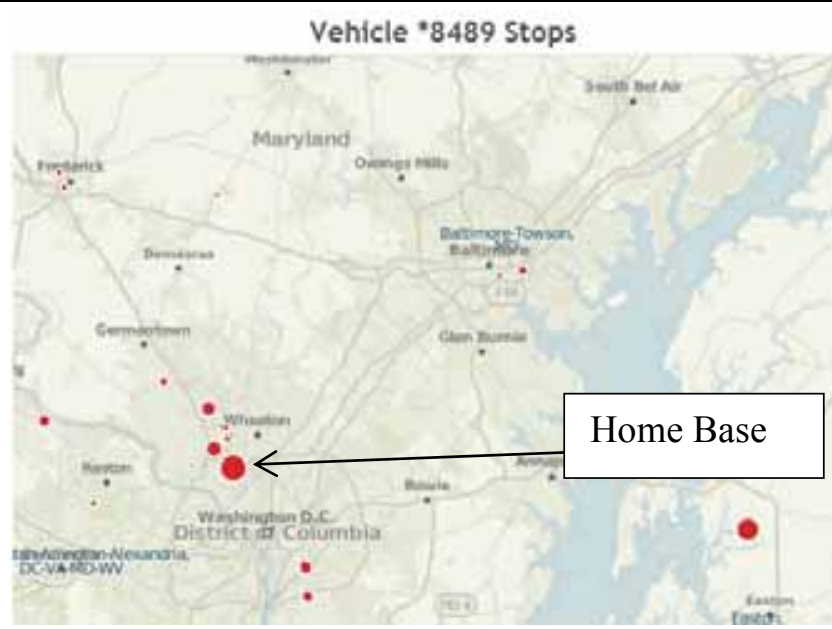

Figure B-49. Vehicle ***8489 stops.

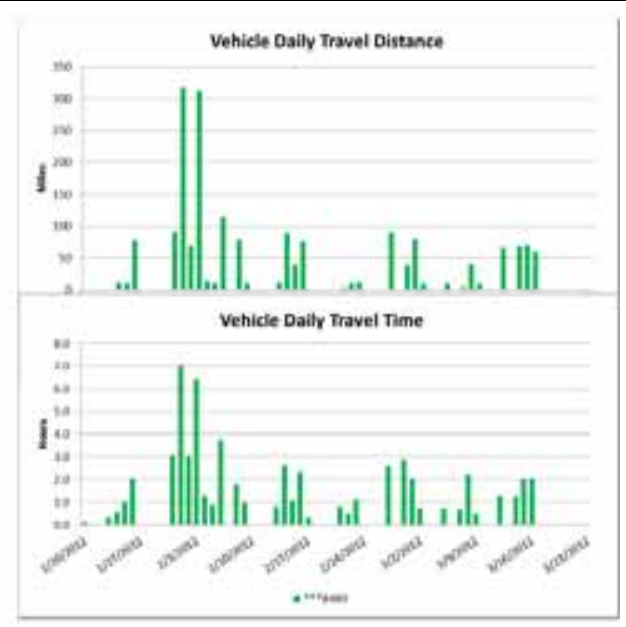

Figure B-50. Vehicle ***8489 history. 


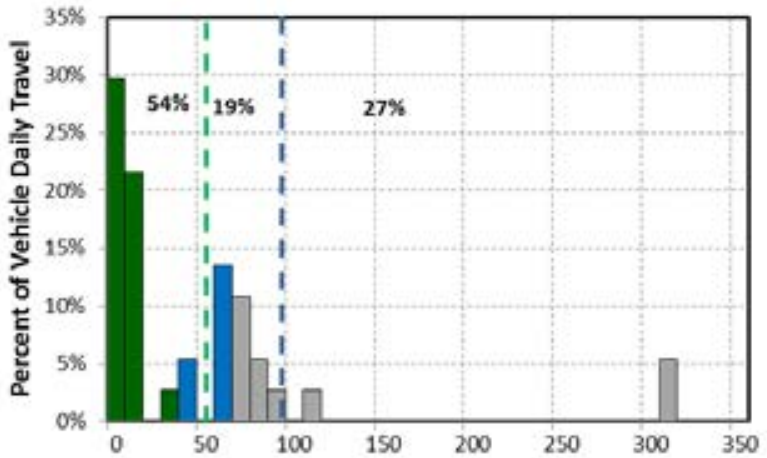

Daily Travel Distance (miles)

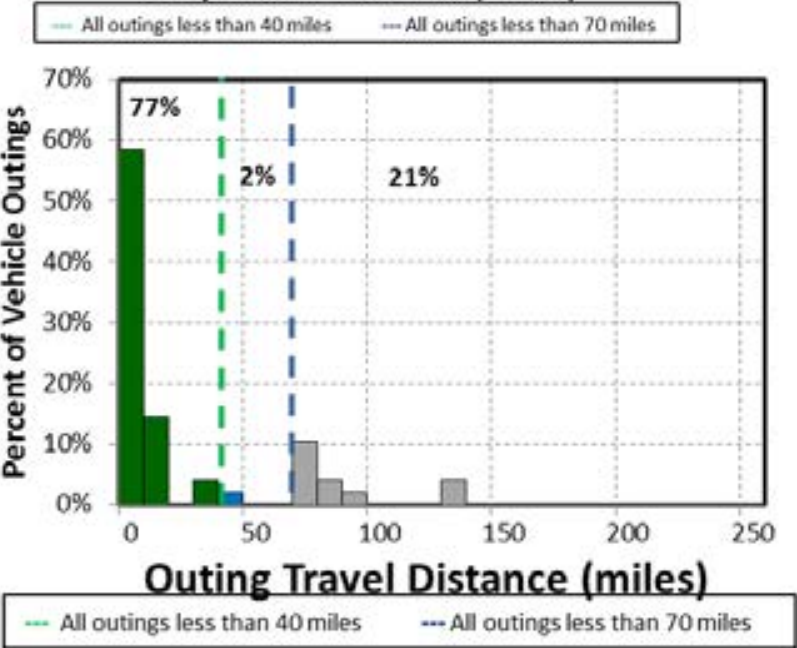

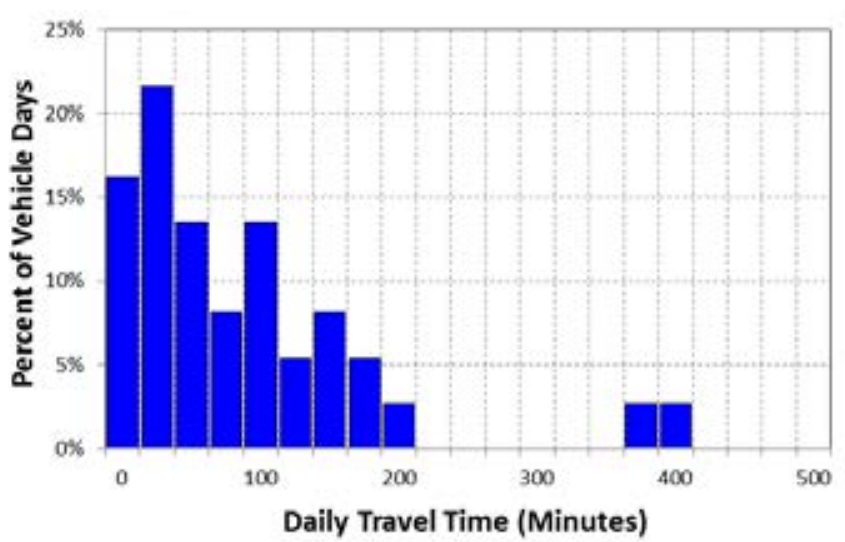

Percent of Trips by Hour of Day

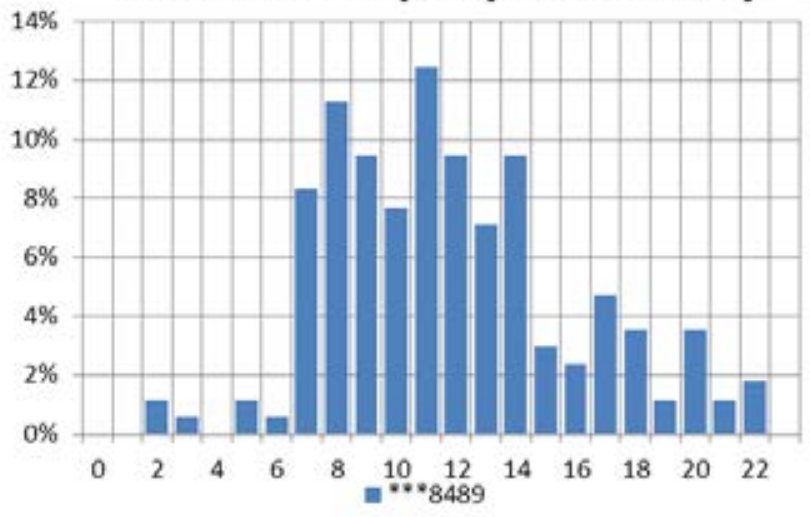

Figure B-51. Vehicle $* * * 8489$ travel graphs. Peak outing of 750.2 miles not shown for clarity of scale.

\section{Vehicle ${ }^{* * *} 8489$ Observations}

Logger 57 collected data on this vehicle for a period of 37 days of the 60 -day study period. Validation occurred on $98.1 \%$ of the input data. NIH reports that this vehicle has a pool mission as a rental vehicle. Data indicate travel offsite, but it typically parks near Service Road South (Figure B-49 and Google Earth figure to the right).

$\mathrm{NIH}$ reports that the vehicle odometer indicated 13,859 miles during the study and the projected annual mileage is 699 miles. The vehicle was used on $62 \%$ of the available days, with an average daily usage of 1.7 hours and a peak daily usage of 7.1 hours on the days it was used. The vehicle was used during typical day shift hours.

Figure B-30 shows $73 \%$ of daily travel and $79 \%$ of outings were within the typically advertised range of a BEV of approximately

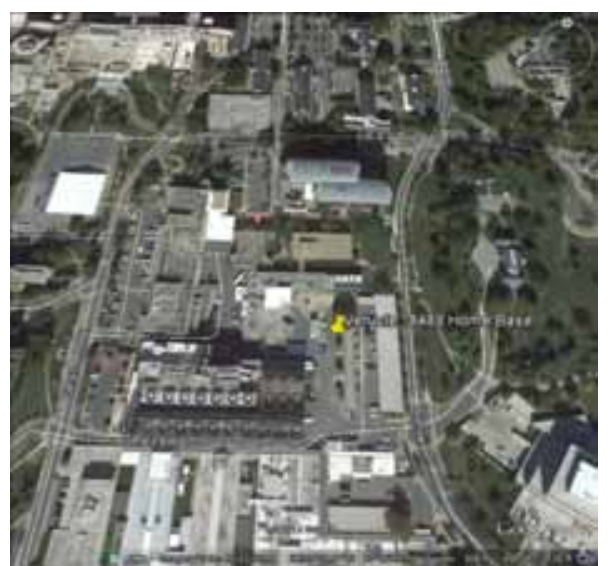
70 miles. Further, $54 \%$ of daily travel and $77 \%$ of outings were within the typically advertised CD mode of 40 miles for PHEVs. The peak outing occurred during a several-day excursion to Durham, NC.

A BEV could not meet all daily travel. PHEVs are available to replace this pool vehicle. 


\begin{tabular}{|l|l|c|}
\hline & Make/Model/Year & Chevrolet Impala/2005 \\
\hline & EPA Class Size & Sedan - Large \\
\hline Mission & Law Enforcement \\
\hline VIN & 2G1WF55K559250758 \\
\hline Parking Location & $* * * 0758$ \\
\hline Fleet Vehicle ID & Gas \\
\hline Fuel Type & $18 / 27 / 21$ \\
\hline & EPA Label/MPG (City/Hwy) & 404 \\
\hline & EPA GHG Emissions (Grams $\left.\mathrm{CO}_{2} / \mathrm{Mi}\right)$ & 58 \\
\hline & Study Logger ID & \\
\hline & Total Vehicle Days/Total Study Days & \\
\hline
\end{tabular}

\begin{tabular}{|l|c|c|c|c|}
\hline \multicolumn{7}{|c|}{ Vehicle $* * * 0758$ Travel Summary } \\
\hline & $\begin{array}{c}\text { Per Day } \\
\text { Average/Peak }\end{array}$ & $\begin{array}{c}\text { Per Outing } \\
\text { Average/Peak }\end{array}$ & $\begin{array}{c}\text { Per Trip } \\
\text { Average/Peak }\end{array}$ & Total \\
\hline Travel Distance (Miles) & Insufficient data & Insufficient data & Insufficient data & Insufficient data \\
\hline Travel Time (Minutes) & Insufficient data & Insufficient data & Insufficient data & Insufficient data \\
\hline Idle Time (Minutes) & Insufficient data & Insufficient data & Insufficient data & Insufficient data \\
\hline
\end{tabular}

\begin{tabular}{|c|c|c|c|c|}
\hline \multicolumn{2}{|c|}{ Total Stops } & \multicolumn{2}{c|}{ Stop Duration } \\
\hline $\begin{array}{c}\text { Distance From } \\
\text { Home Base (Miles) }\end{array}$ & Stops & Percentages & $\begin{array}{c}\text { Stop Duration } \\
\text { (Hours) }\end{array}$ & Stops \\
\hline Less than 10 & Insufficient data & Insufficient data & Less than 2 & Insufficient data \\
\hline 10 to 20 & Insufficient data & Insufficient data & 2 to 4 & Insufficient data \\
\hline 20 to 40 & Insufficient data & Insufficient data & 4 to 8 & Insufficient data \\
\hline Greater than 40 & Insufficient data & Insufficient data & Greater than 8 & Insufficient data \\
\hline
\end{tabular}

\section{Insufficient data}

Figure B-52. Vehicle ***0758 stops .

Figure B-53. Vehicle ***0758 history.

\section{Insufficient data}

Figure B-54. Vehicle ***0758 travel graphs.

\section{Vehicle ${ }^{* * *} 0758$ Observations}

No logger information was transmitted for this vehicle throughout the study period for unknown reasons. NIH reports that this vehicle has a law enforcement mission for K-9 police.

NIH reports that the vehicle odometer indicated 69,279 miles during the study and the projected annual mileage is 9,892 miles. 


\begin{tabular}{|l|l|c|}
\hline Vehicle & M**370 & Chevrolet Impala/2005 \\
\hline & EPA Class Size & Sedan - Large \\
\hline & Mission & Law Enforcement \\
\hline & VIN & 2G1WF55K159250370 \\
\cline { 2 - 3 } & Parking Location & North Drive \\
\hline & Fleet Vehicle ID & $* * * 0370$ \\
\hline & Fuel Type & Gas \\
\cline { 2 - 3 } & EPA Label/MPG (City/Hwy) & $18 / 27 / 21$ \\
\cline { 2 - 3 } & EPA GHG Emissions (Grams $\left.\mathrm{CO}_{2} / \mathrm{Mi}\right)$ & 404 \\
\hline & Study Logger ID & 59 \\
\cline { 2 - 3 } & Total Vehicle Days/Total Study Days & $23 / 60$ \\
\hline
\end{tabular}

\begin{tabular}{|l|c|c|c|c|}
\hline \multicolumn{5}{|c|}{ Vehicle $* * * 0370$ Travel Summary } \\
\hline & $\begin{array}{c}\text { Per Day } \\
\text { Average/Peak }\end{array}$ & $\begin{array}{c}\text { Per Outing } \\
\text { Average/Peak }\end{array}$ & $\begin{array}{c}\text { Per Trip } \\
\text { Average/Peak }\end{array}$ & Total \\
\hline Travel Distance (Miles) & $74.5 / 132.3$ & $122.3 / 363.2$ & $17.5 / 66.1$ & 1,713 \\
\hline Travel Time (Minutes) & $178.0 / 564.0$ & $291.9 / 950.0$ & $41.7 / 246.0$ & 4,086 \\
\hline Idle Time (Minutes) & $89.3 / \mathrm{NA}$ & $146.8 / \mathrm{NA}$ & $21.0 / \mathrm{NA}$ & 2,055 \\
\hline
\end{tabular}

\begin{tabular}{|c|c|c|c|c|}
\hline \multicolumn{2}{|c|}{ Total Stops } & \multicolumn{2}{c|}{ Stop Duration } \\
\hline $\begin{array}{c}\text { Distance From } \\
\begin{array}{c}\text { Home Base } \\
\text { (Miles) }\end{array}\end{array}$ & Stops & Percentages & $\begin{array}{c}\text { Stop Duration } \\
\text { (Hours) }\end{array}$ & Stops \\
\hline Less than 10 & 55 & $80.9 \%$ & Less than 2 & 39 \\
\hline 10 to 20 & 0 & $0 \%$ & 2 to 4 & 6 \\
\hline 20 to 40 & 1 & $1.5 \%$ & 4 to 8 & 4 \\
\hline Greater than 40 & 12 & $17.6 \%$ & Greater than 8 & 19 \\
\hline
\end{tabular}

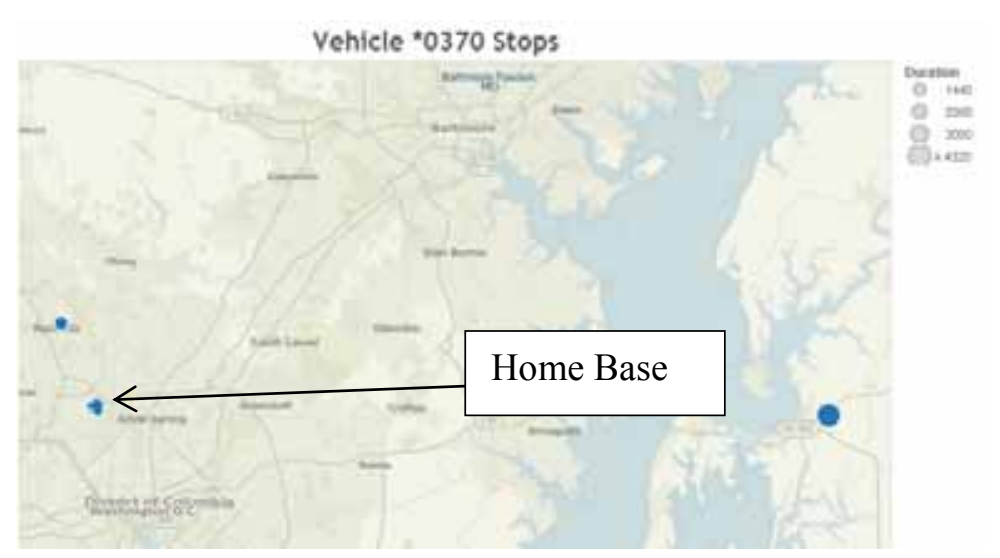

Figure B-55. Vehicle ***0370 stops.

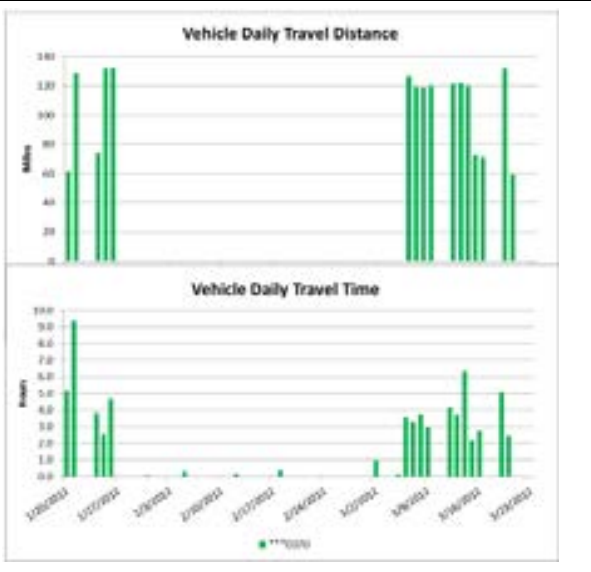

Figure B-56. Vehicle ***0370 history. 

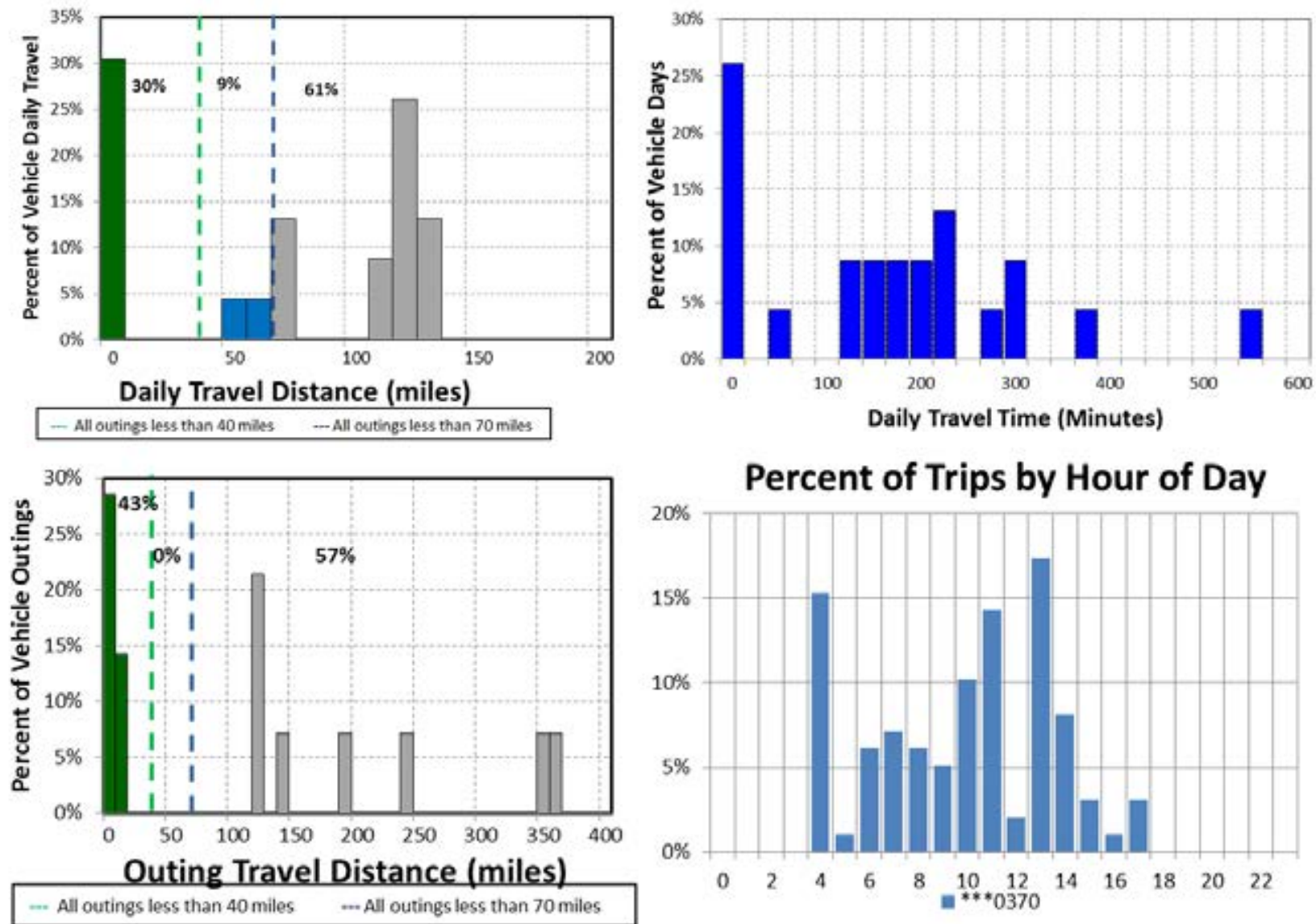

Figure B-57. Vehicle $* * * 0370$ travel graphs.

\section{Vehicle ${ }^{* * *} 0370$ Observations}

Logger 59 collected data on this vehicle for a period of 23 days of the 60-day study period. Validation occurred on $98.6 \%$ of the input data. NIH reports that this vehicle has a law enforcement mission for the K-9 police. Data indicate it typically parks near North Dr in Bethesda and Queenstown, MD (Figure B-55 and Google Earth figure to the right).

NIH reports that the vehicle odometer indicated 71,225 miles during the study and the projected annual mileage is 10,175 miles. The vehicle was used on $38 \%$ of the available days, with an average daily usage of 3.0 hours and a peak daily usage of 9.4 hours on the days it was used. The vehicle was used during typical day shift hours.

Figure B-57 shows $39 \%$ of daily travel and $43 \%$ of outings

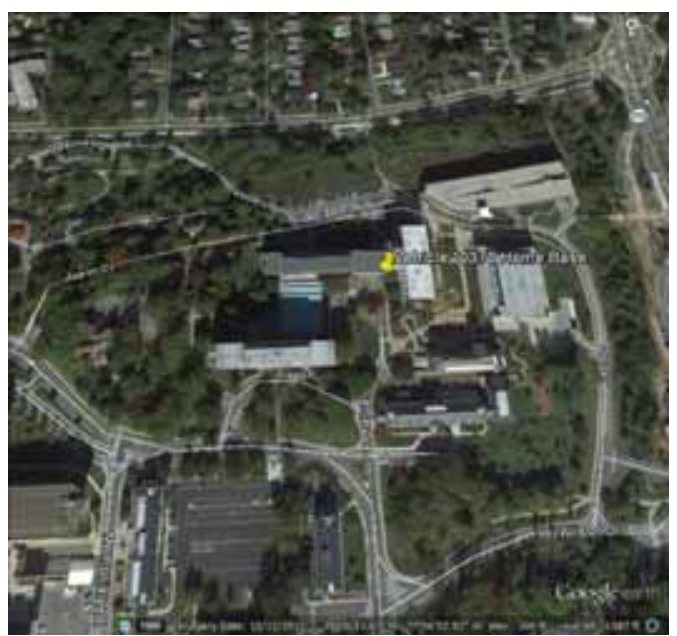
were within the typically advertised range of a BEV of approximately 70 miles. Further, $30 \%$ of daily travel and $43 \%$ of outings were within the typically advertised CD mode of 40 miles for PHEVs.

A BEV could not meet all daily travel of this vehicle. PHEVs are available to replace this vehicle type, assuming no other mission requirements exist for K-9 police. 
Vehicle ${ }^{* * *} 1201$

\begin{tabular}{|l|l|c|}
\hline & Make/Model/Year & Chevrolet HHR/2010 \\
\cline { 2 - 3 } & EPA Class Size & SUV \\
\hline Mission & Pool \\
\hline VIN & Twinbrook Pkwy, Rockville \\
\cline { 2 - 3 } & Parking Location & $* * * 1201$ \\
\hline Fleet Vehicle ID & Gas/E85 \\
\hline Fuel Type & $22 / 32 / 2615 / 21 / 17$ \\
\hline EPA Label/MPG (City/Hwy) & $355 / 365$ \\
\hline & EPA GHG Emissions (Grams $\left.\mathrm{CO}_{2} / \mathrm{Mi}\right)$ & 60 \\
\hline & Study Logger ID & $21 / 61$ \\
\hline
\end{tabular}

\begin{tabular}{|l|c|c|c|c|}
\hline \multicolumn{5}{|c|}{ Vehicle ***1201 Travel Summary } \\
\hline & $\begin{array}{c}\text { Per Day } \\
\text { Average/Peak }\end{array}$ & $\begin{array}{c}\text { Per Outing } \\
\text { Average/Peak }\end{array}$ & $\begin{array}{c}\text { Per Trip } \\
\text { Average/Peak }\end{array}$ & Total \\
\hline Travel Distance (Miles) & $4.0 / 12.8$ & $2.9 / 16.6$ & $0.5 / 3.8$ & 83 \\
\hline Travel Time (Minutes) & $18.0 / 40.0$ & $12.9 / 69.0$ & $2.1 / 9.0$ & 373 \\
\hline Idle Time (Minutes) & $2.1 / \mathrm{NA}$ & $1.6 / \mathrm{NA}$ & $0.3 / \mathrm{NA}$ & 45 \\
\hline
\end{tabular}

\begin{tabular}{|c|c|c|c|c|}
\hline \multicolumn{2}{|c|}{ Total Stops } & \multicolumn{2}{c|}{ Stop Duration } \\
\hline $\begin{array}{c}\text { Distance From } \\
\text { Home Base (Miles) }\end{array}$ & Stops & Percentages & Stop Duration (Hours) & Stops \\
\hline Less than 10 & 96 & $100 \%$ & Less than 2 & 75 \\
\hline 10 to 20 & 0 & $0 \%$ & 2 to 4 & 2 \\
\hline 20 to 40 & 0 & $0 \%$ & 4 to 8 & 1 \\
\hline Greater than 40 & 0 & $0 \%$ & Greater than 8 & 18 \\
\hline
\end{tabular}

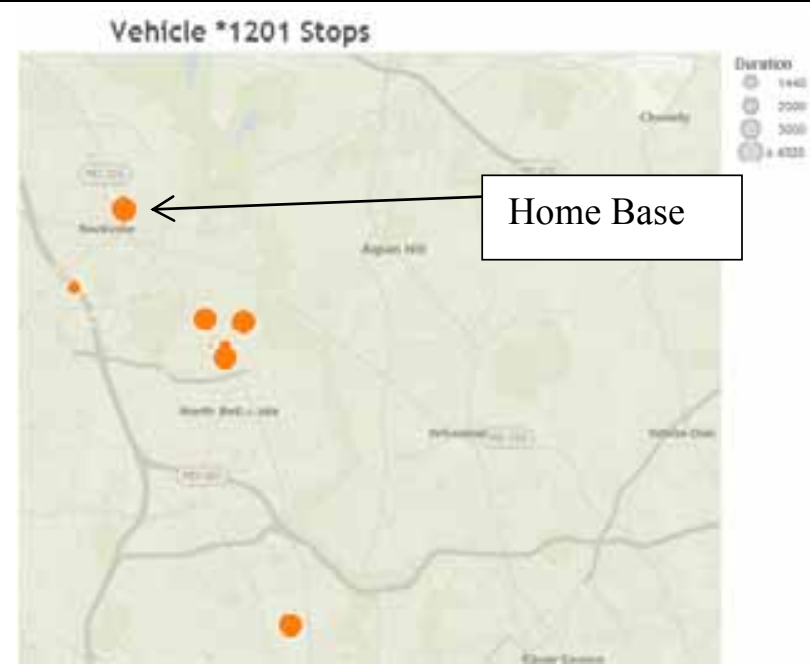

Figure B-58. Vehicle ***1201 stops.

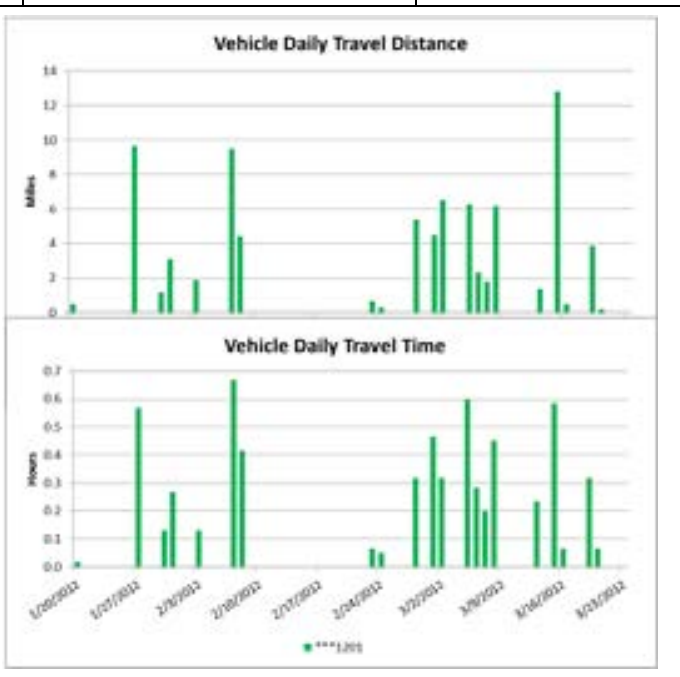

Figure B-59. Vehicle ***1201 history. 

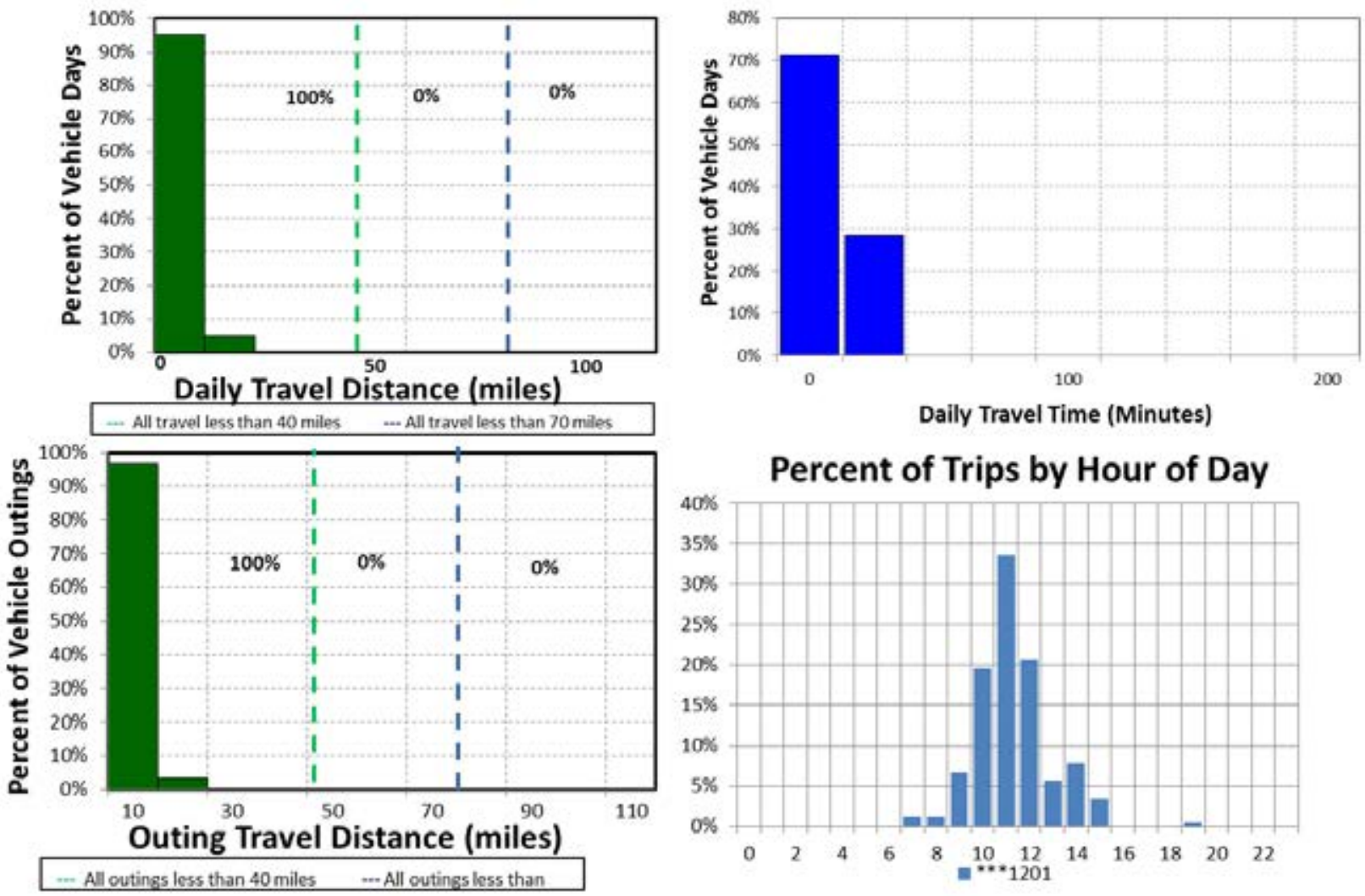

Figure B-60. Vehicle ***1201 travel graphs.

\section{Vehicle ***1201 Observations}

Logger 60 collected data on this vehicle for a period of 21 days of the 61-day study period. Validation occurred on $98.0 \%$ of the input data. NIH reports that this vehicle has a pool mission in administration. Data indicate it typically parks on Twinbrook Parkway in Rockville (Figure B-58 and Google Earth figure to the right).

$\mathrm{NIH}$ reports that the vehicle odometer indicated 2,366 miles during the study and the projected annual mileage is 1,183 miles. The vehicle was used on $34 \%$ of the available days, with an average daily usage of 0.3 hours and a peak daily usage of 0.7 hours on the days it was used. The vehicle was used during typical day shift hours.

Figure B-60 shows all daily travel and all outings were

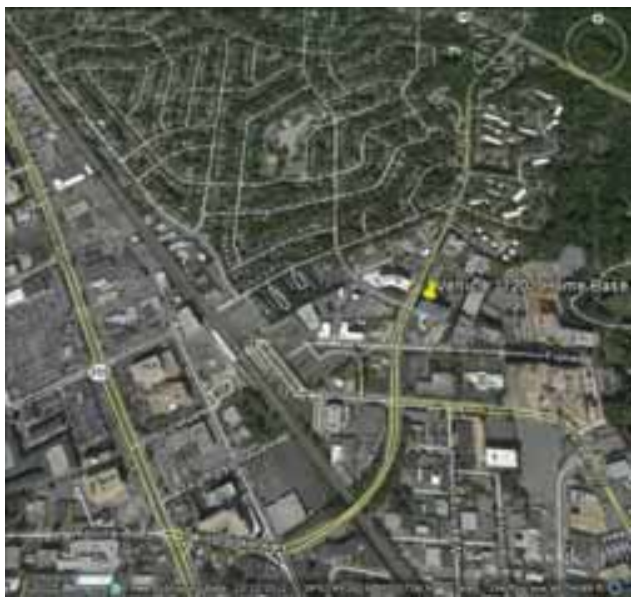
within the typically advertised range of a BEV of approximately 70 miles. Further, all daily travel and all outings were within the typically advertised CD mode of 40 miles for PHEVs.

A BEV could meet all daily travel without additional charging opportunities. PEVs are available to replace this vehicle type, assuming no other mission requirements exist. The survey information suggests no other special requirements exist for this pool activity. 


\section{Appendix C National Fuel Cost and GHG Savings}

Section 5 notes that fuel cost and GHG savings are calculated on a local and a national basis. Local savings are of higher interest to the facility, while national figures are of higher interest in evaluating all sites. Section 5 provides savings on the local level. Table C-1 presents these savings on a national basis for the PEV replacement of monitored vehicles.

Table C-1. Fuel cost and GHG savings on a national basis.

\begin{tabular}{|c|c|c|c|c|c|}
\hline Mission & $\begin{array}{c}\text { Replacement } \\
\text { Model }\end{array}$ & $\begin{array}{l}\text { Extrapolated } \\
\text { U.S. Yearly } \\
\mathrm{CO}_{2} \mathrm{e} \text { Avoided } \\
\text { (lb-CO } \mathrm{CO}_{2} \mathrm{e} / \text { year) }\end{array}$ & $\%$ reduction & $\begin{array}{l}\text { Extrapolated } \\
\text { U.S.Yearly } \\
\text { Fuel Cost } \\
\text { Reduction }\end{array}$ & $\%$ reduction \\
\hline Enforcement & C-Max & 5,087 & $46 \%$ & $\$ 1,432$ & $79 \%$ \\
\hline Pool & Leaf & 4,509 & $50 \%$ & $\$ 1,205$ & $80 \%$ \\
\hline Pool & Rav4 EV & $(168)$ & $-7 \%$ & $\$ 226$ & $58 \%$ \\
\hline Support & VTRUX PU & 671 & $42 \%$ & $\$ 204$ & $77 \%$ \\
\hline Support & eNV200 & 824 & $57 \%$ & $\$ 198$ & $83 \%$ \\
\hline Pool & Rav4 EV & 2,151 & $53 \%$ & $\$ 547$ & $82 \%$ \\
\hline Pool & Outlander & 5,757 & $36 \%$ & $\$ 1,969$ & $75 \%$ \\
\hline Pool & Rav4 EV & 1,129 & $36 \%$ & $\$ 386$ & $75 \%$ \\
\hline Support & Leaf & 867 & $50 \%$ & $\$ 232$ & $80 \%$ \\
\hline Enforcement & Leaf & 7,144 & $57 \%$ & $\$ 1,734$ & $83 \%$ \\
\hline Support & Rav4 EV & 1,609 & $46 \%$ & $\$ 453$ & $79 \%$ \\
\hline Transport & Rav4 EV & 868 & $13 \%$ & $\$ 734$ & $66 \%$ \\
\hline Transport & eNV200 & 2,109 & $36 \%$ & $\$ 726$ & $75 \%$ \\
\hline Transport & Rav4 EV & 1,080 & $33 \%$ & $\$ 400$ & $74 \%$ \\
\hline Support & Rav4 EV & 5,874 & $50 \%$ & $\$ 1,570$ & $80 \%$ \\
\hline Support & eNV200 & 858 & $57 \%$ & $\$ 206$ & $83 \%$ \\
\hline Pool & Fusion & 1,300 & $38 \%$ & $\$ 429$ & $76 \%$ \\
\hline Enforcement & Leaf & 4,928 & $52 \%$ & $\$ 1,273$ & $81 \%$ \\
\hline Enforcement & C-Max & 1,194 & $41 \%$ & $\$ 372$ & $77 \%$ \\
\hline Pool & Rav4 EV & 118 & $13 \%$ & $\$ 100$ & $66 \%$ \\
\hline Total & & 47,910 & $43 \%$ & $\$ 14,394$ & $78 \%$ \\
\hline Total Pool & & 14,797 & $38 \%$ & $\$ 4,861$ & $76 \%$ \\
\hline Total Support & & 10,703 & $50 \%$ & $\$ 2,863$ & $80 \%$ \\
\hline Total Enforcement & & 18,353 & $51 \%$ & $\$ 4,810$ & $81 \%$ \\
\hline Total Transport & & 4,057 & $26 \%$ & $\$ 1,860$ & $71 \%$ \\
\hline
\end{tabular}

As presented in Section 5, 180 BEVs and 84 PHEVs could replace most ICE vehicles in the fleet of 319 vehicles while retaining the ICE passenger vans, heavy-duty trucks, and specialty vehicles. Using an average savings per vehicle, Table $\mathrm{C}-2$ provides the avoided GHG and fuel cost savings should these replacements occur. 
Table C-2. Extrapolated GHG emissions avoided and fuel cost savings for the entire fleet.

\begin{tabular}{ccccc} 
& $\begin{array}{c}\text { Extrapolated U.S. } \\
\text { Yearly } \mathrm{CO}_{2} \text { e Avoided } \\
\left(\text { lb-CO } \mathrm{CO}_{2} \text { e/year }\right)\end{array}$ & \% reduction & $\begin{array}{c}\text { Extrapolated U.S. } \\
\text { Yearly Fuel Cost } \\
\text { Reduction (\$/year) }\end{array}$ & \% reduction \\
\hline Mission & 39,246 & $43 \%$ & $\$ 11,695$ & $78 \%$ \\
Pool & 382,783 & $45 \%$ & $\$ 110,584$ & $79 \%$ \\
Enforcement & 157,685 & $45 \%$ & $\$ 45,288$ & $79 \%$ \\
Transport & 6,364 & $39 \%$ & $\$ 2,061$ & $76 \%$ \\
Total & 586,078 & $45 \%$ & $\$ 169,629$ & $79 \%$ \\
\hline
\end{tabular}

